\title{
GUIMIT 2019, Guía Mexicana de Inmunoterapia. Guía de diagnóstico de alergia mediada por IgE e inmunoterapia aplicando el método ADAPTE
}

\author{
GUIMIT 2019, Mexican Guideline on Immunotherapy. \\ Guideline on the diagnosis of IgE-mediated \\ allergic disease and immunotherapy following \\ the ADAPTE approach
}

Désirée Larenas-Linnemann, ${ }^{1}$ Jorge A. Luna-Pech, ${ }^{2}$ Noel Rodríguez-Pérez, ${ }^{3}$ Mónica RodríguezGonzález,4 Alfredo Arias-Cruz, ${ }^{5}$ María Virginia Blandón-Vijil, ${ }^{1}$ María del Carmen CostaDomínguez, 4 Blanca E. Del Río-Navarro, ${ }^{6}$ Alan Estrada-Cardona,7 Elsy Maureen NavarreteRodríguez, ${ }^{6}$ José Antonio Ortega-Martell, ${ }^{8}$ César Fireth Pozo-Beltrán, 9 Herson Brito-Díaz, ${ }^{10}$ María del Rosario Canseco-Raymundo, ${ }^{11}$ Enrique Emanuel Castelán-Chávez, ${ }^{12}$ Margarita Gabriela Domínguez-Silva, ${ }^{12}$ Alberto José Escalante-Domínguez, ${ }^{13}$ José Luis Gálvez-Romero, ${ }^{14}$ María Guadalupe García-Reyes, ${ }^{15}$ Javier Gómez-Vera, ${ }^{16}$ Sandra Nora González-Díaz, ${ }^{5}$ María Gracias Belinda Guerrero-Núñez, ${ }^{17}$ Dante Hernández-Colín, ${ }^{18}$ Alejandra Macías-Weinmann, ${ }^{5}$ David Alejandro Mendoza-Hernández, ${ }^{19}$ Néstor Alejandro Meneses-Sánchez, ${ }^{6}$ María Dolores Mogica-Martínez, ${ }^{11}$ Carol Vivian Moncayo-Coello, ${ }^{20}$ Manuel Montiel-Herrera, ${ }^{21}$ Patricia O’Farril-Romanillos, ${ }^{22}$ Ernesto Onuma-Takane, ${ }^{1}$ Margarita Ortega-Cisneros, ${ }^{23}$ Lorena RangelGarza, ${ }^{24}$ Héctor Stone-Aguilar, ${ }^{25}$ Carlos Torres-Lozano, ${ }^{26}$ Edna Venegas-Montoya, ${ }^{27}$ Guillermo Wakida-Kusunoki, ${ }^{28}$ Carlos Macouzet-Sánchez, ${ }^{5}$ Armando Partida-Gaytán, ${ }^{19}$ Aída Inés López-García, ${ }^{29}$ Ana Paola Macías-Robles, ${ }^{22}$ María de Jesús Ambriz-Moreno, ${ }^{30}$ Amyra Ali Azamar-Jácome, ${ }^{19}$ Carlos Báez-Loyola, ${ }^{1}$ Claudia Yusdivia Beltrán-De Paz, ${ }^{31}$ Chrystopherson Caballero-López, ${ }^{29}$ Juan Carlos Fernández de Córdova-Aguirre, 32 Roberto Fernández-Soto,33 José Santos Lozano-Sáenz, 34 José Joel Oyoqui-Flores, 35 Roberto Osorio-Escamilla, ${ }^{36}$ Fernando Ramírez,37 Daniela Rivero-Yeverino, ${ }^{29}$ Socorro Orozco-Martínez, ${ }^{19}$ María Isabel Rojo-Gutiérrez, ${ }^{20}$ Eric Martínez, ${ }^{38}$ Miguel Alejandro Medina-Ávalos39

\footnotetext{
${ }^{1}$ Fundación Clínica y Hospital Médica Sur, Ciudad de México, México

${ }^{2}$ Universidad de Guadalajara, Departamento de Disciplinas Filosóficas Metodológicas e Instrumentales, Jalisco, México

3 Universidad Autónoma de Tamaulipas, Tamaulipas, México

4Hospital Español de México, Ciudad de México, México

5Universidad Autónoma de Nuevo León, Facultad de Medicina y Hospital Universitario Dr. José Eleuterio González, Centro Regional de Alergia e Inmunología Clínica, Monterrey, Nuevo León, México
} 
${ }^{6}$ Secretaría de Salud, Hospital Infantil de México Federico Gómez, Servicio de Alergia e Inmunología Clínica, Ciudad de México, México

7Grupo Costamed, Quintana Roo, México

${ }^{8}$ Universidad Autónoma del Estado de Hidalgo, Instituto de Ciencias de la Salud Área de Medicina, Hidalgo, México 9 Hospital General con Especialidades Juan María Salvatierra, Subdirección de Enseñanza e Investigación, Baja California Sur, México

${ }^{10}$ Instituto de Seguridad Social del Estado de México y Municipio, Hospital Materno Infantil, Servicio de Alergia, Estado de México, México

${ }^{11}$ Instituto Mexicano del Seguro Social, Centro Médico Nacional La Raza, Servicio de Alergia e Inmunología, Ciudad de México, México

${ }^{12}$ Instituto Mexicano del Seguro Social, Hospital General Regional 1, Servicio de Alergia e Inmunología Clínica, Ciudad de México, México

13Hospital General de Tijuana, Servicio de Alergia, Tijuana, México

${ }^{14}$ Instituto de Seguridad y Servicios Sociales de los Trabajadores del Estado, Hospital Regional de Alta Especialidad, Puebla, México

15Instituto de Seguridad y Servicios Sociales de los Trabajadores del Estado, Hospital Regional Dr. Valentín Gómez Farías, Jalisco, México

${ }^{16}$ Instituto de Seguridad y Servicios Sociales de los Trabajadores del Estado, Hospital Regional López Mateos, Ciudad de México, México

17Universidad del Noreste Tampico, Tamaulipas, México

${ }^{18}$ Instituto Jalisciense de Investigación Clínica, Jalisco, México

${ }^{19}$ Secretaría de Salud, Instituto Nacional de Pediatría, Ciudad de México, México

${ }^{20}$ Secretaría de Salud, Hospital Juárez de México, Servicio de Alergia, Ciudad de México, México

${ }^{21}$ Centro Médico ABC, Ciudad de México, México

${ }^{22}$ Instituto Mexicano del Seguro Social, Centro Médico Nacional Siglo XXI, Hospital Especialidades, Ciudad de

México, México

${ }^{23}$ Grupo Hospitalario Puerta de Hierro, Jalisco, México

${ }^{24}$ Práctica privada, San Luis Potosí, México

25Hospital San José de Hermosillo, Sonora, México

${ }^{26}$ Instituto Mexicano del Seguro Social, Unidad Médica de Alta Especialidad, Departamento de Inmunología Clínica

y Alergia, Jalisco, México

27Instituto Mexicano del Seguro Social, Unidad Médica de Alta Especialidad 25, Nuevo León México

${ }^{28}$ Petróleos Mexicanos, Hospital Central Sur de Alta Especialidad, Ciudad de México, México

${ }^{29}$ Benemérita Universidad Autónoma de Puebla, Facultad de Medicina, Hospital Universitario de Puebla, Puebla,

México

30 Práctica privada, Tamaulipas, México

${ }^{31}$ Práctica privada, Ciudad de México, México

${ }^{32}$ Instituto Ecuatoriano de Seguridad Social, Pichincha, Ecuador

33Práctica privada, Guanajuato, México

34Médica San Ángel, Veracruz, México

35Práctica privada, Michoacán, México

${ }^{36}$ Práctica privada, Puebla, Puebla

37Secretaría de Salud, Instituto Nacional de Enfermedades Respiratorias Ismael Cosío Villegas, Servicio de Alergia, Ciudad de México, México

${ }^{38}$ Instituto Mexicano del Seguro Social, Hospital General de Zona 1, Oaxaca, México

39Instituto de Seguridad y Servicios Sociales de los Trabajadores del Estado, Veracruz, México

\section{ORCID}

Désirée Larenas-Linnemann, 0000-0002-5713-5331; Jorge A. Luna-Pech, 0000-0001-6278-964X; Noel Rodríguez-Pérez, oooo-0003-0253-4877; Mónica Rodríguez-González, o00o-0002-9149-1137; Alfredo Arias-Cruz, oooo-0002-4077-4225; María Virginia Blandón-Vijil, oooo-0002-1194-1901;

María del Carmen Costa-Domínguez, oooo-0001-9335-5094; Blanca E. Del Río-Navarro, 0000-0001-6441-8869; Alan Estrada-Cardona, o000-0002-0422-5712; Elsy Maureen Navarrete-Rodríguez, o0oo-0001-9876-3206; José Antonio Ortega-Martell, oooo-0003-0828-950X; César Fireth Pozo-Beltrán, 000o-0002-8282-1851; Herson Brito-Díaz, oooo-0002-2613-0335; María del Rosario Canseco-Raymundo, oooo-0002-1567-7941; Enrique Emanuel Castelán-Chávez, oooo-0002-6868-0482;

Margarita Gabriela Domínguez-Silva, 0000-0001-6921-4072;

Alberto José Escalante-Domínguez, 0000-0003-3326-6596; José Luis Gálvez-Romero, 0000-0002-6560-3596; María Guadalupe García-Reyes, oooo-0oo2-2428-3821; Javier Gómez-Vera, oooo-0001-9595-2335; 
Sandra Nora González-Díaz, o00o-0002-3612-0042; María Gracias Belinda Guerrero-Núñez, 0000-0002-4862-8759; Dante Hernández-Colín, oooo-0002-2424-9455; Alejandra Macías-Weinmann, oooo-0003-4007-2255; David Alejandro Mendoza-Hernández, oooo-0002-6162-7136;

Néstor Alejandro Meneses-Sánchez, o0oo-0002-6180-8965; María Dolores Mogica-Martínez, 0000-0002-6305-0174; Carol Vivian Moncayo-Coello, oooo-0001-7517-3991; Manuel Montiel-Herrera, 0000-0002-1282-9874; Patricia O’Farril-Romanillos, 0000-0002-7186-1372; Ernesto Onuma-Takane, o000-0002-5097-5856; Margarita Ortega-Cisneros, oooo-0002-4285-6769; Lorena Rangel-Garza, 00oo-0001-6510-4722; Héctor Stone-Aguilar, oooo-0002-7863-8499; Carlos Torres-Lozano, o0oo-0002-1770-531X; Edna Venegas-Montoya, oooo-0001-7223-6651; Guillermo Wakida-Kusunoki, oooo-0003-4465-9918; Carlos Macouzet-Sánchez, o000-0002-5948-6784; Armando Partida-Gaytán, 0000-0002-8868-9257; Aída Inés López-García, oooo-0002-6737-5566; Ana Paola Macías-Robles, 000o-0003-1413-6526; María de Jesús Ambriz-Moreno, 0000-0001-5618-6797; Amyra Ali Azamar-Jácome, 0000-0002-0824-4443; Carlos Báez-Loyola, o000-0002-0878-0270; Claudia Yusdivia Beltrán-De Paz, 0000-0003-1345-2930; Chrystopherson Caballero-López, 0000-0001-9003-3006; Juan Carlos Fernández de Córdova-Aguirre, 0000-0002-4788-5868; Roberto Fernández-Soto, 0000-0002-8963-7360; José Santos Lozano-Sáenz, o000-0002-1354-8556; José Joel Oyoqui-Flores, 0000-0003-0215-5893; Roberto Osorio-Escamilla, 0000-0002-5041-3773; Fernando Ramírez, oooo-0002-7767-3495; Daniela Rivero-Yeverino, oooo-0002-7586-2276; Socorro Orozco-Martínez, oooo-0002-6167-3984; María Isabel Rojo-Gutiérrez, oooo-0003-4562-4477; Eric Martínez, 0000-0002-4543-0755; Miguel Alejandro Medina-Ávalos, 0000-0003-1880-4587

Correspondencia: Désirée Larenas-Linnemann

marlar1@prodigy.net.mx

Recibido: 2019-04-10

Aceptado: 2019-05-14

DOI: 10.29262 /ram.v66i5.631

Este artículo debe citarse como: Larenas-Linnemann D, Luna Pech JA, Rodríguez-Pérez N, Rodríguez-González M, Arias-Cruz A, Blandón-Vijil MV, et al. GUIMIT 2019, Guía Mexicana de Inmunoterapia. Guía de diagnóstico de alergia mediada por IgE e inmunoterapia aplicando el método ADAPTE. Rev Alerg Mex; 2019;66(Supl 1):1-105.

Declaraciones de potenciales conflictos de intereses

Todos los autores declararon la existencia o no de potenciales conflictos de interés. Los siguientes autores, indicaron relaciones con la industria farmacéutica: Virginia Blandón-Vijil: Promeco; María del Carmen Costa Domínguez: UCB; Blanca Estela Del Río-Navarro: UCB, Astra, Liomont; Désirée Larenas-Linnemann: Amstrong, Astrazeneca, Boehringer Ingelheim, DBV Technologies, Grunenthal, GSK, MEDA, Menarini, MSD, Novartis, Pfizer, Sanofi, Siegfried, UCB, sin relación con el trabajo aquí sometido; Carol Vivian Moncayo-Coello: Astra, Sanofi, Sandoz, Grunenthal; Elsy Maureen Navarrete-Rodríguez: UCB, Sanofi, GSK; Armando Partida-Gaytán: GSK, Healthy Kids Polanco; César Fireth Pozo-Beltrán: Astra, Laboratorio de Alergia Molecular; Noel Rodríguez-Pérez: ALK-Abelló.

\section{Abstract}

Background: In Mexico, allergen immunotherapy (AIT) and immunotherapy with hymenoptera venom (VIT) is traditionally practiced combining aspects of the European and American school. In addition, both types of extracts (European and American) are commercially available in Mexico. Moreover, for an adequate AIT/VIT a timely diagnosis is crucial. Therefore, there is a need for a widely accepted, up-to-date national immunotherapy guideline that covers diagnostic issues, indications, dosage, mechanisms, adverse effects and future expectations of AIT (GUIMIT 2019).

Method: With nationwide groups of allergists participating, including delegates from postgraduate training-programs in Allergy/Immunology-forming, the guideline document was developed according to the ADAPTE methodology: the immunotherapy guidelines from European Academy of Allergy and Clinical Immunology, German Society for Allergology and 
Clinical Immunology, The American Academy of Allergy, Asthma and Immunology and American College of Allergy, Asthma, and Immunology were selected as mother guidelines, as they received the highest AGREE-II score among international guidelines available; their evidence conforms the scientific basis for this document.

Results: GUIMIT emanates strong or weak (suggestions) recommendations about practical issues directly related to in vivo or in vitro diagnosis of IgE mediated allergic diseases and the preparation and application of AIT/VIT and its adverse effects. GUIMIT finishes with a perspective on AIT modalities for the future. All the statements were discussed and voted on until $>80 \%$ consensus was reached.

Conclusion: A wide and diverse group of AIT/VIT experts issued transculturized, evidence-based recommendations and reached consensus that might improve and standardize AIT practice in Mexico.

Keywords: Skin prick test; Intradermal skin test; In vitro diagnosis of allergy; Molecular allergy diagnosis; Immunotherapy with allergens; Subcutaneous immunotherapy; Sublingual immunotherapy, Immunotherapy with hymenoptera venom; Anaphylaxis; Adrenaline; Allergenic extract

\section{Resumen}

Antecedentes: En México, la inmunoterapia con alérgenos (ITA) y con veneno de himenópteros (VIT) se practica tradicionalmente combinando criterios de las escuelas europea y estadounidense; los dos tipos de extractos están comercialmente disponibles en México. Para una ITA adecuada es crucial un diagnóstico oportuno.

Objetivo: Presentar GUIMIT 2019, Guía Mexicana de Inmunoterapia 2019, de base amplia, actualizada, que abarca temas de diagnóstico, indicaciones, dosificación, mecanismos, efectos adversos de la ITA y expectativas con esta modalidad de tratamiento.

Método: Con la participación de múltiples grupos mexicanos de alergólogos, que incluían los centros formadores universitarios en alergia e inmunología, se desarrolló el documento de la guía según la metodología ADAPTE. Las guías de inmunoterapia de la European Academy of Allergy and Clinical Immunology, The American Academy of Allergy, Asthma and Immunology, German Society for Allergology and Clinical Immunology y del American College of Allergy, Asthma, and Immunology se seleccionaron como guías fuente, ya que recibieron la puntuación AGREE-II más alta entre las guías internacionales disponibles; su evidencia conforma la base científica de GUIMIT 2019.

Resultados: En GUIMIT 2019 se emiten recomendaciones fuertes o débiles (sugerencias) acerca de temas directamente relacionados con el diagnóstico in vivo o in vitro de las enfermedades alérgicas mediadas por IgE, la preparación y aplicación de ITA o VIT y sus efectos adversos; se incluye la revisión de las modalidades de ITA para el futuro. Todos los argumentos que se exponen fueron discutidos y votados con $>80 \%$ de aprobación.

Conclusión: Un grupo amplio y diverso de expertos en ITA y VIT emitió recomendaciones transculturizadas basadas en evidencia, que alcanzaron consenso; con ellas se pretende mejorar y homologar la práctica de la inmunoterapia en México.

Palabras clave: Pruebas cutáneas por punción; Pruebas intradérmicas; Diagnóstico de alergia in vitro; Diagnóstico molecular; Inmunoterapia con alérgenos; Inmunoterapia subcutánea; Inmunoterapia sublingual; Inmunoterapia con veneno de himenóptero; Anafilaxia; Adrenalina; Extracto alergénico 


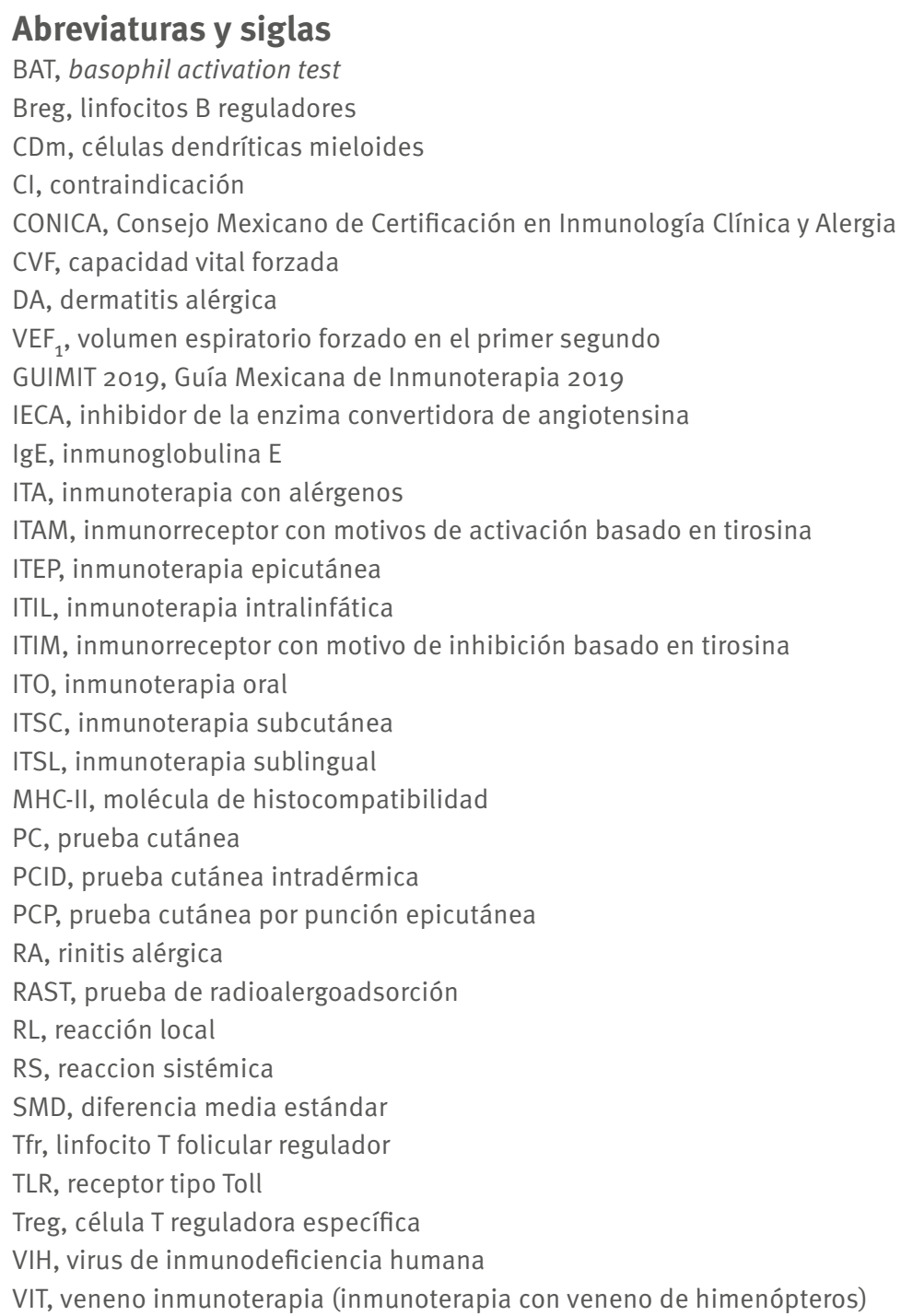

\section{Introducción}

La inmunoterapia con alérgenos (ITA) permanece como el único tratamiento causal de numerosas patologías alérgicas, por ello es una de las herramientas principales con los cuales cuenta el alergólogo para el manejo de sus pacientes. En 2011 se publicó la última guía mexicana enfocada a este tema. ${ }^{1}$ Desde esta fecha se han dado a conocer nuevos desarrollos en inmunoterapia subcutánea (ITSC), inmunoterapia sublingual (ITSL) y de nuevas vías de administración de la ITA. ${ }^{2,3}$ La ITSL ya está oficialmente reconocida por la Global Initiative on Asthma para el manejo de asma alérgica, y también tiene autorización oficial en Estados Unidos. Además, en México, nuevos proveedores estadounidenses y europeos de alérgenos han podido registrar sus productos, aumentando con ello las opciones de extractos alergénicos estandarizados y de alta calidad en México. De forma similar, en el área del diagnóstico de las patologías mediadas por IgE se están ofreciendo nuevas opciones en nuestro país, en especial en la modalidad de alergia molecular, así como la prueba de activación de basófilos, entre otras. 
Finalmente, se ha observado que en la guía de 2011 había áreas importantes por desarrollar que no se incluyeron. Por ello, en 2018 un grupo de alergólogos expertos en ITA se reunió para enfrentar la tarea de renovar la Guía Mexicana de Inmunoterapia en su versión 2019 (GUIMIT 2019), cuyo resultado se presenta en este documento. Este documento está planeado para ser actualizado en un periodo de tres a cinco años, dependiendo de los nuevos desarrollos en el área. Para la siguiente actualización se planea utilizar una metodología semejante a la actual.

\section{Objetivo de la guía}

El objetivo de GUIMIT 2019 es establecer recomendaciones y sugerencias con fundamento en medicina basada en evidencia, siguiendo la metodología del sistema GRADE y los lineamientos ADAPTE para la transculturización de guías, con el fin de homogeneizar la aplicación de pruebas de diagnóstico de alergia mediada por inmunoglobulina $\mathrm{E}$ (IgE), in vitro e in vivo, así como todo lo relacionado con la prescripción, preparación y administración de inmunoterapia específica con alérgenos (ITA) y con veneno de himenóptero (VIT) a estándares actualizados y de la mejor calidad posible, dentro del contexto nacional. Entre sus objetivos específicos, GUIMIT 2019 resolvió abordar la ITA para rinitis alérgica, conjuntivitis alérgica, asma alérgica, dermatitis atópica y alergia al látex. GUIMIT no aborda alergia alimentaria. Con ello se visualiza optimizar y homologar los procedimientos diagnósticos y terapéuticos que el alergólogo brinda a sus pacientes con enfermedades alérgicas mediadas por $\operatorname{IgE}$ de todas las edades y niveles del servicio de salud. Así, GUIMIT se dirige a los alergólogos que ejercen en México y a los centros formadores de alergólogos-inmunólogos. En el proceso de desarrollo de GUIMIT 2019 se ha buscado unificar criterios entre todos los grupos, involucrándolos desde el inicio en el desarrollo de la guía para que finalmente avalen su contenido. Por medio de una encuesta electrónica abierta (Surveymonkey ${ }^{\circledR}$ ), antes de su publicación se buscó el punto de vista de todo el gremio nacional de alergólogos acerca de aspectos discutibles de la guía, para así generar expectativa en su lanzamiento y aumentar su visibilidad.

Queda claro que este documento puede servir como una guía para recomendar o sugerir decisiones clínicas, pero en ningún momento busca sustituir la libre toma de decisiones del médico

\section{Metodología}

\section{Grupo de desarrollo de la guía}

En el primer paso del desarrollo de GUIMIT, los tres coordinadores principales (Désirée Larenas Linnemann, Jorge Luna Pech, Noel Rodríguez Pérez) definieron los capítulos por desarrollar, posterior a lo cual se asignó un coordinador por cada capítulo (figura A1). Enseguida se invitó a los dos colegios de la especialidad, el Colegio Mexicano de Inmunología Clínica y Alergia y el Colegio Mexicano de Pediatras Especializados en Inmunología y Alergia, al igual que CONICA, así como a todos los centros formadores de alergólogos en nuestro país a colaborar, brindándoles la oportunidad de asignar a uno de sus adscritos como miembro del grupo de desarrollo de la guía. Además, se invitó a cada coordinador de capítulo a seleccionar y agregar de uno a tres expertos más. El grupo de desarrollo de la guía incluye alergólogos de todas las regiones del país, del sector público y del sector privado. Algunos han dirigido el desarrollo de guías nacionales previas y tienen conocimiento metodológico específico para este fin y varios otros han participado en otras guías y están familiarizados con el proceso. 


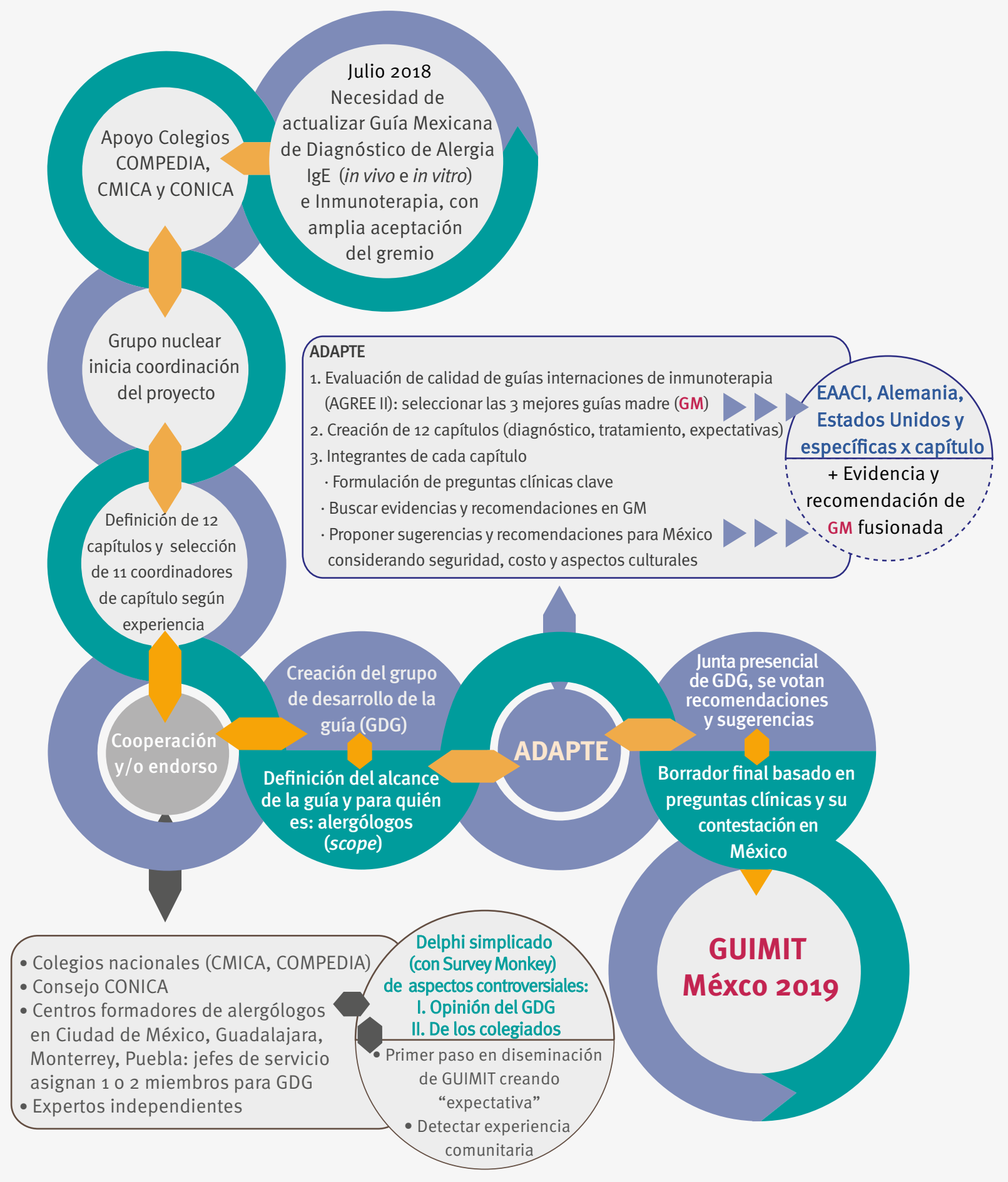

Figura A1. Proceso de desarrollo de GUIMIT. GM = guías madre, IgE = inmunoglobulina E, GDG = grupo de desarrollo de la guía. 


\section{Metodología ADAPTE y AGREE-II}

Para el desarrollo de GUIMIT 2019 se decidió seguir la metodología ADAPTE (figura A2). El primer paso en esta metodología fue desarrollar un documento con los objetivos de una guía (scope). Una vez que en el scope se estableció el enfoque de la guía, se realizó una búsqueda de literatura enfocada a guías clínicas internacionales que tratan los temas expresados en el scope. El siguiente paso fue la evaluación de la calidad de las guías encontradas con AGREE-II, herramienta propuesta por expertos en metodología de la Universidad de McMaster, Ontario, Canadá. ${ }^{4}$

La herramienta AGREE-II califica 23 elementos de las guías clínicas, agrupados en seis dominios, relacionados con contenido de la guía, autores involucrados, rigor de la metodología, presentación, declaración de conflicto de intereses e independencia editorial, entre otros. Cada elemento se califica en una escala ordinal tipo Likert de 1 a 7; se promedia la puntuación de los elementos por dominio y después se promedia la puntuación de los dominios para la calificación final de la guía. Así, AGREE-II permite identificar las mejores guías en el mundo, pero también las más adaptables a la realidad local; estas sirvieron como guías madre (GM).

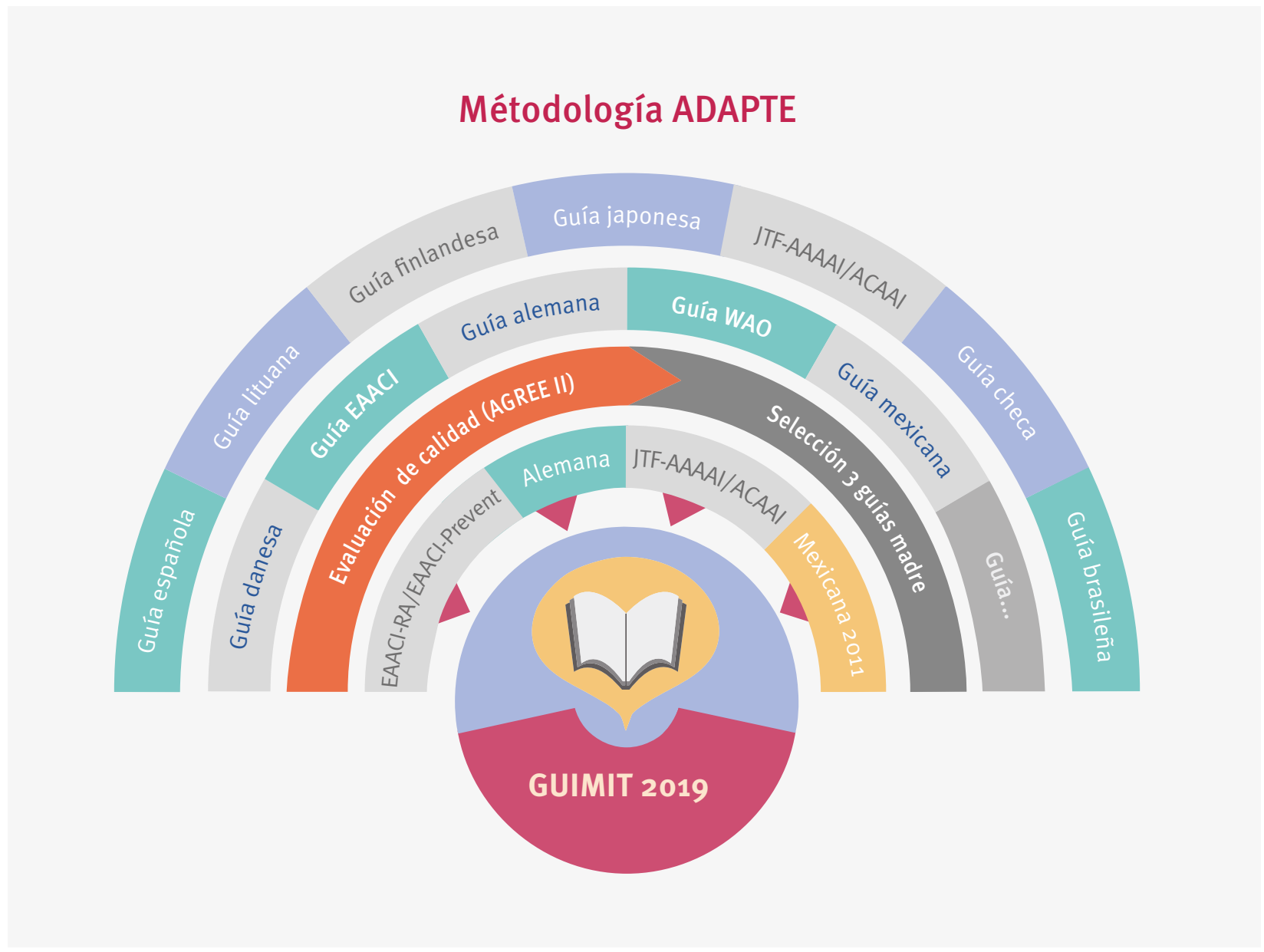

Figura A2. Metodología ADAPTE. EAACl = European Academy of Allergy and Clinical Immunology; JTF-AAAAI/ACAAI = Joint Task Force American Academy of Allergy, Asthma and Immunology/American College of Allergy, Asthma and Immunology. 
Según las necesidades por cubrir con la guía y la información encontrada en las GM se procedió a formular las preguntas clínicas clave. Posteriormente se buscó contestar las preguntas, según la información de cada GM. El penúltimo paso consistió en fusionar la evidencia y el nivel de recomendación de las GM en cada pregunta clave y emitir una recomendación o sugerencia local, en este caso para México, tomando en cuenta el costo y la seguridad de las alternativas y las oportunidades y obstáculos en nuestro país.

\section{Metodología GUIMIT}

En primer lugar se realizaron búsquedas en Medline y Embase desde enero de 2008 hasta julio de 2018, utilizando combinaciones lógicas de los siguientes términos: [allerg*AND immunotherapy OR desensitization] AND [guideline OR practice parameter OR position paper OR statement OR consensus]. La recopilación de guías de ITA se verificó en forma cruzada y se completó con las identificadas en una búsqueda activa por parte de miembros del equipo que se contactaron con expertos locales y regionales de ITA para detectar también los artículos publicados en la literatura "gris" (literatura no convencional, semipublicada o no visible en las plataforma electrónicas). Se seleccionaron todos los documentos nacionales, regionales o mundiales con lineamientos para ITA.

Se encontró una publicación en la cual todas las guías de ITA 1980-2016 fueron calificadas con AGREE-II, ${ }^{5}$ cuya información se complementó con nuevas evaluaciones usando AGREE-II, realizadas por duplicado por miembros de GUIMIT, de las guías de 2016 a la fecha.

Fue de esta forma como se seleccionaron como GM las tres guías mejor calificadas: de la European Academy of Allergy and Clinical Immunology, sección rinitis (EAACI-RA, AGREE-II 6.5/7) ${ }^{6}$ y sección prevención (EAACI-Prevent, AGREE-II $6.2 / 7) ;{ }^{7}$ de la Sociedad Alemana de Alergología e Inmunología Clínica (Deutsche Gesellschaft für Allergologie und Klinische Immunologie [DGAKI, AGREE-II 6.0/7] $)^{8}$ y los parámetros prácticos del Joint Task Force American Academy of Allergy, Asthma and Immunology/American College of Allergy, Asthma and Clinical Immunology (JTF-AAAAI/ACAAI, AGREE-II 4.6/7), ${ }^{9}$ utilizando como base la Guía Mexicana de Inmunoterapia 2011, evaluada por AGREE-II con 5.1/7. ${ }^{1}$ Respecto a algunos capítulos, la información no fue abordada en las GM. En estos casos, los miembros del capítulo seleccionaron sus propias GM siguiendo el mismo proceso, tal como se manifiesta al inicio de esos capítulos.

Para cada pregunta clínica clave se buscó el nivel de evidencia y recomendación en las GM (figura A3). Los resultados se tabularon junto con la página de la GM donde se mencionan (tabla fuente 1); esta información se encuentra disponible en internet. En el anexo 1 se indican los números DOI (digital objective indicator) que direccionan al documento digital en la web. Así, las tablas fuente 1 pueden consultarse por capítulo con los DOI del anexo 1, donde también se señalan los DOI correspondientes a las tablas que contienen las fusiones de las evidencias y de las recomendaciones de las GM, al igual que el nivel de recomendación que emitirán los expertos de GUIMIT para México (tabla fuente 2). En una junta presencial de dos días de todos los integrantes del grupo de desarrollo de la guía, a fines de abril de 2019, se consensuaron las recomendaciones y las sugerencias y se tomó nota del porcentaje de acuerdo.

En un último paso se integraron los textos del manuscrito de la guía en su forma final. Las notas del lado derecho de los textos contienen lo que GUIMIT sugiere o recomienda, el porcentaje de acuerdo entre los miembros del grupo de desarrollo de la guía de GUIMIT, seguido por el nivel de la evidencia fusionado de las GM y el nivel de recomendación fusionado. 


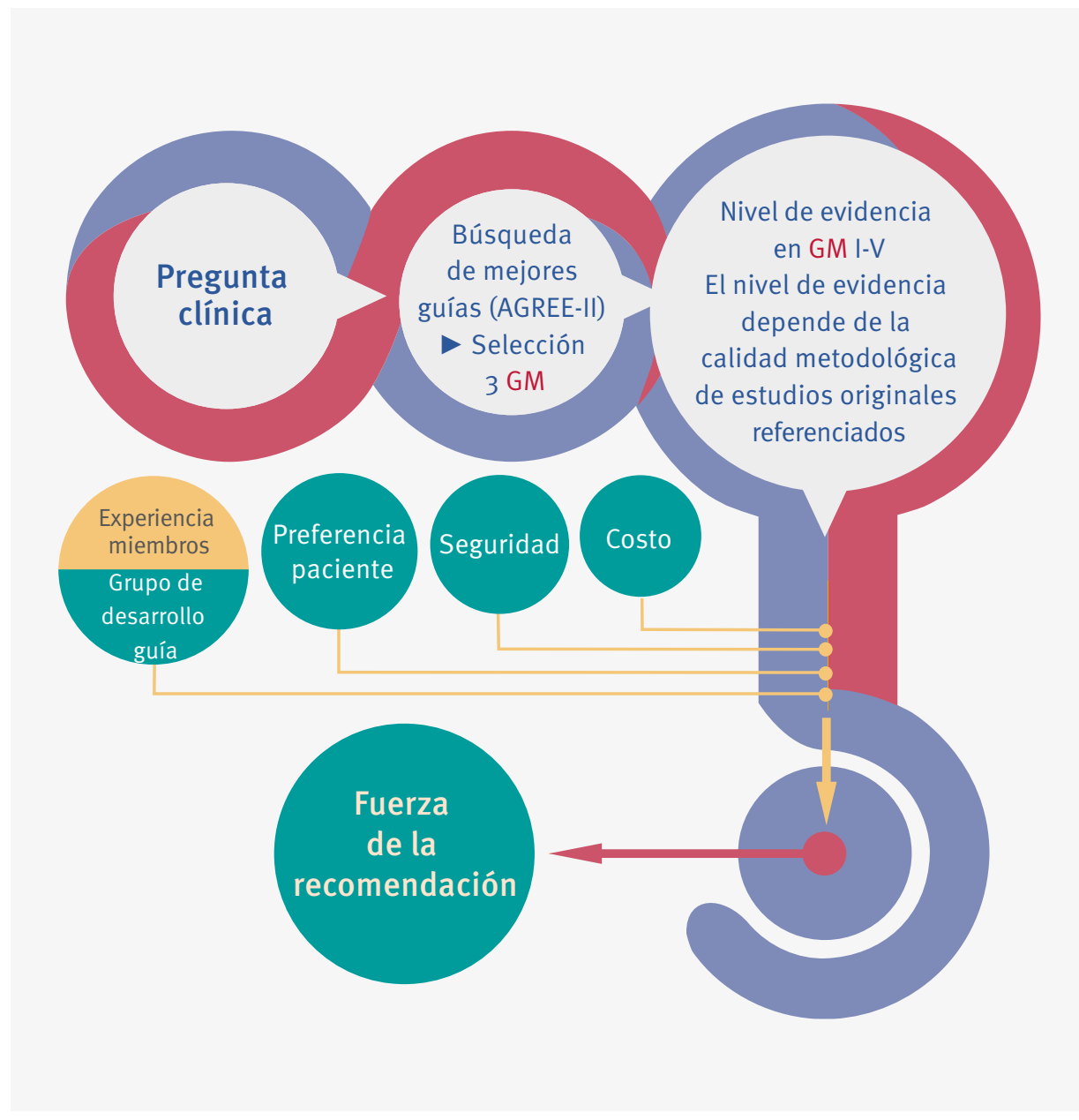

Figura A3. De pregunta clínica a recomendación o sugerencia para México. GM = guías madre.

\section{Nivel de evidencia indirecta}

Cuando la GM no emite nivel de evidencia ni recomendación acerca de cierto aspecto que se consideró de importancia, pero al mismo tiempo se hace referencia a algunos estudios que podrían aportar al nivel de evidencia, los expertos GUIMIT emitieron la evidencia y eventualmente el nivel de recomendación, calculado según estuviese presente en los documentos referenciados en la GM y usando la escala de niveles de evidencia del Oxford Centre for Evidence-Based Medicine (cuadro A1).

\section{Puntos de buena práctica}

En todos los capítulos existen aspectos que los miembros GUIMIT consideran de importancia, pero que no se encuentran en las GM ni en los artículos referenciados en ellas. Un ejemplo son los señalados en publicaciones muy recientes o la experiencia no publicada de los médicos locales, los cuales se presentan como "puntos de buena práctica" y tienen que tomarse como tal, sin el sostén de la fuerza de la evidencia en la literatura especializada como el resto del texto. 


\begin{tabular}{|c|c|c|c|}
\hline Recomendación & & & Nivel de evidencia \\
\hline A & $1 \mathrm{a}$ & & $\begin{array}{l}\text { Revisiones sistemáticas (con homogeneidad*) } \\
\text { de estudios clínicos aleatorizados }\end{array}$ \\
\hline A & $1 \mathrm{~b}$ & & $\begin{array}{l}\text { Estudios clínicos aleatorizados individuales (con } \\
\text { intervalo de confianza estrecho") }\end{array}$ \\
\hline A & $1 C$ & & Eficiencia demostrada por la práctica clínica \\
\hline $\mathrm{B}$ & \multirow{5}{*}{$\begin{array}{l}\text { O } \\
\text { extrapolaciones } \\
\text { de } 1\end{array}$} & $2 \mathrm{a}$ & $\begin{array}{l}\text { Revisiones sistemáticas (con homogeneidad*) de } \\
\text { estudios de cohorte }\end{array}$ \\
\hline$B$ & & $2 b$ & $\begin{array}{l}\text { Estudios de cohorte individuales (incluyendo estudios } \\
\text { clínicos aleatorizados de baja calidad, por ejemplo, } \\
\text { con seguimiento }<80 \% \text { ) }\end{array}$ \\
\hline $\mathrm{B}$ & & $2 C$ & Investigación de 'resultados', estudios ecológicos \\
\hline B & & $3 a$ & $\begin{array}{l}\text { Revisiones sistemáticas (con homogeneidad*) de } \\
\text { estudios casos-controles }\end{array}$ \\
\hline $\mathrm{B}$ & & $3 b$ & Estudios individuales de casos-controles \\
\hline C & $\begin{array}{l}\text { O extrapolacio- } \\
\text { nes de } 203\end{array}$ & 4 & $\begin{array}{l}\text { Serie de casos (y estudios de cohorte o de caso-control } \\
\text { de baja calidad) }\end{array}$ \\
\hline D & $\begin{array}{l}\text { O inconsisten- } \\
\text { cias }\end{array}$ & 5 & $\begin{array}{l}\text { Opinión de expertos sin valoración crítica explícita o } \\
\text { basada en fisiología, investigación de banco o “prime- } \\
\text { ros principios” }\end{array}$ \\
\hline
\end{tabular}

*Por homogeneidad se entiende una revisión sistemática libre de variaciones relevantes (heterogeneidad) en las direcciones y grados de los resultados entre los estudios individuales. No todas las revisiones sistemáticas con heterogeneidad estadísticamente significativa deben ser preocupantes, y no todas las heterogeneidades preocupantes deben ser estadísticamente significativas. Los estudios que muestran heterogeneidad preocupante deben etiquetarse con un signo ", al final de su nivel designado. Para profundizar en la explicación consúltese el documento original: https://www.cebm.net/2009/06/oxford-centre-evidence-based-medicine-levels-evidence-march-2009/

Puntos de discusión sin evidencia sólida: experiencia comunitaria según Delphi modificado

El grupo de desarrollo de la guía finalmente se percató que existen situaciones relacionadas con el tema de esta guía que no se encuentran en las GM, en sus artículos referenciados ni en publicaciones más recientes, pero que se consideraron de importancia para la elaboración de un buen proceso diagnóstico o una buena ITA o VIT. En algunos casos se trata de puntos de controversia y desacuerdo con lo estipulado en las GM, por la realidad diferente en la cual ejercen los médicos alergólogos en México. Frecuentemente se trata de detalles del manejo clínico. Para estos puntos se decidió buscar la experiencia comunitaria entre los expertos de GUIMIT, mediante una encuesta electrónica anónima, tipo Delphi, pero en una sola ronda (Delphi simplificado) de 30 preguntas clínicas. Su resultado también se presenta en los capítulos.

\section{Resultados}

Cada capítulo de la guía se estructura de la siguiente forma: se inicia con un resumen de las preguntas clínicas clave, su respuesta y el porcentaje de acuerdo entre el grupo de desarrollo de la guía, las dos preguntas corridas por el proceso Delphi simplificado con su respuesta y los puntos de buena práctica más notables del capítulo. 


\section{Capítulo 1. Pruebas diagnósticas}

\subsection{Pruebas diagnósticas in vivo (cuadro 1.1)}

\section{Cuadro 1.1. Resumen de pruebas diagnósticas in vivo}

En pacientes con sospecha de enfermedad alérgica (rinitis o conjuntivitis alérgica, asma alérgica, alergia a himenópteros, algunos casos de dermatitis atópica, alergia a alimentos o medicamentos, ¿se recomiendan las pruebas cutáneas in vivo para identificar hipersensibilidad inmediata mediada por lgE?

En niños (incluyendo lactantes) y adultos (incluyendo $>65$ años) con sospecha de enfermedad alérgica mediada por IgE, ¿las PCP confieren mayor precisión, reproducibilidad, comodidad y seguridad en comparación con la PCID?

Las PCP in vivo contrastadas con pruebas para determinar IgE específica in vitro en pacientes con sospecha de enfermedad alérgica mediada por lgE, ¿se consideran la primera opción para determinar sensibilización por IgE y basar la ITA?

En pacientes con sospecha de enfermedad alérgica mediada por IgE, ¿es adecuado tener un panel específico de alérgenos para realizar pruebas cutáneas acorde con la relevancia geográfica de la región donde vive el paciente para incrementar la precisión diagnóstica?

En pacientes a quienes se planea realizar pruebas cutáneas, ¿se recomienda evitar ciertos medicamentos a fin de evitar un probable efecto supresor farmacológico de la reacción cutánea y cuánto tiempo antes?

En pacientes a quienes se planea realizar PCP, ¿se recomienda cumplir con criterios de preparación previos al procedimiento a fin de incrementar al perfil de seguridad del procedimiento?

En pacientes a quienes se realizan pruebas cutáneas, ¿se recomienda tener un criterio uniforme para elaborar la prueba e interpretar y registrar sus resultados para evitar elucidaciones inadecuadas del resultado y orientar adecuadamente la ITA?

En pacientes con rinitis o conjuntivitis alérgica y asma, las pruebas de reto nasal o conjuntival o el reto bronquial, respectivamente, en comparación con las PCP, ¿pueden aumentar la precisión diagnóstica para la selección de alérgenos para la ITA?

En pacientes que ya están en ITA, ¿se recomienda repetir las pruebas cutáneas como marcadores de eficacia del tratamiento o para decidir la duración del tratamiento?
Recomiendan: Sí, así como en algunos casos de urticaria aguda con sospecha de alergia alimentaria $100 \%$

Recomiendan: Sí.

Las PCP son menos sensibles y más específicas que las PCID; estas no deben $\quad 100 \%$ hacerse en preescolares

Recomiendan: Sí.

Las pruebas in vitro son complementarias o de primera instancia cuando la PCP está contraindicada

Recomiendan: Sí $100 \%$

Recomiendan: Sï** $100 \%$

Recomiendan: Sí゙** $100 \%$

Recomiendan: Sí.

Considerar técnica empleada, fabricante, concentración de extracto, dispositivo y $100 \%$ evaluar resultado en milímetros

Sugieren: Sí.

Prueba complementaria en tercer nivel de $\quad 100 \%$ atención en salud

Recomiendan: No

Experiencia clínica común de los expertos GUIMIT (Delphi simplificado) ${ }^{\ddagger}$ : evidencia $1 \mathrm{C}$

Para hacer la prueba cutánea menos invasiva se pueden utilizar extractos con mezclas por grupos homólogos (mezcla de árboles, mezcla de pastos). Si es positiva, ¿deberá prescribirse inmunoterapia con la mezcla?

Para hacer la prueba cutánea menos invasiva se pueden utilizar extractos con mezclas por grupos homólogos (mezcla de árboles, mezcla de pastos, etcétera). Posteriormente se deben repetir algunas pruebas cutáneas para desglosar los alérgenos de las mezclas positivas, para definir con qué alérgenos preparar la ITA

No, $33 \%$ sugiere no y $31 \%$ recomienda no

No hay consenso: $28 \%$ recomienda sí, $24 \%$ sugiere sí, 31 \% sugiere no

* Se buscó nivel de evidencia y recomendación en cada guía madre (tablas fuente 1); se fusionaron evidencias y recomendaciones para emitir una recomendación para cierta acción (tablas fuente 2 ). Los vínculos a estas tablas se encuentran en el anexo 1.

** Pero depende del medicamento (cuadro 1.3).

*** Véase cuadro 1.2. ${ }^{\ddagger}$ Contestación anónima de los 57 expertos GUIMIT. Con amplio consenso se obtiene un nivel de evidencia 1C, según CEBM. IgE = inmunoglobulina $\mathrm{E}, \mathrm{PCP}=$ prueba cutánea por punción epicutánea, $\mathrm{PCID}=$ prueba cutánea intradérmica, ITA = inmunoterapia con alérgenos. 


\subsubsection{Introducción}

El tratamiento efectivo de las enfermedades alérgicas depende de establecer un diagnóstico preciso y adecuado. La inmunoterapia con alérgenos (ITA) está indicada en pacientes con alergia mediada por inmunoglobulina E (IgE) como causa de sus síntomas y es el único tratamiento causal. El médico alergólogo seleccionará cuáles alérgenos incluirá en la ITA para la identificación adecuada del o los alérgenos probablemente causales con base en la historia clínica, la exploración física y la confirmación de la sensibilización IgE específica. Desde hace más de 150 años, las pruebas cutáneas continúan siendo el procedimiento diagnóstico preferido para la mayoría de los casos en los que se sospeche componente alérgico y se desee establecer sensibilización IgE mediada, aun cuando algunos aspectos podrían provocar variabilidad en sus resultados, como el dispositivo utilizado, el tipo de extractos, el color de piel y la técnica de aplicación. En este capítulo se revisará la utilidad clínica de las pruebas cutáneas y se analizarán aspectos que podrían incrementar su valor predictivo, no solo para confirmar sensibilización alérgica sino como guía para la elección del tratamiento antialérgico.

\subsubsection{Selección de guías madre específicas para este capítulo}

Debido a que en las tres guías oficiales de inmunoterapia no se incluyó el tema de pruebas diagnósticas, para elaborar este capítulo fue necesario extraer evidencia de tres guías clínicas adicionales. Para ello se realizó una búsqueda sistemática en la literatura de guías acerca de diagnóstico de alergia in vivo publicadas en los últimos 12 años (debido a que las guías contemporáneas sobre este tema son escasas), para su posterior evaluación de calidad por medio del instrumento AGREE-II, la cual fue realizada por duplicado por dos evaluadores independientes. Así, las guías mejor calificadas para el capítulo fueron el documento de estándares europeos de pruebas cutáneas de la European Academy of Allergy and Clinical Immunology/Global Allergy and Asthma European Network de $2013,{ }^{10}$ la guía de pruebas cutáneas de la Sociedad Alemana de Alergología e Inmunología Clínica de 2011, ${ }^{11}$ y la actualización de los parámetros prácticos estadounidenses de American Academy of Allergy, Asthma and Immunology/American College of Allergy, Asthma and Clinical Immunology de 2008. ${ }^{12}$

\subsubsection{Pruebas cutáneas como herramienta para identificar hipersensibilidad in - mediata mediada por IgE}

Las pruebas cutáneas por punción epicutánea (PCP) o pruebas de prick (prick test en la literatura anglosajona) son un método mínimamente invasivo con resultados de rápida disponibilidad y alta reproducibilidad (cuando se realizan por personal entrenado) para confirmar sensibilización por IgE in vivo. Se ha considera que tienen aproximadamente $90 \%$ de sensibilidad y especificidad y buena correlación con pruebas de reto nasales y bronquiales. Se realizan aplicando una pequeña cantidad de extracto alergénico sobre la piel de los antebrazos o de la espalda del paciente. Mediante una punción epicutánea con una aguja fina que atraviesa la gota hasta la parte superficial de la piel, se logra la penetración de pequeñas cantidades de extracto alergénico, justo debajo de la epidermis. Si existen células cebadas sensibilizadas con IgE específica, la penetración del alérgeno provocará la liberación de histamina, resultando en una respuesta cutánea con erupción y eritema, que se mide entre los 15 a 20 minutos.

GUIMIT recomienda las PCP como la herramienta diagnóstica de primera línea para identificar sensibilización alérgica mediada por IgE en pacientes con rinoconjuntivitis y asma alérgicas, alergia a alimentos con sospecha de reacción tipo I y dermatitis
PCP indicadas en

rinoconjuntivitis, asma, dermatitis atópica, alergia himenópteros y alergia alimentaria

Recomendamos: Sí, $100 \%$ Evidencia: III, III, IV, III, Ilb Recomendación: C, C, D, C, B 
atópica asociada con sensibilización por alimentos o aeroalérgenos y las sugiere en hipersensibilidad a medicamentos. Las PCP se han utilizado también en algunos casos de urticaria o angioedema agudo (sobre todo con sensibilidad a alimentos), aunque su utilidad en estos casos es controversial (las guías europeas no las recomiendan, a diferencia de la guía norteamericana).

Otras pruebas in vivo útiles para identificar reacciones con mecanismos diferentes a IgE (por ejemplo, las pruebas de parche) pueden usarse como parte del protocolo diagnóstico, pero no son útiles para decidir qué alérgenos usar en la ITA.

\subsubsection{Pruebas cutáneas in vivo: punción epicutánea versus intradérmica}

GUIMIT recomienda preferir las PCP sobre las pruebas cutáneas intradérmicas (PCID). Las PCID son aplicadas por inyección intracutánea con jeringas de 0.3 o $1.0 \mathrm{~mL}$, son más invasivas, incómodas y dolorosas, utilizan concentraciones de alérgeno mucho menores que las PCP (100 a 1000 veces más diluidas que las de las PCP, en volúmenes pequeños, de 0.02 a $0.05 \mathrm{~mL}$ ); aunque se consideran muy sensibles, son menos específicas que las PCP y pueden provocar resultados falsos-positivos y reacciones irritantes por traumatismos en la piel. Las PCID tienen menor correlación clínica que las PCP, lo que disminuye su utilidad potencial como herramienta para orientar ITA, además de que requieren mayor habilidad técnica para su aplicación y tienen mayor riesgo de reacciones adversas, incluyendo anafilaxia y muerte. Según datos estadounidenses, entre 2000 y 2008 se reportaron seis desenlaces fatales con PCID. Las PCID se leen entre 10 y 15 minutos después de su realización. Una ventaja de la PCID es que permiten evaluar reacciones cutáneas tardías, que aparecen seis a 12 horas después de la aplicación, y en ocasiones son visibles hasta 24 horas después.

Pese a la creencia de que la reactividad cutánea pudiera ser menor en los lactantes y ancianos, GUIMIT recomienda las PCP en pacientes desde un mes de vida, sin embargo, las PCID deben evitarse en niños pequeños. GUIMIT sugiere que, de ser posible, las PCID se limiten a casos de hipersensibilidad por veneno de insectos (previa PCP negativa), reacciones a algunos medicamentos (sobre todo para evaluar reacciones tardías [ $>24$ horas]) y en los pacientes adultos con fuerte sospecha clínica a ciertos alérgenos y PCP negativas.

\subsubsection{Pruebas cutáneas versus pruebas de IgE específica in vitro}

Aun cuando la determinación de IgE sérica específica para alérgenos in vitro en sus diferentes variantes son herramientas diagnósticas útiles y novedosas (véase apartado 1.2. Diagnóstico de alergia mediada por IgE con estudios in vitro), GUIMIT recomienda que las PCP (cuando son realizadas por personal entrenado, con técnica y extractos adecuados) se consideren como la primera opción para confirmar sensibilización por IgE y para fundamentar la ITA. Las pruebas in vitro se pueden realizar como complemento de las PCP y son muy útiles en casos específicos (como síndrome de alergia oral o pesquisa de casos de anafilaxia, o alta sospecha clínica con PCP negativas) y son la primera opción diagnóstica cuando exista contraindicación para PCP (cuadro 1.2).

Entre las ventajas que tienen las PCP versus las pruebas in vitro son su menor costo, la rapidez y facilidad en su interpretación después de la aplicación del alérgeno en la piel (minutos versus días o semanas), la mayor variabilidad para probar alérgenos poco comunes (algunos medicamentos, frutas frescas y vegetales de las que no se dispone prueba específica in vitro, o que se restringen al panel disponible). La concordancia entre pruebas de IgE específica in vitro y PCP es variable, pero se estima entre 70 y $90 \%$, aunque en general las pruebas séricas son menos específicas que las PCP. Además, en
Alergia a medicamentos Sugerimos Sí, $100 \%$ Evidencia: III Recomendación C

$\left\{\begin{array}{l}\text { A favor de PCP versus PCID } \\ \text { Recomendamos: Sí, } 100 \% \\ \text { Evidencia: Ila } \\ \text { Recomendación: C }\end{array}\right.$

PCP en adultos $>65$ años $P C P$ en niños $<2$ años

Recomendamos: Sí, $100 \%$

Evidencia: III, III

Recomendación: C, C

PCID en adultos $>65$ años

Sugerimos: Sí, $100 \%$

PCID en niños $<\mathbf{2}$ años

Recomendamos: No, $100 \%$

Evidencia: IV, IV

Recomendación: D, /D

A favor de PCP versus in

vitro

Recomendamos: Sí, 77 \%

Evidencia: Ilb

Recomendación: C 
Cuadro 1.2. Contraindicaciones para las pruebas cutáneas (punción epicutánea e intradérmica) para alergia in vivo

Afección importante de la piel en el área de la prueba (eccema activo, dermografismo, urticaria, etcétera)

Estado general alterado o muy debilitado

Consumo reciente o actual de medicamentos que afecten el resultado de la prueba in vivo (cuadro 1.3)

Asma inestable o descontrolada

Sospecha de riesgo alto de reacción sistémica grave o con antecedente de anafilaxia reciente (hasta 4 a 6 semanas previas); en este último caso, además, se recomienda evitar hacer pruebas cutáneas ya que puede producirse un resultado falso-negativo

Tratamiento con betabloqueadores, los cuales constituyen una contraindicación relativa, considerando su potencial para afectar farmacodinámicamente la respuesta a la adrenalina, en caso de requerirse

Embarazo, contraindicación relativa, considerando la posibilidad remota de inducir una reacción alérgica sistémica que pudiese inducir contracciones uterinas o requerir adrenalina (que podría provocar constricción de la arteria umbilical)

casos con IgE sérica muy elevada a menudo son detectados niveles de anticuerpos IgE específicos no relevantes para el cuadro clínico del paciente, lo que puede provocar imprecisión diagnóstica. A la fecha no existen estudios comparativos que hayan mostrado eficacia de la ITA en pacientes seleccionados únicamente con base en los resultados de pruebas in vitro. ${ }^{13}$

\subsubsection{Alérgenos por incluir en las pruebas cutáneas}

En los últimos años se han realizados estudios de mapeo que han permitido conocer los aeroalérgenos más prevalentes de pruebas cutáneas positivas en diferentes zonas de México, y se ha demostrado con claridad que el ácaro del polvo casero Dermatophagoides pteronyssinus es el alérgeno con mayor positividad en el país (>50\%), independientemente de la región geográfica. ${ }^{14}$ La sensibilización a pólenes en pacientes mexicanos es diferente a la reportada en Europa y Norteamérica, por lo que los paneles para pruebas cutáneas sugeridos en las guías madre no son totalmente adecuados para México. Un estudio multicéntrico con PCP cegadas de 628 pacientes mexicanos demostró que además de ácaros (56\%), los pólenes de gramíneas (sobre todo Cynodon dactylon, $26 \%$ ) y árboles (principalmente Fraxinus americana, Quercus ilex y Prosopis, 22 a 24 \%) son los aeroalérgenos más frecuentemente positivos, con algunas variaciones según la zona geográfica. Entre los epitelios, los de gato (22\%) y los de mezclas de cucaracha (Blatella germánica y Periplaneta americana $[21 \%]$ ) son los más prevalentes. La positividad para polen de malezas y hongos es menos común (entre 6 y $14 \%$ ). ${ }^{15}$

En consecuencia, GUIMIT recomienda que en México, en el panel de pruebas cutáneas se incluyan siempre Dermatophagoides $s p$., pólenes de gramíneas (principalmente Cynodon dactylon), árboles (incluyendo Fraxinus americana, Quercus ilex y Prosopis), y complementariamente, epitelios (por ejemplo, de gato, perro y cucaracha), pólenes de malezas y hongos intradomiciliarios (por ejemplo, Aspergillus o Alternaria alternata), y que el resto del panel se ajuste a criterio del alergólogo considerando región donde viva el paciente, restringiendo alérgenos con poca presencia en la región y considerando reactividad cruzada.

No es posible establecer un número determinado de alérgenos en el panel para pruebas cutáneas; sin embargo, con base en datos de un estudio paneuropeo que mostró que con un panel de siete alérgenos se encontró una PCP positiva en $35 \%$ de los casos, y que agregando más alérgenos el porcentaje solo aumentó 1 a $2 \%,{ }^{16}$ GUIMIT establece que no es necesario incluir un número muy grande de alérgenos en las pruebas y sugiere que un panel estándar en México incluya como máximo 40 alérgenos. 
Las pruebas cutáneas con extractos con mezclas de alérgenos homólogos (mezclas de varios pastos, malezas, etcétera) pueden ser útiles como cribado, pero también pueden inducir resultados falsos-negativos. En estos casos, sobre todo cuando se trate de mezclas con tres o más alérgenos, GUIMIT sugiere hacer pruebas posteriores con alérgenos individuales (en caso de historia clínica sugestiva), como un mejor indicador Punto buena práctica: $100 \%$ para orientar la ITA. No se recomienda que la ITA sea preparada con dichas mezclas.

\subsubsection{Suspensión previa de medicamentos}

Tomando en cuenta el efecto supresor farmacológico de la reacción cutánea y para incrementar la confiabilidad de la prueba, GUIMIT recomienda evitar algunos medicamentos antes de realizar las pruebas cutáneas (cuadro 1.3).

Recomendamos: Sí, $100 \%$. Evidencia: Ilb Recomendación: C

\begin{tabular}{|c|c|c|c|}
\hline Tipo de medicamento & Ejemplo & $\begin{array}{l}\text { Acción sugerida o recomendada por GUIMIT } \\
\text { (nivel de evidencia, grado de recomendación) }\end{array}$ & $\begin{array}{l}\text { Tiempo de suspensión } \\
\text { previo a la prueba }\end{array}$ \\
\hline $\begin{array}{l}\text { Antihistamínicos } \mathrm{H}_{1} \\
\text { de primera generación }\end{array}$ & $\begin{array}{l}\text { Clorfeniramina, difenhidramina, } \\
\text { hidroxizina, meclozina y otros }\end{array}$ & Se recomienda suspender ( $1 C, B)$ & $\sim 7$ días \\
\hline $\begin{array}{l}\text { Antihistamínicos } \mathrm{H}_{1} \\
\text { de segunda generación }\end{array}$ & $\begin{array}{l}\text { Fexofenadina, loratadina/desloratadina } \\
\text { cetirizina/levocetirizina y otros }\end{array}$ & Se recomienda suspender ( $1 \mathrm{C}, \mathrm{B})$ & $\sim 7$ días* \\
\hline $\begin{array}{l}\text { Antidepresivos con efecto } \\
\text { antihistamínico }\end{array}$ & $\begin{array}{l}\text { Antidepresivos tricíclicos (imipramina, } \\
\text { amitriptilina, doxepina y otros) }\end{array}$ & Se recomienda suspender ( $1 C, B)$ & $\sim 7$ días \\
\hline Antihistamínicos $\mathrm{H}_{2}$ & Ranitidina y otros & Se sugiere suspender $(2 \mathrm{~b}, \mathrm{C})$ & 1 día \\
\hline $\begin{array}{l}\text { Inhibidores de receptores } \\
\text { de leucotrienos }\end{array}$ & Montelukast, zafirlukast y otros & Se recomienda no suspender ( $1 \mathrm{~b}, \mathrm{~B})$ & No interfiere \\
\hline \multirow{2}{*}{$\begin{array}{l}\text { Corticosteroides } \\
\text { sistémicos }<10 \text { días }\end{array}$} & $\begin{array}{l}\text { Prednisolona o equivalente, } \\
<50 \text { mg/día (adultos) } 0<1 \mathrm{mg} / \mathrm{kg} \text { (niños) }\end{array}$ & Se recomienda no suspender ( $2 \mathrm{~b}, \mathrm{~B})$ & No interfiere \\
\hline & $\begin{array}{l}\text { Prednisolona o equivalente, } \\
>50 \mathrm{mg} / \text { día (adultos) o }>1 \mathrm{mg} / \mathrm{kg} \\
\text { (niños) }\end{array}$ & Se sugiere suspender $(2 b, C)$ & 3 días** \\
\hline $\begin{array}{l}\text { Corticosteroides } \\
\text { sistémicos }>10 \text { días }\end{array}$ & $\begin{array}{l}\text { Prednisolona o equivalente, dosis } \\
\text { mínima } 10 \mathrm{mg} / \text { día }\end{array}$ & Se sugiere suspender $(3, \mathrm{C})$ & 1 a 3 semanas ${ }^{\star \star \star}$ \\
\hline $\begin{array}{l}\text { Corticosteroides tópicos } \\
\text { cutáneos }\end{array}$ & $\begin{array}{l}\text { Cualquier potencia (hidrocortisona, } \\
\text { lobetasna, ometasona, betametasona, } \\
\text { y otros }\end{array}$ & Se recomienda suspender (1b, B) & $\sim 7$ días \\
\hline
\end{tabular}
y otros

Corticosteroides tópicos nasales y en aerosol, antihistamínicos $\mathrm{H}_{1}$ Mometasona, budesonida, fluticasona, budesonida, olopatadina, azelastina Se recomienda no suspender (2b, B) No interfieren oftálmica y otros

\begin{tabular}{llll} 
Anestésicos locales & Combinación lidocaína-prilocaína & Se sugiere no suspender ${ }^{\ddagger}$ (2b, C) & No interfieren \\
\hline $\begin{array}{l}\text { Inhibidores de calcineurina } \\
\text { (tópicos) }\end{array}$ & Tacrolimus, pimecrolimus & Se recomienda suspender (1c, B) & $\sim 7$ días
\end{tabular}
(tópicos)

* Ketotifeno y astemizol son excepciones, que se recomienda suspender $\sim 30$ días antes del estudio.

** El consumo de corticosteroides sistémicos hasta por 10 días tiene muy poco potencial para afectar el resultado del estudio en piel y solo se sugiere descontinuarlo (evidencia baja) si la dosis diaria es $\geq 50 \mathrm{mg} \mathrm{(} \geq 1 \mathrm{mg} / \mathrm{kg}$ en niños) de prednisolona o equivalente.

$\star \star \star$ Evidencia baja, GUIMIT sugiere que se pueden suspender considerando la dosis, la duración del esquema y la enfermedad de base, a criterio del médico alergólogo tratante.

‡ Algunos anestésicos locales, como la combinación lidocaína/prilocaína, aunque pueden retrasar la aparición del eritema, al parecer no afectan la formación de la erupción, por lo que GUIMIT sugiere no suspenderlos. 


\subsubsection{Preparación para las pruebas cutáneas}

Las PCP son seguras y solo en raras ocasiones pueden ocasionar reacciones alérgicas sistémicas (por ejemplo, rinorrea y rara vez anafilaxia) y con las PCID incluso existen reportes de desenlace fatal (véase apartado 1.1.4). Por ello, GUIMIT recomienda contar con médicos entrenados y equipo de emergencia en el lugar donde son realizadas. Las reacciones graves usualmente son inmediatas o tempranas, por lo que GUIMIT recomienda indicar al paciente esperar por lo menos 30 minutos en el centro sanitario después las pruebas. El riesgo incrementa cuando se hacen pruebas cutáneas para látex, medicamentos o alimentos y es mucho menor con extractos de aeroalérgenos.

Para realizar la PCP, la enfermedad alérgica debe estar clínicamente controlada (por ejemplo, asma sin síntomas actuales). GUIMIT recomienda utilizar medidas objetivas previas al procedimiento para establecer el grado de estabilización del cuadro alérgico del paciente y como valor basal en caso de presentar una reacción sistémica durante o después de las pruebas cutáneas. Estas medidas incluyen oximetría de pulso, presión arterial y, en asma, espirometría o flujo espiratorio pico. Si hay antecedente de choque anafiláctico, GUIMIT sugiere no hacer PCID, pero si se decide llevarla a cabo, se sugiere canalizar una vena periférica para acceso vascular antes del procedimiento, y aunque no hay datos sólidos de su utilidad real, eventualmente se podría hacer las PCID con titulación gradual (iniciando con extractos más diluidos). En estos pacientes, un nivel incrementado de triptasa sérica es un factor de riesgo para anafilaxia.

Si existe el antecedente de reacción por veneno de insecto, GUIMIT sugiere que la prueba cutánea se realice al menos cuatro a seis semanas después del evento, e incluso repetirla en intervalos de tres a seis meses, ya que puede haber una reacción falsanegativa inicial. El grupo de trabajo de GUIMIT considera importante resaltar que los pacientes que toman betabloqueadores pueden tener mayor riesgo en caso de una reacción anafiláctica porque pueden ser menos reactivos a la adrenalina. ${ }^{17}$

Debe revisarse la estabilidad y fecha de caducidad de los extractos alergénicos, los cuales deben almacenarse a una temperatura de 2 a $8{ }^{\circ} \mathrm{C}$, para mantener su estabilidad. Para revisar las características mínimas ideales del lugar donde debe realizar la PCP véase el capítulo 7.

Para fines preventivos médico-legales, GUIMIT recomienda obtener el consentimiento informado por escrito del paciente (y el asentimiento en los menores de edad), con cumplimiento de la normativa vigente de los colegios mexicanos de inmunología y alergia (véase capítulo 7).

\subsubsection{Técnica de aplicación, interpretación y registro de resultados}

Los resultados de las pruebas cutáneas pueden tener variaciones dependiendo de la técnica de aplicación, la habilidad del personal aplicador, el dispositivo utilizado, la calidad de los extractos alergénicos y la forma de registrar e interpretar los resultados, para cuya consistencia y confiabilidad es imperativo que el personal que aplique las pruebas esté adecuadamente adiestrado y sea monitorizado por el especialista, y de preferencia haber aprobado una prueba de proficiencia (véase capítulo 7). Un aspecto particular en México, evidenciado en un estudio comparativo, es que diferentes extractos alergénicos para pruebas cutáneas utilizados en el país mostraron gran variación en su concentración proteica, debido al origen heterogéneo de los productos y a un control de calidad deficiente en algunos fabricantes. GUIMIT sugiere utilizar, siempre que sea posible, extractos de alta estabilidad, con una concentración uniforme y buen control de calidad. ${ }^{18} \mathrm{Si}$ bien para hacer las PCP pueden utilizarse diferentes dispositivos, los expertos de GUIMIT recomiendan evitar los dispositivos que produzcan una pápula de $3 \mathrm{~mm}$ o menos en el
Personal entrenado y equipo

de emergencia, esperar 30

minutos.

Recomendamos: Sí, 100 \%.

Evidencia: III

Recomendación: C

Medidas objetivas de mo-

nitoreo previo a PCP

Recomendamos: Sí $100 \%$.

Evidencia: IV

Recomendación: D

$\{$ Punto buena práctica: $100 \%$

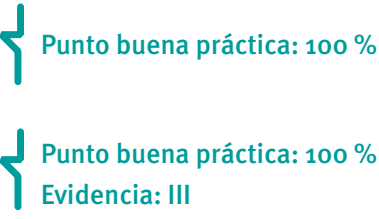

Punto buena práctica: $100 \%$

Personal proficiente y

criterio uniforme para

registrar e interpretar

resultados de PCP

Recomendamos: Sí, $100 \%$

Evidencia: Ilb

Recomendación: C

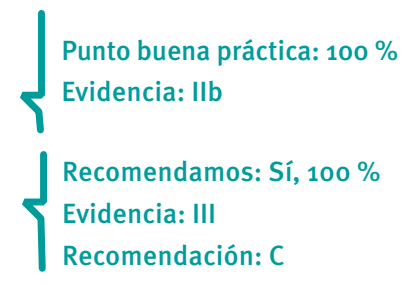


control negativo, o interpretar sus resultados con cautela ante el riesgo de resultados falsos-positivos. Es preferible utilizar una lanceta especial con una punta de metal de longitud de $1 \mathrm{~mm}$, dado el menor traumatismo y la mejor reproducibilidad comparada con las PCP realizadas con lancetas de sangrado. Existen aplicadores con puntas múltiples que permiten varias determinaciones simultáneas en una misma aplicación. La elección del dispositivo depende de su disponibilidad, facilidad de uso, seguridad, confort para el paciente, costo y preferencia o experiencia del médico. ${ }^{19}$

La lectura de los resultados de las PCP se hace entre los 15 y 20 minutos siguientes, midiendo el promedio del tamaño de la roncha y del eritema y reportándolos en milímetros. Toda PCP debe incluir un control negativo (usualmente glicerina a $50 \%$ o solución fisiológica con fenol a $4 \%$ ) y positivo (fosfato de histamina a $0.1 \%$ ); el control positivo sirve para evitar pruebas falsas-negativas y es de utilidad si no se producen pápulas por cualquiera de los extractos alergénicos. Para considerar un resultado positivo, la pápula resultante de la punción del extracto alergénico debe ser por lo menos $3 \mathrm{~mm}$ superior al diámetro mayor de la roncha del control negativo. A mayor reacción cutánea en una PCP, habrá mayor probabilidad de que ese alérgeno tenga relevancia clínica. No obstante, no es posible predecir la gravedad de una reacción alérgica con base en los resultados de la PCP. La formación de seudópodos siempre es indicador de reacción positiva.

Una PCP se considera negativa cuando no se producen ronchas con diámetro mayor o igual a $3 \mathrm{~mm}$ por encima del control negativo con alguno de los extractos alergénicos, excepto el control positivo. La prueba no se considerará válida cuando los extractos de alérgenos o el control positivo no generen una pápula (figura 1.1).

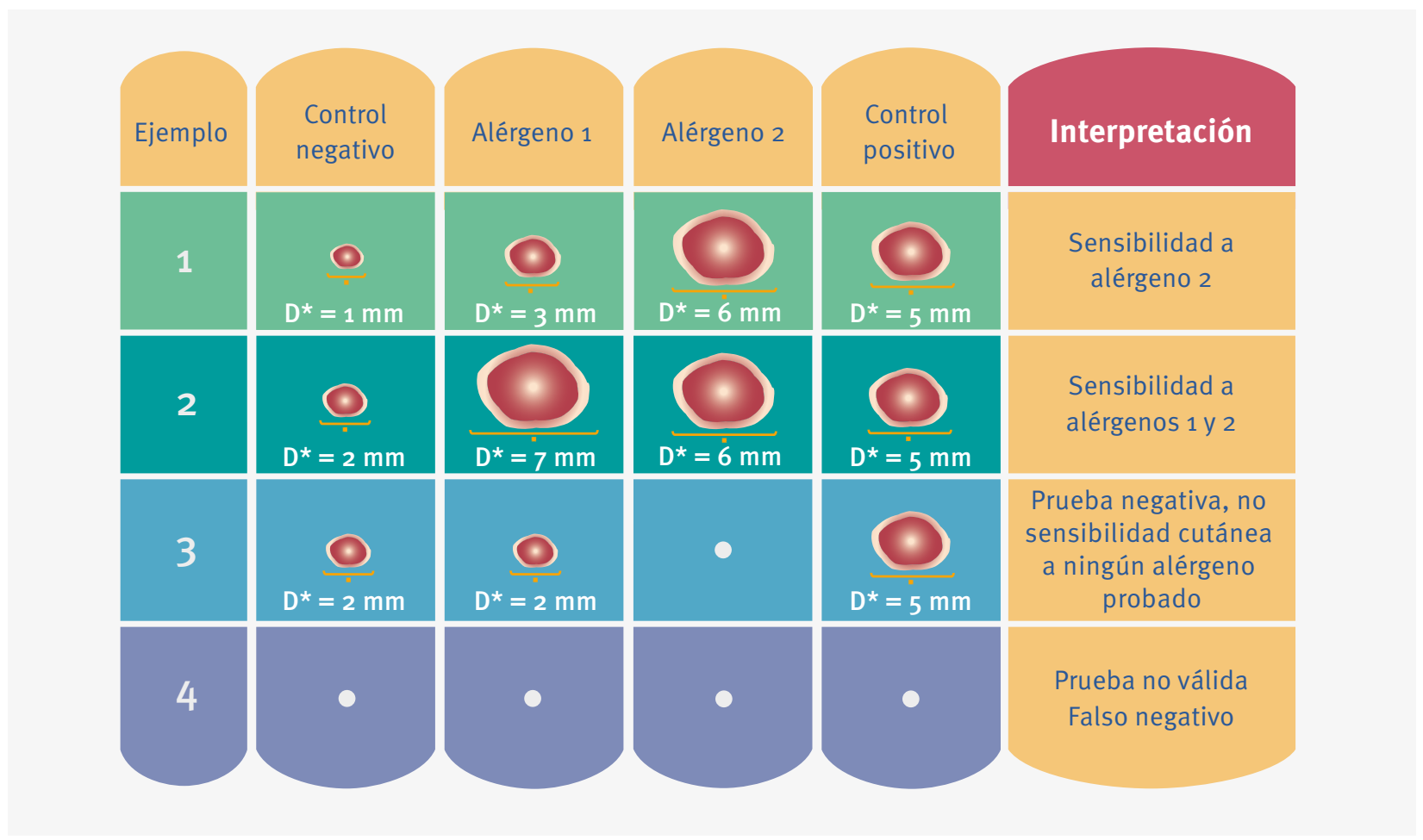

Figura 1.1. Forma correcta de registrar el resultado de las pruebas cutáneas. La recomendación es medir en milímetros el diámetro mayor de la pápula y del eritema o el diámetro promedio obtenido con la fórmula $D+$ d/2 (diámetro mayor + diámetro perpendicular a este entre 2). Se ilustran cuatro ejemplos. *D = diámetro mayor. Fuente: GUIMIT 2011. 
Otro método consiste en graduar las reacciones en "cruces" (de 0 a 4), aunque es menos preciso y subjetivo y tiene menor expresión cuantitativa.

Es importante mencionar que la falta de reactividad cutánea no siempre significa que la alergia esté descartada; ante duda diagnóstica razonable se podrán indicar otros métodos complementarios de diagnóstico, sin olvidar la premisa de que el criterio clínico siempre regirá por encima de todo.

\subsubsection{Pruebas de provocación y otras técnicas diagnósticas complementarias de las pruebas cutáneas en alergia respiratoria}

Algunas pruebas de provocación o retos con aeroalérgenos pueden incrementar la precisión diagnóstica para fines de orientar la ITA, tanto para identificar sensibilización cuando las pruebas cutáneas o de IgE específica sean negativas pero exista historia clínica sugestiva, como para distinguir cuál alérgeno es relevante y cuál no. Además, permiten investigar "nuevos" alérgenos potenciales, monitorizar la eficacia del tratamiento y documentar sensibilidad ocupacional. Las pruebas de reto nasal y conjuntival se consideran el estándar de oro para establecer sensibilidad clínica y han demostrado buena correlación con las PCP, ayudando a establecer su grado de sensibilidad y especificidad. Sin embargo, se carece de estudios clínicos que midan la respuesta a los retos nasales o bronquiales específicos como parámetro de eficacia primaria de la ITA.

Las pruebas de reto conjuntival se realizan por lo general cuando hay sospecha de alergia ocular localizada, pero en algunos casos pueden ser útiles también para investigar alergia nasal. Este reto evalúa síntomas de prurito o picor con índices objetivos, incluyendo volumen de lágrima, cantidad de moco y eritema bulbar o palpebral. Las pruebas de reto nasal se interpretan con mediciones subjetivas (síntomas) y mediciones objetivas de resistencia a la vía aérea nasal, número de estornudos y la medición de mediadores inflamatorios en secreciones nasales. Los retos bronquiales específicos (con alérgenos) proveen un estimado de la sensibilidad clínica de la vía aérea baja.

GUIMIT recomienda que las pruebas de reto respiratorias se realicen solo por personal entrenado y en centros hospitalarios de tercer nivel de atención.

Otras pruebas complementarias para evaluar la inflamación en la vía respiratoria (por ejemplo, óxido nítrico exhalado o análisis de aliento condensado) y el análisis de fluidos (por ejemplo, aspirado nasal o bronquioalveolar) pueden ayudar a definir los fenotipos o predecir la gravedad, pero no son útiles para orientar la ITA. De forma similar, las pruebas de reto en alergia alimentaria u ocupacional tienen valor diagnóstico, pero son muy poco útiles para decidir los alérgenos para la ITA.

\subsubsection{Pruebas cutáneas como marcadores de eficacia de ITA}

No hay evidencia de que una reducción en el tamaño de la pápula en la PCP sea un marcador confiable de desensibilización a nivel individual. Incluso, se ha sugerido que el uso repetido de pruebas in vivo podría inducir nuevas sensibilizaciones. ${ }^{20}$ GUIMIT no recomienda la repetición de pruebas cutáneas durante la ITA para fines de monitoreo de respuesta al tratamiento o como criterio para continuar o eventualmente suspender la ITA, ya que esta decisión se toma considerando la evolución clínica del paciente. Una posible excepción es la ITA para veneno de insectos, en donde se sugiere repetir las pruebas cada tres a cinco años.

GUIMIT sugiere la repetición de pruebas cutáneas únicamente en casos de sospecha clínica de nuevas sensibilizaciones (cambio en el tipo de exposición que provoca los síntomas), cambio de domicilio del paciente a otra región o país o por cambio de alergólogo con pruebas cutáneas previas hechas hace más de tres años o con reporte
Como complemento de PCP

en tercer nivel:

Reto nasal, conjuntival,

bronquial

Sugerimos: Sí, $100 \%$

Evidencia: Ila, Ila, III

Recomendación: B, B, C 
incompleto. Un reporte completo debe contener los nombres de los alérgenos probados, la concentración de los extractos utilizados, el fabricante, la técnica y el dispositivo empleado y el resultado reportado en milímetros, además del resultado de los controles negativo y positivo.

\subsection{Diagnóstico de alergia mediada por IgE con estudios in vitro (cuadro 1.4)}

\section{Cuadro 1.4. Resumen de diagnóstico con estudios in vitro}

Expertos de GUIMIT recomiendan o sugieren conforme evidencia en guías madre*

Acuerdo

En pacientes con sospecha de alergia por aeroalérgenos, alimentos y veneno de himenópteros, ¿existen métodos in vitro para identificar una respuesta de hipersensibilidad mediada por lgE?

- Alergia a aeroalérgenos

Recomiendan: Sí

$100 \%$

- Alergia a alimentos

Recomiendan: Sí

$100 \%$

- Alergia a veneno de insectos

Recomiendan: Sí

$100 \%$

En pacientes con alergia mediada por IgE, tanto niños como adultos, ¿qué método es el más indicado para realizar diagnóstico in vitro?

- Immunocap

- Immulite

- Rast

En pacientes con alergia mediada por IgE, tanto niños como adultos, ¿la prueba de activación de basófilos (BAT) está indicada para realizar el diagnóstico ex vivo ante sospecha de enfermedad alérgica?

En pacientes con alergia mediada por IgE, tanto niños como adultos, ¿el diagnóstico molecular podría aumentar la precisión diagnóstica y con ello mejorar la exactitud de su manejo?

En pacientes con alergia mediada por IgE, tanto niños como adultos, ¿existen alérgenos especie-específicos (ácaros, arboles, gramíneas, malezas, hongos, himenópteros, epitelios) para el diagnóstico de alergia que orienten hacia la formulación de la ITA?

En pacientes con alergia mediada por IgE, tanto niños como adultos, si no hay un alérgeno especie-específico involucrado solo positividad a panalérgenos, ¿son una indicación para inmunoterapia?

Experiencia clínica común de los expertos GUIMIT (Delphi simplificado): ** evidencia 1C

En un paciente con pruebas cutáneas positivas a 50 más pólenes no homólogos (de diferentes grupos), ¿es costo-efectivo solicitar el diagnóstico molecular para definir el contenido exacto de la ITA propuesta?

En un paciente con datos clínicos sugestivos de alergia al ácaro de polvo casero pero prueba de punción cutánea negativa, ¿se solicita diagnóstico in vitro con InmunoCAP?

\section{Puntos de buena práctica}

$\begin{array}{ll}\text { Recomiendan: Sí } & 100 \% \\ \text { Recomiendan: Sí } & 100 \% \\ \text { Recomiendan: No } & 100 \% \\ \text { Sugieren: Sí } & 100 \%\end{array}$

Sugieren: Sí

$100 \%$

Sugieren: Sí para todas las opciones

$100 \%$

Sugieren: No

$100 \%$

Sí, $37 \%$ recomienda y $45 \%$ sugiere

Sí, $30 \%$ recomienda y $52 \%$ sugiere

En pacientes con sospecha clínica de alergia, ¿qué podría utilizarse como método de cribado para el diagnóstico de alergia?

- IgE total

Sugieren: No

$100 \%$

- Phadiatop

Sugieren: Sí

$100 \%$

¿Se pueden comparar los resultados de diferentes sistemas de pruebas in vitro

Recomiendan: No

$100 \%$

(InmunoCAP, Inmulite, RAST, etcétera)?

¿La prueba de activación de basófilos (BAT) tiene ventajas sobre las pruebas de reto nasal o bronquial?

Sugieren: Sí, no se expone al paciente a

$100 \%$

* Se buscó nivel de evidencia y recomendación en cada guía madre (tablas fuente 1); se fusionaron evidencias y recomendaciones para emitir una recomendación para cierta acción (tablas fuente 2). Los vínculos a estas tablas se encuentran en el anexo 1.

** Contestación anónima de los 57 expertos GUIMIT. Con amplio consenso se obtiene un nivel de evidencia 1c, según CEBM. 


\subsubsection{Introducción}

Aunque la PCP todavía mantienen su lugar, históricamente reconocido desde hace más de 100 años como prueba de primera elección en el diagnóstico de las enfermedades alérgicas mediadas por IgE, ${ }^{13}$ desde hace décadas los especialistas han buscado métodos de diagnóstico alternativos, inicialmente en virtud de que no en todos los pacientes se pueden realizar la PCP (véase cuadro 1.2) y los médicos no especialistas en alergia no tienen acceso a ellas. Sin embargo, con la evolución de los conocimientos y descubrimientos en este campo, últimamente también ha quedado claro que las PCP no siempre reflejan la absoluta realidad de la alergia más importante del paciente. Por ello, las pruebas in vitro, que primero surgieron como pruebas alternativas para pacientes que no podían ser sometidos a PCP, cada vez están cobrando un lugar de mayor importancia en el abordaje diagnóstico integral del paciente alérgico. ${ }^{21}$

En el paciente que muestre polisensibilización el diagnóstico molecular en suero, la PCP podría orientar hacia la presencia de panalérgenos y al ajuste en los extractos a elegir para la ITA; de igual manera, en los pacientes con historia clínica positiva para alergia a veneno de himenópteros, pero con resultados ambiguos en pruebas cutáneas que podrían indicar alergia a varios véspidos, el diagnóstico molecular podría ser de utilidad.

Otra prueba que permite medir la activación de los basófilos sin tener que retar al paciente es la BAT (basophil activation test), que estimula a los basófilos ex vivo. En este apartado dedicado a las pruebas in vitro, primero se revisan aquellas con alérgeno completo y posteriormente se abordará el diagnóstico molecular, la selección del paciente y su interpretación, incluyendo aquellas con panalérgenos.

\subsubsection{Selección de guías madre específicas para diagnóstico in vitro}

Para el tema sobre diagnóstico de alergia mediada por IgE con estudios in vitro fue necesario buscar nuevas GM, dado que no se aborda en las originalmente establecidas como tales en GUIMIT. Se realizó una búsqueda de literatura enfocada en guías acerca del diagnóstico de alergia, particularmente sobre el diagnóstico in vitro y diagnóstico molecular. Solo se encontraron tres guías recientes, evaluadas con AGREE-II por dos expertos independientes. La guía de la European Academy of Allergy and Clinical Immunology sobre diagnóstico in vitro obtuvo $2.7 / 7$ puntos (39\%), ${ }^{22}$ la guía del National Institute of Allergy and Infectious Diseases 2.4/7 puntos (34\%), ${ }^{23}$ la guía de la World Allergy Organization sobre diagnóstico in vitro 3.58/7 (51 \%) ${ }^{24}$ y la guía Hoffmann-BAT 2.48/7 puntos $(35 \%) .{ }^{25}$ Aunque todas obtuvieron puntuación relativamente baja, las dos guías madre seleccionadas para este capítulo de diagnóstico in vitro fueron las primeras dos y la última se utilizó específicamente para la prueba de activación de basófilos.

\subsubsection{Métodos in vitro para identificar una respuesta de hipersensibilidad mediada por IgE}

Se sugiere el uso de las pruebas serológicas para la detección de IgE específica en pacientes con sospecha de alergia a aeroalérgenos, alimentos y veneno de insectos.

La IgE sérica total inicialmente fue utilizada como método de cribado para la evaluación de la presencia de enfermedad alérgica mediada por IgE. Sin embargo, sus valores predictivos positivos y negativos son bajos, debido a que puede elevarse en condiciones no alérgicas, como infestación por parásitos, y viceversa. Hasta $50 \%$ de los pacientes con enfermedad alérgica presenta niveles de IgE total en el rango normal. Por ello, el valor de IgE total no debe utilizarse como método de cribado para el diagnóstico de alergia. Actualmente existen métodos como Phadiatop que pueden servir de tamizaje 
ya que confirman o excluyen la presencia de sensibilización mediada por IgE ante un grupo de determinados alérgenos.

Se han desarrollado diversas técnicas in vitro para la medición de IgE específica, como la prueba de radioalergoadsorción (RAST), ensayo por quimioluminiscencia y ensayo con polímero acarreador hidrofílico. La sensibilidad de la IgE específica para aeroalérgenos varía de 60 a $80 \%$, con una especificidad de $90 \%$, dependiendo del método utilizado. Se ha reportado una sensibilidad para el ácaro del polvo casero en prueba cutánea de $80 \%$ y para IgE específica por microarreglo ImmunoCAP de 78.9\%, con una concordancia entre ambas pruebas para aeroalérgenos de $80.6 \%$.

El diagnóstico de alergia de base molecular es un enfoque utilizado para indagar la sensibilización alérgica de un paciente a nivel molecular, utilizando moléculas alergénicas naturales o recombinantes purificadas (componentes alergénicos) en lugar de extractos de alérgenos completos. Desde su introducción, han ganado terreno gradualmente en los protocolos diagnósticos de rutina; actualmente existen más de 130 moléculas alergénicas disponibles comercialmente para pruebas de IgE específicas in vitro.

Las pruebas in vitro para el diagnóstico de alergia alimentaria ayudan en la toma de decisiones y complementan las pruebas in vivo. El estándar de oro para el diagnóstico es la prueba de provocación oral. Se sugiere el uso de pruebas de IgE específica para valorar sensibilización a alimentos y correlacionar con cuadro clínico para diagnóstico de alergia alimentaria mediada por IgE. Esta guía está enfocada a inmunoterapia para aeroalérgenos, por lo que no se profundizará en el tema.

\subsubsection{Método para realizar diagnóstico in vitro: Immunocap, Immulite y RAST}

Los niveles de IgE específica en suero originalmente se medían utilizando la prueba RAST. Más recientemente esta prueba ha sido reemplazada por pruebas enzimáticas marcadas con fluorescencia, cuyos resultados son más sensibles.

Actualmente se encuentran disponibles métodos aún más precisos para medición de la IgE específica. Estos métodos son ImmunoCAP (Thermofisher Scientific/Phadia), ImmuLite (Siemens Healthcare Diagnostics) y HyTEC88 (Hycor Biomedical), que muestran buena precisión, reproducibilidad y reportan hasta el mismo límite de cuantificación de $0.1 \mathrm{kUA} / \mathrm{L}$. La automatización ha mejorado la precisión, reproducibilidad y linealidad a un estándar de desempeño $<15 \%$ de los coeficientes de variación, marcador de excelencia para los ensayos clínicos. La sensibilidad y la validez interna de las pruebas in vitro varían según la técnica empleada, siendo las más recomendadas ImmunoCAP e Immulite; recomendamos que la técnica RAST ya no se utilice.

Es importante señalar que no se pueden comparar los resultados de diferentes sistemas de prueba, ya que no son equivalentes y cada uno tiene su propio punto de corte. ${ }^{23}$ Immulite sobreestimó todos los niveles de IgE específica versus ImmunoCap, entre dos y cinco veces. ${ }^{26}$ Si se va a monitorizar una IgE específica, siempre se deberá utilizar la misma prueba. ${ }^{27}$

\subsubsection{Posibles indicaciones para prueba in vitro de determinación de IgE específica}

Las pruebas in vitro se deben realizar en quienes esté contraindicado realizar pruebas cutáneas (cuadro 1.2), como pacientes con dermatitis atópica grave, dermografismo, que no pueden suspender los antihistamínicos o que tienen una patología grave, como cardiopatía inestable. Una ventaja de las pruebas in vitro es que el consumo de medicamentos antialérgicos no interfiere con los resultados. Además, se pueden usar las pruebas in vitro como complemento a la PCP:
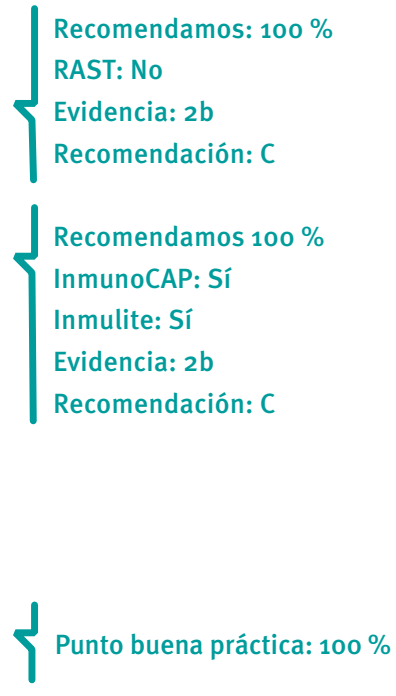

Recomendamos: Sí, $100 \%$

Evidencia: $2 b$

Recomendación: C 
- Para determinar con mayor precisión el nivel de sensibilización.

- Para confirmar sensibilización después de una PCP positiva: en la escuela europea es frecuente que solo se prescriba ITA a pacientes con ambas pruebas positivas: PCP e in vitro (esporádicamente, el estrés puede provocar reactividad cutánea falsapositiva $^{28}$ ).

- En un paciente con fuerte sospecha clínica de alergia a cierto alérgeno, pero con PCP negativa (una BAT o prueba de reto podría estar indicada).

- En pacientes con múltiples PCP, para detectar presencia de panalérgenos y con ello reducir en número de alérgenos para ITA.

\subsubsection{Prueba de activación de basófilos (BAT) en el diagnóstico de la alergia a aeroalérgenos}

En la alergia mediada por IgE, los mastocitos y los basófilos se sensibilizan fijando anticuerpos IgE a receptores de alta afinidad en su superficie. ${ }^{29}$ Los mastocitos se encuentran en el tejido, mientras que los basófilos son fácilmente accesibles en la sangre. Al desencadenar basófilos in vitro con concentraciones decrecientes de alérgenos, se puede determinar la dosis de activación más baja, correspondiente a la sensibilidad al umbral del alérgeno de los basófilos. ${ }^{25}$

La BAT se utiliza si las pruebas cutáneas o IgE específica en suero sean negativas, con un cuadro clínico sugestivo de alergia. En la BAT se aíslan los basófilos de una muestra de sangre del paciente. Ex vivo se exponen los basófilos al o los alérgenos investigados y se mide la concentración de moléculas de activación del basófilo (CD63 o CD203c). La BAT presenta sensibilidad moderada (50 a $85 \%$ ), según el tipo de alérgeno, pero con alta especificidad (85 a $100 \%$ ). Así, se puede realizar una exposición ex vivo del alimento, himenóptero o medicamento con los basófilos del paciente y de esta manera aumentar la rentabilidad diagnóstica in vitro por su alta especificidad.

La ventaja de la BAT es que no se requiere suspender el antihistamínico; además, en comparación con las pruebas de provocación nasal o bronquial, el paciente no se expone al alérgeno, por lo que resulta útil y más segura cuando es necesario realizar pruebas para el diagnóstico de rinitis, conjuntivitis o asma, así como para alergia alimentaria. Los expertos aún discuten su validez para alergia a medicamentos, ya que la prueba no está estandarizada y es altamente dependiente de la competencia del operador. ${ }^{25}$

\subsubsection{Diagnóstico molecular: utilidad en la determinación exacta de los alérgenos}

El diagnóstico molecular no detecta la presencia de IgE específica en el suero del paciente a alérgenos completos, sino a ciertas moléculas alergénicas individuales (por ejemplo, no a Phleum pratense, sino a Phl p 1, Phl p 2, Phl p 5, etcétera). Es una herramienta útil para distinguir una sensibilización genuina de la sensibilización por reactividad cruzada en pacientes polisensibilizados. Esta información podría ayudar al médico que se enfrenta a una PCP con múltiples resultados positivos (por ejemplo, fresno y pasto bermuda) a determinar el alérgeno relacionado con los síntomas clínicos y cuáles son los alérgenos con positividad por reactividad cruzada. Las ventajas del uso de alergia molecular son los siguientes:

- Aporta mayor precisión diagnóstica.

- Permite distinguir moléculas clínicamente relevantes.

- En ciertos casos puede brindar información sobre el pronóstico del paciente.

Las desventajas del diagnóstico molecular son la necesidad de estudios multicéntricos a gran escala y basados en diferentes poblaciones, para evaluar los patrones de

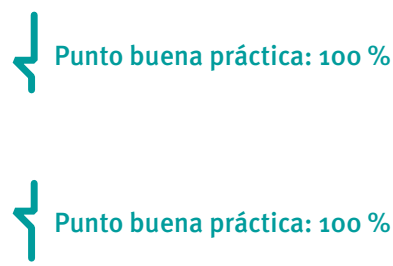

Sugerimos: Sí, $100 \%$

Evidencia: $2 b$

Recomendación: C

Punto buena práctica: $100 \%$ 
sensibilización y con ello la elección correcta de las moléculas por analizar, el costo de la prueba y la necesidad de un especialista capacitado en alergia para la correcta interpretación de los resultados.

\subsubsection{Indicaciones para el uso del diagnóstico molecular}

- Pacientes polisensibilizados con síntomas poco claros o que no responden al tratamiento.

- Pacientes en quienes la historia clínica y los métodos tradicionales de diagnóstico de alergia no pueden identificar el alérgeno causal.

- Pacientes con múltiples sensibilizaciones a pólenes en la prueba cutánea y que tengan indicada ITA. ${ }^{30,31}$

Existen algunas otras indicaciones para pacientes con alergia a himenópteros (véase capítulo 6) y alergia alimentaria, que no es parte del objetivo de esta guía.

La ITA es un tratamiento que dura entre tres y cinco años. La identificación del o de los alérgenos primarios es importante para otorgar la mejor eficacia y seguridad en el paciente. Estudios han demostrado que en $50 \%$ puede estarse indicando erróneamente ITSL o ITSC cuando esta se basa en el resultado de la PCP. ${ }^{31}$

El diagnóstico molecular de alergia con alérgenos simples o micromatrices de alergia múltiple es un ejemplo típico de la medicina de precisión ${ }^{21,32}$ que mejora la especificidad del diagnóstico de sensibilización a aeroalérgenos; especialmente en pacientes polisensibles, se puede aplicar en las alergias alimentarias e, incluso, puede revelar anafilaxia inexplicada. ${ }^{33}$

\subsubsection{Moléculas alergénicas especie-específicas para aeroalérgenos: selección correcta de extractos (cuadro 1.5)}

Por grupo alergénico podemos mencionar las siguientes moléculas alergénicas especieespecíficas:

- Ácaros: los ácaros más comunes son Dermatophagoides pteronyssinus y Dermatophagoides farinae; sus alérgenos principales son Der p 1 y Der $\mathrm{p} 2$ (juntos identifican 63 a $97 \%$ de las sensibilizaciones), así como Der f 1 y Der f 2. Estudios recientes demuestran que Der p 23, presente en la superficie de las partículas fecales del ácaro (forma aerotransportada de los alérgenos grupo 1 del ácaro) es altamente alergénica.

- Árboles: Cup a 1 es un marcador de la familia Cupressaceae, Bet v 1 es el alérgeno mayor del polen de los Fagales, Ole e 1 es el alérgeno más común en la sensibilización por polen de olivo y se usa como marcador para alergia por reacción cruzada con fresno. Pla a 1 y Pla a 2 son los marcadores especie-específicos para sensibilización al árbol del plátano de sombra.

- Gramíneas: los grupos más importantes son los de la familia Pooideae y Panicoideae, que pueden contener proteínas de reactividad cruzada; si bien Phl p 1 es el principal marcador para alergia a gramíneas, otros alérgenos mayores que podrían utilizarse como marcadores son Phl p 5 y Phl p 2 (sirven cuando Phl p 1 es negativo); en estos pólenes, la reactividad cruzada se puede medir a través de $\mathrm{Phl} \mathrm{p} \mathrm{4,} \mathrm{Phl} \mathrm{p} \mathrm{7,}$ Phl p 11 o Phl p 12 (determinantes de carbohidratos de reactividad cruzada [CCD] o panalérgenos). En la familia Panicoideae, los alérgenos especie-específicos son Pas n 1, Sor h 1 y Cyn d 1.

- Malezas: los alérgenos especie-específicos de malezas que se pueden utilizar son Amb a 1 (como marcador de Ambrosia), Art v 1 (como marcador de Artemisa) y
Sugerimos: Sí, $100 \%$

Evidencia: 2a

Recomendación: B

Sugerimos: Sí, $100 \%$

Evidencia: $2 a$

Recomendación: B 


\begin{tabular}{|c|c|c|c|c|c|c|c|c|}
\hline $\begin{array}{c}\text { Fuente } \\
\text { alergénica }\end{array}$ & $\begin{array}{l}\text { Alérgeno especie- } \\
\text { específico }\end{array}$ & $\begin{array}{l}\text { Posible } \\
\text { utilidad } \\
\text { para ITA }\end{array}$ & Reactividad cruzada & Profilina & Polcalcina & LTP & Tropomiosina & $\begin{array}{l}\text { Lipoca- } \\
\text { lina }\end{array}$ \\
\hline Ambrosia & Amb a 1 & Sí & $\begin{array}{l}\text { Amb a } 4 \text { (homólogo } \\
\text { de Art v 1) }\end{array}$ & $\begin{array}{l}\text { Amb } \\
\text { a } 8\end{array}$ & $\begin{array}{l}\text { Amb a } 9 \\
\text { Amb a } \\
10\end{array}$ & Amb a 6 & & \\
\hline Artemisia * & Art $\vee 1$, Art $\vee 3$ & Sí & $\begin{array}{l}\text { Art v } 6 \text { (homólogo } \\
\text { de Amb a 1) }\end{array}$ & Art $\vee 4$ & Art $\vee 5$ & Art v 3 & & \\
\hline Parietaria & Par j 2 & Sí & Marcador de LTP & Parj 3 & Par j 4 & $\begin{array}{l}\text { Par j 1, } \\
\text { Par j } 2\end{array}$ & & \\
\hline Salsola & Sal k 1 & Sí & & Sal k 4 & & & & \\
\hline $\begin{array}{l}\text { Chenopo- } \\
\text { dium }\end{array}$ & Che a 1 & Sí & & Che a 2 & Che a 3 & & & \\
\hline
\end{tabular}

\begin{tabular}{|c|c|c|c|c|c|c|c|c|c|}
\hline Phleum & Phl p 1, Phl p 5 & Sí & $\begin{array}{l}\text { Alérgenos menores, } \\
\text { a menudo en canti- } \\
\text { dades insuficientes } \\
\text { en el extracto utili- } \\
\text { zado para la ITA }\end{array}$ & Phl p 12 & Phl p 7 & & & & \\
\hline Abedul & Bet $v 1$ & Sí & $\begin{array}{l}\text { PR10 (homólogos } \\
\text { Bet v 1) de otros } \\
\text { pólenes de árboles } \\
\text { o alimentos }\end{array}$ & Bet $v 2$ & Bet v 4 & & & & $\begin{array}{l}\text { Bet } \\
\text { v } 1\end{array}$ \\
\hline Olivo & Ole e 1 & Sí & & Ole e 2 & Ole e 3 & $\begin{array}{l}\text { Ole e } 7 \\
\text { (poca re- } \\
\text { actividad } \\
\text { cruzada } \\
\text { con otras } \\
\text { LTP) }\end{array}$ & & & \\
\hline Cipres & Cup a 1 & Sí & Cry j 1 & & & & & & \\
\hline $\begin{array}{l}\text { Plátano } \\
\text { de sombra }\end{array}$ & $\begin{array}{l}\text { Pla a } 1 \\
\text { Pla a } 2\end{array}$ & Sí & 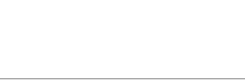 & & & Pla a 3 & & & \\
\hline $\begin{array}{l}\text { Cedro japo- } \\
\text { nés }\end{array}$ & Cry j 1 & Sí & & & & & & & \\
\hline Aliso (Alnus) & Aln g 1 & Sí & $\begin{array}{l}\text { PR1o (homólogos } \\
\text { Bet v 1) }\end{array}$ & & & & & & $\begin{array}{l}\text { Aln } \\
\text { g } 1\end{array}$ \\
\hline Ácaros & $\begin{array}{l}\text { Der p 1, } \\
\text { Der p 2, } \\
\text { Derf } 1 \text {, } \\
\text { Derf } 2\end{array}$ & Sí & $\begin{array}{l}\text { Cruce con otros } \\
\text { ácaros }\end{array}$ & & & & $\begin{array}{l}\text { Der p } 10 \\
\text { (se comporta } \\
\text { como pan- } \\
\text { alérgeno, cruce } \\
\text { con camarón, } \\
\text { cucarachas, } \\
\text { nemátodos). } \\
\text { Es reconocido } \\
\text { por } 81 \% \text { de los } \\
\text { sujetos alérgicos } \\
\text { a ácaros }\end{array}$ & & \\
\hline Cucaracha & $\begin{array}{l}\text { Bla g } 1 \text {, } \\
\text { Bla g } 2, \\
\text { Per a } 1\end{array}$ & Sí & & & & & $\begin{array}{l}\text { Bla g } 7 \\
\text { Per a } 7\end{array}$ & Bla g 4 & \\
\hline
\end{tabular}




\begin{tabular}{|c|c|c|c|c|c|c|c|c|c|}
\hline $\begin{array}{c}\text { Fuente } \\
\text { alergénica }\end{array}$ & $\begin{array}{c}\text { Alérgeno especie- } \\
\text { específico }\end{array}$ & $\begin{array}{l}\text { Posible } \\
\text { utilidad } \\
\text { para ITA }\end{array}$ & Reactividad cruzada & Profilina & Polcalcina & LTP & Tropomiosina & $\begin{array}{l}\text { Lipoca- } \\
\text { lina }\end{array}$ & PR-10 \\
\hline Gato & Fel d 1 & Sí & $\begin{array}{l}\text { Fel d } 2 \text { (cruce con } \\
\text { albúminas séricas } \\
\text { de mamíferos) }\end{array}$ & & & & & Fel d 4 & \\
\hline Perro & Can $\mathrm{f}_{1}$ & Sí & $\begin{array}{l}\text { Can f } 3 \text { (cruce con } \\
\text { albúminas séricas } \\
\text { de mamíferos) }\end{array}$ & & & & & $\begin{array}{l}\text { Can } \mathrm{f}_{1} \\
\text { Can } \mathrm{f} 2\end{array}$ & \\
\hline Alternaria & Alt a 1 & Sí & & & & & & & \\
\hline Aspergillus & $\begin{array}{l}\text { Asp f } 1 \\
\text { Asp f } 2 \\
\text { Asp f } 3\end{array}$ & & $\begin{array}{l}\text { Asp f } 6 \text { (cruce con } \\
\text { otros hongos) }\end{array}$ & & & & & & \\
\hline $\begin{array}{l}\text { Cladospo- } \\
\text { rium }\end{array}$ & Cla h 8 & & & & & & & & \\
\hline$C C D$ & $\begin{array}{l}\text { Phl p } 4 \text { MUXF3 }_{3} \\
\text { Jug r } 2\end{array}$ & & & & & & & & \\
\hline
\end{tabular}

La nomenclatura de las moléculas alergénicas se realiza con el nombre latino de la familia (género y especie). Por ejemplo, los alérgenos que comiencen con Art v corresponden a Artemisia. Un número se adjunta al nombre para designar a los diferentes alérgenos de la especie (Art v 1, Art v 5, etcétera), según el orden de identificación del alérgeno.

Artemisia: Art v 3 muestra posible reacción cruzada con otras LTP como Pru p 3, Cor a 8; podría intervenir en los síndromes polen-alimento de las malezas. Phleum: Phl p 2, Phl p 4, Phl p 6, Phl p 11 (sin datos concluyentes para indicación de ITA)

Abedul: se asocia con síndrome de alergia oral. En México es un marcador de sensibilización a Alnus.

Olivo: marcador de sensibilización de fresno y olivo ruso. Ole e 9 (marcador de riesgo de reacción a inmunoterapia).

Ácaro: Der p 23 (proteína altamente alergénica que se encuentra en la superficie fecal del ácaro, forma aerotransportada de los alérgenos del ácaro Der p 1). Cucaracha: asociada con asma en edad pediátrica dependiente de la exposición.

Perro: Can $\mathrm{f}_{5}$ (calicreína prostática de perro asociada con asma severa).

Alternaria: factor de riesgo para asma en niños y adultos.

Aspergillus: responsable de aspergilosis broncopulmonar alérgica (Asp f 2, Asp f 4, Asp f 6); Asp f 1, Asp f 3 son responsables de asma alérgica. Cladosporium: responsable de alergia respiratoria.

$C C D=$ determinantes de carbohidratos de reactividad cruzada; marcadores alergénicos de CCD en diagnóstico molecular son responsables de pruebas cutáneas múltiples positivas.LTP = proteína transportadora de lípidos, .

ambos podrían cruzar como Art v 6 para Amb a 1 (sin embargo, si Art v 1 es negativo no se requiere ITA para Artemisia). Lo mismo aplica para Art v 1 con Amb a 4 (pero si Amb a 1 es negativo no se requerirá ITA para Ambrosia). Cabe mencionar que con el extracto total, los pacientes presentarían PCP positivas a ambos, pero con las moléculas alergénicas especie-específicas solo se prescribirá ITA con el alérgeno al cual presenta positividad. Par j 2 es un marcador específico para Parietaria y Pla L 1 se usa como marcador especie-específico para plántago.

- Hongos: el alérgeno especie-específico para indicación de ITA para Alternaria es Alt a 1. La hipersensibilidad para Aspergillus fumigatus sugestiva para diagnóstico de aspergilosis broncopulmonar está determinada por Asp f 2, Asp f 4 y Asp f 6, sin embargo, la sensibilización para Asp f 1 y Asp f 3 se asocia con asma alérgica.

- Epitelios: El Fel d 1 es el alérgeno especie-específico para alergia a gato. Puede contener lipocalcinas que pueden provocar PCP positivas a otros animales (Fel d 4, Mus m 1, Equ c 1, Can f 1 y 2). Otro alérgeno es Can f 5; la calicreína prostática del perro se asocia con asma grave. Los marcadores específicos de alergia para gato/ perro/caballo son Fel d 1/Can f 1/Can f 2/Can f 5/Equ c 1. 
- Himenópteros: para la sensibilización a abeja y avispa, los alérgenos contienen en su superficie proteínas de cruce, Api m 2, Ves v 2 (hialuronidasa), Api m 5, Ves v 3 (dipeptidil peptidasa), Api m 12, Ves v 6 (vitellogenins), que pueden dar positivo en PCP o IgE específica a extracto completo. Los extractos moleculares de sensibilización especie-específicos para abeja son Api m 1, Api m 3, Api m 4 y Api m 10 y para avispa, Ves $v 1$ y Ves $v 5$ (véase capítulo 6).

\subsubsection{Panalérgenos y la decisión de proporcionar o no ITA}

Los panalérgenos se pueden encontrar en diferentes especies; los pacientes sensibilizados a panalérgenos frecuentemente muestran múltiples pruebas cutáneas o IgE específicas de extracto completo positivas (polisensibilizado), debido a que diferentes extractos contienen familias de panalérgenos de reactividad cruzada. En el análisis del diagnóstico molecular (cuadro 1.5), puede surgir la pregunta $i s i$ se debe indicar ITA en pacientes de cualquier edad con alergia respiratoria si no hay un alérgeno especie-específico involucrado, solo positividad a panalérgenos? GUIMIT sugiere que no. A continuación, se revisan los grupos de panalérgenos descritos.

- Polcalcinas (proteínas fijadoras de calcio): no están presentes en los alimentos, presentan alta reactividad cruzada entre familias de pólenes (gramíneas, árboles y malezas), por lo que son marcadores de polisensibilización. Se desconoce su importancia clínica y su positividad no es indicación para ITA. Los alérgenos moleculares de diagnóstico de polcalcinas son Bet v 4, Phl p 7, Art v 5, Che a 3.

- Homólogos de Bet v 1 (PR-10): asociados con síndrome de alergia oral. Se ha sugerido que la ITA para polen de abedul mejora no solo los síntomas respiratorios relacionados con el polen, sino también las reacciones adversas relacionadas con alimentos, sin embargo, todavía no hay una evidencia que lo demuestre. Estos panalérgenos tienen alta reactividad cruzada entre el grupo de fagales y alimentos, sobre todo rosáceas. Por lo tanto, la sensibilización a Bet v 1 con síntomas orales, pero sin síntomas respiratorios no se debe considerar una indicación para ITA al polen de abedul. Los alérgenos moleculares de diagnóstico son Bet v 1, Act d 8, Ara h 8, Pru p 1.

- Proteinas transportadoras de lípidos (LTP) respiratorias: relacionadas con reacciones graves cuando son de origen alimentario (frutas, frutos secos, verduras y látex), ya que resisten el calor y la digestión. Se han encontrado como alérgenos mayores (por ejemplo, Par j 1 [Parietaria judaica]) y como menores (Ole e 7 [olivo]), relacionadas con síntomas graves de asma y mayor riesgo a reacción adversa con la ITA. Las LTP respiratorias son Par J 1, Amb a 6, Art v 3, Ole e 7, Pla a 3.

- Profilina: es reconocida en $50 \%$ de los pacientes sensibilizados a pólenes y en 10 a $20 \%$ de los sensibilizados primariamente al polen del abedul. Su importancia clínica como alérgeno respiratorio es variable. Los síntomas relacionados con sensibilización a profilina son los del síndrome de alergia oral. Estudios con la profilina de la palma y estudios de provocación conjuntival con profilina han demostrado que puede actuar como aeroalérgeno, sin embargo, la positividad a ella no es una indicación para ITA. Los alérgenos moleculares para profilinas respiratorias son Bet v 2, Phl p 12. Aln g 2, Que a 2, Art v 4, Amb a 8, Par k 3, Ole e 2, Fra e 2, Cup s 8, Pho d 2.

- Tropomiosina: panalérgeno que comparten los artrópodos, por lo que es responsable de la reactividad cruzada entre ácaros, cucarachas, mariscos (camarón) y parásitos. El diagnóstico molecular es más específico y tiene alto valor predictivo positivo para diagnóstico de alergia a camarón. No se usa para indicación de ITA para alergia a ácaros. Los alérgenos para valorar sensibilización por tropomiosina son Der p 10, Bla g 7 y en los mariscos, Pen a 1, Pan s 1, Oct v 1 , Per v 1 , Cha $\mathrm{f} 1$. 
- CCD: se encuentra en extractos completos o IgE específica de extracto completo, no así en alérgenos recombinantes o purificados. Usar alérgenos de extracto completo puede producir pruebas cutáneas positivas a diferentes alérgenos debido a estos carbohidratos. Se ha demostrado que no tienen relevancia clínica en pacientes alérgicos. En un paciente que solo tiene positividad a CCD, sin positividad a moléculas alérgeno-específicas, no existe indicación para ITA.

En pacientes polisensibilizados (con positividad múltiple en las PCP), GUIMIT sugiere pensar en que puede estar involucrado un panalérgeno o un $\mathrm{CCD}$, que requiera el uso de diagnóstico molecular para mayor precisión diagnóstica.

Sugerimos que la ITA se indique en pacientes con alergia alimentaria y respiratoria en quienes esté involucrado un panalérgeno que sea especie-específico (por ejemplo, abedul: Bet v 1) y presenten síntomas respiratorios asociados; y que la decisión de usar ITA para inhalantes de reacción cruzada no se recomiende con base únicamente en la alergia alimentaria, sino que se prescriba en función de los síntomas respiratorios. ${ }^{34}$

\section{Capítulo 2. Indicaciones para la inmunoterapia específica, subcutánea y sublingual, con alérgenos}

\section{Cuadro 2.1. Resumen de indicaciones para el inicio de inmunoterapia subcutánea e inmunoterapia sublingual}

Existen directrices deseables en todo paciente para decidir inicio de ITA

- Pacientes con sensibilización verificada que se relaciona con síntomas clínicos

- Disponibilidad de alérgenos de alta calidad

- Pacientes en quienes la evitación del alérgeno no es posible o es inadecuada

Además...

Se recomienda indicar ITSC o ITSL en un paciente con:

- Rinitis o rinoconjuntivitis estacional o perenne

- Rinitis con el objetivo de reducir el riesgo de aparición de asma

- Asma leve o moderada controlada

- Asma, con el objetivo de reducir los síntomas, mejorar el control de la enfermedad, reducir uso de medicamentos, disminuir la hiperreactividad de la vía aérea alérgeno específico y mejorar la calidad de vida

- Alergia respiratoria a ácaro, polen de pasto o árboles, con el objetivo de reducir los síntomas de la enfermedad y el uso de medicamentos

- Rinitis y asma coexistente

- Pacientes con alergia respiratoria monosensibilizados

- Pacientes con alergia respiratoria polisensibilizados o monoalérgicos

- Adultos mayores con alergia respiratoria

Se sugiere indicar ITSC o ITSL en un paciente con:

- Asma, con el objetivo de disminuir el riesgo de exacerbaciones y para disminuir la hiperreactividad inespecífica de la vía aérea

- Alergia respiratoria a epitelio o pelo de gato o perro, con el objetivo de reducir los síntomas de la enfermedad y el uso de medicamentos

- Asma grave controlada*

- Pacientes con alergia respiratoria polisensibilizados o polialérgicos

- Dermatitis atópica extrínseca con alérgeno clínicamente relevante**

- Niños de 2 a 5 años con alergia respiratoria

* Valorar riesgos y beneficios, así como considerar esquemas con patrón de seguridad mayor o uso de tratamiento concomitante (véase capítulo 10).

** Evidencia disponible principalmente en alergia a ácaro.

ITA = inmunoterapia con alérgenos, ITSC = inmunoterapia subcutánea, ITSL = inmunoterapia sublingual. 


\subsection{Introducción}

La ITA es un tratamiento a largo plazo que permite obtener beneficios sustanciales en los casos de pacientes con alergia respiratoria, tanto en la sintomatología como en el uso de medicamentos; hasta el momento es el único tratamiento capaz de modificar la historia natural de las enfermedades alérgicas.

La elección del paciente correcto para la prescripción de ITA influirá directamente en la eficacia de esta, así como en la percepción del paciente de sus beneficios; al ser un tratamiento a largo plazo, es crucial identificar el momento adecuado para iniciarla y el paciente idóneo para su uso.

En el presente capítulo explicamos las recomendaciones y sugerencias en torno a las indicaciones de ITA, tanto para ITSC como ITSL, así como sus contraindicaciones (cuadro 2.2).

\subsection{Uso de ITA en niños de 2 a 5 años de edad}

$\mathrm{Al}$ igual que en los adultos, tanto la ITSC como ITSL ha mostrado beneficios en la reducción de síntomas y de medicamentos de pacientes pediátricos con alergia respiratoria, por lo que debe ser considerada su administración en población pediátrica que cuente con indicaciones claras para su uso.

La disyuntiva se presenta en los niños muy pequeños, específicamente de dos a cinco años, en quienes la evidencia disponible es limitada y la opinión en las diferentes guías madre es controversial; la escuela estadounidense y la europea sugieren tanto el uso de ITSC como de ITSL en niños menores de cinco años; sin embargo, hacen énfasis en las preocupaciones sobre seguridad en este grupo etario, sobre todo la comunicación deficiente en las reacciones sistémicas, que podría retrasar el reconocimiento de estas y su manejo temprano.

Si bien es importante considerar que precisamente es en estas edades donde los pacientes podrían obtener mayores beneficios del uso temprano de ITA, la mayor parte de los efectos adjudicados a la misma son extrapolaciones de ensayos clínicos realizados en pacientes de mayor edad o con población mixta, por lo que la decisión de iniciar ITA, ya sea ITSC o ITSL, en este grupo de edad deberá realizarse con cautela y siempre individualizando cada caso y ponderando los posibles beneficios y riesgos.

Por consenso de expertos mexicanos se decidió sugerir iniciar ITA en niños de dos a cinco años, siempre individualizando cada caso y considerando que el perfil de seguridad y la administración domiciliaria hace a la ITSL una modalidad más atractiva para los niños pequeños y sus cuidadores.

\subsection{Uso de ITA en adultos mayores}

La edad por sí misma no imposibilita el uso de ITA y puede considerarse el inicio de la misma en adultos mayores, siempre evaluando los riesgos contra los beneficios de su administración. Si bien la presencia de enfermedades crónicas y el uso de medicamentos como betabloqueadores, inhibidores de la enzima convertidora de angiotensina (IECA) e inhibidores de monoaminooxidasa es más frecuente en los adultos mayores, la ITA (tanto ITSC como ITSL) puede proporcionar beneficios significativos con un perfil de seguridad razonable, por lo que se debe considerar en caso de tener una indicación adecuada y cuando las comorbilidades estén controladas.

La valoración multidisciplinaria resulta fundamental en estos pacientes, ya que existen diversas enfermedades propias de la edad que pudieran simular síntomas de

Sugerimos: Sí

$85 \%$ ITSC

$97 \%$ ITSL

Evidencia: 4/4

Recomendación: D/D

Recomendamos: Sí, $100 \%$ para ITSC e ITSL

Evidencia: $1 \mathrm{~b}, 1 \mathrm{~b}$ Recomendación: B, A 
alergia respiratoria, por lo que es crucial establecer un correcto diagnóstico para percibir los beneficios de la ITA en la sintomatología y reducción del uso de medicamentos en este grupo de la población.

\subsection{Indicaciones para uso de ITSC e ITSL en niños $>5$ años y adultos}

La selección del paciente es fundamental para lograr los beneficios esperados con la ITA; en general, se recomiendan tres directrices básicas para considerar el uso de ITSC o ITSL:

- Pacientes con sensibilización verificada que correlacione con síntomas clínicos.

- Pacientes en quienes evitar el alérgeno no es posible, es inadecuado o insuficiente.

- Disponibilidad de extractos alergénicos de alta calidad.

\subsubsection{Indicaciones para recomendar el inicio de ITA (evidencia alta)}

- Niños y adultos con rinitis o rinoconjuntivitis estacional, con el objetivo de obtener un beneficio a corto y largo plazo.

- Niños y adultos con rinitis o rinoconjuntivitis perenne, con el objetivo de obtener un beneficio a corto y largo plazo

- Niños y adultos con asma, con el objetivo de reducir los síntomas, mejorar el control de asma, reducir el uso de medicamentos, disminuir la hiperreactividad específica de la vía respiratoria y mejorar calidad de vida.

- Niños y adultos con asma y alergia comprobada a ácaro del polvo casero, polen de gramíneas y árboles, con el objetivo de reducir el uso de medicamentos.

- Niños y adultos con asma leve o moderada controlada, con el objetivo de reducir síntomas y uso de medicamentos.

- Niños y adultos con alergia respiratoria monosensibilizados.

- Niños y adultos con alergia respiratoria polisensibilizados o monoalérgicos.

- Niños y adultos con rinitis y asma coexistente.

- Niños y adultos con alergia respiratoria a ácaro, polen de gramíneas o árboles.

Estas recomendaciones se estipulan con base en el grado de evidencia que se presentó en las diferentes GM y a estudios separados revisados en los que se apoya la eficacia para el grupo de edad específico.

En general se ha demostrado evidencia a favor de usar ITA en niños y adultos con síntomas de alergia respiratoria, ya sea rinitis, rinoconjuntivitis, asma o su combinación, tanto con el objetivo de reducir síntomas y uso de medicamentos, como para mejorar el control de la enfermedad y disminuir la hiperreactividad específica de la vía respiratoria. La información científica a favor de la ITA es especialmente contundente en el caso de pacientes monoalérgicos con síntomas relacionados con ácaros y pólenes de gramíneas o árboles.

Específicamente en asma se recomienda iniciar ITA solo en aquellos pacientes con enfermedad leve o moderada y controlada, ya que el riesgo de reacciones adversas se incrementa considerablemente cuando la enfermedad es grave o no está bajo control.

\subsubsection{Indicaciones para sugerir el inicio de ITA (evidencia moderada o baja)}

Algunas indicaciones para sugerir el inicio de la ITA en pacientes con alergia a aeroalérgenos son las siguientes:

Recomendamos: Sí, $100 \%$

Evidencia: 1b, $2 a$

Recomendación: A,B
Recomendamos: Sí, $100 \%$

Evidencia: $1 b$

Recomendación: A 
- Niños y adultos con asma, con el objetivo de disminuir las exacerbaciones de asma.

- Niños y adultos con asma, con el objetivo de disminuir la hiperreactividad inespecífica de la vía respiratoria.

- Niños y adultos con asma y alergia comprobada a gato o perro, con el objetivo de reducir los síntomas y el uso de medicamentos.

- Niños y adultos con asma moderada o grave controlada, con el objetivo de reducir los síntomas y el uso de medicamentos.

- Niños y adultos con alergia respiratoria polisensibilizados o polialérgicos.

- Niños y adultos con dermatitis atópica.

- Niños y adultos con alergia respiratoria a gato o perro.

En los pacientes con asma moderada o grave y que requieran ITA se deberá evaluar minuciosamente el grado de control de la enfermedad, evaluando individualmente los riesgos y beneficios. Sugerimos iniciar solo cuando la enfermedad se encuentre controlada, de preferencia con volumen espiratorio forzado durante el primer segundo/capacidad vital forzada $\left(\mathrm{VEF}_{1} / \mathrm{CVF}\right)>70 \%$, por la susceptibilidad incrementada para presentar efectos adversos sistémicos en este grupo de individuos. Si bien se consideró realizar una sugerencia en contra del uso de ITA, se reconoce que esta medida terapéutica podría ser de gran ayuda para el control a largo plazo de la enfermedad con potenciales beneficios en la reducción de uso de medicamentos e, incluso, de las exacerbaciones. ${ }^{35} \mathrm{Se}$ podría considerar iniciar con la forma más segura de ITA, con ITSL.

Debido a que la evidencia es menos contundente a favor del uso de ITSC o ITSL en pacientes con alergia comprobada a epitelios de animales, la decisión de iniciar ITA en estos pacientes se considera una sugerencia de acuerdo con los expertos de GUIMIT, sin embargo, se espera que muchos de estos pacientes se beneficien con el tratamiento.

El uso de ITA en pacientes polisensibilizados o polialérgicos ha sido motivo de controversia en todo mundo, con la escuela europea a favor del uso de monoterapia mientras que la escuela americana ha propuesto la posibilidad de realizar mezclas de alérgenos en ITA. La experiencia en México muestra que muchos de los pacientes están polisensibilizados con síntomas comprobados a múltiples alérgenos, por lo que sugerimos iniciar ITA en este grupo de pacientes, priorizando los alérgenos relacionados con los síntomas presentes y siguiendo las reglas de mezclas en ITSC e ITSL. En el Delphi simplificado, con base en la experiencia comunitaria de expertos mexicanos, se sugirió considerar eficaz y segura una ITSC o ITSL con una mezcla de cuatro alérgenos no homólogos.

En pacientes con dermatitis atópica se sugiere iniciar ITA en pacientes con dermatitis atópica extrínseca y con aeroalérgeno clínicamente relevante, ya que ha demostrado eficacia, sobre todo en alergia a ácaros.

\subsubsection{Pacientes en quienes no se sugiere o recomienda iniciar ITA}

- No se sugiere en niños y adultos con rinitis o rinoconjuntivitis estacional en modalidad preestacional y pre-coestacional.

- No se recomienda en niños y adultos con asma grave no controlado con el objetivo de reducir síntomas y uso de medicamentos.

Aun cuando las GM recomiendan el uso de ITSC preestacional y pre-coestacional en niños y adultos con rinitis estacional, la mayoría de las regiones de México tienen estacionalidad poco marcada, lo cual hace no recomendable el uso de este esquema de ITSC e ITSL. Sin embargo, existen excepciones para algunas partes en el norte del país, donde existe clara estacionalidad. 
Si bien las GM sugieren el inicio de ITSC en asma moderada o grave para reducir los síntomas, con base en resultados consistentes de estudios individuales, la preocupación sobre la seguridad en los pacientes con asma grave hace que se sugiera no iniciar tratamiento en población mexicana, sobre todo cuando no se tiene control de la enfermedad. La sugerencia puede cambiar si baja el nivel de gravedad y la enfermedad se encuentra estable y controlada y en quienes se planeé utilizar medicamentos coadyuvantes como estrategia para mejorar la tolerancia y el perfil de seguridad (véase capítulo 10).

\subsubsection{Circunstancias clínicas para las que no se sugiere iniciar ITA}

Algunas circunstancias clínicas para las que no se recomienda iniciar ITA son, entre otras:

- Niños y adultos con asma, con el objetivo de mejorar el PEF o $\mathrm{VEF}_{1}$.

- Niños y adultos con asma y alergia a hongos, con el objetivo de reducir los síntomas y el uso de medicamentos

- Niños y adultos con alergia respiratoria y monosensibilizados a hongos

- Niños y adultos con alergia respiratoria y monosensibilizados a cucaracha

Debido a la poca información encontrada o a evidencia inconsistente, no se puede hacer recomendación a favor o en contra del inicio de ITA en pacientes con alergia respiratoria y monosensibilización a hongos o cucaracha, ni en pacientes con asma con el objetivo de mejorar la función respiratoria.

Específicamente en hongos, existe un número muy limitado de estudios que demuestren su eficacia, además de que existe preocupación importante por la calidad y seguridad de los extractos. Hay que realizar un abordaje individualizando, evaluando riesgos y beneficios en los casos que cuenten con una indicación bien establecida y un alérgeno adecuado (especialmente Alternaria y Cladosporium).

\subsection{Contraindicaciones para el uso de ITA (cuadro 2.2)}

La ITA es un tratamiento que cuando está bien indicado conlleva muchos beneficios para los pacientes, pero es importante considerar que existen situaciones especiales en las que su uso no es deseable porque existe preocupación en relación con la seguridad y el balance de riesgos y beneficios.

Es de suma importancia recordar que los pacientes alérgicos no están exentos de comorbilidades y que en todo momento se preferirá iniciar ITA en quienes las enfermedades subyacentes se encuentren controladas, con o sin tratamiento. En casos de duda recomendamos un abordaje multidisciplinario, con el objetivo de determinar si se inicia ITA o no y en qué modalidad, respetando siempre los deseos de los pacientes y familiares.

Los expertos de GUIMIT consideramos que existen pocas contraindicaciones absolutas para el inicio de ITSC o ITSL ya que, en determinadas circunstancias, algunos pacientes podrían beneficiarse de su uso. Sin embargo, resaltamos la importancia de individualizar cada caso y ponderar los riesgos y beneficios.

\subsubsection{Contraindicaciones relativas para el uso de ITA}

- Asma grave no controlada: por razones de seguridad es una contraindicación (CI) para el uso de ITA tanto en niños como en adultos, ya que estos pacientes están en mayor riesgo de presentar reacciones sistémicas. Se podrá valorar su uso en casos
No se puede hacer recomendación a favor o en contra $100 \%$ Evidencia: $2 a$ Recomendación: B 
especiales, considerando riesgos y beneficios. La ITSL podría ser una buena opción inicial. En los casos en los que se planeé utilizar medicamentos coadyuvantes como estrategia para mejorar la tolerancia y el perfil de seguridad de ITA se podrá valorar su uso (véase capítulo 10).

- Embarazo: es una contraindicación relativa para iniciar ITA. Aun cuando estudios retrospectivos sugieren que no hay un riesgo alto de prematurez o anormalidades fetales, debido a la preocupación por la seguridad no recomendamos su inicio durante el embarazo, sobre todo en fase de incremento de dosis. Se puede considerar inicio de ITSC durante el embarazo cuando la indicación es una condición de alto riesgo, como anafilaxia causada por alergia a himenópteros.

- Uso de betabloqueadores: el tratamiento con fármacos betabloqueadores es una contraindicación para ITA, pero no para VIT, aunque se recomienda en lo posible cambiar por fármaco alternativo. En preparaciones tópicas es una contraindicación relativa. El tratamiento con betabloqueadores no incrementa la frecuencia de anafilaxia, sin embargo, hay menor respuesta a adrenalina, por lo que no se recomienda iniciar inmunoterapia a menos que exista una indicación clara y necesaria de su uso (VIT) y siempre valorando riesgos y beneficios.

- Uso de inmunosupresores e inmunomoduladores: aunque faltan datos específicos, es lógico suponer que el tratamiento con inmunosupresores o inmunomoduladores puede reducir la eficacia de ITA, además, aún no se conoce a fondo el efecto de la ITA sobre la respuesta inmune de estos pacientes. Se reconoce que la contraindicación es hipotética y que no hay estudios que apoyen esta aseveración.

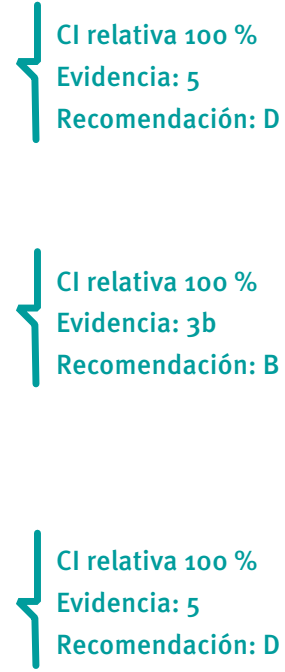

Cl relativa $100 \%$

Evidencia: $3 \mathrm{~b}$

Recomendación: B

$\mathrm{Cl}$ relativa 100

Recomendación: D

Cuadro 2.2. Comorbilidades que contraindican, limitan o no el uso de ITSC e ITSL

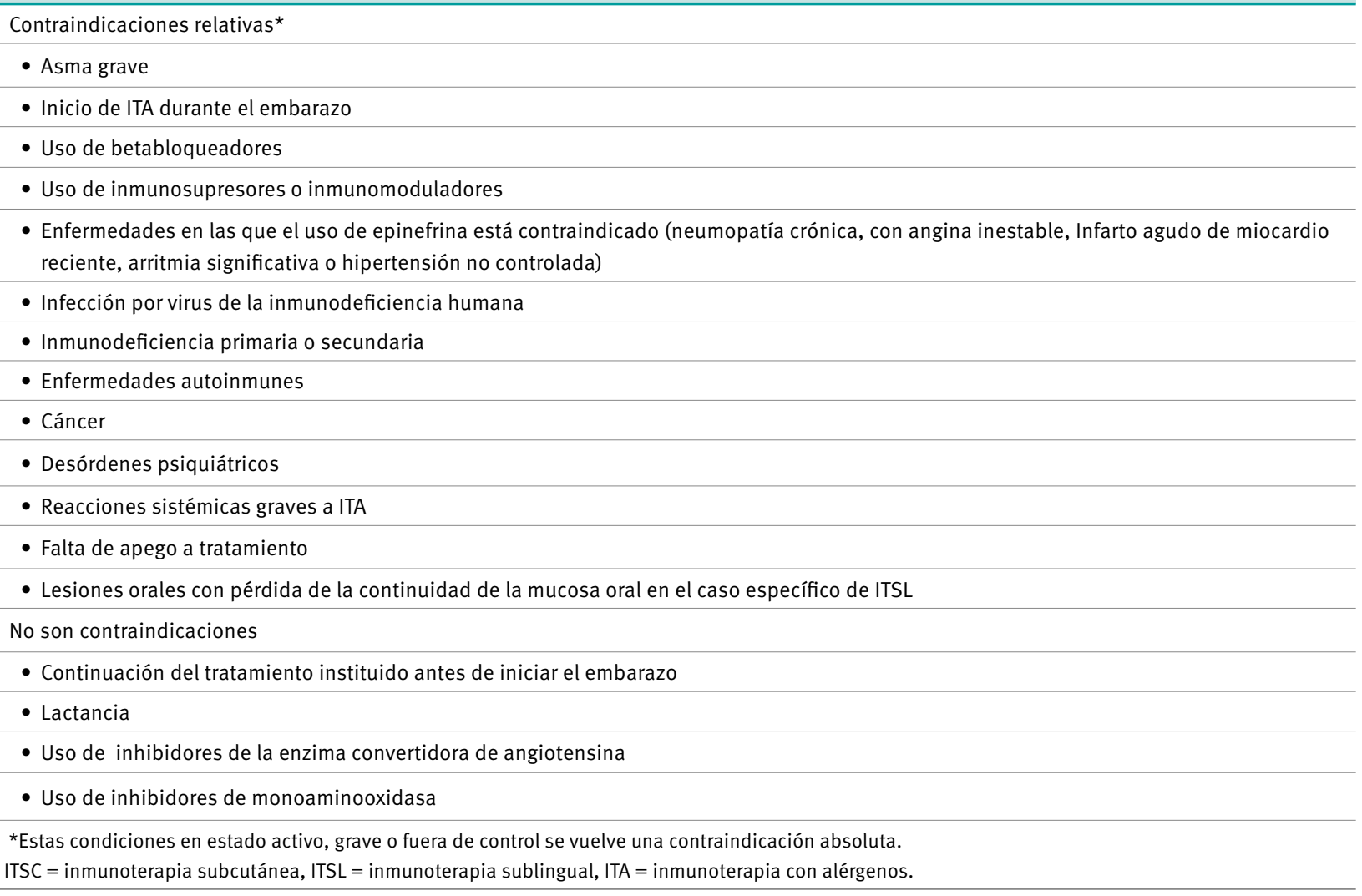


- Enfermedades en las que está contraindicada la adrenalina: se deben buscar alternativas a ITA en pacientes con condiciones que repercutan en su capacidad de sobrevivir a reacciones alérgicas sistémicas, tales con neumopatía crónica, angina inestable, infarto agudo de miocardio reciente, arritmia significativa o hipertensión no controlada. Solo se recomendará su uso en los pacientes en quienes se evidencie una clara indicación, así como un claro beneficio mayor que el riesgo.

- Infección por virus de inmunodeficiencia humana (VIH): en pacientes con infección por VIH controlada con terapia antirretroviral de gran actividad, con carga viral indetectable y cuenta normal de CD4, se puede iniciar ITSC ya que se han reportado casos exitosos. De cualquier forma, se deben valorar los riesgos y beneficio de forma individual. No se deberá iniciar en VIH estadio C.

- Inmunodeficiencia primaria o secundaria: la ITA está contraindicada en pacientes con inmunodeficiencia grave, sin embargo, en aquellos con inmunodeficiencia leve y con clara indicación se pueden beneficiar con la ITA.

- Enfermedades autoinmunes: se puede iniciar ITA en pacientes con enfermedad autoinmune local y controlada, aunque este tipo de entidades en periodo de actividad clínica constituyen una contraindicación para su uso.

- Cáncer: el antecedente de haber padecido cáncer o cursar con neoplasia estable sin necesidad de tratamiento no son contraindicaciones per se para iniciar ITA, sin embargo, la ITA estará contraindicada en los pacientes con enfermedad en periodo activo o sintomática y en quienes se utilicen esquemas terapéuticos de remisión con inmunosupresores.

- Desórdenes psiquiátricos: la presencia de desórdenes psiquiátricos es una contraindicación relativa para uso de ITSC, sobre todo porque podría ser más difícil identificar signos y síntomas tempranos de reacciones adversas graves. Además, en los pacientes que las padecen puede presumirse mayor riesgo de desapego al tratamiento.

- Reacciones sistémicas $(R S)$ graves a ITA: la historia de RS graves con ITSC es un claro factor de riesgo para futuras RS graves. Aunque se podría valorar el inicio de tratamiento bajo supervisión estricta, en estos casos también se podría ponderar cambiar a ITSL, respetando una fase de aumento de dosis de mínimo un mes.

- Falta de apego al tratamiento: es una contraindicación relativa para el uso de ITSC por preocupaciones concernientes a la eficacia, así como a la seguridad.

- Lesiones orales activas: pacientes con enfermedades crónicas de la mucosa oral no son candidatos específicamente al uso de ITSL hasta la mejoría de las lesiones.

\subsubsection{No son contraindicaciones para uso o continuación de ITA}

- Inicio de embarazo cuando ya se alcanzó dosis terapéutica de ITA: se puede continuar ITA en las mujeres que iniciaron su embarazo cuando ya se habían alcanzado dosis terapéuticas efectivas de la ITA. No se recomienda incrementar la dosis durante la gestación.

- Lactancia: no hay evidencia de un incremento de riesgo por iniciar o continuar ITSC en general en la madre que lacta o el bebé alimentado al seno materno, por lo que esta no es una contraindicación para su uso.

- Uso de IECA: no hay contraindicación para ITSC con aeroalérgenos en pacientes tratados con este grupo de fármacos, pero sí es contraindicación relativa para VIT. Tampoco se ha evidenciado incremento del riesgo de reacciones adversas locales o sistémicas a la ITA en pacientes con uso de estos medicamentos.

- Uso de inhibidores de monoaminooxidasa: no hay contraindicación para ITSC en pacientes tratados con estos agentes. Aunque existe un riesgo teórico de interacción farmacéutica, la evidencia al respecto se sostiene únicamente con un reporte de caso. $\left\{\begin{array}{l}\text { Cl relativa } 100 \% \\ \text { Evidencia: } 5 \\ \text { Recomendación: D }\end{array}\right.$

Cl relativa $100 \%$

Evidencia: $3 \mathrm{~b}$

Recomendación: B

$\mathrm{Cl}$ relativa $100 \%$

Evidencia: 5

Recomendación: D

$\mathrm{Cl}$ relativa $100 \%$

Evidencia: 4

Recomendación: C
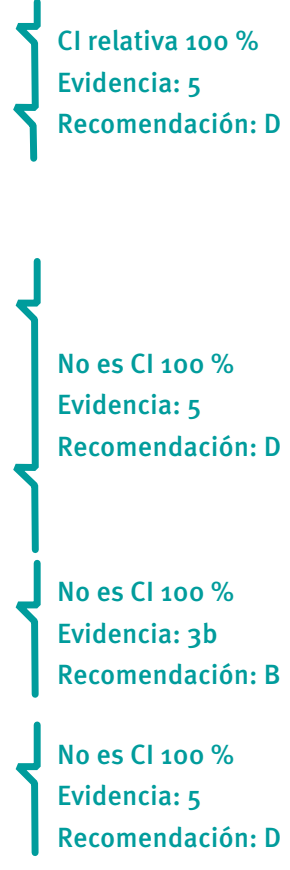

http://www.revistaalergia.mx 
En el capítulo 9 se abordan con más detalle los eventos adversos con la ITA y su manejo. En los capítulos 4 y 5 se describe la frecuencia de los eventos adversos y cómo aumentar el perfil de seguridad en torno a la aplicación de la ITSC.

\subsection{ITA en prevención de la aparición de enfermedades alérgicas}

Dada la conocida propensión de los pacientes atópicos de presentar no solo una sino varias enfermedades alérgicas, una línea de investigación recurrente es el uso de ITA con el objetivo de prevenir progresión de la enfermedad alérgica o nuevas sensibilizaciones. Han sido numerosos los esfuerzos por responder esta interrogante. Específicamente las iniciativas europeas se han dado a la tarea de recopilar la información disponible para poder dar recomendaciones respecto al uso de ITA con este fin.

Los expertos de GUIMIT recomendamos el uso de ITSC o ITSL con el fin de prevenir la aparición de asma en pacientes con rinitis alérgica, ya que existe evidencia a favor de la disminución del riesgo y se ha reconocido como el único tratamiento capaz de modificar el curso de la enfermedad. Sin embargo, no recomendamos el uso de ITA en los pacientes sensibilizados con el objetivo de prevenir nuevas sensibilizaciones.

Finalmente, la evidencia actual no permite emitir recomendación a favor o en contra del uso de ITA en niños con dermatitis atópica para prevenir la aparición de otras manifestaciones alérgicas.
ITA preventiva para asma

en RA

Recomendamos: Sí

Evidencia: $1 \mathrm{~b}$

Recomendación: B

Prevenir nuevas sensibili-

zaciones

Recomendamos: No $100 \%$

Evidencia: $1 \mathrm{~b}$

Recomendación: B

Prevención en DA

No se puede emitir reco-

mendación $97 \%$

Evidencia: $1 \mathrm{~b}$

Recomendación: B

\section{Capítulo 3. Mecanismos de acción de la inmunoterapia específica con alérgenos (cuadro 3.1)}

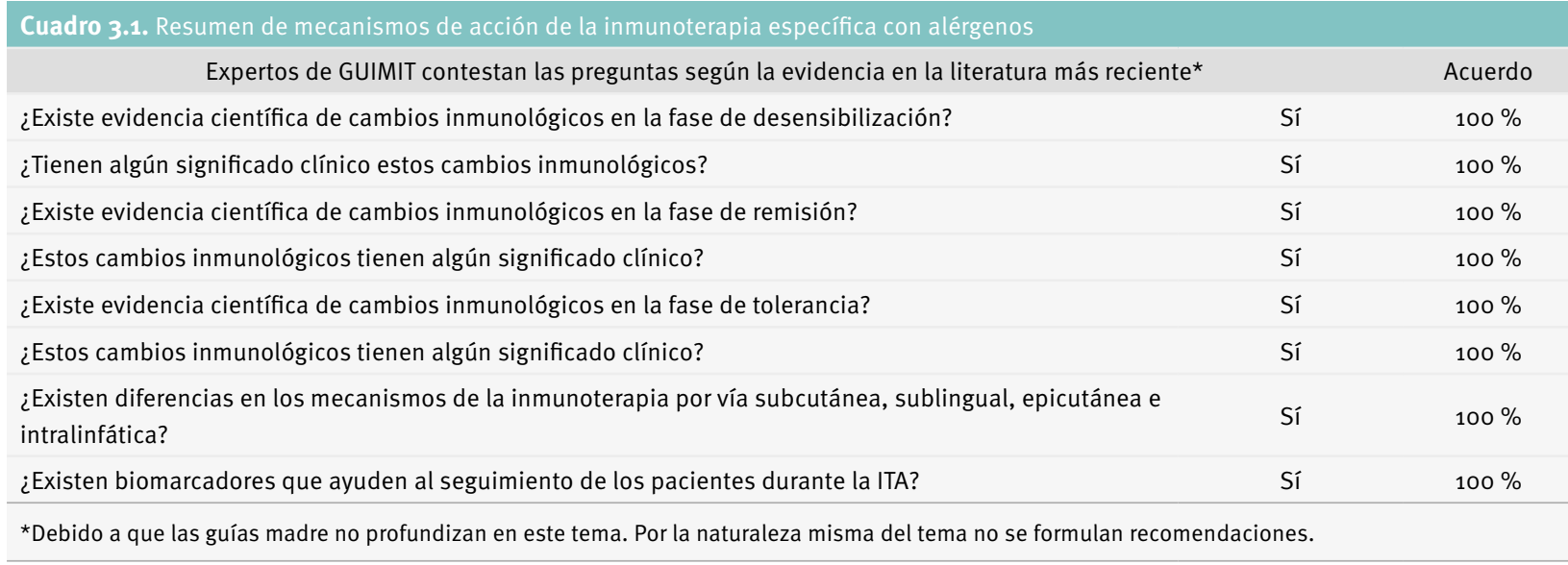

\subsection{Introducción}

La inmunoterapia específica con alérgenos hasta ahora es el único tratamiento que puede modificar la historia natural de las enfermedades alérgicas mediadas por IgE y cada vez se conocen mejor los mecanismos por los que puede inhibir la respuesta inflamatoria alérgica en el paciente.

Durante el tratamiento con inmunoterapia, el sistema inmunológico pasa por diferentes etapas desde la sensibilización inicial, hipersensibilidad e inflamación después del contacto con el alérgeno, a la fase de desensibilización en la que hay menor reactivi- 


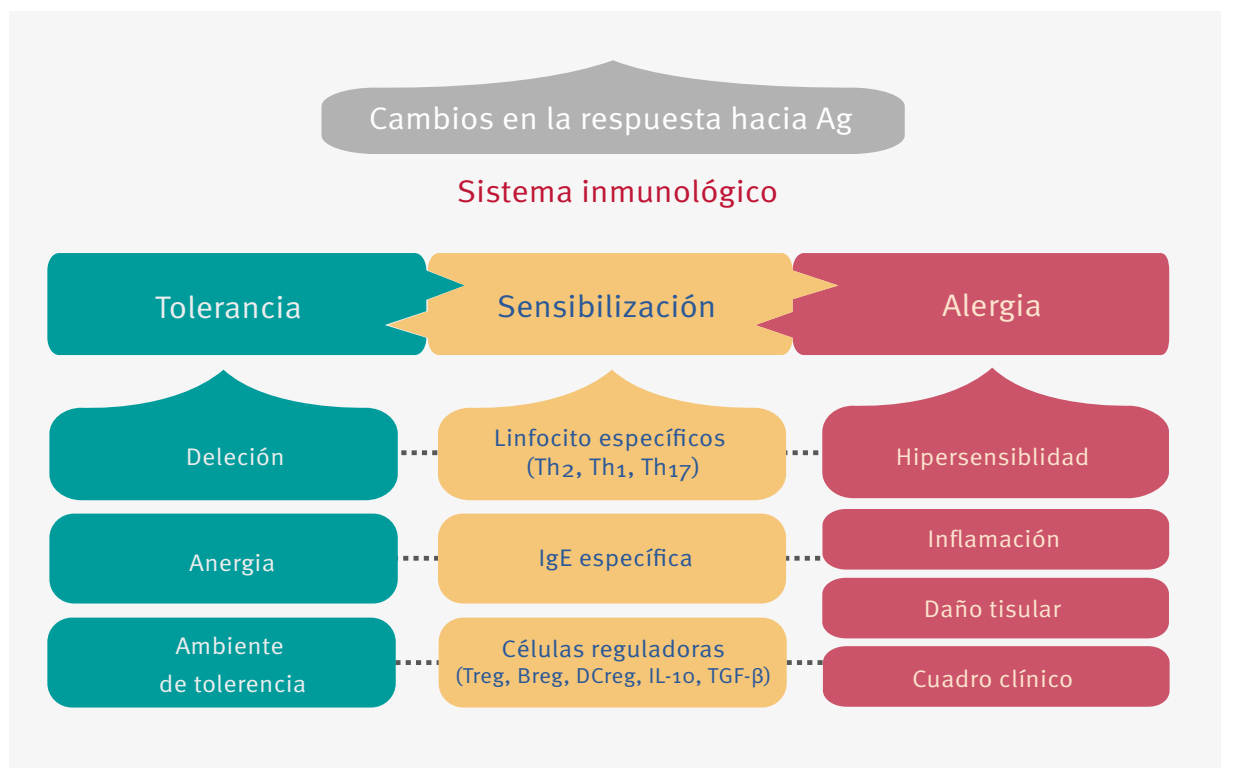

dad hacia el alérgeno (figura 3.1). Después viene la fase de remisión, en la cual ya no hay respuesta inflamatoria con la exposición al alérgeno, pero que puede ser temporal, solo mientras se recibe el tratamiento o poco tiempo después de suspenderlo, hasta llegar a la fase de tolerancia en la que la falta de respuesta inflamatoria es permanente a pesar de no estar recibiendo el tratamiento. El objetivo en este capítulo es revisar la evidencia científica sobre los cambios inmunológicos que ocurren en cada estas etapas durante el tratamiento y el significado clínico que se espera en el paciente. También se describen las diferencias en los mecanismos de acción dependiendo de la ruta de aplicación de la inmunoterapia y el conocimiento actual sobre biomarcadores para el seguimiento. ${ }^{36-46}$

\section{2. ¿Existe evidencia científica de cambios inmunológicos en la fase de desensi- bilización?}

Sí. La reactividad de las células cebadas y de los basófilos disminuye rápidamente desde la administración de las primeras dosis de inmunoterapia. Se ha encontrado que este efecto puede ser ocasionado por aumento en los receptores inhibidores tipo 2 para histamina (HR2) en diferentes células inmunológicas (células cebadas, basófilos, linfocitos y eosinófilos). Inicialmente hay un incremento de la IgE específica para el alérgeno y después un descenso gradual, así como incremento paulatino de otros isotipos de inmunoglobulinas: IgG1, IgG4 e IgA, que funcionan como bloqueadores de la respuesta alérgica hacia el alérgeno. Estos anticuerpos ayudan a bloquear a los alérgenos, formando una reacción antígeno-anticuerpo y así prevenir la unión del alérgeno a la IgE, evitando la activación no solo de células cebadas y basófilos, sino también de eosinófilos, linfocitos B y células dendríticas. La actividad de las células innatas linfoides tipo 2 (IL-C2) también se ha encontrado disminuida en esta etapa del tratamiento con inmunoterapia.

\section{3. ¿Tienen algún significado clínico estos cambios inmunológicos?}

Sí. Esta disminución rápida en la reactividad de células efectoras ayuda a evitar reacciones anafilácticas graves ante la exposición accidental al alérgeno y es la justificación para el uso de esquemas de inmunoterapia rápida o ultrarrápida para diferentes alérgenos.
Figura 3.1. Conceptos relacionados con tolerancia, sensibilización y alergia. El sistema inmunológico puede aprender a responder hacia un alérgeno (sensibilización) con la activación de linfocitos específicos y la síntesis de IgE específica hacia epítopos del alérgeno. Esta fase se puede controlar con células reguladoras que induzcan un estado normal de tolerancia hacia este alérgeno o se puede perder el control respondiendo exageradamente hacia el alérgeno (hipersensibilidad) causando inflamación, daño tisular y manifestaciones clínicas. 


\section{4. ¿Existe evidencia científica de cambios inmunológicos durante la fase de remisión?}

Sí. La inmunoterapia favorece la producción de mediadores como la quinurenina y el ácido retinoico. La quinurenina es un metabolito del triptófano por la vía de la indolamina 2,3 dioxigenasa y al igual que el ácido retinoico, metabolito activo de la vitamina $\mathrm{A}$, induce la expresión del factor de transcripción Foxp3 en linfocitos T que ayuda a la producción de citocinas reguladoras como la interleucina 10 (IL-10), el factor beta de crecimiento y transformación (TGF- $\beta$ ) y las interleucinas 27 y 35 (IL-27, IL-35), que atenúan la inflamación alérgica local. Estos mediadores y citocinas también inducen cambios en las células presentadoras de antígenos, especialmente en las células dendríticas de piel y mucosas, para que disminuyan sus moléculas de histocompatibilidad (MHC-II) para presentar alérgenos, de tal forma que disminuyan también las moléculas coactivadoras (CD80, CD86) de linfocitos T y para que produzcan IL-10 y TGF- $\beta$, volviéndose células dendríticas tolerogénicas o reguladoras. Ambas citocinas (IL-10 y TGF- $\beta$ ) tienen efecto antiinflamatorio local y son capaces de inhibir la proliferación de células $\mathrm{T}$ e inducir el cambio de linfocitos Th2, Th2A y linfocitos B a poblaciones reguladoras tolerogénicas ( $\mathrm{T}$ reguladores y $\mathrm{B}$ reguladores). Estas citocinas y mediadores liberados localmente también atenúan la actividad de las células cebadas locales y la activación de otras células efectoras que contribuyen a la inflamación alérgica, como basófilos y eosinófilos. Además, la liberación de IL-10 y TGF- $\beta$ sirve para reforzar la producción de anticuerpos bloqueadores IgG e IgA. En especial, los subtipos IgG4 tienen un papel muy importante ya que pueden intercambiar cadenas pesadas y ligeras en su fracción de unión al antígeno (Fab) y esta característica los convierte en anticuerpos heterobivalentes (dos especificidades diferentes) con afinidad moderada para interactuar con el alérgeno, compitiendo con los anticuerpos $\operatorname{IgE}$ y bloqueando el efecto inflamatorio al unirse a receptores inhibidores Fc $\gamma$ RIIB (CD32) en células presentadoras y efectoras de la respuesta alérgica. Estos receptores inhibidores tienen motivos ITIM (inmunorreceptores con motivos de inhibición basados en tirosina) en vez de ITAM (inmunorreceptores con motivos de activación basados en tirosina), con lo cual pueden inhibir las funciones celulares (figura 3.2).

\section{5. ¿Tienen algún significado clínico estos cambios inmunológicos?}

Sí. En esta fase se produce disminución sostenida en la reactividad hacia el alérgeno que ayuda a que no se presenten síntomas con la exposición. Esta falta de respuesta se presenta durante el tratamiento, pero al suspender la inmunoterapia esta remisión es temporal y puede durar solo de dos a 24 semanas. De aquí la importancia de completar el tratamiento en forma adecuada para llegar hasta una fase de tolerancia a largo plazo.

\section{6. ¿Existe evidencia científica de cambios inmunológicos en la fase de tole- rancia?}

Sí. Se ha encontrado que la tolerancia inmunológica durante la inmunoterapia está asociada con la inducción de células T reguladoras específicas para el alérgeno (Treg). Las células Treg expresan el factor de transcripción Foxp3 y producen citocinas reguladoras, tales como IL-10, IL-35 y TGF- $\beta$. Además de estas citocinas, los linfocitos Treg pueden inhibir la actividad de células presentadoras y efectoras a través de otras moléculas inhibidoras como PD-1 (molécula 1 de la muerte celular programada), CTLA-4 (antígeno 4 de linfocitos T citotóxicos), receptores para IL-2 (CD25) y receptores para adenosina (CD39, CD73), manteniendo así el ambiente de tolerancia hacia el alérgeno. En esta fase, los linfocitos B reguladores (Breg) específicos para el alérgeno también 


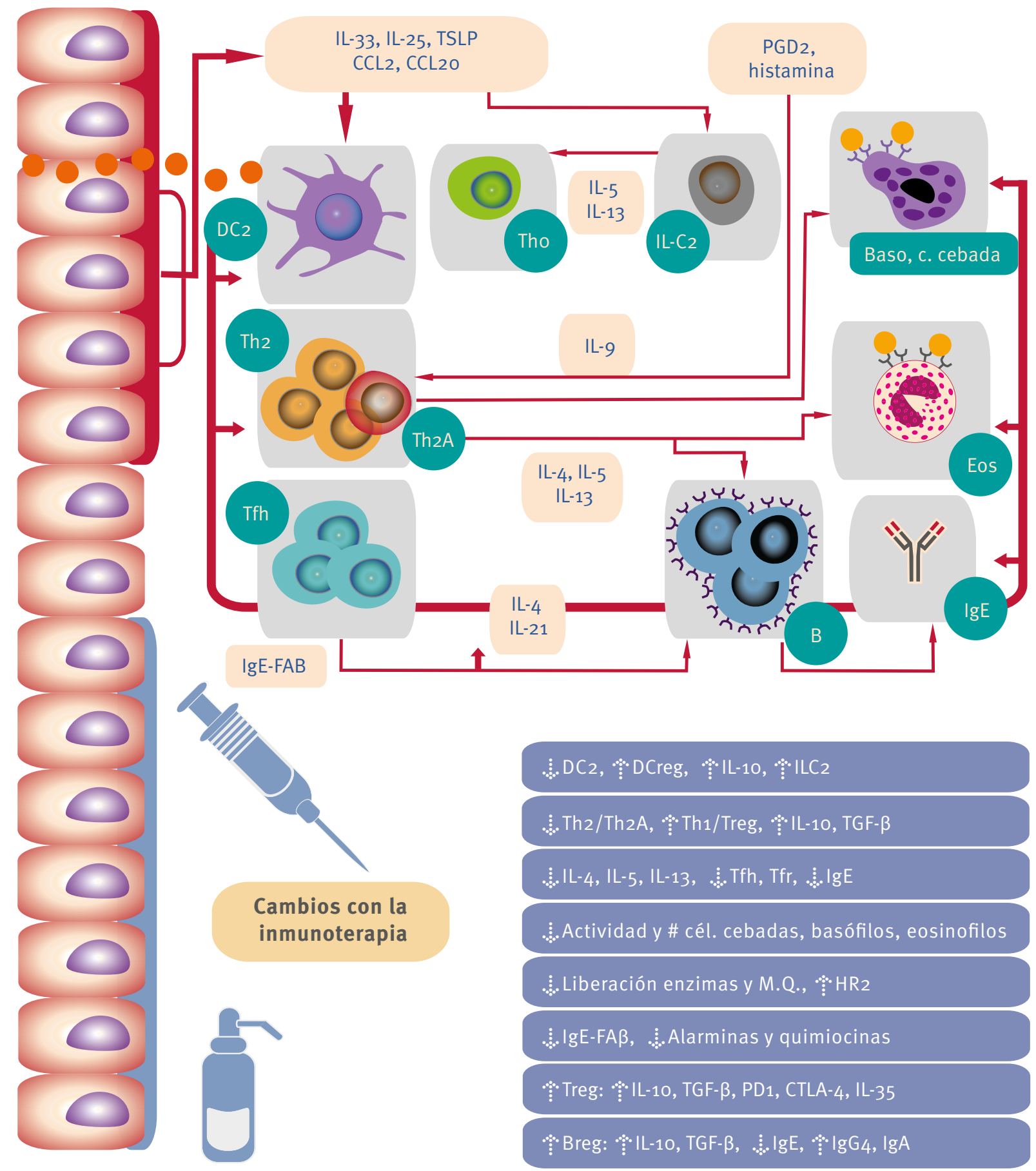

Figura 3.2. La exposición a dosis repetidas del alérgeno en un paciente genéticamente susceptible favorece la liberación de alarminas y quimiocinas del epitelio, con la activación de células innatas linfoides tipo 2 y células dendríticas tipo 2 que favorecen el cambio de patrón de linfocitos Tho hacia Th2 y Th2A. Estos linfocitos Th2 y Th2A, junto con los linfocitos T cooperadores, favorecen la activación de linfocitos B y la síntesis de IgE específica para el alérgeno. La IgE se une a receptores FcyRl y FcyRII en células efectoras (células cebadas, basófilos, eosinófilos) y en células presentadoras ( $\left.\mathrm{DC}_{2}, \mathrm{TH}_{2} / \mathrm{Th}_{2} \mathrm{~A}, \mathrm{~B}\right)$, para aumentar su activación en la reexposición al alérgeno. En el esquema se describen los principales cambios que ocurren durante la inmunoterapia para bloquear esta respuesta inflamatoria alérgica. 
contribuyen a la producción de IL-10, TGF- $\beta$ e IL-35, además de inducir la producción de IgG4 e IgA, disminuyendo la síntesis de IgE. La tolerancia a largo plazo puede producirse a través de la persistencia de estos mecanismos y con la participación de linfocitos $\mathrm{T}$ foliculares reguladores (Tfr) en ganglios linfáticos inductores de la anergia (inhibición) y deleción (desaparición) de clonas de linfocitos Th2 específicos hacia el alérgeno (figura 3.3).

\section{7. ¿Tienen algún significado clínico estos cambios inmunológicos?}

Sí. Esta fase puede tener efectos permanentes en la respuesta inmunológica a pesar de que se suspenda el tratamiento y ese es el objetivo final de la inmunoterapia específica con alérgenos.

\section{8. ¿Existen diferencias en los mecanismos de la inmunoterapia por vía subcutánea, por vía sublingual, por vía epicutánea y por vía intralinfática?}

Sí. Se han documentado algunas diferencias entre los mecanismos de acción de la inmunoterapia, de acuerdo con la vía de administración de esta: subcutánea (ITSC), sublingual (ITSL), oral (ITO), epicutánea (ITEP) o intralinfática (ITIL). Las diferencias en las formas de inmunoterapia dependen del sitio donde se efectúa su acción. En la ITSC, la inducción de mecanismos de desensibilización, remisión y tolerancia ocurren en las células de Langerhans en la piel y en los ganglios linfáticos cercanos al sitio de

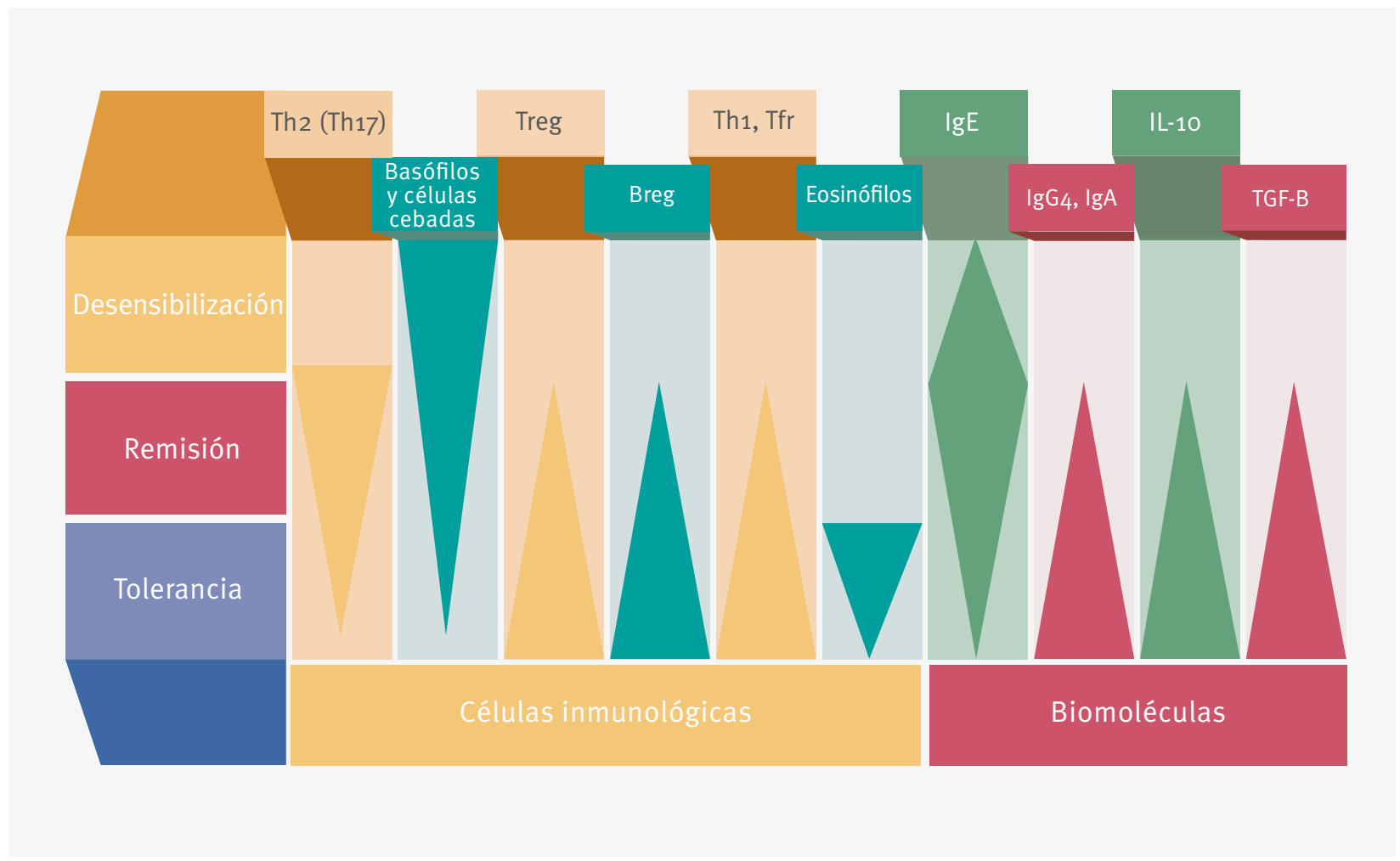

Figura 3.3. La inmunoterapia tiene efectos tanto en la activación y número de células inmunológicas, como en la producción de diferentes biomoléculas. Estos efectos inmunológicos se producen con velocidades diferentes durante las fases del tratamiento. 
aplicación (axilares). Mientras que en la ITSL, una vez captado el alérgeno por las células dendríticas de la mucosa oral, este es transportado a los ganglios linfáticos regionales, específicamente al anillo de Waldeyer, para la producción del cambio del perfil hacia linfocitos Th1, así como a linfocitos Treg Foxp $3^{+}$y la inducción de linfocitos B para la producción de IgA secretoria local específica para el alérgeno.

En la ITO, contrario a lo que se produce en la ITSL, el alérgeno se administra en forma acuosa o en cápsulas y de forma inmediata es deglutido y en su mayor parte absorbido en la mucosa intestinal, donde es captado por las células presentadoras de antígeno de esta mucosa y llevado hacia las placas de Peyer en el intestino, donde predominantemente se produce polarización hacia Treg Foxp $3^{+}$, con producción de IL-10 y TGF- $\beta$.

La ITEP se ha intentado como un método de inmunoterapia desde mediados del siglo XX. Actualmente se aplica a través de parches que contienen el alérgeno requerido. Se dejan en la piel por 48 horas y se aplican semanalmente. La aplicación de la cubierta del parche no solo disminuye la capa córnea de la epidermis, sino que también activa los queratinocitos para producir citocinas proinflamatorias e incrementar la penetración del antígeno en la epidermis. Este antígeno es entregado a las células de Langerhans que migran hacia los ganglios linfáticos regionales induciendo la activación de linfocitos Treg LAP ${ }^{+}$que pueden inhibir directamente la activación de las células cebadas en piel. Debido a que la epidermis no está vascularizada, el riesgo de efectos sistémicos o efectos adversos también es mínimo.

La ITIL se administra por inyección directa del alérgeno en los ganglios linfáticos inguinales, guiada por palpación o ultrasonido. Una vez que el alérgeno es inyectado a los ganglios linfáticos, este es fagocitado por las células dendríticas foliculares y sus péptidos son presentados con moléculas de histocompatibilidad MHC-II a las células $\mathrm{B}$ en la zona clara del centro germinal. Estás células B se activan y se diferencian en plasmablastos, células plasmáticas y células B de memoria, después de lo cual salen del ganglio a través del vaso linfático eferente y pueden secretar IgG4 específica para el alérgeno.

Se ha observado que solo la inmunización intralinfática estimula la producción de la subclase $\operatorname{IgG} 2$ a dependiente de Th1, asociada con mejoría en la protección contra anafilaxia inducida por alérgeno. También se ha encontrado producción de IgG1 y de citocinas como IFN- $\gamma$, IL-10 e IL-2.

\section{9. ¿Existen biomarcadores que ayuden al seguimiento de los pacientes durante la inmunoterapia?}

Sí. La identificación y validación de biomarcadores potenciales de la respuesta a la inmunoterapia es aún motivo de estudio y se considera que puede mejorar la selección y el manejo clínico de los pacientes que la reciban. Entre estos biomarcadores en estudio se encuentran marcadores moleculares como la IgE total, la IgE específica, el radio IgE específica/IgE total, las pruebas de inhibición de IgE como la unión y presentación facilitada del alérgeno por IgE, la IgG4 específica, las pruebas de activación de basófilos (CD63, DAO) o marcadores celulares como los de células reguladoras (DCreg, Treg, Breg), los de células dendríticas tipo 2 (DC2) y linfocitos Th2a, o patrones de citocinas (IL-4, IL-10, TGF- $\beta$, IFN- $\gamma$ ) y también marcadores epigenéticos de metilación o desacetilación de genes promotores específicos de patrones linfocitarios.

Aún no existen biomarcadores validados y aceptados que puedan predecir la respuesta clínica a la inmunoterapia en forma $100 \%$ confiable, pero seguramente el mejor entendimiento de la fisiopatología de las enfermedades alérgicas y de los mecanismos de acción de la inmunoterapia para inducir y mantener un estado permanente de tolerancia ayudará a su mejor utilización en un futuro cercano. 


\section{Capítulo 4. Criterios para ITSC según las escuelas estadouni- dense y europea y su aplicabilidad en México}

\subsection{Introducción}

La ITSC ha demostrado ser eficaz y segura en el tratamiento curativo de las enfermedades alérgicas para las cuales está indicada. En esta modalidad de ITA existen dos escuelas avaladas y aplicadas en nuestro país: la estadounidense y la europea. En este capítulo se comparan ambas y se formulan puntos de buena práctica sobre su aplicabilidad en México. En la última parte de este capítulo se presentan los datos acerca de la seguridad y eventos adversos de la ITSC para ambas escuelas (apartado 4.4). A modo de resumen presentamos en la figura 4.1 los puntos más destacados de ambas, los cuales se desarrollan en este capítulo.

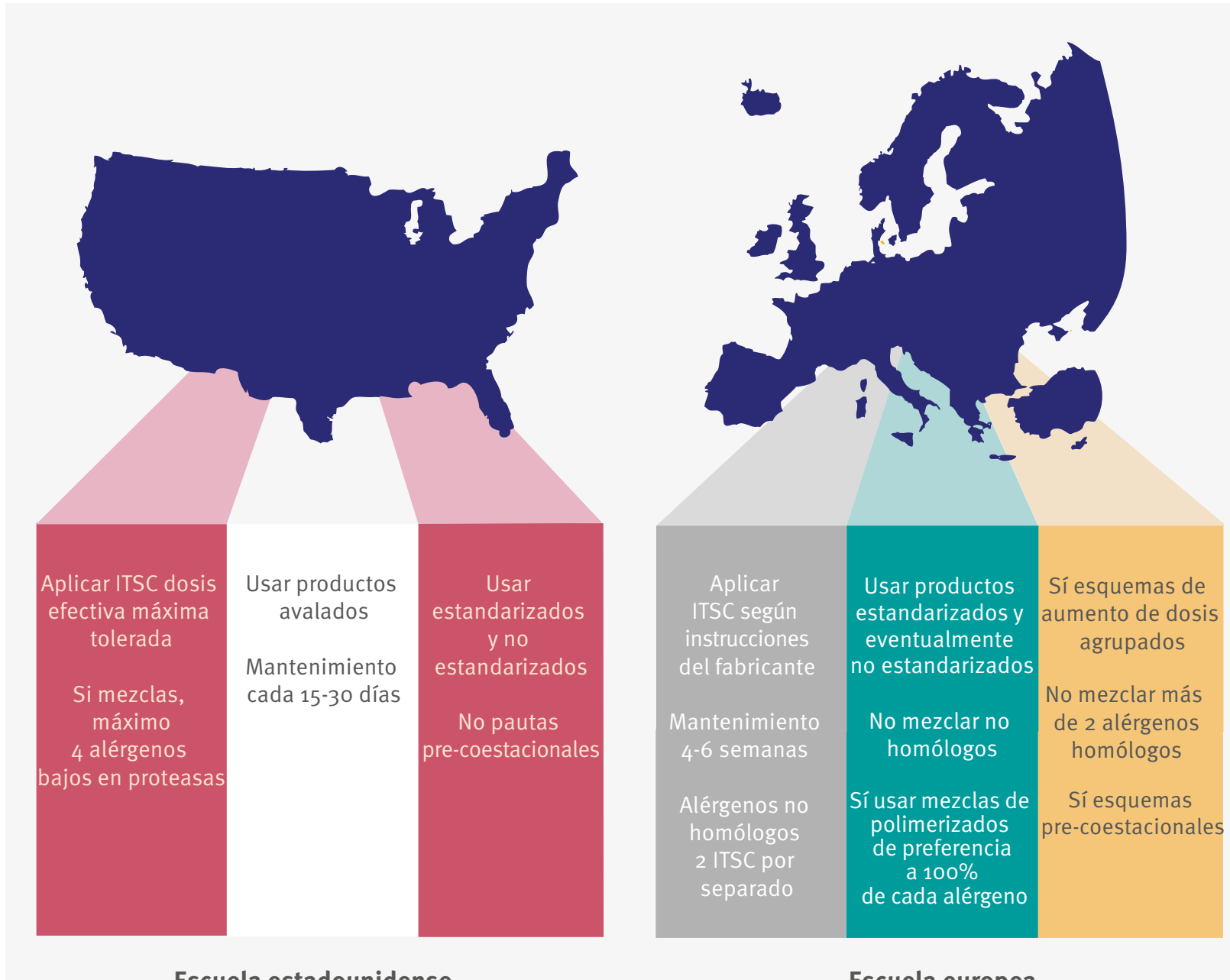

Escuela estadounidense

Escuela europea

Figura 4.1. Aspectos más importantes de las escuelas europea y estadounidense en los que muestran diferencias respecto a la inmunoterapia subcutánea (ITSC). 


\subsection{ITSC en la escuela estadounidense: dosificación, preparación del frasco de mantenimiento y esquemas de aplicación}

\section{Cuadro 4.1. Resumen de criterios en inmunoterapia subcutánea según la escuela estadounidense \\ La eficacia y seguridad de la ITSC según la escuela estadounidense, ¿es dependiente de alcanzar la dosis terapéutica recomendada o la dosis máxima tolerada? \\ ¿Es recomendable iniciar con una fase de aumento de dosis y de qué duración? ITSC convencional}

Expertos de GUIMIT recomiendan o sugieren conforme evidencia en guías madre*

¿Es recomendable iniciar con fase rápida de aumento de dosis y de qué duración? En racimo, rápida, ultrarrápida

¿El intervalo entre cada aplicación de la inmunoterapia es de 15-30 días?

¿La fase de mantenimiento es de tres años?

¿El volumen del frasco para inmunoterapia es de 3-5 $\mathrm{mL}$ ?

¿Es recomendable hacer mezclas con alérgenos no relacionados?

¿Cuántos alérgenos máximo por frasco?

¿Cuáles alérgenos mezclar y cuáles no?

¿Mezclar alérgenos estandarizados con no estandarizados?

¿La aplicación de alérgenos en el consultorio versus aplicación domiciliaria incrementa el perfil de seguridad?

¿Se toma frecuencia cardiaca, frecuencia respiratoria, tensión arterial, saturación de oxígeno y flujometría antes de la aplicación?

¿Se realizará un cuestionario de salud antes de la aplicación?

¿En qué caso se debe posponer la aplicación de ITSC?

¿Existen algunas condiciones en las cuales se tenga que evaluar reducir la dosis programada por administrar?

¿Cuál es la frecuencia de las reacciones adversas en ITSC?

- De todas las dosis administradas

- De todos los pacientes

- En México
Recomiendan: Sí

Acuerdo

Recomiendan: Sí

3-6 meses

$100 \%$

Esquemas rápidos son más seguros con extractos modificados o de depósito. Se revisan en la ITSC conforme la escuela europea

Recomiendan: Sî

$85 \%$

Recomiendan: Sî $100 \%$

Sugieren: Sí $100 \%$

Recomiendan: Sí, respetando contenido de proteasas.

Sugieren: Considerar preparar viales

$100 \%$ separados

Recomiendan: Considerar efecto de autodilución

$100 \%$

Recomiendan: No mezclar alérgenos con alto contenido de proteasas con alérgenos de bajo contenido

Recomiendan: Sí

$100 \%$

Sugieren: Sí

$100 \%$

Sugieren: Sí

$100 \%$

Sugieren: Sí

$100 \%$

Recomiendan: Sí Toda condición que aumente el riesgo de efectos adversos

$100 \%$ de ITA

Sugieren: Sí

Dosis perdidas, aumento de contacto con $\quad 100 \%$ alérgeno

$100 \%$

Sistémicas: $0.3 \%$ de inyecciones Locales $26-82 \%$

$3.7 \%$

Locales graves: $0.002 \%$

Sistémicas: $0.3 \%$ de infecciones, $1.6 \%$ de pacientes 
En comparación con los esquemas continuos, ¿las modalidades pre y coestacional podrían ser de utilidad para México?
Sugieren: No.

Resultan ineficaces y no tienen aplicación $\quad 100 \%$ en México

Experiencia clínica común de los expertos GUIMIT (Delphi simplificado): ${ }^{\star \star}$ evidencia $1 \mathrm{C}$

Sí, 59 \% recomienda y 34 \% sugiere.

Tomando la precaución de conservar la dosis de mantenimiento y no mezclar alérgeLa dilución limita el número de alérgenos que pueden ser agregados al concentrado de mantenimiento si se quiere administrar una dosis terapéutica.

En cuanto a la duración de ITSC por alergia respiratoria, si se observa una mejora clínica lenta o muy gradual (hasta avanzado el segundo año), ¿se debe extender la Sí, 19 \% recomienda y 56 \% sugiere ITSC hasta por 5 años?

Según la escuela estadounidense se debe administrar la ITSC en un solo vial con cada alérgeno a dosis fraccionada, por ejemplo, con 3 alérgenos cada uno a un tercio de la dosis habitual

$100 \%$ sugiere que no $100 \%$ recomienda incluir $100 \%$ de la dosis terapéutica de cada alérgeno incluido

* Se buscó nivel de evidencia y recomendación en cada guía madre (tablas fuente 1); se fusionaron evidencias y recomendaciones para emitir una recomendación para cierta acción (tablas fuente 2). Los vínculos a estas tablas se encuentran en el anexo 1. ** Contestación anónima de los 57 expertos GUIMIT. Con amplio consenso se obtiene un nivel de evidencia 1C, según CEBM.

\subsubsection{Eficacia}

La eficacia de la ITSC ha sido demostrada en numerosos metaanálisis basados en estudios doble ciego, aleatorizados, controlados con placebo, tanto en adultos como en niños con rinitis alérgica, asma alérgica e hipersensibilidad a veneno de insectos, en los que se observó reducción estadísticamente significativa en la escala de síntomas y en el uso de medicamentos, así como mejoría en la calidad de vida. Debido a que la inmunoterapia es el único recurso terapéutico disponible enfocado al mecanismo fisiopatológico subyacente (véase capítulo 3), este posee efecto modificador de la evolución de las enfermedades alérgicas mencionadas, es un tratamiento personalizado y a la medida de las necesidades de cada paciente y su eficacia se incrementa conforme se alcance la dosis máxima recomendada o la dosis terapéutica de cada antígeno incluido en el extracto para ITA. Sin embargo, en general la ITA con dosis baja no es efectiva. Aunque la ITA con dosis altas de mantenimiento incrementa la posibilidad de eficacia clínica, también incrementa el riesgo de reacciones adversas sistémicas. Los expertos de GUIMIT advierten proceder con cautela especialmente en los pacientes altamente sensibles.

\subsubsection{Dosis terapéutica recomendada o máxima tolerada (efectiva de mantenimiento) en la escuela estadounidense}

Según la escuela estadounidense, es el alergólogo quien prepara el vial de la ITSC, seleccionando qué alérgenos agregar individualmente, evaluando en conjunto los datos obtenidos de la historia clínica de exacerbación de síntomas con exposición y estacionalidad y los resultados de las pruebas de IgE específica, in vivo o in vitro. Aunque los alérgenos seleccionados varían de paciente en paciente, debe asegurarse que se mantiene la dosis terapéutica recomendada de cada uno, un dato fijo.

Al prescribir o preparar un extracto alergénico para ITA, en principio debe considerarse la necesidad de administrar una dosis terapéuticamente efectiva de cada alérgeno

Adulto $100 \%$

Recomendamos: Sî

Evidencia: la

Recomendación: A

Niño $100 \%$

Recomendamos: Sí

Evidencia: Ib

Recomendación: B

Punto buena práctica: $100 \%$ 
indicado, de lo contrario puede administrarse inmunoterapia ineficaz en dosis subterapéutica por el efecto de dilución.

El concentrado de mantenimiento debe ser mezclado de tal modo que se administre la dosis considerada como terapéuticamente efectiva de cada componente. Se considera dosis de mantenimiento a la dosis terapéuticamente eficaz, sin causar efectos adversos locales o sistémicos significativos, sin que necesariamente se alcance la dosis efectiva proyectada en algunos casos, pero siempre dentro del rango terapéutico eficaz.

El concentrado de mantenimiento puede ser obtenido directamente del fabricante, como en los extractos europeos. En menor proporción, en Estados Unidos se puede obtener patient named product, extractos no diluibles de aplicación directa al paciente según las recomendaciones del fabricante, o preparados por el especialista, quien prescribe la ITA bajo condiciones estériles, tomando el volumen necesario desde el concentrado del fabricante para alcanzar la dosis terapéutica de cada alérgeno individual.

Según resultados analíticos, existen diferencias considerables en el contenido del alérgeno mayor en los extractos no estandarizados, algunas atribuidas a diferencias en el contenido alérgeno de la fuente de pólenes. Aunque se esperaría que los extractos estandarizados muestren menor variabilidad entre lotes, el contenido del alérgeno mayor de productos estandarizados varía entre las empresas productoras (cuadro 4.2).

La dosis de mantenimiento se considera como la máxima concentración individual o mezcla de alérgenos usada como terapéuticamente efectiva. Algunos pacientes pueden

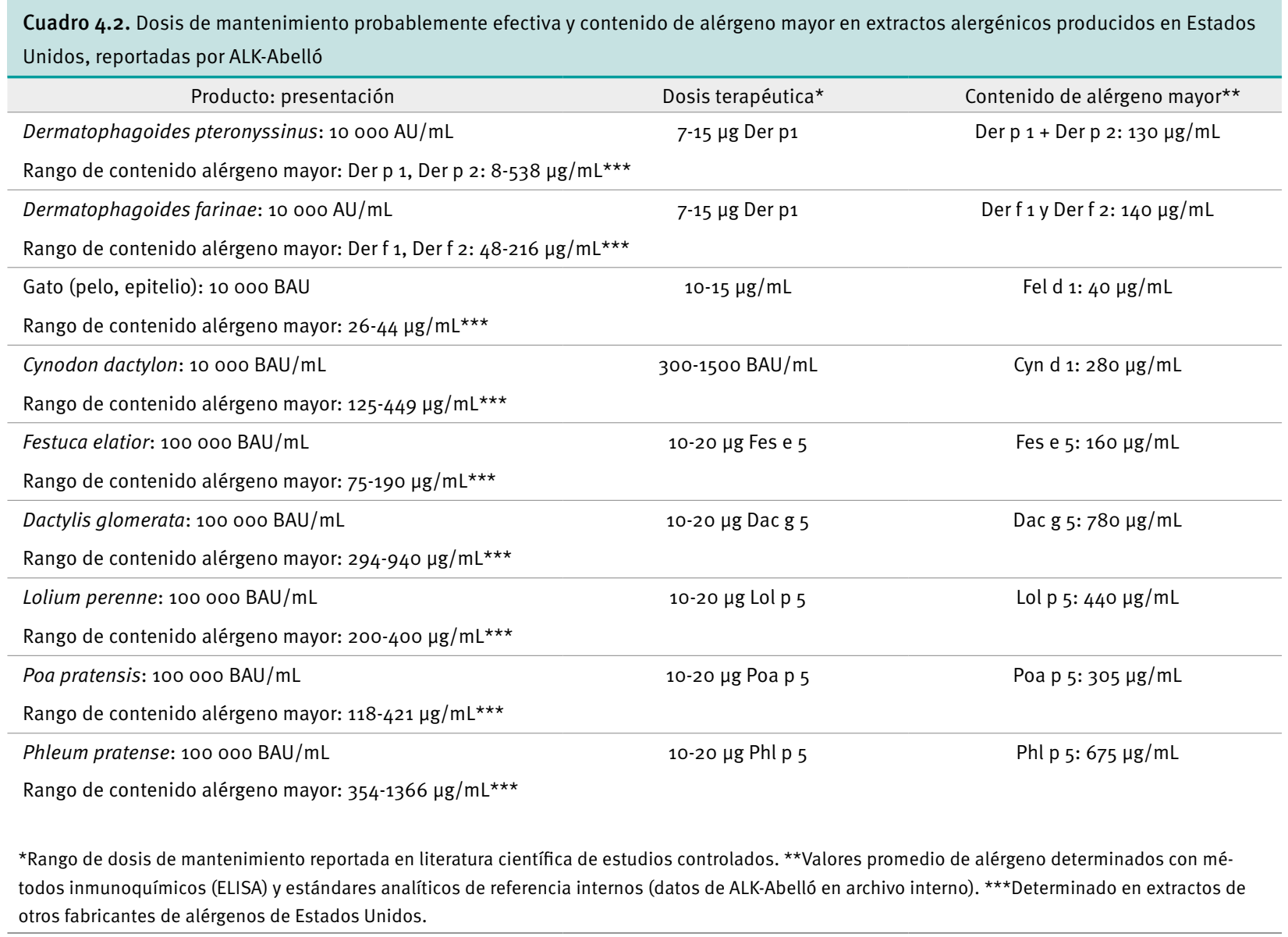


no tolerar la dosis terapéutica máxima proyectada debido a RS o reacciones locales (RL) grandes, entonces la dosis de mantenimiento para ese paciente será la máxima tolerada, excepto en la inmunoterapia con veneno de insectos, por ejemplo: dosis máxima tolerada $100 \mathrm{AU}$, rango de dosis efectiva proyectada de 500 a $2000 \mathrm{AU}$ para ácaros dermatofagoides (cuadro 4.3). Todas las diluciones pueden ser calculadas con la fórmula general aplicable para alérgenos estandarizados y no estandarizados o PNU (cuadro 4.4).

\subsubsection{ITSC según la escuela estadounidense: fase de aumento de dosis, esquema de aplicación y duración}

En las guías estadounidenses, la fase de incremento de dosis se recomienda para todos los esquemas de administración de ITSC, con la finalidad de disminuir la incidencia de efectos colaterales, en especial las reacciones sistémicas. No hay un esquema fijo o único,

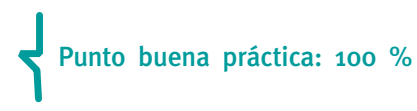
Recomendamos $100 \%$ esquema convencional Evidencia: 1 Recomendación: A

\begin{tabular}{cccc} 
Cuadro 4.3. Dosis de mantenimiento probablemente efectiva de alérgenos estandarizados o no estandarizados* \\
\hline Procedencia & Estandarización & $\begin{array}{l}\text { Dosis de mantenimiento } \\
\text { probablemente efectiva }\end{array}$ & Comentarios
\end{tabular}

\section{Estados Unidos/México Materia prima importada en polvo seco o liofiliza- do de Estados Unidos, reconstituido por empresas mexicanas}

No

Usarfórmula general para obtener

$1: 20,1: 10 \mathrm{p} / \mathrm{v} \quad$ dosis de mantenimiento

Ejemplo:

4 dosis de $0.5 \mathrm{~mL}$ para 4 meses $=$ frasco

de mantenimiento $2 \mathrm{~mL} \mathrm{1:200}$
Con dicha fórmula puede obtenerse dosis de mantenimiento efectiva de cada uno de los alérgenos incluidos, vigilando efecto de autodilución

Desde un vial de 1:20 $\mathrm{p} / \mathrm{v}$

$\begin{array}{ll}\text { México } & \text { No } \\ \text { Materia prima local, proce- } & \text { estandarizados } \\ \text { so de elaboración local } & 1: 10 \mathrm{p} / \mathrm{v}\end{array}$

$V_{2}=\left(V_{1} \div C_{1}\right) \times C_{2}-V_{2}=(2 \div 200) \times 20$

$\mathrm{V}_{2}=0.2 \mathrm{~mL}$ y $1.8 \mathrm{~mL}$ de diluyente

so de elaboración local

$1: 10 \mathrm{p} / \mathrm{v}$

Desde un vial de 1:10 $\mathrm{p} / \mathrm{v}$

$V_{2}=\left(V_{1} \div C_{1}\right) \times C_{2}-V_{2}=(2 \div 200) \times 10$

$\mathrm{V}_{2}=0.1 \mathrm{~mL}$ y $1.9 \mathrm{~mL}$ de diluyente
El contenido proteico y de alérgeno (fijación de IgE) de algunos productos mexicanos es muy bajo; para alcanzar dosis de mantenimiento efectiva se necesita agregar mucho extracto al vial*

\section{Estados Unidos}

Importados como producto

terminado para diluir por

el especialista que indica

inmunoterapia

(Cox et al. ${ }^{9}$ )

\begin{tabular}{|c|c|}
\hline $\begin{array}{l}\text { Estandarizados } \\
\mathrm{AU}, \mathrm{BAU}: 10 \mathrm{~K}- \\
100 \mathrm{~K}\end{array}$ & $\begin{array}{l}\text { Usar fórmula general para dosis de } \\
\text { mantenimiento. Misma fórmula para no } \\
\text { estandarizados y estandarizados. }\end{array}$ \\
\hline $\begin{array}{l}\text { No } \\
\text { estandarizados } \\
\text { p/v: 1:10, } 1: 20 \\
\text { PNU: } 10 \mathrm{~K}, 20 \mathrm{~K}\end{array}$ & $\begin{array}{l}\text { Ejemplo: } \\
4 \text { dosis de } 0.5 \mathrm{~mL} \text { para } 4 \text { meses }=\text { frasco } \\
2 \mathrm{~mL} \text { de } 1500 \mathrm{AU} \text {, desde } 10000 \mathrm{AU} / \mathrm{mL}\end{array}$ \\
\hline & $\begin{array}{l}V_{2}=V_{1} \times\left(C_{1} \div C_{2}\right) \\
V_{2}=2 \times(1500 \div 10000) \\
V_{2}=0.3 \mathrm{~mL} \text { y } 1.7 \mathrm{~mL} \text { de diluyente }\end{array}$ \\
\hline
\end{tabular}

Estandarizados Usar fórmula general para dosis de AU, BAU: $10 \mathrm{~K}$ -

$0.3 \mathrm{~mL}$ y $1.7 \mathrm{~mL}$ de diluyente

\begin{tabular}{lc} 
D p, D f & $500-2000 \mathrm{AU}$ \\
\hline Gato (pelo, piel) & $1000-4000 \mathrm{BAU}$ \\
\hline Pastos (polen) & $1000-4000 \mathrm{BAU}$ \\
\hline Cynodon & $300-1500 \mathrm{BAU}$ \\
\hline Ambrosia & $1000-4000 \mathrm{AU}$ \\
\hline Perro & $¿$ ? $15 \mu \mathrm{g} \mathrm{Can} \mathrm{f1}$ \\
\hline Polen & $0.5 \mathrm{~mL}$ \\
(no estandarizado) & $1: 100-1: 200 \mathrm{p} / \mathrm{v}$ \\
\hline Hongos & Dosis máxima \\
& tolerada \\
\hline Himenópteros & $100-200 \mu \mathrm{g}$
\end{tabular}

*Se recomienda usar la fórmula según cuadro 4.4.

*Larenas-Linnemann D, Esch RE, Guidos-Fogelbach G, Rodriguez-Pérez N. A comparison of in vitro potency between European and Mexican allergen extracts and US (CBER/FDA) reference extracts. Allergol Immunopathol (Madr). 2010;38(4):170-173.

$\mathrm{p} / \mathrm{v}=$ peso/volumen, $\mathrm{V}_{1}=$ volumen vial del paciente por preparar, $\mathrm{C}_{1}=$ concentración vial del paciente por preparar, $\mathrm{V}_{2}$ (desconocido) $=$ volumen necesario (concentrado del fabricante) para alcanzar dosis requerida, $\mathrm{C}_{2}=$ concentración del extracto (concentrado del fabricante) por utilizar, PNU = unidades de nitrógeno proteico. 
Cuadro 4.4. Fórmula para cálculo de $\mathrm{mL}$ de cada alérgeno para agregar al vial del paciente

$$
V_{\text {paciente }} \times C_{\text {paciente }}=V_{\text {fabricante }} \times C_{\text {fabricante }} \quad \cdots, V_{\text {fabricante }}=V_{\text {paciente }} \times\left(C_{\text {paciente }} \div C_{\text {fabricante }}\right)
$$

$\mathrm{V}_{\text {paciente }}=$ volumen del vial del paciente por preparar.

$\mathrm{C}_{\text {paciente }}=$ concentración del vial del paciente por preparar.

$\mathrm{V}_{\text {fabricante }}($ desconocido $)=$ volumen del concentrado del fabricante que se agregará al vial del paciente para alcanzar la dosis requerida.

$\mathrm{C}_{\text {fabricante }}=$ concentración del extracto (de fábrica) por utilizar (se invierte si se usan concentraciones con divisiones como 1:100).

\section{Si se usan extractos PNU, AU o BAU}

$$
V_{\text {fabricante }}=V_{\text {paciente }} \times\left(C_{\text {paciente }} \div C_{\text {fabricante }}\right)
$$

Ejemplo 1. Para ITSC para alergia a Dermatophagoides se decide dar $500 \mathrm{AU}$ de dosis proyectada, con aplicaciones de $0.5 \mathrm{~mL}$ y preparar un vial para 10 dosis.

Preparar $5 \mathrm{~mL}\left(\mathrm{~V}_{\text {paciente }}\right)$ de $1000 \mathrm{AU} / \mathrm{mL}\left(\mathrm{C}_{\text {paciente }}\right)$ desde un concentrado de $10000 \mathrm{AU}\left(\mathrm{C}_{\text {fabricante }}\right)$. Se requiere calcular $\mathrm{V}_{\text {fabricante }}$ (desconocido).

$$
\begin{gathered}
V_{\text {fabricante }}=V_{\text {paciente }} \times\left(C_{\text {paciente }} \div C_{\text {fabricante }}\right) \\
5 \mathrm{~mL} \times(1000 \mathrm{AU} \div 10000 \mathrm{AU})=5 \times 0.1=0.5 \mathrm{~mL}
\end{gathered}
$$

Así, agregará o.5 mL del concentrado del fabricante y aforará con $4.5 \mathrm{~mL}$ de diluyente (u otros alérgenos) para preparar el frasco de $5 \mathrm{~mL}$ de su paciente con $1000 \mathrm{AU} / \mathrm{mL}$. Cada dosis de $0.5 \mathrm{~mL}$ tendrá $500 \mathrm{AU}$, dosis proyectada para ácaros.

Si se usan extractos de peso/volumen $(p / v)$

$$
V_{\text {fabricante }}=\left(V_{\text {paciente }} \div C_{\text {paciente }}\right) \times C_{\text {fabricante }}
$$

Ejemplo 2. Para ITSC para alergia al fresno se decide dar una dosis proyectada para mantenimiento de $0.5 \mathrm{~mL}$ de un frasco 1:200 $\mathrm{p} / \mathrm{v}$ y preparar un vial para 6 dosis.

$$
\begin{gathered}
\text { Preparar } 3 \mathrm{~mL}\left(\mathrm{~V}_{\text {paciente }}\right) \text { de 1:200 } \mathrm{p} / \mathrm{v}\left(\mathrm{C}_{\text {paciente }}\right) \text { desde un concentrado de 1:10 } \mathrm{p} / \mathrm{v}\left(\mathrm{C}_{\text {fabricante }}\right) \text {. Se requiere calcular } \mathrm{V}_{\text {fabricante }} \text { (desconocido). } \\
V_{\text {fabricante }}=\left(V_{\text {paciente }} \div C_{\text {paciente }}\right) \times C_{\text {fabricante }} \\
V_{\text {fabricante }}=(3 \mathrm{~mL} \div 200) \times 10(0.015 \times 10)=0.15
\end{gathered}
$$

Así, agregará $0.15 \mathrm{~mL}$ del concentrado del fabricante y aforará con $2.85 \mathrm{~mL}$ de diluyente (u de otros alérgenos) para preparar el frasco de $3 \mathrm{~mL}$ de su paciente con 1:200 p/v. Cumplirá con una dosis proyectada de $0.5 \mathrm{~mL}$ de una concentración de 1:200 para extractos no estandarizados

sino rangos de intervalos, volumen y duración total que se individualizan conforme la tolerancia de cada paciente: una a tres dosis por semana en la ITSC convencional para una duración de tres a seis meses. Generalmente se inicia con 1000 o máximo 10000 veces menor a la dosis de mantenimiento (cuadro 4.5).

Los esquemas de aumento de dosis con administración agrupada se pueden realizar con alérgenos acuosos, pero generalmente se realizan con modificados o polimerizados que reducen el riesgo a eventos adversos, por ello se comentan en el apartado 4.3.

Para los esquemas en racimo, rápidos y ultrarrápidos, la frecuencia de reacciones sistémicas es mayor comparada con la de la ITSC convencional. Por ello, los expertos GUIMIT insisten que solo deben realizarse en unidades médicas especializadas con infraestructura para la atención inmediata de dichas reacciones. Se sugiere considerar medicación previa con antihistamínicos, glucocorticoides, omalizumab o antileucotrienos, dado que en algunos estudios se ha observado que disminuyen las reacciones adversas
Sugerimos: $100 \%$ Evidencia: no emitida

Recomendación: no emitida Punto buena práctica: $100 \%$ http://www.revistaalergia.mx 
Cuadro 4.5. Preparación de los frascos de la fase de aumento de dosis: aplicación 1-3 por semana en 6 dosis en aumento de 0.05 a 0.5 mL

\begin{tabular}{|c|c|c|c|c|c|}
\hline \multirow[b]{2}{*}{ Número de frasco } & \multirow{2}{*}{$\begin{array}{l}\text { Concentración } \\
\text { final del frasco } \\
\text { preparado } \\
\text { vol/vol }\end{array}$} & \multicolumn{4}{|c|}{ Técnica de preparación del frasco } \\
\hline & & $\begin{array}{c}\text { Frasco original del que } \\
\text { se tomará la dosis } \\
\text { vol/vol }\end{array}$ & $\begin{array}{l}\text { Volumen por diluir } \\
\text { del frasco original } \\
(\mathrm{mL})\end{array}$ & $\begin{array}{l}\text { Diluyente } \\
\text { por agregar } \\
(\mathrm{mL})\end{array}$ & $\begin{array}{l}\text { Volumen final } \\
\qquad(\mathrm{mL})\end{array}$ \\
\hline Mantenimiento & $1: 1$ & $1: 1$ & 5.0 & 0.0 & 5.0 \\
\hline Frasco 3 & $1: 10$ & $1: 1$ & 0.5 & 4.5 & 5.0 \\
\hline Frasco 2 & $1: 100$ & $1: 10$ & 0.5 & $4 \cdot 5$ & 5.0 \\
\hline Frasco 1 & $1: 1000$ & $1: 100$ & 0.5 & $4 \cdot 5$ & $5 \cdot 0$ \\
\hline \multicolumn{6}{|c|}{ En pacientes altamente sensibles agregar una dilución extra } \\
\hline Frasco o & 1:10 000 & 1:1 000 & 0.5 & 4.5 & 5.0 \\
\hline
\end{tabular}

Los colores corresponden a la tapa de los frascos. El frasco rojo es mantenimiento y el platinado (en este caso gris) el más diluido. Adaptado de Larenas-Linnemann D, et al. Guía Mexicana de Práctica Clínica de Inmunoterapia 2011. Rev Alerg Mex 2011;58(1):3-75. ${ }^{1}$

sistémicas. Los esquemas acelerados son más seguros con extractos modificados o adsorbidos (véase apartado 4.3).

Una vez que el paciente alcanza la dosis de mantenimiento, el intervalo entre las inyecciones a menudo puede ser incrementado progresivamente, según lo tolere, hasta un intervalo de dos a cuatro semanas para los alérgenos inhalables y hasta 4 a 8 semanas para venenos. Algunos sujetos pueden tolerar intervalos más largos entre las inyecciones de las dosis de mantenimiento.

La decisión sobre la continuación de la inmunoterapia efectiva debe considerarse generalmente después de tres a cinco años de tratamiento. La gravedad de la enfermedad, la velocidad de la respuesta del paciente, los beneficios sostenidos del tratamiento y la conveniencia del tratamiento son todos factores que deben ser considerados para determinar si continuar o detener la inmunoterapia.

Debido a que uno de los factores que puede alterar la potencia de la ITA es el tiempo que se mantiene el o los alérgenos en el frasco, por su tendencia de adherirse al vidrio del vial; por ello se sugiere proporcionar frascos de mantenimiento de 3 a $5 \mathrm{~mL}$ que no durarán más de seis meses.

\subsubsection{ITSC en pacientes polialérgicos: cómo mezclar alérgenos}

En la escuela estadounidense de inmunoterapia, mezclar alérgenos es práctica común, bajo el conocimiento de que la dilución limita el número de alérgenos que pueden ser agregados al concentrado de mantenimiento. Al mezclar siempre se tomará en cuenta que para una ITA efectiva se requiere administrar la dosis terapéutica de cada constituyente (véase apartados 4.2.1 y 4.2.2). Así, el número de alérgenos incluidos en el extracto debe limitarse al número máximo que permita administrar dicha dosis clínicamente efectiva de cada uno. Por ello el conocimiento de reactividad cruzada entre familias y especies de alérgenos es crucial, para elegir el alérgeno que cruza para el vial de la ITA (cuadro 4.6). Un paciente puede responder a múltiples alérgenos en la prueba por punción, debido a alergia a un panalérgeno. Si un paciente tiene cinco o más reactivos de pólenes positivos en la prueba, GUIMIT sugiere diagnóstico molecular (véase apartado 1.2.6).

En función de la alta variación en el contenido del alérgeno mayor en los extractos no estandarizados, idealmente se recomienda usar alérgenos estandarizados si están disponibles y estos pueden mezclarse con alérgenos no estandarizados.
Recomendamos: $85 \%$

Evidencia: I

Recomendación: B

Recomendamos: $100 \%$

Evidencia: II

Recomendación: B 


\begin{tabular}{|c|c|c|c|}
\hline Familia/subfamilia & Nombre científico & Nombre común & Comentarios \\
\hline Cupressaceae & Juniperus ashei & Cedro de montaña & $\begin{array}{l}\text { Reactividad cruzada fuerte entre familia debido a marcada } \\
\text { homología de alérgenos mayores } 1 \text { y } 2\end{array}$ \\
\hline Taxodioidea & Criptomeria japónica & Cedro japonés & \\
\hline Pinaceae & Pinus strobus & Pino blanco & No reacción cruzada con familia Cupressaceae \\
\hline Poaceae & Phleum pratense & Pasto (hierba) timotea & $\begin{array}{l}\text { Reactividad cruzada fuerte debido a marcada homología } \\
\text { entre grupos de alérgenos mayores } 1,2 / 3 \text { y } 5\end{array}$ \\
\hline Pooideae cloridoideae & Cynodon dactilis & Grama & $\begin{array}{l}\text { Muy baja alergenicidad cruzada entre Pooideae debido a la } \\
\text { ausencia de los grupos } 2 \text { y } 5 \text { de alérgenos mayores }\end{array}$ \\
\hline Panicoideae & Sorghum halepense & Pasto Johnson & \\
\hline \multirow{2}{*}{ Sapindaceae } & Acer negundo & Acer negundo & \multirow{2}{*}{ Disparidad entre Acer negundo y otros Acer } \\
\hline & Acer rubrum & Maple rojo & \\
\hline \multirow{2}{*}{ Urticaceae } & Urtica dioica & Ortiga & \multirow{2}{*}{ Muy baja alergenicidad cruzada con otras familias } \\
\hline & Parietaria jaudica & Parietaria & \\
\hline \multirow{2}{*}{ Betulaceae } & Betula verrucosa & Abedul plateado & \multirow{2}{*}{$\begin{array}{l}\text { Fuerte alergenicidad cruzada entre miembros de Betulaceae } \\
\text { por homología de los grupos } 1 \text { y } 2 \text { de alérgenos mayores }\end{array}$} \\
\hline & Alnus glutinosa & Aliso europeo & \\
\hline Fagaceae & Quercus alba & Encino blanco & $\begin{array}{l}\text { Fuerte alergenicidad cruzada entre Betulaceae y Fagaceae } \\
\text { por homología entre grupos } 1 \text { y } 2 \text { de alérgenos mayores }\end{array}$ \\
\hline \multirow{2}{*}{ Amarantae } & Amaranthus retroflexus & Quelite, verdolaga & \multirow{2}{*}{$\begin{array}{l}\text { Fuerte reactividad cruzada entre especies de Amaranthus } \\
\text { Fuerte reactividad cruzada entre especies de Atriplex }\end{array}$} \\
\hline & Atriplex canescens & Hierba mala & \\
\hline \multirow[t]{2}{*}{ Chenopodioideae } & Kochia escoparia & Sarsa ardiente & $\begin{array}{l}\text { Quenopodiáceas muestran mayor diversidad } \\
\text { y una reactividad cruzada variable }\end{array}$ \\
\hline & Salsola pestifer & Rodadora, cardo & Puede poseer alérgenos únicos \\
\hline \multirow[t]{2}{*}{ Oleaceae } & Olea europea & Olivo & $\begin{array}{l}\text { Fuerte reactividad antigénica cruzada entre familia } \\
\text { Olaceae por homología de grupo } 1 \text { de alérgeno mayor }\end{array}$ \\
\hline & Fraxinus exelcior & Fresno & Escoger alérgenos de especie dominante local \\
\hline \multirow{6}{*}{ Asteraceae } & Ambrosia artemisifolia & Ambrosia enana & Fuerte reactividad cruzada entre especies de Ambrosia \\
\hline & Ambrosia trifida & Ambrosia gigante & Fuerte reactividad cruzada entre especies de Artemisia \\
\hline & Artemisia vulgaris & Artemisa vulgar & Escoger alérgeno de especie dominante local \\
\hline & Artemisia tridentata & Artemisa & $\begin{array}{l}\text { Reacción antigénica cruzada menor o baja entre Ambrosia, } \\
\text { Artemisia y Xanthium }\end{array}$ \\
\hline & Iva xanthifolia & Ambrosia falsa & \\
\hline & Xanthium comunis & Abrojo & \\
\hline
\end{tabular}

Adaptado de Weber RW. Guidelines for using pollen cross-reactivity in formulating allergen immunotherapy. J Allergy Clin Immunol 2008;122:219-221.45

Se recomienda fuertemente nunca mezclar alérgenos con alta actividad enzimática (cucaracha, mohos [ácaros origen europeo]) con alérgenos con baja actividad enzimática (pólenes) por riesgo potencial de degradación en estos últimos (cuadro 4.7).

El conocimiento de las interrelaciones alergénicas de pólenes es crucial para la formulación de extractos para inmunoterapia con aeroalérgenos. La alergenicidad cruzada debe considerarse para alcanzar dosis óptimas del alérgeno principal, causante de los síntomas, y reducir el riesgo de reacciones adversas. Esto podría suceder al usar para la ITA dos alérgenos con alta homología de grupos de alérgeno mayor, porque sería como si uno duplicara la dosis.
Recomendamos: $100 \%$ Evidencia: no emitida Recomendación: no emitida 
Cuadro 4.7. Reglas para la mezcla de alérgenos según su contenido de proteasas

\begin{tabular}{|c|c|c|c|c|}
\hline Alérgenos & Insectos & Mohos & Ácaros & Comentarios \\
\hline Insectos & 0 & 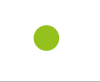 & . & $\begin{array}{l}\text { Extractos de cuerpo entero contienen niveles de proteasas muy altos; susceptibles a } \\
\text { efectos de proteasas endógenas, a menos que sean almacenados en glicerina } 50 \%\end{array}$ \\
\hline Mohos & O & O & O & Extractos de mohos no parecen ser susceptibles a efectos adversos de proteasas \\
\hline Ácaros & 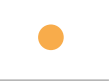 & O & 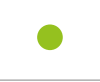 & $\begin{array}{l}\text { Alérgenos de ácaros Dermatophagoides resisten a proteasas de mohos e insectos si se } \\
\text { almacenan en glicerina }>10 \%\end{array}$ \\
\hline Pólenes & & & 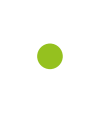 & $\begin{array}{l}\text { Extractos alergénicos de polen son susceptibles a efectos adversos de proteasas de } \\
\text { insectos y mohos; son compatibles con extractos de ácaros si son almacenados en } \\
\text { glicerina }>10 \%\end{array}$ \\
\hline Gato epitelio/pelo & 0 & 0 & 0 & $\begin{array}{l}\text { Fel d } 1 \text { y otros alérgenos de gato son altamente resistentes a efectos de proteasas de } \\
\text { insectos y mohos }\end{array}$ \\
\hline Perro epitelio/pelo & 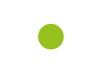 & ○ & ○ & $\begin{array}{l}\text { Alérgenos de perro son susceptibles a la mayoría de extractos de mohos, pero más } \\
\text { estables al mezclarse con alérgenos de insectos }\end{array}$ \\
\hline
\end{tabular}

Riesgo de degradación por proteasas al mezclar grupos de alérgenos con menor o mayor contenido de proteasas. Favorable Riesgo bajo Riesgo moderado o alto. Modificado de Esch RE. Allergen immunotherapy: what can and cannot be mixed? J Allergy Clin Immunol. 2008;122(3):659-660.46

\subsection{ITSC en la escuela europea: dosificación, preparación del frasco de mantenimiento y esquemas de aplicación (cuadro 4.8)}

\section{Cuadro 4.8. Resumen de criterios en inmunoterapia subcutánea según la escuela europea}

Expertos de GUIMIT recomiendan o sugieren conforme evidencia en guías madre ${ }^{\star}$

Acuerdo

¿Es recomendable iniciar con una fase de incremento de dosis y de qué duración? En racimo

Recomiendan: Sí, 4 semanas

$100 \%$

¿Es recomendable iniciar con una fase de incremento de dosis y de qué duración? Rápido

Recomiendan: Sí, 1-3 días

$100 \%$

¿Es recomendable iniciar con una fase de incremento de dosis y de qué duración? Ultrarrápido

¿El intervalo de tiempo entre cada aplicación de la inmunoterapia es de 4-6 semanas?

Recomiendan: Sí, 3.5-4 horas

$100 \%$

Recomiendan: Sí

$85 \%$

¿El volumen del frasco para inmunoterapia es...?

Según información aportada por el

fabricante

$100 \%$

¿Pueden hacerse mezclas con alérgenos no relacionados?

Sugieren: No

$100 \%$

¿Cuántos alérgenos máximo por frasco?

Recomiendan: No, eventualmente 2

$100 \%$

¿Qué alérgenos se mezclan y cuáles no?

Recomiendan: No

$100 \%$

¿Pueden mezclarse alérgenos estandarizados con no estandarizados?

Recomiendan: No

$100 \%$

Experiencia clínica común de los expertos GUIMIT (Delphi simplificado): ** evidencia $1 \mathrm{C}$

En el manejo de un paciente con alergia a 2 alérgenos no homólogos (por ejemplo ácaro y polen de pasto) con IT según la escuela europea, ¿se debe administrar la ITSC en dos

Sí, $20 \%$ recomienda, $30 \%$ sugiere, inyecciones (una por cada alérgeno) simultáneamente, con 30 minutos de espera posterior a la inyección?

$15 \%$ neutral

$100 \%$ sugiere: No

Se debe administrar la ITSC en un solo vial con cada uno de los alérgenos a dosis fraccionada (por ejemplo, tres alérgenos: cada uno a un tercio de la dosis habitual)

$100 \%$ recomienda incluir $100 \%$ de la dosis terapéutica de cada alérgeno incluido

* Se buscó nivel de evidencia y recomendación en cada guía madre (tablas fuente 1); se fusionaron evidencias y recomendaciones para emitir una recomendación para cierta acción (tablas fuente 2). Los vínculos a estas tablas se encuentran en el anexo 1.

** Contestación anónima de los 57 expertos GUIMIT. Con amplio consenso se obtiene un nivel de evidencia 1c, según CEBM. 


\section{4·3.1 Eficacia y dosificación de la ITA}

La evidencia de eficacia de la ITSC generada las últimas dos décadas proviene casi exclusivamente de estudios realizados en Europa con productos de ese continente por diversos fabricantes, aunque también existen otros fabricantes europeos con poca evidencia.

En Europa, los extractos que entrega el fabricante son el producto final, listo para ser administrado al paciente. De tal manera, el médico europeo no se preocupa por la dosificación ni por preparar los viales. Es más, es frecuente que el paciente recoja su vial en la farmacia. El papel del alergólogo es definir qué extracto se utilizará en la ITA. Así, la inmunoterapia será aplicada según la información e instrucciones dadas el fabricante del producto. Cada producto tiene su dosis terapéutica recomendada. Es importante contar con documentación o bibliografía que avale la eficacia y seguridad de cada producto, dada la heterogeneidad entre los mismos.

Al momento de terminar GUIMIT, en México se contaba con productos estandarizados listos para usar de fabricación europea de las marcas IPI, Inmunotek y algunos de ALK-Abelló.

\subsubsection{ITSC según la escuela europea: fase de aumento de dosis, esquema de aplicación y duración}

La fase de aumento de dosis para la ITSC conforme las guías europeas varía según el fabricante. Varios productos ya cuentan con esquemas agrupados. Durante la fase de mantenimiento las inyecciones se administran con intervalos de cuatro a ocho semanas y el volumen generalmente varía entre 0.5 y $0.8 \mathrm{~mL}$, según las instrucciones del fabricante. GUIMIT recomienda que la duración de la ITSC sea igual que en el esquema estadounidense, de al menos tres años, ya que ha demostrado tener eficacia a largo plazo, aún años después de terminarla. Con esquemas más cortos no se ha logrado evidenciar una eficacia más allá del tiempo de aplicación.

\subsubsection{ITSC con esquemas de aumento de dosis con administración agrupada}

Ya que en Europa los esquemas de aumento de dosis con administración agrupada son comunes, en las GM no se hace mención directamente a los mismos ni a su nivel de evidencia y recomendación. Sin embargo, en los estudios en que se basan para concluir niveles de evidencia y grados de recomendación están aplicados diferentes esquemas de aumento de dosis con administración agrupada, usando productos modificados, estandarizados y listos para usar, como por ejemplo alérgenos polimerizados (véase capítulo 8).

La ventaja de los esquemas en racimo (cluster), rápidos (rush) y ultrarrápidos es que permiten llegar a la dosis máxima con mayor rapidez, pero, sobre todo, con menores visitas al consultorio. En el esquema en racimo se aplican dos a tres dosis por visita a intervalos de 30 minutos y en días no secuenciales para una duración de cuatro a ocho semanas; en la inmunoterapia rápida, cada 15 a 60 minutos para alcanzar la dosis de mantenimiento en uno a tres días. En la ITSC ultrarrápida la dosis de mantenimiento se alcanza en 3.5 a cuatro horas (cuadro 4.9).

Actualmente varios fabricantes de ITSC en Europa ya cuentan con estudios e instrucciones del producto para poder realizar esquemas de aumento de dosis con administración agrupada. En México se sugiere aplicarlos usando productos modificados que tengan estudios de seguridad en este tipo de esquemas y tomando todas las precauciones necesarias para el manejo de reacciones sistémicas. Al realizar estos esquemas se recomienda medicación previa con antihistamínico para evitar o minimizar las RS, siempre aplicarlos bajo vigilancia médica y esperar al menos 30 minutos después de la aplica-

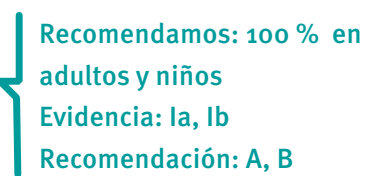

Recomendamos: 4-8 semanas $100 \%$.

Evidencia: V Recomendación: D Recomendamos: $100 \%$ Evidencia: I Recomendación: A

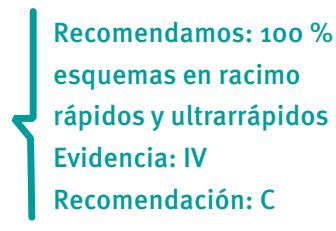

1 Punto buena práctica: $100 \%$ 
Cuadro 4.9. Esquemas de aumento de dosis de inmunoterapia subcutánea con administración agrupada

\begin{tabular}{llll}
\hline & & Dosis por sesión & Duración de fase de aumento de dosis \\
\hline Convencionales & $1-3$ dosis semanales & 3 a 6 meses \\
\hline En racimo (cluster) & 20 más dosis por sesión con intervalo de 30 minutos, semanalmente & 4 semanas \\
\hline Rápidos (rush) & 20 más dosis por sesión con intervalos de 15 a 30 minutos, diariamente & 1 a 3 días \\
\hline Ultra rush & 2 aplicaciones en una sesión, un solo día & 3.5 a 4 horas
\end{tabular}

ción. En México se sugiere administrarlos con cautela en tanto se obtiene experiencia en este tipo de esquemas.

\subsubsection{ITSC según la escuela europea en pacientes polialérgicos: mezclar o no mezclar}

Se recomienda hacer mezclas entre máximo dos alérgenos de la misma familia o biológicamente relacionados. No se recomienda hacer mezclas entre alérgenos de familias no relacionadas, para evitar una reducción innecesaria de las dosis de alérgenos, así como evitar mezclar alérgenos con alta y baja cantidad de proteasas para impedir la degradación enzimática. Hay que considerar que en este tipo de inmunoterapia se usan productos terminados, los cuales al mezclarse se diluyen perdiendo así su estandarización y la garantía de eficacia dada por el fabricante. Existen fabricantes que venden mezclas de alérgenos de dos formas: mezclas al 100, en las cuales cada alérgeno mantiene su concentración plena, y mezclas diluidas (por ejemplo, al mezclar tres alérgenos, cada uno está a $1 / 3$ de su dosis). Los expertos GUIMIT expresan su preferencia para las mezclas al 100.

En pacientes polialérgicos a alérgenos no relacionados biológicamente, la escuela europea sugiere otra solución: elegir los dos alérgenos de mayor relevancia clínica y aplicarlos por separado. Según la experiencia clínica común, los expertos de GUIMIT sugieren aplicarlos simultáneamente con un tiempo de espera de 30 minutos posterior a la aplicación (recomendación D).

\subsubsection{Pautas pre y coestacionales de ITSC en la escuela europea}

Las pautas pre y coestacionales se refieren a esquemas de aplicación de ITSC únicamente antes y durante la estación polínica y que se suspenden fuera de la estación, logrando con ello un ahorro considerable. Se sugiere que la fase de incremento de dosis se realice de ocho a 12 semanas antes del comienzo de la estación polínica. Así se obtiene la mayor eficacia y además se disminuye el riesgo de reacciones adversas, que se ven con mayor frecuencia al incrementar dosis durante la estación. Durante la fase coestacional, en muchos casos es posible continuar con la aplicación de la ITSC sin reducir la dosis de mantenimiento. Sin embargo, es necesario individualizar la evaluación de cada paciente antes de la aplicación.

Las pautas pre y pre-coestacionales se recomiendan para rinitis alérgica estacional con un beneficio documentado a corto plazo, sin embargo, su efecto a largo plazo es dudoso. En nuestro medio no sugerimos aplicar este tipo de esquemas, porque en la mayor parte del país se presenta una temporada de polinización prolongada. Sin embargo, existen lugares en el norte de México donde las temporadas de polinización no son tan prolongadas y las estaciones son más marcadas, en los cuales estas pautas se podrían aplicar con una correcta valoración; aun así, hay que tomar en cuenta que dará mejora durante la estación, pero sin efecto a largo plazo.
Sugerimos: $100 \%$ en adultos y niños

Evidencia: I, I Recomendación: A-B; B-C Punto buena práctica Sugerimos: No, $100 \%$ en adultos ni niños Evidencia: Sí, I, I Recommendación: Sí, A, B Punto buena práctica: $100 \%$ 


\subsection{ITSC: seguridad y prevención de eventos adversos}

En el capítulo 9 abordaremos más a detalle los eventos adversos con ITA y su manejo. En el apartado siguiente presentamos la frecuencia de los eventos adversos y cómo aumentar la seguridad alrededor de la aplicación de ITSC.

\subsubsection{Frecuencia de las reacciones adversas locales y sistémicas}

Con la aplicación de extractos nativos en Estados Unidos, la frecuencia de RL se reporta en 26 a $82 \%$ de los pacientes y en 0.7 a $4 \%$ de las inyecciones. En cuanto a las RS, un estudio prospectivo multicéntrico en Estados Unidos reportó una frecuencia de $0.3 \%$ por inyección y $3.7 \%$ por paciente. Con estos mismos alérgenos y concentración en México, en una serie retrospectiva de casos encontramos una frecuencia de RS de $1.6 \%$ por paciente y $0.3 \%$ por inyección; $; 7$ otro centro reportó 0.5 y $0.08 \%$, respectivamente. ${ }^{48} \mathrm{La}$ frecuencia de RS en estudios prospectivos, retrospectivos y encuestas en Europa se reporta en $2.1 \%$ (encuesta europea) a $5.2 \%$ (Alemania) de los pacientes y en aproximadamente $0.06 \%$ (Alemania) de las inyecciones.

Respecto a las RS graves o fatales, los especialistas estadounidenses han estudiado el tema detalladamente. La frecuencia de fatalidad es de aproximadamente 1 por cada 2.5 a 4 millones de inyecciones, con una reducción en la frecuencia durante la última década. ${ }^{49} \mathrm{El}$ mayor factor de riesgo para un desenlace fatal fue asma grave o no controlada con $\mathrm{VEF}_{1}<70 \%$ al momento de la administración $(>50 \%$ de los casos), seguida por activación de síntomas durante el pico de la estación de polinización $(25 \%)$, reacción sistémica previa e inicio de frasco nuevo. ${ }^{50}$ El Paul Ehrlich Institute reporta RS entre 0.002 y $0.0076 \%$ ( 2 a 7.6 por cada 100000$)$ de inyecciones con alérgenos nativos en Europa, sin fatalidades. Para los alergoides, los reportes de RS varían aún más: entre 0.0005 y $0.1 \%$. Este último cálculo se obtuvo de un reporte retrospectivo de casos realizado por Casanovas et al., con 20 millones de aplicaciones de ITSC de alergoides: en tres años encontraron RS con $0.1 \%$ de las inyecciones, sin eventos fatales. ${ }^{51}$

En gran parte, las RL dependen de la dosis de mantenimiento administrada. Con dosis de mantenimiento óptimas (véase apartados 4.2.1 y 4.2.2) es muy frecuente ver RL leves con duración de menos de 24 horas. Con dosis subóptimas es raro ver RL. Aunque las RL son predictores bajos de RS, las RL grandes (erupciones mayores a $2.5 \mathrm{~cm}$ de diámetro o repetitivas) sí lo son. De los pacientes que presentaron una RS, $32 \%$ había presentado RL grave, comparados con $8 \%$ del grupo control sin reacción sistémica.

\subsubsection{Cuidados previos a la aplicación de ITSC}

Tanto en Estados Unidos como en Europa, la recomendación para aplicar la inmunoterapia en unidades médicas está basada en la percepción de mayor rapidez y eficacia para reconocer y tratar apropiadamente una reacción anafiláctica, y, por lo tanto, un menor riesgo de reacciones sistémicas graves o fatales, asignando un mayor riesgo a la práctica de aplicar la ITA en casa. Sin embargo, no existe un estudio comparativo de estas dos opciones que demuestre aumento en el riesgo con administración domiciliaria; al contrario, existe en reporte retrospectivo de más de 2 millones aplicaciones de ITA en domicilio con un esquema lento de aumento de dosis y en pacientes de bajo riesgo, que incluso mostraron menos RS. ${ }^{52}$

En conclusión, GUIMIT sugiere que la ITSC sea aplicada en una unidad médica por personal médico entrenado para tratar reacciones sistémicas graves con material

Sugerimos: $100 \%$

Evidencia: 2a

Recomendación: B $\left\{\begin{array}{l}\text { Sugerimos: } 100 \% \\ \text { Evidencia: IV } \\ \text { Recomendación: C, D }\end{array}\right.$ 
y equipo adecuados para este fin (véase capítulo 7). De no ser posible tal práctica, una alternativa sería aplicar la ITSC en la oficina de un médico de primer contacto adiestrado en tratar anafilaxia. Finalmente, GUIMIT considera una posición válida la administración en el domicilio, siempre y cuanto el especialista en alergia seleccione a los pacientes con mayor riesgo de reacciones graves y en ellos no les permita la aplicación domiciliaria.

\subsubsection{Identificación sin equivocación del paciente y de su vial}

Antes de aplicar la ITSC se deben atender dos puntos importantes de seguridad:

- Identificar adecuadamente el o los frascos de ITA del paciente.

- Determinar la dosis por administrar.

Para la identificación correcta de cualquier sustancia que se aplicará a seres humanos, en este caso ITA, se necesitan dos identificadores (por ejemplo, nombre del paciente $\mathrm{y}$ fecha nacimiento o el número de expediente). ${ }^{53}$

\subsubsection{Evaluación del paciente preadministración de la ITSC}

Este último punto se relaciona directamente con el riesgo de una reacción adversa según la detección de factores de riesgo en el paciente cuando acude a su aplicación. Diversas circunstancias pueden aumentar la frecuencia de RS y RS grave por la ITSC (cuadro 4.10). ${ }^{50,54,55}$ Sobre todo no se debe aplicar ITSC en pacientes con asma no controlada.

GUIMIT sugiere tomar signos vitales basales, flujometría y usar un breve cuestionario estándar preaplicación (figura 4.2).

Si se identifica algún factor de riesgo de anafilaxia, se debe reducir la dosis de la inmunoterapia o posponer su aplicación (cuadro 4.11). La mejor evidencia en este sentido proviene de una encuesta entre 1000 alergólogos certificados.

\begin{tabular}{l} 
Cuadro 4.10. Factores de riesgo para reacciones sistémicas durante inmunoterapia subcutánea \\
\hline Síntomas concomitantes de alergia y potencial exposición alergénica \\
\hline Infección concomitante \\
\hline Mastocitosis \\
\hline Reacciones sistémicas con ITSC previas \\
\hline Uso de betabloqueadores* \\
\hline Asma no controlada o asma grave \\
\hline Alto grado de sensibilización \\
\hline Exceso de aumento de dosis en fase de incremento de dosis \\
\hline Sobredosis del extracto alergénico \\
\hline Falla al seguir las recomendaciones para la reducción de la dosis cuando se cambia a un lote nuevo \\
\hline Ejercicio de alta intensidad una hora antes o en el intervalo de 2 a 3 horas posteriores a la ITSC \\
*Las reacciones sistémicas no son más frecuentes, pero hay pobre respuesta a la adrenalina. ITSC = inmunoterapia \\
subcutánea.
\end{tabular}

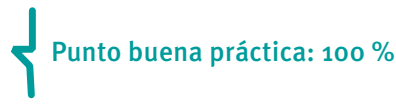

Sugerimos: $100 \%$

Evidencia: IV

Recomendación: C, D

Signos vitales y cuestionario:

Sugerimos: $100 \%$

Evidencia: no emitida

Recomendación: no emitida

Posponer o reducir dosis

Sugerimos: $100 \%$

Evidencia: III

Recomendación: C 


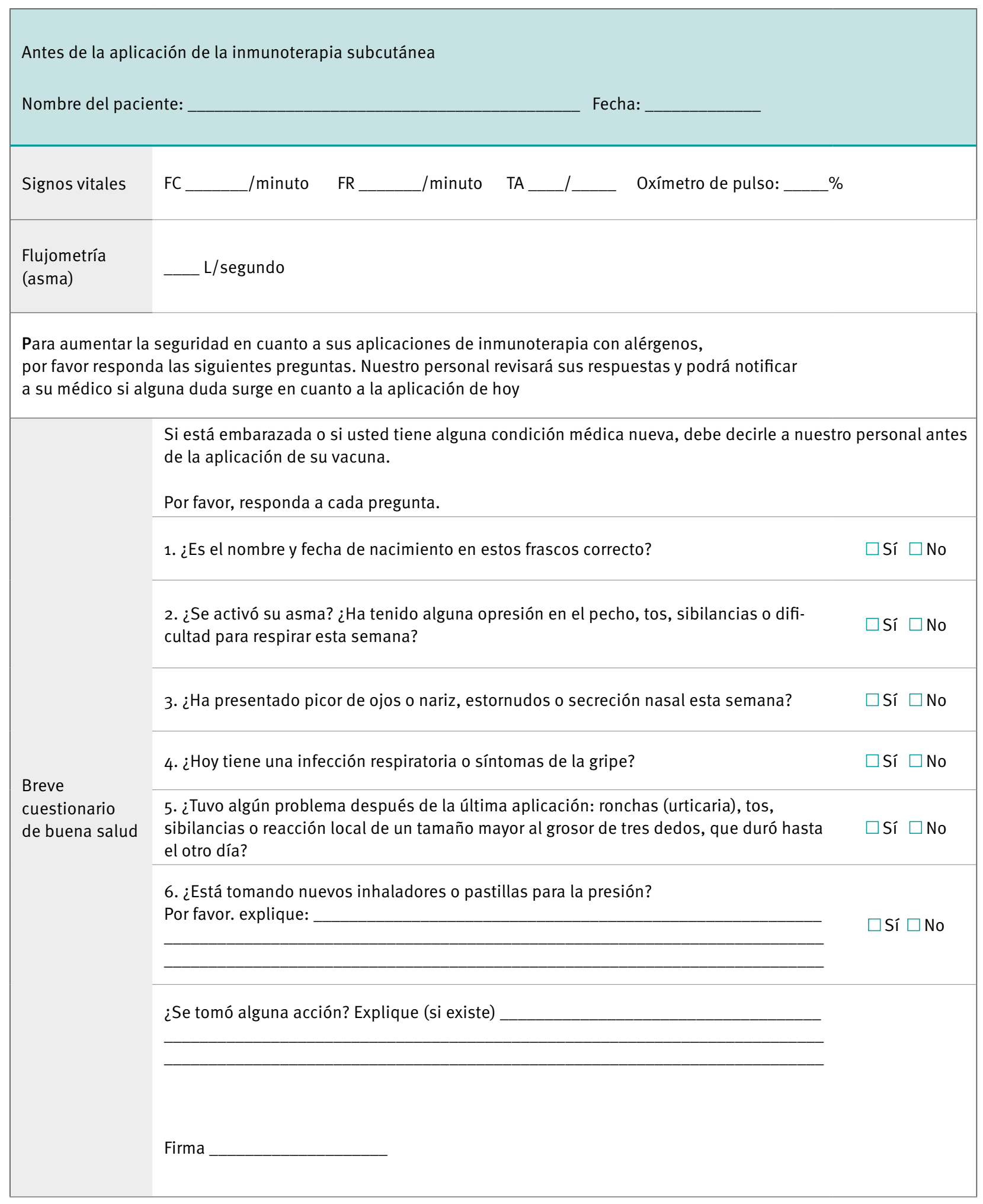

Figura 4.2. Cuestionario no validado pero sugerido por GUIMIT para valoración ordenada del paciente antes de la administración de inmunoterapia subcutánea. 


\subsubsection{Cuidados posteriores a la aplicación de ITSC}

Se recomienda que el paciente espere 30 minutos después de la aplicación de ITSC dado que $80 \%$ de las reacciones sistémicas se han reportado en ese lapso y cuando Punto buena práctica: $100 \%$ se presentan reacciones graves. En las últimas dos décadas ya no ha habido RS grado $\mathrm{V}$ con inicio $>30$ minutos posaplicación. ${ }^{49} \mathrm{Se}$ han reportado RS grados I y II cuando existe absorción rápida desde el tejido subcutáneo hacia la circulación sistémica. Por ello, es aconsejable no realizar ejercicio ni tomar un baño caliente durante las dos horas posteriores a la aplicación y posponer la realización de ejercicio extremo hasta después de tres a cuatro horas.

\section{Cuadro 4.11. Ajustes en el esquema de aplicación de inmunoterapia subcutánea}

Situación que obliga a posponer dosis

- Exacerbación de asma o $\mathrm{VEF}_{1}$ o flujometría $<70$ \% al valor predicho

- Exacerbación aguda de alergia

- Infecciones agudas, respiratorias y no respiratorias

\begin{tabular}{|c|c|}
\hline Situación que obliga a reducir la dosis & Cómo reducir la dosis \\
\hline - Primera aplicación de frasco nuevo & $50 \%$ \\
\hline $\begin{array}{l}\text { - Reacciones locales grandes repetitivas }>25 \mathrm{~mm} \\
\text { (más si duran hasta el otro día) }\end{array}$ & Dosis previa o hasta $50 \%$ \\
\hline - Reacción sistémica previa & $\begin{array}{l}\text { Leve: dosis previa. } \\
\text { Moderada-grave: } 1 / 10 \text { dosis }\end{array}$ \\
\hline - Varias reacciones sistémicas & Evaluar si es necesario suspender la ITSC \\
\hline - Paciente altamente sensible + exposición estacional & $50 \%$ \\
\hline \multicolumn{2}{|l|}{$\begin{array}{l}\text { - Lapso prolongado entre dosis (extractos acuosos)* } \\
\text { 1) Fase de aumento de dosis. Tiempo desde última ITSC }\end{array}$} \\
\hline$<2$ semanas & Aumentar normalmente \\
\hline $2-3$ semanas & Repetir última dosis \\
\hline 3-4 semanas & Regresar 1 dosis \\
\hline 4-5 semanas & Regresar 2 dosis \\
\hline 6-8 semanas & Reiniciar desde frasco 1 \\
\hline \multicolumn{2}{|l|}{ 2) Fase de mantenimiento. Tiempo desde última ITSC } \\
\hline$<5$ semanas & Aplicar normalmente \\
\hline $5-6$ semanas & Regresar 1 dosis \\
\hline 6-8 semanas & Regresar 2 dosis $/ 50 \%$ \\
\hline 2-3 meses & Reiniciar frasco: desde $0.05 \mathrm{~mL}$ \\
\hline 3-4 meses & Frasco previo desde $0.05 \mathrm{~mL}$ \\
\hline$>4$ meses & Reiniciar desde frasco 1 \\
\hline $\begin{array}{l}\text { - Lapso prolongado entre dosis (extractos de alergoides o adsorbi- } \\
\text { dos) }{ }^{\star \star}\end{array}$ & $\begin{array}{l}\text { Mantenimiento }<8 \text { semanas: seguir normal. } \\
>8 \text { semanas: consultar recomendación del fabricante }\end{array}$ \\
\hline
\end{tabular}

* Según experiencia de aproximadamente 1000 alergólogos miembros de la American Academy of Allergy, Asthma and Immunology. Adaptado de Larenas-Linnemann DE, Gupta P, Mithani S, Ponda P. Survey on immunotherapy practice patterns: dose, dose adjustments, and duration. Ann Allergy Asthma Immunol. 2012;108(5):373-378.

** De preferencia seguir con la dosis normal o suspender. Es discutible si al reducir dosis se pierde eficacia. 


\section{Capítulo 5. Inmunoterapia sublingual (cuadro 5.1)}

\section{Cuadro 5.1. Resumen de inmunoterapia sublingual}

Expertos de GUIMIT recomiendan o sugieren conforme evidencia en guías madre*

Acuerdo

Para productos específicamente vendidos para ITSL, ¿existe una dosis de mantenimiento probablemente eficaz?

Recomiendan: Sí

$100 \%$

¿Cuál será la dosis de mantenimiento ITSL probablemente eficaz?

Sugieren: 5-50 $\mu \mathrm{g}$ de alérgeno

mayor diarios

$100 \%$

Para productos de ITSL líquida, preparados a partir de frascos con extracto alergénico concentrado, ¿existe dosis de mantenimiento probablemente eficaz en relación con la dosis de la ITSC?

Sugieren: Sí

$100 \%$

Para extractos naturales, ¿cuál será esta dosis de mantenimiento diaria respecto a la ITSC?

50-200 \% de la mensual de ITSC

$100 \%$

En la fase de mantenimiento, ¿la ITSL debe aplicarse diariamente para obtener mayor eficacia?

¿La fase de mantenimiento es por lo menos de 3 años?

Recomiendan: Sí

$100 \%$

Recomiendan: Sí

$100 \%$

En pacientes polialérgicos con indicación de ITSL, ¿es recomendable hacer mezclas con alérgenos no relacionados?

Neutral

$100 \%$

¿Cuántos alérgenos máximo por frasco?

Sugieren: 2 alérgenos no

homólogos

$100 \%$

Recomiendan: Respetar el conteni-

do biológico de proteasas.

¿Cuáles mezclar y cuáles no?

Sugieren: Considerar preparar

$100 \%$

¿Existe evidencia de que agregar adyuvantes en la forma de productos bacterianos pueda mejorar la eficacia?

¿En algún caso se debe posponer la aplicación de ITSL?

¿Existen condiciones en las cuales se tenga que evaluar reducir la dosis programada?

viales separados

Sugieren: Sí

$100 \%$

Recomiendan: Sí

$100 \%$

Recomiendan: Sí

$100 \%$

¿Cuál es la frecuencia de reacciones adversas sistémicas en ITSL?

- De todas las dosis administradas

$0.056 \%$

$100 \%$

- De todos los pacientes

- Reacciones graves

La modalidad pre y coestacional, ¿podría ser de utilidad para México en comparación con los esquemas continuos?

Locales: $50-75 \%$,

Sistémicas: $0.08 \%$, Graves: $1.1 \%$

de los pacientes

Es eficaz. Sugieren: no (no hay efecto a largo plazo)

$100 \%$

Experiencia clínica común de los expertos GUIMIT (Delphi simplificado): ** evidencia $1 \mathrm{C}$

Tomando la precaución de conservar la dosis de mantenimiento y no mezclar alérgenos con alto y bajo contenido de proteasas, ¿la ITSL con hasta 4 alérgenos mezclados en un vial es efectiva y segura?

Sí, 37 \% recomienda y $45 \%$ sugiere

En un paciente que no presenta mejora al año de aplicar ITSL

- ¿Se debe continuar la aplicación de ITSL para ver si presenta mejora al inicio de su 20 año de aplicación?

No, $29 \%$ recomienda no y

$51 \%$ sugiere no

- ¿Es probable que se presente mejoría al cambiar a ITSC?

Sí, 11 recomienda y $55 \%$ sugiere

\section{Puntos de buena práctica}

¿El volumen del frasco de mantenimiento para ITSL es de 5-10 $\mathrm{mL}$ ?

* Se buscó nivel de evidencia y recomendación en cada guía madre (tablas fuente 1); se fusionaron evidencias y recomendaciones para emitir una recomendación para cierta acción (tablas fuente 2). Los vínculos a estas tablas se encuentran en el anexo 1.

** Contestación anónima de los 57 expertos GUIMIT. Con amplio consenso se obtiene un nivel de evidencia 1C, según CEBM.

ITSC = inmunoterapia subcutánea, ITSL = inmunoterapia sublingual. 


\subsection{Introducción}

Estudios de alta calidad, doble ciego placebo controlado han mostrado claramente la eficacia y seguridad de la ITSL, como la guía de la European Academy of Allergy and Clinical Immunology, sección rinitis/World Allergy Organization-Inmunoterapia Sublingual, respecto a pólenes y ácaros del polvo casero; la evidencia para extractos de caspa de animal y hongos es menos sólida y para cucaracha es casi nula (véase capítulo 2). Con ello, la ITSL se presenta como una buena modalidad para pacientes que no pueden acudir regularmente a la aplicación de la ITSC o que prefieren no recibir inyecciones. Además, el nivel de seguridad de la ITSL es más elevado que el de la ITSC. Hasta el momento no se han encontrado reacciones grado V (véase capítulo 9) con la ITSL y las reacciones grado IV son sumamente raras. Por ello, la ITSL también podría ser una opción para los pacientes que no toleran la ITSC. En el ámbito internacional especializado se ha discutido este punto, porque se han documentado eventos adversos sistémicos al cambiar a ITSL en pacientes que presentaron eventos adversos sistémicos con ITSC. Por ello, particularmente en estos casos es importante iniciar la ITSL con una adecuada fase de aumento de dosis, ya que reportes en Europa han demostrado que el inicio directamente con la dosis máxima (como se acostumbra en esa parte del mundo) no es bien tolerado. ${ }^{56,57}$ En el Reino Unido, con la fase de aumento de dosis no se registraron problemas en dos pacientes con anafilaxia posterior a ITSC. ${ }^{58}$

\subsection{Selección de guías madre específicas para ITSL}

Para el capítulo de ITSL se tuvieron que buscar dos nuevas GM, dado que una no cubría esta modalidad (JTF-AAAAI/ACAAI) y las otras dos tenían un criterios similares, ya que ambas reflejan los conceptos de la escuela europea relacionados con ITSL y compartieron parcialmente los mismos autores principales. Por ello, la base conceptual fue la evaluación de la calidad según AGREE-II de guías enfocadas a ITSL y publicadas los últimos 10 años, para seleccionar las dos con mejor puntuación; ya se contaba con una evaluación según AGREE-II de varias guías publicadas recientemente, ${ }^{5}$ pero de otras no. La más prometedora de estas últimas, la guía del JTF-AAAAI/ACAAI-SLIT $2017,{ }^{59}$ logró un promedio de 3.15 puntos en la evaluación independiente AGREE-II de dos expertos. Así, las dos guías sobre ITSL con mejor calidad que se seleccionaron como GM adicionales para este y los siguientes capítulos fueron la guía de la World Allergy Organization $^{40}$ y la japonesa-SLIT. ${ }^{60}$

\subsection{Dosificación de la ITSL, frecuencia y duración}

Algunos estudios han mostrado que la eficacia de ITSL depende de la dosis y posiblemente de otros factores. Así, al igual que para la ITSC, la eficacia de la ITSL es dosisdependiente.

Con lo analizado se podría sugerir que la dosis diaria de ITSL se encuentra posiblemente entre 50 y $200 \%$ de la dosis mensual de ITSC. Además, es muy probable que mientras menor sea el volumen de administración, mayor el gradiente de concentración transmucosa y posiblemente mayor su absorción (punto de buena práctica). Esto fue demostrado para la diferencia entre las tabletas para ITSL: la biodisponibilidad depende de la formulación y es mayor para la tableta liofilizada versus la comprimida. ${ }^{61}$

Todas las GM mencionan explícitamente que la administración de la ITSL es diaria o incluyen estudios doble ciego placebo controlado que así la administraron.

Durante el primero año del tratamiento se observa reducción de síntomas y medicación con ITSL; se recomienda la administración durante al menos un año para ácaro

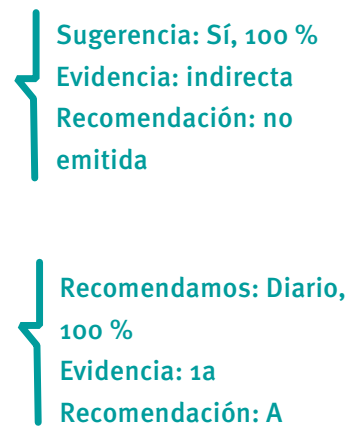


de polvo casero, porque se demostró eficacia a los 12 meses y el efecto aún persistió un año después. Para polen de pasto se recomienda administrar por tres años, porque se ha podido documentar un efecto a mediano plazo (dos a cinco años posteriores a la administración), que continúa después de haber terminado la inmunoterapia (EAACI-Prevent y guía japonesa-SLIT). Para el efecto a largo plazo, más de cinco años después de haber terminado la ITA, la evidencia es baja. La ITSL por dos años no logró mantener el efecto clínico benéfico un año después, ${ }^{62}$ con lo que se confirma la necesidad de una duración de mínimo tres años para obtener un efecto benéfico posterior a su terminación.

Las GM no hacen mención del volumen del frasco, pero un volumen entre 5 y $10 \mathrm{~mL}$ parece adecuado, para que dure de 2 a 4 meses.

El inicio de la fase de mantenimiento 12 semanas antes de la estación de polinización tiene un mejor efecto terapéutico (guía japonesa-SLIT). La ITSL con esquema pre-coestacional es una alternativa para el manejo de la rinoconjuntivitis estacional ya que es efectiva para reducir los síntomas durante su aplicación, es segura y reduce costos. Sin embargo, no se ha podido demostrar la inducción de tolerancia con este tipo de esquema y carece de efecto a largo plazo, por lo que no lo sugerimos para México.

\subsection{Dosis de la ITSL según guías madre y estudios originales referenciados}

Solo pueden formularse aseveraciones respecto a la dosis de ITSL relativa a la dosis de mantenimiento mensual con ITSC, revisando las dosis documentadas como efectivas para ITSL en los estudios originales referenciados por las GM. En el cuadro 5.2 se indican las dosis eficaces encontradas en estudios de alta calidad, expresadas tanto en unidades usadas por el fabricante, como en microgramos de alérgenos mayores. Dado que los ensayos usados para la determinación de microgramos de alérgeno mayor pueden variar, se debe ser cauteloso en comparar los resultados entre fabricantes (capítulo 8), por ello tiene mayor validez la comparación de la potencia de los extractos analizados en un mismo laboratorio. Existen algunos reportes referenciados en las GM que usaron este método. ${ }^{63-67}$ Estos estudios mostraron que existe gran variación entre los productos en el mercado en México ${ }^{18}$ y que tampoco en Europa está bien definida la dosis de la ITSL, dado que existe gran variación entre las dosis de ITSL de los productos de diferentes fabricantes.

En el cuadro 5.2 se indican rangos para las dosis de mantenimiento probablemente efectivas en ITSL, en relación con las dosis recomendadas para ITSC. ${ }^{63-80}$

\subsection{Fase de mantenimiento: cómo comparar la dosis diaria de ITSL con la dosis mensual de ITSC}

La guía EAACI-RA y la alemana indican que los metaanálisis han mostrado heterogeneidad considerable en el nivel de eficacia entre los diferentes productos y las diferentes dosis para ITSL. Como consecuencia, recomiendan usar productos con evidencia de eficacia documentada en estudios clínicos, si están disponibles. Los expertos de GUIMIT se percataron que parte de la heterogeneidad en los estudios clínicos también se debe a múltiples diferencias en el diseño de los estudios, en la población estudiada y en la definición exacta de los parámetros de eficacia. ${ }^{81}$

Al momento de elaborar GUIMIT solo se contaba con escasos alérgenos y productos para ITSL cuya eficacia había sido comprobada en estudios clínicos, en parte porque varios de los alérgenos más prevalentes en México se consideran de menor importancia en Europa. Afortunadamente, en las GM se aborda el caso de los alérgenos "huérfanos" (pocos pacientes europeos con alergia a ellos y analizados en escasos estudios clínicos); al respecto se señala aceptable administrar ITA sin el respaldo de
Recomendamos:

Mínimo 3 años, $100 \%$

Evidencia: $1 \mathrm{~b}$

Recomendación: B

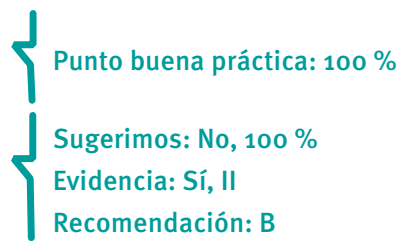

Sugerimos: $100 \%$ Evidencia: Indirecta Recomendación: C

Sugerimos: $100 \%$

Evidencia: 1a

Recomendación: A 


\begin{tabular}{|c|c|c|c|c|c|c|c|}
\hline \multirow[b]{2}{*}{ Alérgeno } & \multicolumn{5}{|c|}{ Inmunoterapia sublingual } & \multirow[b]{2}{*}{ Dosis mensual ITSC } & \multirow{2}{*}{$\begin{array}{l}\text { Dosis } \\
\text { diaria } \\
\text { ITSL/ } \\
\text { mensual } \\
\text { SCIT }\end{array}$} \\
\hline & Fabricante & $\begin{array}{l}\text { Tableta o } \\
\text { líquido }\end{array}$ & $\begin{array}{c}\text { Dosis diaria } \\
\text { (unidades fabricante) }\end{array}$ & $\begin{array}{l}\text { Dosis diaria } \\
\text { (alérgeno mayor } \\
\text { en } \mu \mathrm{g})^{\star}\end{array}$ & $\begin{array}{l}\text { Dosis diaria } \\
\text { (BAU) }\end{array}$ & & \\
\hline \multicolumn{8}{|c|}{ Polen de pasto $65,68,69$} \\
\hline Phleum pratense & ALK-Abelló & Tableta & $75.000 \mathrm{SQ}-\mathrm{U}$ & $15 \mu \mathrm{g} \mathrm{Phl} \mathrm{p} 5$ & 6200 & 1000-4000 BAUी & 1.5 \\
\hline 5-pastos & Stallergènes & Tableta & $300 \mathrm{IR}$ & $25 \mu \mathrm{g}$ Phl p 5 & 8200 & 1000-4000 BAU & 2 \\
\hline \multicolumn{8}{|l|}{ Polen de árboles ${ }^{70}$} \\
\hline 3-árboles ${ }^{\ddagger}$ & ALK-Abelló & Líquido $0.4 \mathrm{~mL}$ & $28.6 \mathrm{SQ}-\mathrm{U}$ & $\begin{array}{c}4.3 \mu \mathrm{g} \\
\text { Bet v } 1, \text { Aln g } 1 \text {, } \\
\text { Cor a } 1 \\
\text { (850 ooo SQ-U } \\
\text { mensual) }\end{array}$ & $\begin{array}{c}\text { Sin } \\
\text { información }\end{array}$ & $100000 \mathrm{SQ}-\mathrm{U}$ & 0.35 \\
\hline \multicolumn{8}{|c|}{ Polen de maleza ${ }^{71-74}$} \\
\hline Ambrosia & Greer & Líquido & $48 \mu \mathrm{g} \mathrm{Amb}$ a $1^{\star \star}$ & $48 \mu \mathrm{g}$ Amb a 1 & $\begin{array}{c}\text { Sin } \\
\text { información }\end{array}$ & $6-12 \mu \mathrm{g} \mathrm{Amb}$ a $1^{\Uparrow}$ & 5 \\
\hline Ambrosia & ALK-Abelló & Tableta & $12 \mathrm{Amb}$ a 1 unit & 12 Amb a 1 unit & $\begin{array}{c}\text { Sin } \\
\text { información }\end{array}$ & 6-12 $\mu \mathrm{g} \mathrm{Amb}$ a 1 & $1-2$ \\
\hline \multicolumn{8}{|c|}{ Ácaro de polvo casero para rinitis alérgica75,76 y asma35,77-79 } \\
\hline Dpt + Df: 1:1:1:1 & ALK-Abelló & Tableta & $\begin{array}{c}6 \mathrm{SQ} \\
\mathrm{HDM}=10,000 \mathrm{JAU} ; \\
12 \mathrm{SQ} \mathrm{HDM}^{\star \star \star}\end{array}$ & $\begin{array}{c}6 \mathrm{SQ}-\mathrm{U}=7.5 \mu \mathrm{g} \\
\text { grupos } 1 \text { у } 2\end{array}$ & $\begin{array}{c}\text { Sin } \\
\text { información }\end{array}$ & $\begin{array}{l}\text { 500-2000 AUी } \\
7 \text { Der } p \text { 1 } \\
\text { Con análisis } \\
\text { ALK--Abelló } \\
\text { Estados Unidos: } \\
\text { 1-8 Der } p \text { 1, Der f 1; } \\
\text { 0.1-9 Der } p \text { 2, } \\
\text { Der } f 2\end{array}$ & $\begin{array}{c}1 \\
\text { (rango } \\
1-7 \text { ) }\end{array}$ \\
\hline Dpt + Df: $1: 1$ & Stallergènes & Tableta & 300 IR & $\begin{array}{l}16 \mu g \text { Der } p 1 \\
68 \mu g \text { Der } f_{1} \\
(84 \text { grupo } 1)\end{array}$ & $\begin{array}{c}\text { (Algunos } \\
\text { calcularon } \\
15000 \mathrm{AU})^{\ddagger \ddagger}\end{array}$ & $\begin{array}{c}\text { 500-2000 AUी } \\
\text { 7 Der p 1- } \\
\text { Con análisis Inbio: } \\
\text { 4-10 Der p 1, } \\
\text { Der f 1;0.65-7 } \\
\text { Der p 2, Der f } 2\end{array}$ & $\begin{array}{c}8 \\
\text { (rango } \\
8-20 \text { ) }\end{array}$ \\
\hline
\end{tabular}

*Fuente: publicaciones en revistas indexadas o información para prescribir (package insert).

${ }^{\ddagger}$ Árboles Betula verrucosa, Corylus avellana y Alnus glutinosa.

${ }^{\star *} 94 \%$ recibió esta dosis. Los que no toleraron quedaron con la dosis menor de $18 \mu \mathrm{g}$ Amb a 1 diario.

$\star \star \star$ La dosis elegida para su comercialización en europea es de 12 SQ-U (por mayor eficacia en los parámetros secundarios en estudio de búsqueda de dosis) y en Japón 6 SQ-U/10,000 JAU.

${ }^{\ddagger \neq}$ https://www.aaaai.org/ask-the-expert/allergen-immunotherapy-IR-units

?JTF-AAAAI/ACAAI 2011

- Haugaard L, Dahl R, Jacobsen L. A controlled dose-response study of immunotherapy with standardized, partially purified extract of house dust mite: clinical efficacy and side effects. J Allergy Clin Immunol. 1993;91(3):709-722 ${ }^{80}$ (referenciado en JTF-AAAAI/ACAAI 2011).

$\mathrm{Dpt}=$ Dermatophagoides pteronyssinus, $\mathrm{Df}=$ Dermatophagoides farinae, 1:1:1:1 = cantidades iguales de Der $\mathrm{p}$ 1: Der $\mathrm{p}$ 2: Der $\mathrm{f}$ 1: Der $\mathrm{f}$ 2; 1:1 = cantidades iguales de Der p 1: Der f 1, no se menciona grupo 2 ; IR = index of reactivity, JAU = Japanese allergy units, SQ-U = standard quality unit. 
documentación clínica sólida. Asimismo, la guía EAACI-Prevent considera la existencia de un efecto de clase: si la ITA funciona para determinado alérgeno, también lo hará para otro diferente.

La dosis que finalmente resulta eficaz para ITSL con polen de pasto se encuentra en el mismo rango de dosis para productos muy distintos y de diferente fabricante: 75000 SQ-U (que contiene $15 " \mu \mathrm{g}$ Phl p 5) y $300 \mathrm{I}$ R (que contiene $25 \mu \mathrm{g}$ Phl p 5). Para la tableta que se disuelve con rapidez (ALK-Abelló) se registra una dosis semejante a la dosis con mayor eficacia para el ácaro del polvo casero (6 SQ-U, que contiene $15 \mu \mathrm{g}$ total de alérgeno mayor sumando los grupos 1 y 2), pero la dosis ideal para la tableta de disolución más lenta fue mayor ( $300 \mathrm{IR}=80 \mu \mathrm{g}$ total de alérgeno mayor sumando los grupos $1 \mathrm{y}$ 2), que podría considerarse la dosis tope con mejores resultados que $500 \mathrm{IR}$, tanto en un estudio europeo ${ }^{75}$ como en uno japonés. ${ }^{82}$

Para el polen de árboles y Ambrosia se han reportado dosis efectivas entre 4.5 y $48 \mu \mathrm{g}$ del alérgeno mayor (cuadro 5.2). Si bien la variación es de un factor 10, aun así se encuentra en el mismo rango de microgramos en el cual se encuentra la dosis mensual recomendada para la ITSC (6 a $12 \mu \mathrm{g} \mathrm{Amb} \mathrm{a} \mathrm{1).} \mathrm{Por} \mathrm{ello,} \mathrm{GUIMIT} \mathrm{sugiere}$ que la dosis diaria de ITSL se encuentra posiblemente entre 50 y $200 \%$ de la dosis mensual de ITSC.

\subsection{ITSL con extractos disponibles en México}

Del análisis de la evidencia en las GM respecto el contexto de los extractos disponibles en México, los expertos GUIMIT observan que:

- Todas las GM recomiendan usar productos con evidencia en estudios clínicos.

- En México se cuenta con una tableta de extracto liofilizado para ITSL. Se encuentra la dosis eficaz en estudios realizados con ella.

- En México no se dispone de extractos para ITSL con documentación clínica de eficacia considerada sólida por las GM.

- El rango de la dosis diaria para ITSL no presenta una variación demasiado alta (cuadro 5.2) y al parecer es similar a la dosis mensual considerada eficaz para ITSC (5 a $20 \mu \mathrm{g}$ del alérgeno mayor).

- En México se dispone de extractos concentrados, estandarizados y no estandarizados, pero también de extractos más diluidos. ${ }^{18,66,83}$

- Solo se pueden usar extractos naturales para ITSL extrapolando las dosis usadas para ITSC con extractos adsorbidos, lo que puede carecer de validez.

Para ITSL con extractos estandarizados, GUIMIT recomienda:

- Emplear de preferencia este tipo de extractos de alérgenos.

- Usar la dosis recomendada por el fabricante.

Para ITSL con extractos no estandarizados GUIMIT sugiere:

- Para alérgenos solo disponibles como extractos no estandarizados o sin estudios de dosis-respuesta, considerar una dosis mínima diaria para ITSL entre 50 y $200 \%$ de la dosis mensual de ITSC.

- Considerar que es probable que un volumen menor $(<0.4 \mathrm{~mL})$ sea más eficaz que un volumen mayor $(1 \mathrm{~mL})$.

- Usar solo viales con alta concentración del alérgeno (por ejemplo, 1:10 p/v) para preparar ITSL. 


\subsection{Fase de aumento de dosis}

Las GM no mencionan fase de aumento de dosis, dado que desde el principio se administra la dosis máxima en la mayoría de los productos comercializados para ITSL. Con esta práctica se han reportado reacciones locales las primeras semanas en 40 a $75 \%$ de los pacientes. Los expertos de GUIMIT consideran preferible una fase de aumento de dosis no mayor a un mes, para mejorar la seguridad sin retrasar demasiado la dosis efectiva. En esta fase se podría iniciar con una dosis de 1/1000 veces la dosis de mantenimiento, con aumento cada tercer día.

\subsection{ITSL en pacientes polialérgicos}

Las diferentes guías solo recomiendan el uso de mono-ITSL por carecer de estudios doble ciego placebo controlado con poli-ITSL en pacientes polisensibilizados, probablemente debido a que en los países europeos solo se vende mono-ITSL como producto terminado, ya sea en forma líquida o en tabletas. En ninguna GM se indica cuántos alérgenos incluir en la ITSL. Existe suficiente evidencia que demuestra efectividad utilizando mono-ITSL y en los artículos originales citados en las GM hay evidencia para ITSL dual en un solo frasco $^{84} \mathrm{o}$ en frascos separados. ${ }^{85,86}$ La SLIT con 10 alérgenos parece carecer de eficacia en estudios de provocación, sin embargo, hasta el momento se carece de evidencia para ITSL con tres a nueve extractos. Por otro lado, se ha demostrado que la ITSL con multialérgenos es segura, aunque se discute su eficacia (World Allergy Organization).

Para un paciente polisensibilizado que es polialérgico para alérgenos homólogos relacionados biológicamente, las GM recomiendan máximo mezclar dos alérgenos homólogos. La guía alemana no recomienda las mezclas, argumentando que los extractos se diluyen al mezclarlos y que puede haber degradación por la presencia de proteasas. Estos dos argumentos no aplican para la ITSL con extractos naturales, como se preparan en México; no debe existir un efecto dilucional si se prepara la ITSL a partir de extractos concentrados provenientes de Estados Unidos con el cálculo adecuado de la dosis de mantenimiento de cada componente. Además, la degradación proteica, por las proteasas presentes en algunos extractos, se reduce al mínimo al evitar mezclar alérgenos con alto contenido de proteasas con los de bajo contenido (capítulo 4).

Por ende, debido a que en México los alergólogos formulan la inmunoterapia y disponen con escalas de síntomas pueden evaluar a los pacientes con eficacia y seguridad al agregar más de un alérgeno en la ITSL, apegándose a las reglas de las mezclas de antígenos. En este sentido, no hay mayor diferencia al mezclar extractos estandarizados o no, porque al estandarizar un extracto no cambia su composición. Para aumentar la eficacia, sugerimos mezclar solo alérgenos relevantes en la historia clínica del paciente; mientras más acotada la inmunoterapia, mayor será su eficacia. El principio de "no mezclar" aplica para los extractos europeos, dado que se venden como producto terminados y no están diseñados para ser manipulados.

\subsection{Agregar adyuvantes al vial de la ITSL}

Algunas preparaciones de ITSL incluyen adyuvantes con el objetivo de ampliar el efecto terapéutico mediante la modulación de la respuesta inmune o mejorar el perfil de seguridad. Los probióticos se han investigado como adyuvantes en modelos murinos; con ellos ha mejorado la inducción de la tolerancia. ${ }^{87}$

Sin mencionar directamente la vacuna bacteriana, la guía japonesa explica su posible mecanismo de acción al estimular la inmunorregulación: refiere que la mucosa oral con-
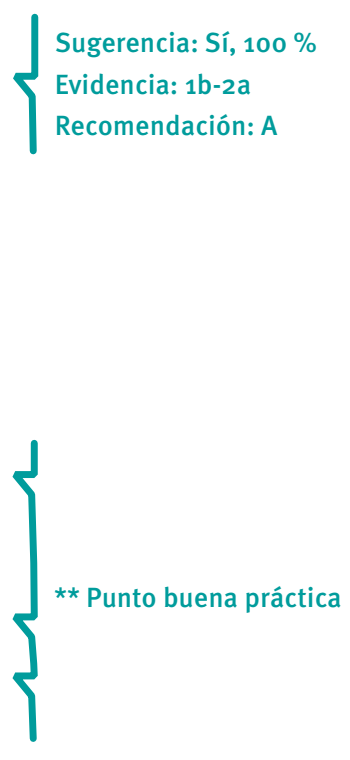

Sugerencia: Sí, $100 \%$ Evidencia: No emitida Recomendación: No emitida 
tiene células dendríticas mieloides $(\mathrm{CDm})$, cuya superficie contiene abundantes receptores tipo Toll 2 y 4 (TLR-2 y TLR-4) que se activan con productos bacterianos. Su activación estimula la expresión de moléculas coestimuladoras B7H1 (PD-L1) y B7H3 y la producción y liberación de IL-10. Las CDm también estimulan las células Treg. GUIMIT sugiere utilizar productos bacterianos en pacientes que además de enfermedades alérgicas tengan infecciones de vías respiratorias recurrentes, pero no sugiere utilizarlos en todos.

\subsection{Seguridad de la ITSL: eventos adversos, cuándo posponer o reducir dosis}

En general, la ITSL se considera segura y bien tolerada. La frecuencia de reacciones graves fue de $1.1 \%$ de los pacientes tratados. Con la ITSL, en el esquema europeo sin fase de aumento de dosis, 40 a $75 \%$ de los pacientes presenta eventos adversos locales, especialmente en la mucosa oral (prurito oral o disestesias, edema de la mucosa oral, irritación de la faringe) o dolor abdominal. Entre 4 y $8 \%$ de los pacientes que usan ITSL en tableta interrumpen el tratamiento por reacciones locales intensas.

Recomendamos siempre aplicar la primera dosis de ITSL en el consultorio y esperar 30 minutos; sugerimos aplicar la primera dosis de cada nuevo vial bajo supervisión. Además, recomendamos posponer la aplicación de ITSL o reducir su dosis bajo ciertas condiciones (cuadro 5.3). Después de una o más reacciones sistémicas graves con ITSL, el médico y el paciente deben discutir si es pertinente continuar el tratamiento.

\begin{tabular}{|c|c|}
\hline Posponer aplicación & ¿Por cuántos días? \\
\hline Exacerbación de asma o asma no controlada: se reiniciará ITSL & $\begin{array}{l}\text { Una vez que el asma esté contro- } \\
\text { lada }\end{array}$ \\
\hline Asma grave & $\begin{array}{c}\text { Tan pronto reduzca el nivel } \\
\text { de gravedad }\end{array}$ \\
\hline Síntomas de alergia activada (más riesgo de evento adverso) & 5-7 días \\
\hline $\begin{array}{l}\text { Durante una infección aguda de las vías respiratorias altas } \\
\text { (en pacientes con asma) }\end{array}$ & 3-5 días \\
\hline Gastroenteritis aguda & 3-5 días \\
\hline
\end{tabular}

ITSL debe posponerse cuando hay lesiones en la cavidad oral por:

- Extracción de una pieza dentaria.

- Cirugía en cavidad oral. 7 días

- Al caerse un diente.

- Úlcera o lesión en cavidad oral.

\begin{tabular}{lc}
\hline Reducir dosis & ¿A cuánto? \\
\hline Después de un periodo sin administración (7 días) & 1 gota \\
\hline Al presentarse síntomas sistémicos después de su administración ${ }^{*}$ & 1 gota \\
\hline Reiniciar desde frasco 1 & 1 gota (frasco 1) \\
\hline Después de 3 semanas sin aplicación & \\
\hline Suspender ITSL & \\
\hline
\end{tabular}

Al desarrollarse esofagitis eosinofílica

Indefinido

*La guía japonesa sugiere que en estos casos eventualmente se puede cambiar al método aplicación-escupe (sobre todo en reacciones adversas gastrointestinales). ITSL = inmunoterapia sublingual.

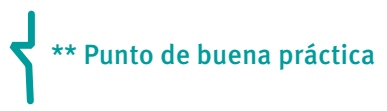

Recomendamos: $100 \%$

Evidencia: No emitida

Recomendación: D

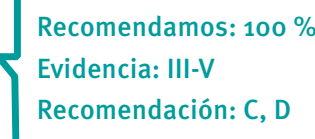

$\left\{\begin{array}{l}\text { Recomendamos: } 100 \% \\ \text { Evidencia: III-V } \\ \text { Recomendación: C, D }\end{array}\right.$

$\{* \star$ Punto de buena práctica

http://www.revistaalergia.mx 


\section{Capítulo 6. Inmunoterapia para veneno de himenópteros y otros insectos (cuadro 6.1)}

Cuadro 6.1. Resumen inmunoterapia para veneno de himenópteros y otros insectos

Expertos de GUIMIT recomiendan o sugieren conforme evidencia en guías madre*

Acuerdo

¿Cuáles son las indicaciones para la inmunoterapia específica con veneno de himenópteros?

- Pacientes con antecedentes de reacción sistémica (RS) a una picadura de himenópteros y con evidencia demostrable de anticuerpos IgE específicos clínicamente relevantes

Recomiendan: Sí

$100 \%$

- Pacientes mayores de 16 años con antecedentes de una reacción sistémica limitada a la piel y evidencia demostrable de anticuerpos IgE específicos clínicamente relevantes

- Adultos y niños con antecedentes de una reacción sistémica a la hormiga de fuego importada y evidencia demostrable de anticuerpos IgE específicos clínicamente relevantes

- Pacientes adultos que experimentan reacciones locales grandes frecuentes e incapacitantes

En pacientes con indicación para VIT pero en condiciones especiales, ¿se recomienda la inmunoterapia específica para veneno de himenóptero?

- Enfermedad cardiovascular estable

- Uso de betabloqueadores y IECA

- Neoplasias estables o en remisión

- Enfermedad autoinmune multiorgánica

- Iniciar durante el embarazo

- Continuar durante embarazo

- Mastocitosis

Sugieren: Sí

Sugieren: Sí

Sugieren: Sí

Sugieren: hasta que esté en remisión o controlada

Sugieren: Sí

Recomiendan: Sí

Recomiendan: Sí

¿Cuáles son las dosis de mantenimiento recomendadas para la inmunoterapia específica con veneno de himenópteros?

- Veneno de himenópteros (dosis para veneno de cada insecto)

- Cuerpo entero de hormigas de fuego

Recomiendan: $100 \mu \mathrm{g}$

Recomiendan: $0.5 \mathrm{~mL}$ de 1:100 p/v

$100 \%$

$100 \%$

¿Qué característica debe tener el extracto alergénico de himenóptero para iniciar ITA con veneno?

De himenóptero volando (abeja, avispa, etcétera)

Para ITA contra alergia a hormiga roja

¿La duración de la fase de mantenimiento de la VIT es de mínimo 3 a 5 años?

¿La premedicación de la inmunoterapia con antihistamínicos disminuye la aparición reacciones locales o sistémicas?
Recomiendan: Extracto estandarizado de veneno

$100 \%$

Sugieren: Extracto de cuerpo completo

Recomiendan: Sí

$100 \%$

Recomiendan: Sí

$100 \%$

Experiencia clínica común de los expertos GUIMIT (Delphi simplificado): ** evidencia $1 \mathrm{C}$

Después de 5 años de VIT, sin reacción sistémica en los últimos 3 años y con negativi-

dad en pruebas cutáneas y serológicas, ¿se debe suspender la VIT?

En un paciente con mastocitosis sistémica nunca se suspende la VIT, pero se aplica con intervalos de cada 6-8 semanas
Sí, $37 \%$ recomienda y $43 \%$ sugiere

Sí, $13 \%$ recomienda y $55 \%$ sugiere

* Se buscó nivel de evidencia y recomendación en cada guía madre (tablas fuente 1); se fusionaron evidencias y recomendaciones para emitir una recomendación para cierta acción (tablas fuente 2). Los vínculos a estas tablas se encuentran en el anexo 1.

** Contestación anónima de los 57 expertos GUIMIT. Con amplio consenso se obtiene un nivel de evidencia 1C, según CEBM.

IECA = inhibidores de la enzima convertidora de angiotensina, ITA = inmunoterapia con alérgenos, VIT = veneno inmunoterapia. 


\subsection{Introducción}

La frecuencia de reacciones adversas en personas con alergia al veneno de los himenópteros en México va en aumento. Una de las razones es la migración de la hormiga roja desde los estados del sur de Estados Unidos hacia los estados del norte de México. Entre los diferentes miembros de las familias del orden Hymenoptera se encuentran Apidae (abeja, abejorro), Vespidae (avispa y avispón) y Formicidae (hormiga de fuego y hormiga cosechadora). Aunque son miembros del mismo orden o de la misma familia, cada una de estas especies tiene su propio veneno. Por ello es de suma importancia intentar identificar el insecto causal, tomando en cuenta su distribución geográfica. Las reacciones adversas pueden ser RL grandes $(>10 \mathrm{~cm}$, con duración de $>24$ horas hasta siete días) o RS. ${ }^{88}$

Las RS ocurren en 0.4 a $0.8 \%$ de los niños y hasta en $4 \%$ de los adultos. Las reacciones anafilácticas por veneno de los himenópteros son más comunes en los individuos $<20$ años y en los hombres; constituyen $10 \%$ de los casos de anafilaxia que se presentan a los departamentos de urgencias y en Estados Unidos se reportan 40 a 50 casos fatales al año por este motivo. Actualmente no existen estadísticas mexicanas al respecto. Con una buena VIT, el riesgo de anafilaxia por picaduras subsecuentes se puede reducir de 40 a $60 \%$ a menos de $5 \% .{ }^{89}$

En este capítulo se presentan las indicaciones para la administración de VIT, incluso en pacientes con otras patologías coexistentes. Se describen detalles de los extractos, la dosificación y el esquema de aplicación con eventual medicación previa. Finalmente, también se comenta la decisión de terminar o continuar la VIT.

\subsection{Indicación para la administración de VIT}

Después de la atención inicial de un paciente con picadura de un himenóptero, sigue la pregunta de si existe indicación para VIT (figura 6.1). La selección de los pacientes debe basarse en la historia clínica y la evidencia demostrable de anticuerpos IgE específicos mediante pruebas cutáneas (por punción e intradérmicas) o pruebas in vitro.

Respecto a los adultos existe copiosa evidencia sobre la recomendación de la inmunoterapia específica en caso de RS, independientemente de la gravedad de estas. Los pacientes $<16$ años que presentan antecedentes de síntomas solo cutáneos por las picaduras de himenópteros generalmente no requieren VIT, aunque dependiendo del riesgo de exposición, en algunos casos podría estar justificada la indicación. De acuerdo con la guía europea, en niños no existe suficiente evidencia para indicar VIT por RL grandes, dado que estas muy rara vez predisponen a RS posteriores, a diferencia de la RL grandes en adultos. Se concluye que los pacientes $<16$ años con solo antecedentes de síntomas cutáneos por las picaduras de himenópteros generalmente no requieren VIT, mientras que GUIMIT la sugiere para algunos casos específicos de RL grandes. Como indicaciones específicas se resumen las siguientes:

- Adultos y niños con antecedentes de reacción adversa sistémica grave por picadura de abeja o véspidos y evidencia demostrable de anticuerpos IgE específicos para el insecto implicado.

- Pacientes $>16$ años con antecedentes de una RS leve (limitada a la piel) por picadura de abeja o véspidos y evidencia demostrable de anticuerpos IgE específicos para el insecto implicado.

- Adultos y niños con antecedentes de reacción adversa sistémica por picadura de hormiga de fuego importada y evidencia demostrable de anticuerpos IgE específicos para este insecto.
Recomendamos: Sí para 1-3, $100 \%$

Evidencia: I

Recomendación: A 


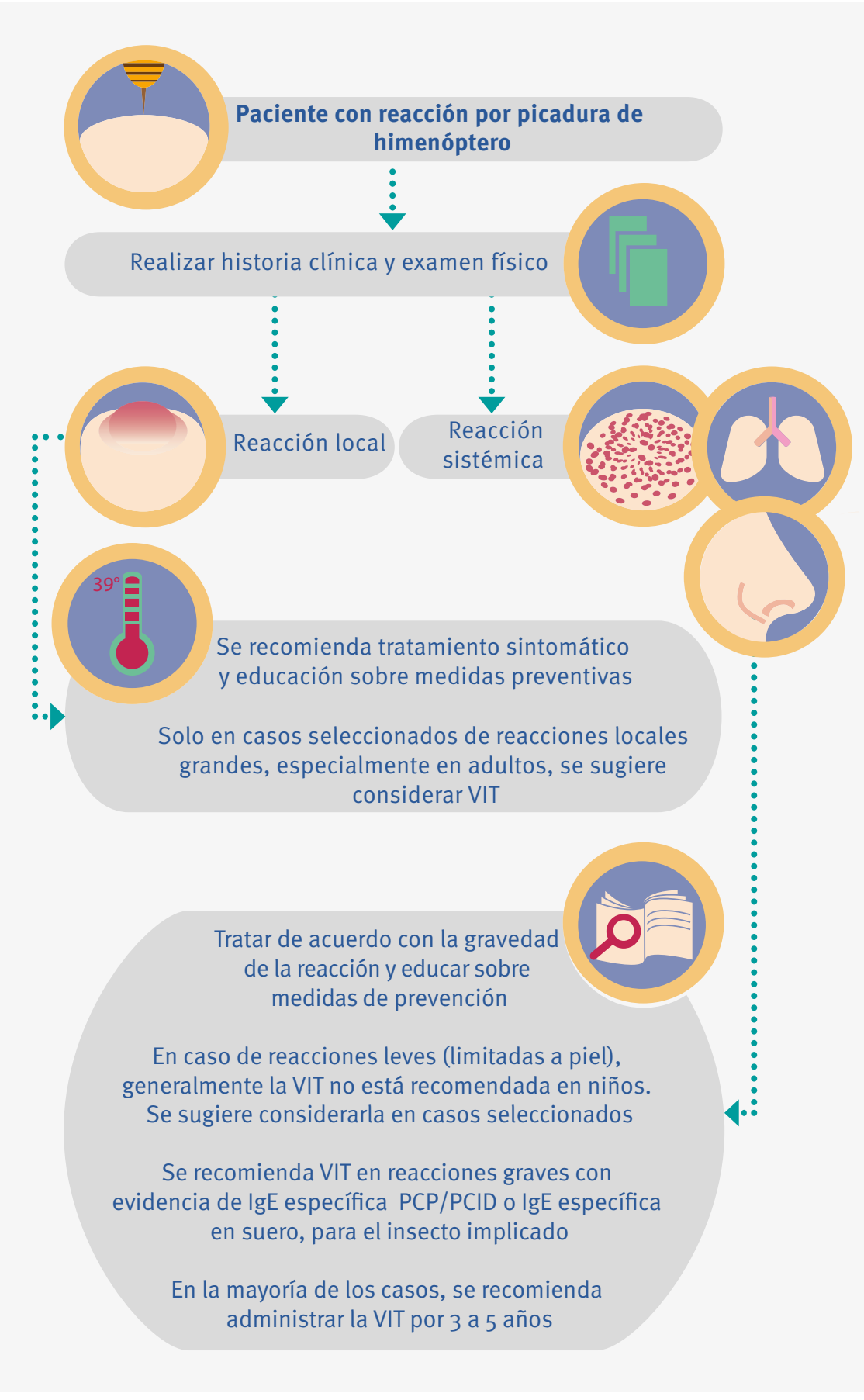

- Pacientes adultos y niños que experimentan RL grandes frecuentes e incapacitantes por picadura de himenóptero y evidencia demostrable de anticuerpos IgE específicos para el insecto implicado.

Recomendamos la medición de triptasa sérica basal en todos los pacientes candidatos a VIT, ya que un nivel aumentado de triptasa sérica basal en pacientes con anafilaxia
Figura 6.1. Proceso de atención e indicación de inmunoterapia específica en casos de reacciones alérgicas por picadura de himenópteros. VIT = veneno inmunoterapia, $\mathrm{PCP}=$ prueba cutánea por punción epicutánea, $\mathrm{PCID}=$ prueba cutánea intradérmica, IgE = inmunoglobulina E.

Sugerimos: Sí, $100 \%$ Evidencia: Adulto, Ila Recomendación: B 
moderada a grave inducida por picadura de himenóptero podría estar relacionado con un trastorno de los mastocitos, asociado a su vez con franco aumento en el riesgo de anafilaxia por futuras picaduras.

\subsection{Indicaciones para VIT en pacientes con otras condiciones médicas}

Las condiciones especiales a las que se hace referencia en esta sección no son per se una contraindicación para la VIT, aunque la evidencia es débil en las GM. El reporte de la experiencia colectiva de casi 1000 alergólogos miembros de The American Academy of Allergy, Asthma and Immunology (publicado después) aumenta el nivel de evidencia. ${ }^{90}$ En todos los casos, el paciente debe ser informado sobre los posibles riesgos. Se debe considerar cuidadosa e individualmente los riesgos y beneficios e incorporar las preferencias del paciente y de otros médicos tratantes en el proceso de toma de decisiones médicas para la indicación de VIT.

En pacientes con enfermedades cardiovasculares, neoplasias o enfermedades autoinmunes se sugiere la indicación de VIT, siempre y cuando dichas condiciones se encuentren estables y controladas o en remisión.

En pacientes que reciben betabloqueadores o IECA se recomienda considerar otras alternativas farmacológicas para el tratamiento cardiovascular. En caso de que esto no sea posible, se sugiere la administración de la VIT con precaución y monitoreo estrecho.

En relación con el embarazo se recomienda en general aplicar las mismas directrices establecidas para la inmunoterapia con aeroalérgenos. Se sugiere iniciar la inmunoterapia durante el embarazo solo si la gravedad de las reacciones y el riesgo alto de sufrir nuevos eventos de picadura lo justifican. Si durante la VIT ocurre un embarazo, se recomienda continuar con su administración, valorando siempre los riesgos y beneficios.

En los pacientes con mastocitosis, aun cuando exista mayor riesgo de reacciones por la VIT se recomienda su indicación dependiendo del riesgo de exposición a futuros eventos de picaduras. Al indicar VIT se recomienda asegurarse de que el paciente traiga siempre consigo adrenalina y tener un plan de acción para su administración. GUIMIT sugiere administrar VIT en pacientes con:

- Enfermedad cardiovascular estable.

- Uso de IECA y betabloqueadores.

- Neoplasias estables o en remisión.

- Enfermedad autoinmune multiorgánica.

- Inicio de embarazo.

- Continuar durante embarazo (recomendación).

- Mastocitosis (recomendación).

\subsection{Demostración de IgE específica contra veneno de himenópteros}

Para demostrar la presencia de IgE específica contra veneno de himenópteros se dispone de pruebas serológicas y cutáneas. Más recientemente se ha sugerido la utilidad de la prueba de activación de basófilos, BAT (véase apartado 1.2).

La decisión de realizar PC para alergia a himenópteros debe basarse en la historia clínica del paciente. En caso de RS, el paciente se considera candidato para la prueba. Las PC deben diferirse tres a seis semanas después de la RS por picadura, debido a que en ese periodo pueden obtenerse resultados falsos-negativos en forma transitoria. Las PC para abeja y véspidos comienzan típicamente con una PCP utilizando $1 \mu \mathrm{g} / \mathrm{mL}$ del veneno. Si el resultado de esta prueba es negativo, se debe realizar PCID, comenzando con una concentración de 0.001 a $0.01 \mu \mathrm{g} / \mathrm{mL}$. Si los resultados son negativos a estas
Sugerimos: $100 \%$ Evidencia: V (1c), Recomendación: D (B) 
concentraciones, se continúan las PCID con incrementos progresivos de 10 veces la concentración hasta que se produzca la respuesta positiva o se alcance una concentración máxima de $1 \mu \mathrm{g} / \mathrm{mL}$. En las PC para hormigas de fuego se utiliza extracto de cuerpo entero y se inician con una dilución 1:100 p/v. Si esta prueba es negativa se deben realizar PCID con una dilución inicial de 1:1000 000 p/v, con incrementos progresivos de 10 veces la concentración hasta que se produzca una respuesta positiva o se alcance una concentración máxima de 1:1000 p/v. Se considera positiva una prueba cuando después de 15 a 20 minutos se genera una roncha de 3 a 5 mm o más en comparación con el control negativo.

Aunque se prefieren las PC debido a su mayor sensibilidad, se pueden realizar pruebas in vitro para la detección de IgE sérica específica (ImmunoCAP). Las pruebas in vitro son útiles si los resultados de las $\mathrm{PC}$ son negativos a pesar de existir una evidente historia de RS por la picadura de un himenóptero. Generalmente se recomienda iniciar la VIT si hay un resultado negativo de la PC, pero un resultado positivo de la prueba in vitro en pacientes con RS.

Si bien el diagnóstico con PC o prueba in vitro es suficiente para decidir el tratamiento, los pacientes que presentan anafilaxia con IgE específica negativa y aquellos con sensibilización múltiple constituyen un reto diagnóstico especial. El uso potencial de pruebas moleculares con alérgenos recombinantes puede mejorar el diagnóstico y facilitar la identificación de sensibilización específica en casos de reactividad cruzada entre venenos de diferentes familias, géneros o especies de himenópteros. Actualmente para pruebas de diagnóstico molecular se encuentran disponibles los alérgenos recombinantes Api $m 1$ (abeja), Ves v 1, Ves v 5 (avispa chaqueta amarilla); y Pol d 5 (avispa Polistes).

\subsection{Dosis de la VIT}

Recomendamos comenzar la inmunoterapia con una dosis de hasta $1 \mu \mathrm{g}$ y aumentar hasta alcanzar una dosis de mantenimiento de al menos $100 \mu \mathrm{g}$ de veneno. En los pacientes que han experimentado RS por picadura del insecto por la que reciben inmunoterapia y una dosis de mantenimiento de $100 \mu \mathrm{g}$ de veneno (sobre todo por alergia al veneno de abeja) recomendamos aumentar esta última hasta $200 \mu \mathrm{g}$ de veneno por inyección, dosis que ha mostrado ser eficaz para lograr la protección en estos casos. En niños es controversial la eficacia de $50 \mu \mathrm{g}$ de veneno como dosis de mantenimiento.

Para la inmunoterapia con extracto de cuerpo entero de hormiga de fuego se recomienda una dosis de mantenimiento de $0.5 \mathrm{~mL}$ de una dilución $1: 100 \mathrm{p} / \mathrm{v}$ con extracto de Solenopsis invicta o una mezcla de extractos de esta y Solenopsis richteri.

Existe el riesgo de presentar reacciones anafilácticas por la administración de VIT, sobre todo en pacientes con mastocitosis. En el cuadro 6.2 se desglosan las recomendaciones para reducir el riesgo de reacciones adversas.

\subsection{Características del extracto alergénico de himenóptero para VIT}

Los extractos de veneno de abeja, avispa chaqueta amarilla, avispón de cara blanca y avispa amarilla están disponibles para pruebas de diagnóstico y tratamiento. Los venenos de himenópteros son extractos estandarizados. En forma comercial, en México se encuentran disponibles extractos no estandarizados de abeja y avispa. GUIMIT recomienda la utilización de extractos estandarizados purificados de veneno, los cuales deben ser importados a través de casas comerciales. La evidencia con el uso de este último tipo de extractos ha demostrado menor tasa de eventos adversos locales y sistémicos, así como mayor eficacia.

\author{
Recomendamos: $100 \%$ \\ Himenópteros \\ Evidencia: II \\ Recomendación: B \\ Hormiga \\ Evidencia: III \\ Recomendación: $\mathrm{C}$
}


Cuadro 6.2. Recomendaciones para reducir el riesgo de reacciones adversas por inmunoterapia para alergia a himenópteros

Verificar que el extracto y el paciente sean los correctos antes de la administración de cada inyección

Mantener al paciente en observación durante al menos 30 minutos después de la aplicación de cada inyección

Asegurarse que las enfermedades alérgicas coexistentes (como el asma) estén controladas antes de la administración

Considerar el uso de extractos de depósito en lugar de los acuosos, en caso de estar disponibles

Considerar la administración de omalizumab en pacientes que presentan reacciones sistémicas en forma repetida durante la inmunoterapia

Considerar modificaciones en el progreso de administración de las dosis de la inmunoterapia en pacientes que presentan reacciones sistémicas

Asegurarse de que los pacientes con mayor riesgo portan epinefrina con un plan de acción para su administración

Determinar el nivel basal de triptasa sérica antes del inicio de la inmunoterapia

Considerar la administración previa de antihistamínicos $\mathrm{H}_{1}$ de segunda generación o montelukast

Considerar medicamentos alternativos en pacientes que reciben betabloqueadores o inhibidores de la enzima convertidora de angiotensina

En alergia a picadura de hormiga de fuego importada se recomienda emplear extracto de cuerpo entero (el único comercialmente disponible). Debido a que este tipo de extractos no está estandarizado, cada nuevo vial debe iniciarse con precaución, de forma similar a como se procede en la ITA (véase capítulo 4).

\subsection{Duración de la fase de mantenimiento de la VIT}

Se recomienda un periodo mínimo de tres años de tratamiento con VIT antes de considerar su interrupción. Si bien algunos expertos recomiendan extender el periodo hasta cinco años, no hay consenso en la evidencia para la definición dicotómica de tres o cinco años, por tal razón, recomendamos que los pacientes que inicien la VIT la continúen durante ese intervalo (tres a cinco años), individualizando cada caso de acuerdo con factores de riesgo (riesgo potencial de exposición frecuente a picaduras, reacciones sistémicas durante la inmunoterapia), respuesta a la inmunoterapia (evidencia de eventos de picadura en el curso del tratamiento sin presentar reacciones adversas sistémicas, negativización de las pruebas cutáneas o reducción significativa en los niveles de IgE sérica específica) y preferencias del paciente.

Recomendamos mantener la inmunoterapia durante un tiempo mayor de cinco años o, incluso, por tiempo indefinido, en pacientes con factores de alto riesgo como reacciones graves que hayan puesto en riesgo la vida antes de la inmunoterapia, RS grave durante la inmunoterapia, nivel basal alto de triptasa sérica y mastocitosis.

\section{8. ¿La premedicación de la inmunoterapia con antihistamínicos disminuye la aparición de reacciones locales o sistémicas?}

Existen niveles altos de evidencia y recomendación para la medicación previa con antihistamínicos en cada dosis de VIT de himenópteros. Los antihistamínicos H1 de segunda generación son los medicamentos que han demostrado reducir la incidencia de reacciones locales y sistémicas leves, pero no de anafilaxia (véase apartado 4.4). Reportes de casos han mostrado la probable utilidad de la medicación previa con montelukast. Recomendamos el uso los antihistamínicos $\mathrm{H} 1$ de segunda generación como medicación previa a la inmunoterapia con veneno de himenópteros.

Ante RS repetidas durante la fase de inducción a la tolerancia, se puede recomendar tratamiento previo con omalizumab (véase capítulo 10).
Recomendamos: Sí, $100 \%$

Evidencia: IV

Recomendación: C

Recomendamos: Sí, $100 \%$

Evidencia: III

Recomendación: C

Recomendamos: Sí, $100 \%$

Evidencia: I,

Recomendación: A

http://www.revistaalergia.mx 


\subsection{Alergia a otros insectos}

Se han documentado reacciones adversas al veneno o picadura/mordedura de insectos distintos a los himenópteros; en general son reportes de casos aislados o series de casos y la mayoría de las reacciones son RL grandes o RS leves a moderadas. Una excepción es el síndrome de Skeeter, reacción alérgica a proteínas salivales del mosquito caracterizada por síntomas locales extensos y síntomas sistémicos que incluyen vómito y malestar general. ${ }^{91}$

Las reacciones por picadura de mosquito van en aumento, sin que se disponga todavía de extractos purificados para su diagnóstico; Peng et al. comprobaron que uno de sus alérgenos mayores es Aed a $3 .{ }^{92}$ Por el momento se sugieren las PC con extracto de cuerpo entero para el diagnóstico. Aunque existen reportes de ITSC en pacientes con reacciones alérgicas a la picadura de mosquito, se considera un tratamiento experimental.

\section{Capítulo 7. Condiciones para realizar pruebas cutáneas y preparar y aplicar inmunoterapia (cuadro 7.1)}

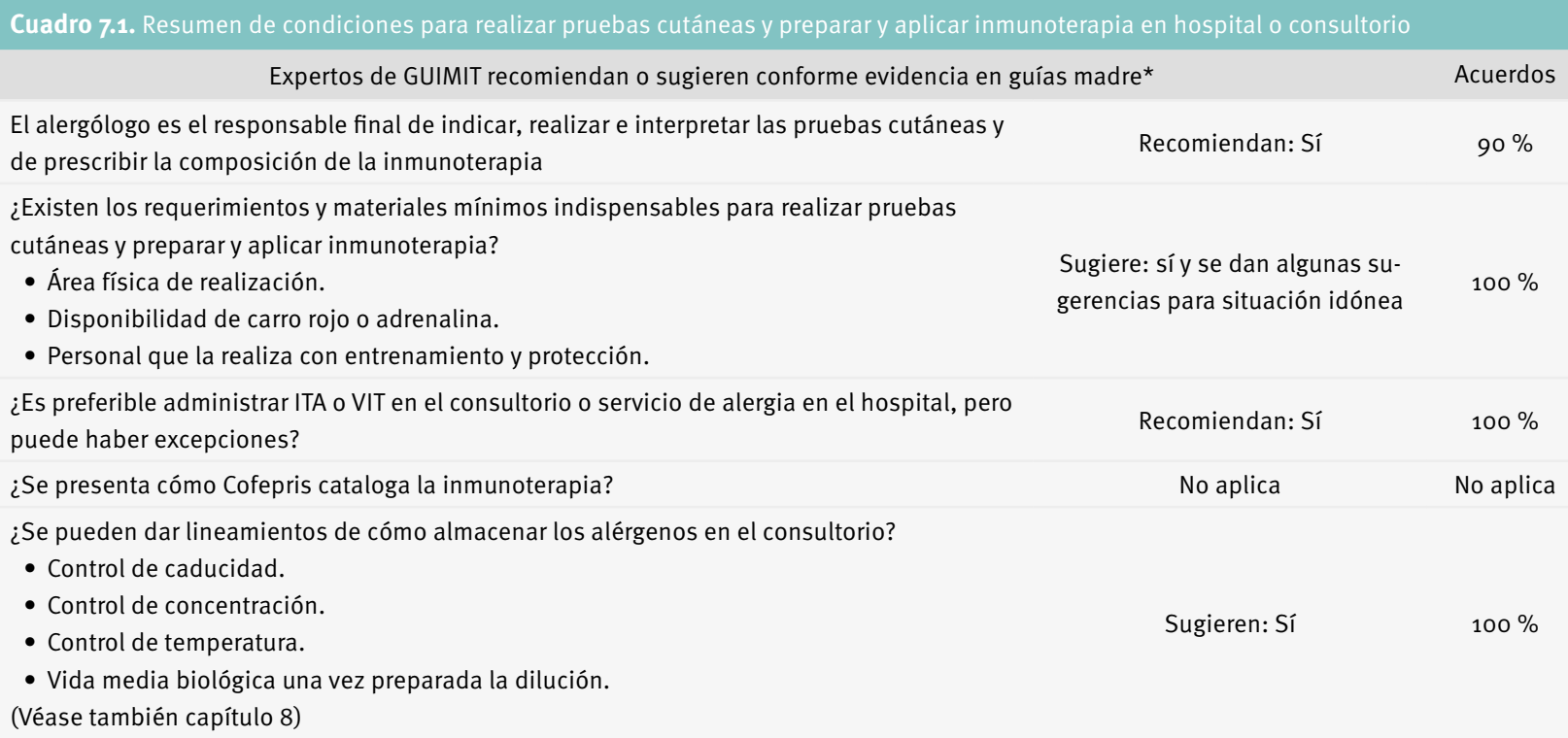

El alergólogo es el responsable final de indicar, realizar e interpretar las pruebas cutáneas y de prescribir la composición de la inmunoterapia

¿Existen los requerimientos y materiales mínimos indispensables para realizar pruebas cutáneas y preparar y aplicar inmunoterapia?

- Área física de realización.

- Disponibilidad de carro rojo o adrenalina.

- Personal que la realiza con entrenamiento y protección.

¿Es preferible administrar ITA o VIT en el consultorio o servicio de alergia en el hospital, pero puede haber excepciones?

¿Se presenta cómo Cofepris cataloga la inmunoterapia?

Recomiendan: Sí

$100 \%$

¿Se pueden dar lineamientos de cómo almacenar los alérgenos en el consultorio?

- Control de caducidad.

- Control de concentración.

- Control de temperatura.

- Vida media biológica una vez preparada la dilución.

(Véase también capítulo 8)

\section{Experiencia clínica común de los expertos GUIMIT (Delphi simplificado): ** evidencia $1 \mathrm{C}$}

Uno de los requerimientos mínimos en el hospital y consultorio (fuera del ambiente hospitalario) para aplicación de ITSC es que haya carro rojo disponible

Sí, $68 \%$ recomienda y $23 \%$ sugiere

Uno de los requerimientos mínimos en el hospital y consultorio para la persona que administra la ITSC y para la persona que prepara la inmunoterapia es utilizar guantes

Puntos de buena práctica

Sí, $25 \%$ recomienda, $39 \%$ sugiere y $33 \%$ neutral

Para el área de preparación de la ITA o VIT

- ¿Se puede poner una mica entre el área de preparación y la cara del personal que prepara?

- Si existe la posibilidad, ¿colocar un filtro HEPA?

Contar con jeringa precargada protegida de la luz con la dosis adecuada para paciente en caso de administración domiciliaria (y en área aplicación pruebas/inmunoterapia)

$\begin{array}{ll}\text { Sí } & 100 \% \\ \text { Sí } & 100 \%\end{array}$

\footnotetext{
* Se buscó nivel de evidencia y recomendación en cada guía madre (tablas fuente 1); se fusionaron evidencias y recomendaciones para emitir una recomendación para cierta acción (tablas fuente 2). Los vínculos a estas tablas se encuentran en el anexo 1.

** Contestación anónima de los 57 expertos GUIMIT. Con amplio consenso se obtiene un nivel de evidencia 1c, según CEBM.
} 


\subsection{Introducción}

La práctica de la alergología en México se lleva a cabo tanto en el medio privado (ambulatorio e intrahospitalario) como en la consulta externa y los servicios hospitalarios de segundo y tercer nivel de los sistemas de salud pública como el Instituto Mexicano del Seguro Social, el Instituto de Seguridad y Servicios Sociales de los Trabajadores del Estado y la Secretaría de Salud, entre otros. Cada entorno tiene sus particularidades, además, cada hospital se rige por sus propias normas o las normas del sector al que pertenece, por lo que será imposible formular lineamientos estrictos para cada uno. Por ello, las directrices encontradas en las GM solo pueden servir como orientación. Los subespecialistas en alergia e inmunología clínica han adaptado a su práctica profesional los conocimientos obtenidos en los centros donde se formaron, a los que suman la experiencia cotidiana y los intercambios de ideas en foros nacionales e internacionales.

En este capítulo se formulan recomendaciones y sugerencias acerca de las condiciones mínimas adecuadas para realizar los procedimientos en relación con el tema de GUIMIT: las PC y la preparación y aplicación de ITA y VIT. La mayoría son fruto del consenso de los expertos de GUIMIT y en ocasiones se fortalecen con evidencia en las GM, pero contextualizadas en la experiencia y el aprendizaje del alergólogo mexicano. Hasta el momento no se había considerado este tema en publicaciones nacionales ni en las guías de ITA previas, por lo que los expertos de GUIMIT decidieron incluirlo en el scope de los objetivos de la guía, en un esfuerzo por mejorar la calidad y seguridad de la ITA.

\subsection{El médico alergólogo es el responsable de las pruebas cutáneas, ITA o VIT}

Los expertos de GUIMIT consideran que el médico alergólogo es el responsable final de indicar, realizar e interpretar pruebas cutáneas y prescribir la composición de ITA o VIT. Se sugiere la referencia de pacientes con sospecha de alergia por parte de médicos de primer contacto u otros especialistas, para que los alergólogos consideren la pertinencia de realizar procedimientos diagnósticos (cuadro 7.2).

Las GM internacionales cuentan con nivel de evidencia y recomendación bajo en relación con las responsabilidades de cada gremio, porque se basan en realidades diferentes no aplicables a México. GUIMIT recomienda que para que se pueda considerar

\begin{tabular}{l} 
Cuadro 7.2. Sugerencias de indicaciones clínicas para referir al alergólogo \\
\hline Cuadros respiratorios frecuentes, especialmente si cursan sin fiebre \\
\hline Cuadros respiratorios en conjunto con síntomas cutáneos sugestivos de alergia \\
\hline Crisis asmática que amenace la vida: referencia obligatoria al alergólogo o neumólogo \\
\hline Asma moderada o grave persistente \\
\hline Crisis asmáticas recurrentes (2 o más en un periodo de seis meses) \\
Necesidad de corticosteroide inhalado a dosis alta o más de 2 ciclos cortos de corticosteroide sistémico \\
en el año previo \\
Conjuntivitis crónica o crónica recurrente sin datos de infección \\
\hline Sospecha de alergia alimentaria* \\
Diagnóstico incierto o presentación atípica de síntomas respiratorios, cutáneos o sospecha de anafilaxia \\
*Es importante confirmar esta sospecha dado la alta frecuencia de sub y sobrediagnóstico, lo que tiene como \\
consecuencia frecuente la decisión errónea de evitación de ciertos alimentos de forma innecesaria.
\end{tabular}

Recomendación: $100 \%$ Evidencia: No emitida Recomendación: no emiten 
que el médico tiene la competencia, habilidades y destrezas necesarias para ejercer el adecuado abordaje diagnóstico de las alergias y prescribir tratamiento con ITA o VIT, cuente con los requisitos establecidos en el Plan Único de Especializaciones Médicas (PUEM), tanto para alergia e inmunología clínica como para alergia e inmunología clínica pediátrica (http://www.sidep.fmposgrado.unam.mx:8080/fmposgrado/programas/ alergia.pdf y http://www.sidep.fmposgrado.unam.mx:8080/fmposgrado/programas/ alergiaped.pdf), así como certificación vigente por CONICA. El directorio actualizado de médicos alergólogos certificados se puede consultar en http://www.conica.org. $\mathrm{mx} /$ directorio.php

\subsection{Equipo de enfermería o apoyo para pruebas diagnósticas}

En caso de contar con personal de enfermería o de apoyo para realizar procedimiento o preparar ITA, el médico alergólogo deberá supervisar su desempeño y habilidades, y proporcionarles la capacitación o el entrenamiento adecuado. Es por lo anterior que este especialista deberá estar cerca físicamente al área donde se llevan a cabo los procedimientos diagnósticos y la aplicación de ITA o VIT. Para el personal que aplica las PCP es deseable que se realicen pruebas de proficiencia para demostrar su capacidad para realizar las PCP con una técnica uniforme, provocando una erupción de tamaño uniforme dentro de los límites de variabilidad aceptables.

\subsection{Aplicación de ITA o VIT fuera del consultorio del alergólogo}

El médico alergólogo es el responsable final de la aplicación de la ITA o VIT, pero puede capacitar a un médico de primer contacto para que continúe la administración de la ITA por razones de logística. Existen circunstancias a nivel nacional bajo las cuales la aplicación en el domicilio puede llegar a ser la única alternativa viable; en estos casos, la administración en domicilio se preferirá en pacientes cuyo perfil clínico haga suponer riesgo bajo para RS. GUIMIT puede sugerir una de estas últimas dos opciones (véase final de este capítulo), siempre y cuando se entreguen instrucciones por escrito acerca de cómo aplicar y qué hacer en caso de RS y el alergólogo deberá vigilar que hayan sido comprendidas y ejecutadas mediante interrogatorio directo durante consultas de seguimiento con el paciente. De no seguir las instrucciones que el alergólogo encargado haya indicado, este último podría quedar libre de responsabilidad en caso de eventos adversos. No se aplicará VIT en el domicilio.

\subsection{Consentimiento y asentimiento informados}

GUIMIT recomienda obtener el consentimiento informado (o asentimiento, en caso de menores de edad), antes de los procedimientos diagnósticos y terapéuticos en el hospital o consultorio. En el sitio web de los colegios y de CONICA, los médicos certificados pueden encontrar los enlaces para tener acceso a los formatos electrónicos para consentimiento informado para PCP e PCID, administración de ITA, así como los formatos para los respectivos asentimientos.

\subsection{Requerimientos mínimos indispensables y óptimos para realizar pruebas cutáneas y preparación de ITA o VIT}

Las guías del JTF-AAAAI/ACAAI consideran el punto del área física solamente en la preparación de ITA, más no hacen recomendaciones respecto al área de la aplicación de las pruebas cutáneas. Las demás guías no mencionan ningún procedimiento. Los exper-

Recomendación $100 \%$; Evidencia: IV Recomendación: D 


\begin{tabular}{l} 
Cuadro 7.3. Material y requerimientos mínimos indispensables para realizar PCP o PCID* \\
\hline Uso de bata para proteger la ropa de calle \\
\hline Uso de guantes por higiene y para evitar sensibilización de quien aplica \\
\hline Disponibilidad de adrenalina (verificando caducidad) y jeringas \\
Antihistamínico oral de segunda generación \\
Broncodilatador inhalado de acción rápida (con dispositivo inhalador de dosis medida o nebulizador y \\
mascarilla) \\
Acceso cercano a servicio de urgencias o disponibilidad de carro rojo. \\
Cercanía de refrigerador para mantener la cadena fría de los extractos diagnósticos entre una prueba \\
y otra \\
*No debe considerarse una lista completa, sino sugerencias adicionales al material necesario para realizarlas \\
(torundas, lancetas, jeringas, alérgenos, viales para diluir, etcétera). \\
PCP = pruebas cutáneas por punción epicutánea, PCID = prueba cutánea intradérmica.
\end{tabular}

tos de GUIMIT recomendamos los requerimientos mínimos respecto a los materiales necesarios en el consultorio o área de alergia en el hospital, enumerados en el cuadro 7.3. Para algunos detalles de procedimientos consúltense los capítulos 4 y 6.

Se sugiere como condición idónea para la realización de PCP o PCID, que el consultorio disponga de un área de trabajo con adecuada iluminación, de preferencia luz del día. La protección del personal que realiza las pruebas es útil para evitar sensibilización y debe incluir cubrebocas, bata y uso de gorro para el pelo o protección de pelo de barba. Los guantes de preferencia deberán ser sin talco y en condiciones ideales libres de látex, resistentes al alcohol isopropílico a $70 \%$. Se sugiere contar con carro rojo en caso de que sea necesario manejar anafilaxia en el paciente sometido a pruebas diagnósticas in vivo, teniendo precaución especial en los pacientes a los que se realicen PCID o en los que se sospeche sensibilización a alimentos, látex, medicamentos o veneno de himenópteros, ya que el riesgo de una reacción adversa sistémica relacionada con el procedimiento será mayor (véase apartado 1.1).

Asimismo, los expertos de GUIMIT recomendamos contar con los materiales y requerimientos mínimos indispensables para la preparación de ITA o VIT que se mencionan en el cuadro 7.4.

\begin{tabular}{l} 
Cuadro 7.4. Material y requerimientos mínimos indispensables para la preparación de inmunoterapia \\
con alérgenos o inmunoterapia con veneno de himenópteros* \\
\hline Uso de cubrebocas \\
\hline Uso de bata para proteger la ropa que se usa en la calle \\
\hline Uso de guantes \\
Adecuada iluminación \\
Realización en zona libre de exposición a contaminantes \\
Limpieza del área de preparación con antiséptico \\
Lugar tranquilo, de preferencia aislado; evitar constante entrada-salida de personal durante \\
la preparación \\
*No debe considerarse una lista completa, sino sugerencias adicionales al material necesario (viales, torundas, \\
jeringas, etcétera).
\end{tabular}

Sugerimos: Sí, $100 \%$ Evidencia: No emitida Recomendación: No emitida 


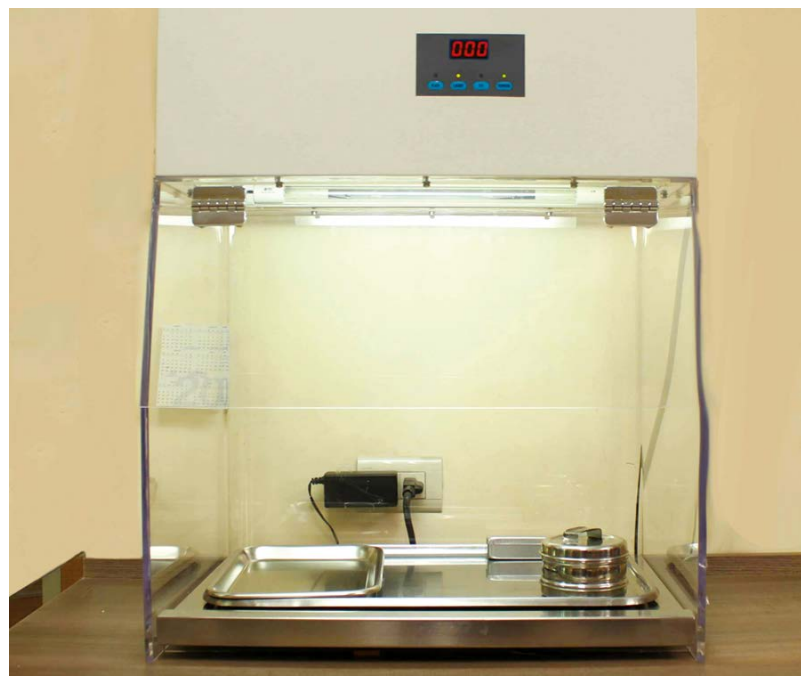

Como parte del material idóneo se sugiere el empleo de guantes, cubrebocas, bata desechable, gorro para el pelo y protector de pelo de barba, tanto para que el personal que prepara ITA o VIT se proteja de sensibilizaciones como para evitar contaminación. Los guantes de preferencia deberán ser sin talco y en condiciones ideales libres de látex, resistentes al alcohol isopropílico a $70 \%$. En condiciones ideales se deberá contar con campana de flujo laminar (figura 7.1) o en su defecto colocar una mica entre el área de preparación y la cara del personal que prepara la ITA o VIT. Si existe la posibilidad, se debe colocar un purificador de aire con filtro HEPA (high efficiency particulate air) en el área de preparación.

Respecto a la administración de ITA, los expertos de GUIMIT recomendamos los materiales y requerimientos mínimos descritos en el cuadro 7.5); para detalles sobre otros procedimientos véase los capítulos 4 o 6 .

GUIMIT sugiere como parte del material idóneo para la administración de ITA o VIT, que los pacientes con asma dispongan de un flujómetro para evaluar la función pulmonar antes de aplicar el tratamiento (véase apartado 4.4.2) y de un oxímetro de pulso $\mathrm{y}$ un carro rojo en el área donde se administre la ITA o VIT, sobre todo en el contexto extrahospitalario.

\footnotetext{
Cuadro 7.5. Material y requerimientos mínimos indispensables para aplicación de inmunoterapia con alérgenos y veneno inmunoterapia*

Administrar en zona con adecuada iluminación

Disponibilidad de adrenalina (verificando caducidad) y jeringas

Antihistamínico oral de segunda generación

Broncodilatador inhalado de acción corta (con dispositivo inhalador de dosis medida o con nebulizador y mascarilla)

Acceso cercano a servicio de urgencias o disponibilidad de carro rojo.

Cercanía de refrigerador para mantener la cadena fría de los extractos de la ITA/VIT

*No debe considerarse una lista completa, sino sugerencias adicionales al material necesario para preparar la (torundas, jeringas, etcétera).

ITA, inmunoterapia con alérgenos, VIT = veneno inmunoterapia.
}

Sugerimos: Sí, $100 \%$ Evidencia: No emitida Recomendación: No emitida 
Para asegurar la cadena fría de los extractos alergénicos para PC, ITA o VIT, los expertos de GUIMIT formulamos las sugerencias en relación con el refrigerador que se señalan en el cuadro 7.6.

\subsection{Administración de ITSC o VIT en consultorio versus domicilio}

Las GM hacen referencia a los cuidados respecto a la condición del paciente antes de la administración de ITA, los cuales se comentan ampliamente en el apartado 4.4.2 y capítulos 6 y 9 . La mayoría de las complicaciones suelen presentarse en los primeros 30 minutos posteriores a la administración de la ITSC o VIT e, incluso, con la primera dosis de ITS, por lo tanto, GUIMIT recomienda:

- Aplicar la ITSC en el consultorio del médico tratante, cuando sea posible.

- Aplicar VIT siempre en el consultorio médico (tratante o referido).

- Observar al paciente en el consultorio al menos 30 minutos después de la ITSC o VIT.

Además sugiere:

- Si por razones logísticas no se puede aplicar la ITSC en el consultorio del médico tratante, aplicarla en otra unidad médica o eventualmente en el domicilio del paciente. En este caso se darán indicaciones por escrito precisas y claras acerca de:

- El esquema de aplicación.

- En pacientes con asma, la medición de flujometría antes de la aplicación de la ITSC y el valor crítico para evitar aplicación.

- Reglas clínicas básicas de seguridad (no aplicar con fiebre, exacerbación aguda de asma, ejercicio físico reciente, etcétera).

- Las reacciones adversas que se puedan presentar.

- Cómo actuar en caso de que se presente una reacción adversa o en emergencias.

- En caso de administración en domicilio, indicar que el paciente tenga adrenalina, con una dosis precargada según su peso (véase párrafo abajo).

Después de la aplicación de ITSC con pauta rápida o ultrarrápida, se supervisará médicamente a los pacientes durante todo el procedimiento y mínimo una hora después de la última dosis.

\section{Cuadro 7.6. Sugerencias para vigilar el mantener la cadena fría en el refrigerador}

Contar con refrigerador exclusivo para material biológico, ITA y VIT, para el almacenamiento de alérgenos. Se requiere mantener la temperatura entre 2 y $8{ }^{\circ} \mathrm{C}$

En el exterior del refrigerador se deben colocar avisos de no abrir y no desconectar, así como contar con el teléfono de contacto del responsable del área y del médico especialista, en caso de urgencias, así como el teléfono y dirección electrónica del o los responsables de la cadena fría

Contar con bitácoras de temperatura máximas y mínimas (Electronic Measuring Instrument TESTO $®$ ) registradas por los termómetros. De preferencia, el equipo debe estar conectado a la planta de emergencia

Descongelar el refrigerador cada 6 a 12 meses, según la indicación del fabricante, o cuando la escarcha del congelador sea mayor a $5 \mathrm{~mm}$ de grosor.

ITA = inmunoterapia con alérgenos, VIT = inmunoterapia con veneno de himenópteros. $\left\{\begin{array}{l}\text { Recomendamos: } 100 \% \\ \text { Evidencia: III } \\ \text { Recomendación: C, D }\end{array}\right.$ 
Los consultorios de los alergólogos que no se ubiquen dentro de un hospital deberán disponer de un carro rojo; aquellos que se encuentren en un medio hospitalario deben asegurar el rápido acceso al servicio de urgencias, previa administración de adrenalina intramuscular, de ser necesario (véase capítulo 9).

Un punto de buena práctica es contar con una jeringa precargada con 0.3 a $0.5 \mathrm{~mL}$ de adrenalina antes de la realización de pruebas cutáneas o de la administración de ITSC o VIT. Las jeringas precargadas con adrenalina siempre tienen que estar protegidas contra la luz (para evitar la degradación farmacológica del medicamento) y permanecer a una temperatura ambiente menor a $25^{\circ} \mathrm{C}$.

\subsection{Normas requeridas por Cofepris para el manejo de ITA}

La Comisión Federal para la Protección de Riesgos Sanitarios (Cofepris) cataloga a la ITA como dispositivos médicos clase 2: auxiliar en el tratamiento de alergia. La ITA no se considera una vacuna biológica, dado que su función no es profiláctica o preventiva, sino auxiliar en el tratamiento de alergia (https://www.gob.mx/promexico/acciones-yprogramas/dispositivos-medicos-26794). Una lista de registros sanitarios de dispositivos médicos otorgados durante 2012 con algunos alérgenos se encuentra en https://www.gob. $\mathrm{mx} / \mathrm{cms} /$ uploads/attachment/file/305188/reg_dm_2012.pdf. No se dispone de un listado más actual públicamente accesible.

\subsection{Almacenamiento de los extractos alergénicos en el consultorio}

Es recomendable seguir cuidadosamente las recomendaciones del fabricante. Los extractos acuosos y glicerinados deben almacenarse a $4{ }^{\circ} \mathrm{C}$ para reducir la pérdida de potencia. Antes de su reconstitución, los extractos liofilizados se pueden conservar a temperatura ambiente. Para detalles del almacenamiento y caducidad de diferentes grados de dilución de los extractos alergénicos véase el capítulo 8 .

\section{Capítulo 8. Extractos alergénicos (cuadro 8.1)}

\subsection{Introducción}

Los extractos alergénicos se pueden presentar en diferentes formas. Históricamente se han empleado extractos acuosos de los alérgenos naturales, que contienen $10 \%$ de glicerina y $0.4 \%$ de fenol como conservador. Según la escuela estadounidense, en la ITSC los viales del paciente se preparan a partir del concentrado del fabricante, que contiene el disolvente con $50 \%$ de glicerina, para mejorar la estabilidad del alérgeno y alargar la vida útil del extracto. Sin embargo, para la aplicación subcutánea, un paciente generalmente no tolera más de $15 \%$ de glicerina. Por ello el diluyente contiene $10 \%$ de glicerina, al igual que los extractos "listos para usar" de los fabricantes europeos.

En busca de formas más seguras de ITSC, desde la década de 1980 en Europa se cambió la formulación acuosa a una formulación de depósito, en la cual el alérgeno natural es adsorbido a un adyuvante como alum, tirosina o glutaraldehído. Otra solución fue cambiar el alérgeno natural a una forma menos alergénica, sin que perdiera su potencia inmunogénica. Así, se desarrollaron los extractos modificados: los alergoides y los extractos depigmentados. Para la ITSC, la escuela europea indica casi exclusivamente extractos adsorbidos, varios de ellos alergoides, mientras que la estadounidense, exclusivamente extractos naturales acuosos o glicerinados. Finalmente, en la era de la biotecnología se han desarrollado extractos recombinantes y los péptidos, que serán revisados en el capítulo 10.

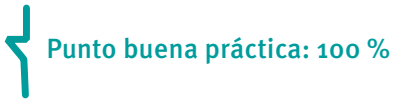

Sugerimos: Sí, $100 \%$

Evidencia: III

Recomendación: C 


\section{Cuadro 8.1. Resumen de extractos alergénicos}

Expertos de GUIMIT recomiendan o sugieren conforme a guías madre*

¿Los siguientes tipos de extractos alergénicos tienen eficacia clínica?

- Extractos naturales acuosos con $0.4 \%$ de fenol

\begin{tabular}{lc} 
Recomiendan: Sí & $100 \%$ \\
Recomiendan: Sí & $100 \%$ \\
Recomiendan: Sí & $100 \%$ \\
Recomiendan: Sí & $100 \%$ \\
\hline Recomiendan: Sí & $100 \%$ \\
Recomiendan: Sí & $100 \%$
\end{tabular}

- Extractos naturales glicerinados (50\% de glicerina)

- Extractos naturales adsorbidos (alum, tirosina)

- Extractos químicamente modificados (depigmentados [Depigoid], alergoides, recombinantes, péptidos)

Recomiendan: Sí

$100 \%$

- Concentración (valoración cuantitativa)

Las siguientes son formas de expresar la potencia de un extracto, se indica cuáles se consideran pruebas de estandarización (EST). En orden de menos a más exactas**

$\begin{array}{ll} & \text { Peso/volumen } \\ \text { Un vitro } & \text { Unidades de nitrógeno proteico }\end{array}$

In vitro

Capacidad de fijación de IgE (inhibición por ELISA)

$-$

EST

EST

Microgramos de alérgeno mayor, incluyendo radioinmunodifusión

EST

ID50EAL (Estados Unidos)

EST

Prueba cutánea por punción (Europa)

¿Existen condiciones específicas para el almacenamiento de los extractos alergénicos?

- Liofilizados en polvo: temperatura ambiental.

- Acuosos, glicerinados y liofilizados recompuestos: $4^{\circ} \mathrm{C}$.

¿Existe una concentración adecuada para un extracto con fines diagnósticos?

¿Existe una concentración adecuada para un extracto con fines terapéuticos?

¿Existe una relación dosis-respuesta y, por ende, se define la dosis de mantenimiento en ITSC? (véase capítulo 4)

¿Existe relación dosis-respuesta y, por ende, se define la dosis de mantenimiento en ITSL? (véase capítulo 5)

¿Se pueden agregar ciertos adyuvantes a la inmunoterapia para aumentar su eficacia?

\section{Experiencia clínica común de los expertos GUIMIT (Delphi simplificado): ${ }^{\star \star \star ~ e v i d e n c i a ~ 1 C ~}$}

Con las concentraciones dadas por los fabricantes no se pueden comparar potencias entre extractos de diferentes fabricantes. Al cambiar un alérgeno de un fabricante por el de otro, por ejemplo, Dermatophagoides de fabricante A a Dermatophagoides de fabricante B, se reiniciará desde frasco 1

Considerando el escenario clínico anterior, si los productos para preparar IT hechos por

diferentes fabricantes se analizaran simultáneamente con la misma técnica (en el mismo labo- Sí, 13 \% recomienda y 40 \% sugiere ratorio o PCP en el mismo paciente), ¿se podrían comparar concentraciones o potencias?

\section{Puntos de buena práctica}

Se puede extrapolar la eficacia demostrada con el extracto de cierto alérgeno a un alérgeno similar (en concentración y calidad)

Sí, 26 \% recomienda y 36 \% sugiere

Recomiendan: Sí (revisar temperatura en refrigerador, véase capítulo 7)

Recomiendan: Sí

$100 \%$

Recomiendan: Sí

$100 \%$

Sugieren: Sí

$100 \%$

Recomiendan: Sí $91 \%$

¿Existen dosis intercambiables entre extractos de diferentes manufactureros (dosis equivalencias)?

¿La calidad de la inmunoterapia se ve afectada por el tipo de diluyente empleado?

$\begin{array}{ll}\text { Sí } & 100 \% \\ \text { No } & 97 \% \\ \text { Sí } & 100 \%\end{array}$

* Se buscó nivel de evidencia y recomendación en cada guía madre (tablas fuente 1); se fusionó evidencia y recomendación para emitir una recomendación para cierta acción (tablas fuente 2). Los vínculos a estas tablas se encuentran en anexo 1. **No se votó, dado que no se cuestiona este hecho.

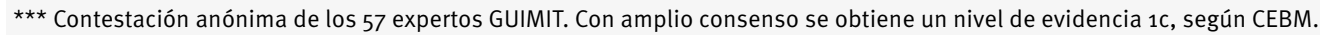


La calidad cualitativa y cuantitativa (potencia) de un extracto es crucial en su eficacia clínica y seguridad. En la segunda parte de este capítulo se revisan las formas como se expresa dicha potencia.

Las guías europeas no detallan las concentraciones de los extractos, dado que en esa parte del mundo se comercializan "productos listos para usar", no diseñados para emplearlos en mezcla, la cual resultará en dilución del producto final si se usan extractos europeos. Por el contrario, la escuela estadounidense ocupa extractos comerciales concentrados, elaborados para ser diluidos y preparar el vial del paciente. En este capítulo se revisan las concentraciones proyectadas para el vial en la fase de mantenimiento de la ITSC según la escuela estadounidense y qué parámetros se toman en cuenta para establecer la dosis adecuada en esta fase. Para la ITSL con líquido se administran extractos naturales, no de depósito, lo que posibilita el cálculo de la dosis en relación con la ITSC elaborada con el mismo tipo de extracto. Se comenta la concentración sugerida de una ITSL así preparada.

Finalmente, existen adyuvantes que se adicionan a la inmunoterapia con el fin de incrementar su eficacia, disminuir sus efectos adversos y mejorar su capacidad inmunogénica. Revisamos algunas opciones.

Varios aspectos de este capítulo carecen de abordaje en las GM.

\subsection{Tipos de extractos alergénicos con eficacia clínica demostrada}

Para ITSC se usa alérgenos no modificados en forma acuosa o en una forma acuosa físicamente adsorbidos a alum o tirosina (depósito), así como alérgenos modificados químicamente (alergoides), que a su vez también pueden estar adsorbidos. Los extractos alergénicos para ITSL se presentan en naturales o modificados y se pueden administrar como soluciones o tabletas.

\subsubsection{En relación con la ITSC}

Aunque en nuestro medio la solución acuosa es la más usada, al igual que en Estados Unidos, cuenta con poca evidencia reciente; la mayoría de los estudios clínicos datan del siglo pasado. En contraste, en las GM abunda evidencia de la eficacia clínica de los extractos adsorbidos o modificados que se emplean en Europa. La GM que contiene un análisis más completo y reciente de la evidencia fue la de EAACI-RA, en la cual se informa un metaanálisis. ${ }^{93}$ En los estudios se demostró un efecto moderado para la ITSC con una diferencia media estándar (DME) $-0.65 .{ }^{93}$ En el análisis de subgrupos se mostró un efecto claramente mayor para alérgenos perennes (DME - 0.91) versus estacionales (DME - 0.37). Los 61 estudios clínicos incluidos en el metaanálisis para ITSC emplearon diversos extractos: adsorbidos a alum o tirosina, polimerizados con glutaraldehído, alergoides y extractos depigmentados o una combinación de ellos. Por ello, aunque la experiencia es amplia, existen pocos estudios con ITSC de extractos naturales. En México ya se dispone comercialmente de extractos con alergoides, en este momento solo de Inmunotek.

\subsubsection{En relación con la ITSL}

El metaanálisis de Dhami et al. mostró un efecto moderado de eficacia para ITSL (DME -0.48). En comparación con la ITSC, en la mayoría de los estudios sobre ITSL se emplearon extractos naturales, en forma líquida o tabletas. En metaanálisis se ha demostrado eficacia para ambas formas de ITSL (mejora en síntomas, DME -0.42 y -0.53 , respectivamente). Para una revisión más detallada de la eficacia véase el capítulo 2 y res-
ITSC: Evidencia de eficacia

Acuoso: $1 \mathrm{~b}$

Glicerinado $50 \%$ : xx

Adsorbido: $1 \mathrm{a}$

Modificado: 1a, 1b

Todos

Recomendación: A

Recombinantes y péptidos

Recomendación: B

ITSL: Evidencia de eficacia

Acuoso: $1 \mathrm{a}$

Glicerinado $50 \%$ : 1 a

Modificado: $2 \mathrm{a}$

Todos:

Recomendación: A

Recombinantes:

Recomendación: B 
pecto a los extractos químicamente modificados, como los recombinantes o péptidos, el capítulo 10, enfocado al futuro de la ITA, porque aún no han sido aprobados en México.

\subsection{Midiendo la calidad de un extracto: pureza, composición y concentración}

Las GM no mencionan detalles acerca de la calidad de los extractos, solo que de preferencia se usen productos estandarizados, por la gran variación de potencia que podrían presentar los no estandarizados (JTF-AAAAI/ACAAI). ${ }^{9}$ Aun cuando provienen de la misma fuente de alérgenos, los extractos varían entre fabricantes debido a los distintos procesos de producción. Por ello, aunque se menciona que en casos seleccionados se podría asumir que existe un efecto de clase (extrapolar la eficacia demostrada con un producto a otro similar), es preferible usar extractos estandarizados cuya eficacia se demostró en estudios clínicos (EAACI-RA, DGAKI). ${ }^{6,8}$

La calidad de un extracto alergénico no solo depende de parámetros cuantitativos (la capacidad total de fijar IgE o la concentración de un alérgeno mayor), sino también de parámetros cualitativos, entre ellos la pureza del extracto (por ejemplo, que no haya polen de otro pasto o de árbol mezclado en un extracto de Phleum pratense) o la presencia de todas las moléculas alergénicas de importancia (por ejemplo, en un extracto de ácaro de polvo casero, un balance entre los alérgenos de los grupos 1 y 2 [y últimamente Der p 23] ${ }^{94}$ ), tal como ALK-Abelló Estados Unidos ha demostrado. ${ }^{67}$ Por ello, la potencia de un extracto solo refleja parte de su calidad.

\subsection{Métodos para medir la potencia de un extracto y estandarización}

En este tema no se obtuvo evidencia de las GM ni se votó, porque se trata de datos duros.

\subsubsection{Estandarización in vitro}

Existen cuatro maneras de expresar la potencia de un extracto in vitro (las primeras dos no se consideran pruebas de estandarización):

- Los extractos no estandarizados se miden en $\mathrm{p} / \mathrm{v}$, que expresa el peso en gramos por volumen en mililitros. La potencia de 1:10 indica que a $1 \mathrm{~g}$ de alérgeno seco (por ejemplo, de Ambrosia) se le adicionó $10 \mathrm{~mL}$ de solución amortiguadora para la extracción.

- Otra expresión para la concentración de un extracto es PNU, en donde 1 PNU es igual a $0.01 \mathrm{~g}$ de nitrógeno proteico. Se encuentra un paso más cerca de la verdadera potencia del extracto, ya que la fracción proteica contiene la fracción alergénica del extracto. No se considera aún estandarización, porque también existen múltiples proteínas no alergénicas.

- Los extractos de ácaro y pólenes se estandarizan según su capacidad total para fijarse al IgE de suero de pacientes alérgicos con inhibición de ELISA.

- En Europa, la estandarización in vitro generalmente se basa en la determinación de la concentración de uno o varios alérgenos mayores (microgramos del alérgeno mayor). Cada fabricante usa su propio ensayo y reactivos para tal determinación (algunos adquiridos del mismo proveedor, Indoor Biotechnologies). En Estados Unidos solo dos extractos se estandarizan con base en el contenido del alérgeno mayor, medido por inmunodifusión radial: Ambrosia (Amb a 1) y epitelio y pelo de gato (Fel d 1) (JTF-AAAAI/ACAAI). En la ITSC se recomienda una dosis mensual de mantenimiento entre 5 y $20 \mu \mathrm{g}$ del alérgeno mayor.
Punto buena práctica: $100 \%$ 
En Estados Unidos, la Food and Drug Administration regula la calidad de los extractos centralizadamente y todos los fabricantes usan las pruebas mencionadas (inmunodifusión radial y ELISA) con reactivos que adquieren de la Food and Drug Administration, la cual no dispone de ensayos estandarizados para epitelio de perro.

\subsubsection{Estandarización in vivo}

- En Estados Unidos, los alérgenos se estandarizan in vivo basados en la potencia de los extractos alergénicos y usando métodos cuantitativos en pruebas cutáneas, que se reportan como BAU y AU (bioavailability units y allergy units). Este método cuantitativo para la determinación de la potencia en pruebas cutáneas de los extractos se conoce como dilución intradérmica para $50 \mathrm{~mm}$ suma del eritema (ID50EAL). El método ID50EAL prepara varias medio-log diluciones de un candidato de referencia y se inyecta $0.05 \mathrm{~mL}$ de manera intradérmica en 15 o 20 sujetos alérgicos "altamente sensibles". La dilución que resulta en un eritema con la suma del diámetro mayor y perpendicular igual a $50 \mathrm{~mm}$ es considerado el objetivo (D50). Dependiendo del promedio de las diluciones D50 de los sujetos probados se le asigna el valor de BAU $/ \mathrm{mL} .{ }^{95}$ La potencia de los subsecuentes lotes se determinará in vitro con el extracto probado in vivo como referencia.

- La estandarización en Europa se realiza mediante pruebas cutáneas por punción versus codeína o histamina. Cada fabricante la realiza con sus propios modelos.

\subsection{Condiciones para el almacenamiento de los extractos alergénicos}

Las GM refieren que los extractos alergénicos necesitan estar refrigerados mientras que otros pueden mantenerse a temperatura ambiente. Los extractos deben almacenarse a $4{ }^{\circ} \mathrm{C}$ para evitar la pérdida de potencia o de acuerdo con lo recomendado por el fabricante. La potencia de los extractos concentrados de inmunoterapia (1:1 vol/vol hasta $1: 10 \mathrm{vol} / \mathrm{vol}$ ) cuando se mantienen a $4{ }^{\circ} \mathrm{C}$ es relativamente constante y permite que los extractos sean utilizados hasta la fecha de expiración, manifestada en la etiqueta del fabricante. Los extractos menos concentrados son sensibles a los efectos de la temperatura y pueden no mantener su potencia. Las mezclas de alérgenos pueden disminuir la pérdida de potencia con el tiempo, porque los alérgenos adicionales pueden prevenir que las proteínas alergénicas se adhieran al vidrio del frasco. La fecha de caducidad de cualquier dilución no debe exceder la expiración del constituyente adicionado a la mezcla con la fecha más temprana de expiración. Estudios con ambrosía a dilución de 1:10 vol/vol demostró estabilidad por 12 meses. Los epitelios de ácaros y epitelios y pelo de gato a 1:10 y 1:100 vol/vol también permanecen estables durante 12 meses.

Sugerimos que los liofilizados se mantengan a temperatura ambiente hasta la fecha de caducidad. Una vez reconstituidos, se sugiere mantenerlos en refrigeración y deben ser extraídos del refrigerador solo por cortos periodos para conservar la fecha de caducidad recomendada por el fabricante. En las diluciones 1:1000 p/v se aconseja una fecha de caducidad de seis meses y para diluciones mayores de 1:10 $000 \mathrm{p} / \mathrm{v}$, de tres meses. En México no hay disponibilidad de albúmina humana para inmunoterapia. La glicerina a $50 \%$ es un buen conservador.

\section{6. ¿Existe una concentración adecuada para un extracto con fines diagnósticos?}

Las GM no especifican la concentración de los extractos con fines de diagnóstico para las PCP, solamente para las intradérmicas. Para las PCP idealmente deben usarse extractos de alérgenos estandarizados. Sobre el contenido de los determinantes alergénicos ma-
Sugerimos $100 \%$

Evidencia: III

Recomendación: C 
yores y menores debe haber consistencia entre los lotes y los resultados de las pruebas cutáneas deben ser comparables cuando se utilizan los mismos extractos de diferentes fabricantes. Los extractos alergénicos utilizados para las PCP se detallan en el cuadro 8.2.

Para las PCID, los extractos utilizados son 1:1000 p/v o 1 a 10 (B)AU/mL, es decir, 100 a 1000 veces más diluidos que la concentración del alérgeno utilizada para la PCP.

\begin{tabular}{|c|c|c|}
\hline Casa comercial & Extracto alergénico & Concentración/mL \\
\hline \multirow{7}{*}{$\begin{array}{l}\text { ALK-Abelló } \\
\text { Estados Unidos }\end{array}$} & \multicolumn{2}{|l|}{ Estandarizados } \\
\hline & $\begin{array}{l}\text { - Pólenes (Bermuda, Phleum, Festuca, Lolium, } \\
\text { Ambrosia) }\end{array}$ & $\begin{array}{c}10000 \\
0 \\
100 \text { ooo BAU }\end{array}$ \\
\hline & - Ácaros & $10000 \mathrm{AU}$ \\
\hline & \multicolumn{2}{|l|}{ No estandarizados } \\
\hline & - Pólenes & $1: 20 \mathrm{p} / \mathrm{v}$ \\
\hline & - Ácaros & $1: 20 \mathrm{p} / \mathrm{v}$ \\
\hline & - Hongos & $\begin{array}{c}1: 10 \text { y } 1: 20 \mathrm{p} / \mathrm{v} \\
10000,20000 \mathrm{PNU}\end{array}$ \\
\hline \multirow{6}{*}{ Inmunotek } & Estandarizados & \\
\hline & $\begin{array}{l}\text { - Ácaros (Dermatophagoides pteronyssinus, } \\
\text { Dermatophagoides farinae, Blomia) }\end{array}$ & $100 \mathrm{HEP}, 100 \mathrm{HEP}, 150 \mu \mathrm{g}$ \\
\hline & $\begin{array}{l}\text { - Hongos (Alternaria, Cladosporium, Aspergillus, } \\
\text { Fusarium, Mucor, Penicillium) }\end{array}$ & $25 \mu \mathrm{g}(3 \mu \mathrm{g}$ Alt a 1$)$ \\
\hline & - Epitelios (gato, perro, caballo) & $50 \mathrm{HEP}, 10 \mu \mathrm{g}$ Can f 1 , \\
\hline & - Insectos (cucaracha germánica, hormiga roja) & $50 \mu \mathrm{g}$ \\
\hline & $\begin{array}{l}\text { - Pólenes (Bermuda, Phleum, Festuca, Lolium, } \\
\text { Ambrosia, árboles, etcétera) }\end{array}$ & $\begin{array}{c}1000 \mu \mathrm{g}, 500 \mu \mathrm{g}, \\
50-100 \mathrm{HEP}, \text { árboles } 500 \mathrm{HEP}\end{array}$ \\
\hline \multirow{8}{*}{ IPI-ASAC } & Estandarizados & \\
\hline & - Pólenes & UB, dependiendo del alérgeno \\
\hline & $\begin{array}{l}\text { Dermatofagoides pteronyssinus y Dermatopha- } \\
\text { goides farinae }\end{array}$ & 58500 UBE y 20175 UBE \\
\hline & - Gato & 94500 UBE \\
\hline & \multicolumn{2}{|l|}{ No estandarizados } \\
\hline & - Perro & 10 o०o PNU \\
\hline & - Hongos & $10178 \mathrm{PNU}$ \\
\hline & - Periplaneta & 5000 PNU \\
\hline Alerquim & Todos los extractos & $1: 20 \mathrm{p} / \mathrm{v}$ \\
\hline \multirow{2}{*}{ Allergomex } & Pólenes y ácaros & $1: 20 \mathrm{p} / \mathrm{v}$ \\
\hline & Cucarachas, hongos, gato y perro & $1: 10 \mathrm{p} / \mathrm{v}$ \\
\hline \multirow{2}{*}{ Rocel } & Pólenes y ácaros & $1: 20 \mathrm{p} / \mathrm{v}$ \\
\hline & Hongos, gato y perro & $1: 10 \mathrm{p} / \mathrm{v}$ \\
\hline $\begin{array}{l}\text { UBE }=\text { unidades } \\
\text { Fuente: informaci }\end{array}$ & $\begin{array}{l}\text { equivalentes, PNU = unidades de nitrógeno proteic } \\
\text { obtenida de los fabricantes. }\end{array}$ & $/ v=$ peso/volumen. \\
\hline
\end{tabular}


Para veneno de himenópteros, las PCID se inician con una concentración de 1:1000 000 $\mathrm{p} / \mathrm{v}$ (véase capítulo 6).

\section{7. ¿Existe una concentración adecuada para un extracto con fines terapéuticos?}

Hay dos fases de la administración de la ITA: la de aumento de dosis y la de mantenimiento, cuando el paciente recibe un tratamiento eficaz. La dosis inicial de inmunoterapia es 1000 a 10000 veces menor que la dosis de mantenimiento (JTF-AAAAI/ACAAI y GUIMIT 2011). ${ }^{1,9}$ Para pacientes altamente sensibles, la dosis inicial podría ser menor.

\subsubsection{Concentración del vial para ITSC según la escuela estadounidense}

Según la escuela estadounidense, si la dosis de mantenimiento de ITSC sugerida para Dermatophagoides es de 500-2000 AU (véase apartado 4.2), con una aplicación de $0.5 \mathrm{~mL}$ durante la fase de mantenimiento, la preparación del vial de mantenimiento debería ser de tal manera que alcance una concentración de 1000 a $4000 \mathrm{AU} / \mathrm{mL}$ (cuadro 8.3). Suponiendo que la dosis de mantenimiento de ITSL fuera de dos gotas $(0.1 \mathrm{~mL})$, en el cuadro 8.3 se sugiere concentraciones para el vial de mantenimiento.

\subsubsection{Concentración del vial para ITSC según la escuela europea}

Según la escuela europea, en relación con los extractos estandarizados, un rango entre 5 y $20 \mu \mathrm{g}$ del alérgeno mayor es la dosis de mantenimiento recomendada para los alérgenos inhalados y $100 \mu \mathrm{g}$ para el veneno de himenópteros. Dependiendo del volumen proyectado por inyectar, el fabricante ajusta la concentración del vial, porque los productos europeos se venden "listos para ser usados".

\subsubsection{Concentración del vial para ITSL}

La dosis de alérgeno para la ITSL debe ser bastante mayor que para la ITSC. Datos iniciales sugirieron entre 5 y 375 veces más, lo que muestra incertidumbre y la gran variación en este parámetro. Un análisis detallado de datos más recientes de ITSL sugiere que la dosis diaria efectiva de ITSL podría variar entre 0.5 a 2 veces la dosis mensual de ITSC (véase capítulo 5), sin embargo, existe controversia relacionada con comparar dosis así, porque la eficacia de la ITSL también depende del vehículo y volumen administrado. Se ha sugerido que la dosis mínima diaria de alérgeno mayor para ITSL debe ser de $5 \mu \mathrm{g}$ diarios (consenso de expertos no mexicanos).

\begin{tabular}{|c|c|c|c|}
\hline Alérgeno & $\begin{array}{l}\text { Dosis proyectada para } \\
\text { mantenimiento ITSC }\end{array}$ & $\begin{array}{c}\text { Concentración vial } \\
\text { de mantenimiento ITSC* }\end{array}$ & $\begin{array}{c}\text { Concentración vial } \\
\text { de mantenimiento ITSL** }\end{array}$ \\
\hline Dermatophagoides sp. & $500-2000 \mathrm{AU}$ & $1000-4000 \mathrm{AU} / \mathrm{mL}$ & $2500-10000 \mathrm{AU} / \mathrm{mL}$ \\
\hline Pólenes de pasto (bermuda o pasto inglés) & $1000-4000 \mathrm{BAU}$ & $2000-8000 \mathrm{BAU} / \mathrm{mL}$ & $5,000-20000 \mathrm{BAU} / \mathrm{mL}$ \\
\hline Extractos en PNU & $3000-5000 \mathrm{PNU}$ & $6000-10000 \mathrm{PNU} / \mathrm{mL}$ & $15000-60000 \mathrm{PNU} / \mathrm{mL}$ \\
\hline Extractos no estandarizados & $0.5 \mathrm{~mL}$ de $1: 100$ a $1: 200 \mathrm{p} / \mathrm{v}$ & $1: 100$ a $1: 200 \mathrm{p} / \mathrm{v}$ & $1: 50 \mathrm{p} / \mathrm{v}$ \\
\hline \multicolumn{4}{|c|}{${ }^{\star}$ Con dosis de $0.5 \mathrm{~mL} .{ }^{* \star}$ Con dosis diarias de 2 gotas $(0.1 \mathrm{~mL})$} \\
\hline
\end{tabular}




\subsection{Extractos alergénicos comercialmente disponibles en México según el tipo de fabricante}

Los extractos disponibles en México son los siguientes:

- Extractos de proveedores estadounidenses: estandarizados y no estandarizados (ALK-Abelló).

- Extractos europeos estandarizados y no estandarizados (ALK-Abelló, Inmunotek, Ipi Asac y Lofarma).

- Extractos nacionales, importados como liofilizados desde Estados Unidos y acondicionados para su venta local, sin estandarización (Alerquim).

- Extractos nacionales, principalmente fabricados con materia prima local, sin estandarización (Allergomex, Rocel).

Los fabricantes de extractos nacionales se reportan con número de registro en trámite, con prórroga para buenas prácticas de fabricación, y sus extractos cuentan con un número de registro de la Secretaría de Salud. Los fabricantes europeos con productos disponibles en México y que disponen de registro sanitario por parte de la Cofepris son ALK-Abelló, Inmunotek, Ipi Asac y Lofarma.

\section{9. ¿Existe una relación dosis-respuesta y, por ende, se define la dosis de man- tenimiento en ITSC?}

En los extractos europeos, la dosis de mantenimiento en ITSC ha sido definida acorde con las recomendaciones del fabricante, porque se menciona que la heterogeneidad de los ensayos clínicos no permite establecer una dosis de mantenimiento universal. Por ello, cada extracto tiene dosis de mantenimiento diferente. El vial que se comercializa proporciona la dosis terapéutica establecida por el fabricante, por lo tanto, su mezcla puede tener efecto dilucional. En caso de realizarse una mezcla, también deberá realizarse un ajuste en el número de aplicaciones mensuales para lograr dicha dosis efectiva mensual o aplicar dos dosis por sesión.

En México y Estados Unidos, donde el médico experto en ITA prepara la formulación, se considera que por grupos de alérgenos existen intervalos de dosis que han mostrado eficacia clínica (véase capítulos 4 y 5 ).

Respecto a los concentrados nacionales y estadounidenses, el concentrado de mantenimiento debe formularse para proporcionar una dosis considerada terapéuticamente efectiva. Este vial se define como "concentrado de mantenimiento" (el cual se establece de acuerdo con su factor de dilución como 1:1 vol/vol). Esta concentración debe proporcionar una dosis efectiva proyectada, objetivo de la fase de mantenimiento de la ITSC. La dosis efectiva usada en los ensayos clínicos se basa en los rangos de dosificación de extractos estandarizados; para alérgenos no estandarizados, la dosis efectiva debe ser estimada e individualizada (ver cuadro de dosis, apartado 4.2).

Algunos sujetos no toleraran la dosis efectiva proyectada y pueden experimentar beneficios clínicos con dosis menores, justo al límite de lo que toleran sin reacciones adversas sistémicas. Por lo tanto, la dosis de mantenimiento es aquella que provee eficacia terapéutica sin eventos adversos locales o sistémicos y no siempre será la inicialmente proyectada como efectiva; no obstante, muy bajas dosis son inefectivas, por ejemplo, diluciones de 1:1000 000, 1:100 000 o 1:10 $000(\mathrm{vol} / \mathrm{vol})$. Lo anterior refuerza que la inmunoterapia siempre debe ser individualizada, tomando en cuenta que la administración de una dosis mayor de mantenimiento incrementa la probabilidad de efectividad clínica, sin embargo, también incrementa el riesgo de reacciones adversas sistémicas.
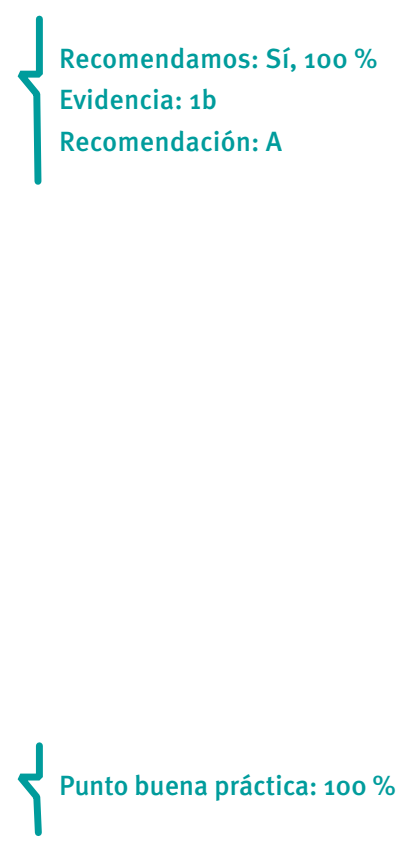

$\{R$ Recomendación: A

http://www.revistaalergia.mx 
Se debe considerar que mezclar extractos no debe generar un efecto dilucional, el cual puede influir con la eficacia de la ITA. Se logra mantener la dosis adecuada para cada alérgeno cuando la mezcla se realiza a partir de viales concentrados, con potencia adecuada para su preparación: 10000 o 100000 (B)AU/mL para los estandarizados y $1: 10$ y $1: 20 \mathrm{p} / \mathrm{v}$ para los no estandarizados.

Al realizar una mezcla para el paciente a partir de un vial concentrado del fabricante de menor concentración (por ejemplo, 1000 (B)AU $/ \mathrm{mL}$ o 1:100 p/v), se debe considerar incrementar el volumen que se toma del vial concentrado para preparar el concentrado de mantenimiento para el paciente, o incrementar el número de aplicaciones mensuales para lograr la dosis efectiva proyectada mensual.

\subsection{0. ¿Existe una relación dosis-respuesta y, por ende, se define la dosis de man- tenimiento en ITSL?}

La dosis de mantenimiento para ITSL se ha definido de acuerdo con las recomendaciones de cada fabricante para los extractos comercializados en Europa y Estados Unidos, estos son pólenes (tabletas o gotas) y ácaros del polvo (tabletas). Debido a que los extractos empleados en los ensayos clínicos son realizados por diferentes fabricantes, cada uno tiene diferentes unidades de medida, lo que hace difícil comparar la potencia de los distintos productos sublinguales e imposibilita establecer una dosis universal para cada uno. No obstante, la cantidad de alérgeno administrada ha sido cuantificada y se ha logrado establecer un rango de dosis de los determinantes antigénicos con algunos de los extractos terapéuticos más prevalentes (Phleum pratensis y Betula verrucosa). Considerando estos hallazgos se puede inferir que la dosis mensual de mantenimiento en ITSL debe ser mucho mayor a la empleada de manera subcutánea (véase capítulo 5).

\subsection{1. ¿Existen dosis intercambiables entre extractos de diferentes manufactureros (dosis equivalentes)?}

Ninguna guía comenta la existencia de dosis intercambiables entre los diferentes fabricantes ni la posibilidad de establecer equivalencias entre las dosis terapéuticas de alérgenos estandarizados y no estandarizados, a pesar de contar con el conocimiento de dosis efectivas para la ITSC para varios alérgenos, mismas que están en relación con la cantidad del alergénico mayor (5 a $20 \mu \mathrm{g}$ por aplicación).

Debido a que existen variaciones entre la cantidad de alérgeno mayor entre los diferentes fabricantes, tanto de alérgenos estandarizados como no estandarizados, en principio se recomienda no considerar la existencia de dosis intercambiables o equivalentes. Si se requiere un cambio en la marca de los extractos, será necesario reiniciar el tratamiento desde la fase de aumento de dosis para evitar efectos secundarios potencialmente graves. Una excepción podría ser comparar la potencia simultáneamente en el mismo laboratorio o con PCP en el mismo paciente, lo que permitiría relacionar directamente la potencia entre extractos. Los expertos GUIMIT lo sugerimos.

\subsection{La calidad de la inmunoterapia se ve afectada por el tipo de diluyente empleado}

Los diluyentes en la inmunoterapia tienen un papel esencial en la preservación y eficacia.

El fenol se utiliza por sus propiedades antibacterianas y preservativas, sin embargo, no estabiliza las proteínas y no impide su desnaturalización y pérdida de potencia.

La glicerina a $50 \%$ y la albúmina sérica humana poseen un efecto estabilizador y preservativo debido a la inhibición de la actividad proteolítica y glucosídica de las enzimas

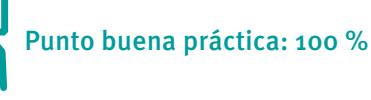

Sugerimos: Sí, $100 \%$

Evidencia: no emitida

Recomendación: no emitida $\left\{\begin{array}{l}\text { Punto buena práctica: No, } \\ 100 \%\end{array}\right.$
$\left\{\begin{array}{l}\text { Punto buena práctica: Sí, } \\ 100 \%\end{array}\right.$ 
presentes en algunos extractos. Se ha mostrado su efectividad en preservar soluciones con altas diluciones, comparada con solución salina y concentraciones menores de glicerina (por ejemplo, de $10 \%$ ). Se recomienda añadir albúmina sérica humana a $0.03 \%$ para evitar la adsorción del alérgeno en la superficie interna del vial de vidrio en las diluciones iniciales, así como para prevenir el efecto deletéreo del fenol sobre los extractos. En concentraciones crecientes no se ha observado efecto sobre la concentración (información obtenida del fabricante).

En México no es posible adquirir albúmina para la preparación de inmunoterapia, sino que viene dentro de los frascos de disolvente para liofilizados comercializados por algunos fabricantes europeos. La disponible en el mercado nacional no sirve para este fin.

Los extractos liofilizados deberán reconstituirse con glicerina a $50 \%$ o albúmina sérica humana para su preservación (disolvente), mientras que la preparación de los viales de ITSC para el paciente no pueden contener más de $10 \%$ de glicerina. Concentraciones mayores causan irritación. Para ITSL se puede emplear concentraciones mayores de glicerina (hasta $50 \%$ ).

\subsection{3. ¿Se pueden agregar ciertos adyuvantes a la inmunoterapia para aumentar su eficacia?}

\subsubsection{Hidróxido de aluminio}

El hidróxido de aluminio se ha utilizado ampliamente como adyuvante de primera generación, ya que al adherirse a las moléculas del alérgeno se genera un conglomerado que funciona como un depósito con liberación prolongada. De esta forma se logra una supresión del pico de la concentración del alérgeno en la circulación sistémica y, por ende, una reducción de los efectos adversos que pudiera provocar. De igual modo se le han atribuido interacciones con la inmunidad innata y adaptativa, potenciando la inmunogenicidad alergénica. Aun así, en algunos pacientes se ha relacionado con inflamación aguda en el sitio de la aplicación y en raras ocasiones con inflamación crónica y la aparición de un granulo más, probablemente secundarias a reacciones alérgicas de contacto o a vasculitis. De presentarse algún tipo de reacción se recomienda utilizar extractos libres de hidróxido de aluminio.

\subsubsection{Agonistas de receptores Toll}

Algunos productos bacterianos, agonistas de los receptores tipo Toll (TLR) se han utilizado como adyuvantes con propiedades inmunomoduladoras. El monofosforil lípido A, derivado de los lipopolisacáridos de Salmonella Minnesota, es un agonista de TLR-4 y estimula la respuesta celular Th1 junto con su patrón de citocinas. En algunos estudios se ha mezclado con gramíneas mostrando efectividad en fase III (grado A para adultos, grado B para niños). TOLAMBA es la fusión de un agonista TRL-9 (oligodeoxinucleótido CpG) al determinante mayor de la ambrosía (Amb a 1). El CpG promueve un efecto antiinflamatorio mediado por inmunidad innata, así como la producción de citocinas reguladoras que finalmente apoyan al cambio de isotipo hacia IgG4. Se ha probado en esquemas convencionales y acelerados, en los cuales ha demostrado ser seguro y eficaz. En México aún no se puede adquirir este tipo de extractos.

\subsubsection{Omalizumab}

La administración concomitante del anticuerpo monoclonal anti-IgE, omalizumab, es eficaz en la inducción de tolerancia y disminución de los efectos adversos en esquemas convencionales y acelerados de la inmunoterapia alérgica específica (véase capítulo 10). $\left\{\begin{array}{l}\text { Punto buena práctica: Sí, } \\ 100 \%\end{array}\right.$

$\left\{\begin{array}{l}\text { Punto buena práctica: Sí, } \\ 100 \%\end{array}\right.$

Sugerimos: Sí, $100 \%$

Evidencia: no emiten

Recomendación: D

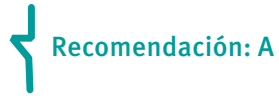

$\left\{\begin{array}{l}\text { Sugerimos: Sí, } 100 \% \\ \text { Evidencia: 1b } \\ \text { Recomendación: A }\end{array}\right.$ 


\subsubsection{Vacuna bacteriana}

Por otro lado, los extractos bacterianos polivalentes o monovalentes, que se obtienen a partir de las cepas patógenas más frecuentes, mejoran la actividad de las células natural killer, que estimulan la producción de TNF- $\alpha$, IL-12, IFN- $\gamma$ en células mononucleares, regulan la expresión de moléculas de adhesión en los fagocitos e inhiben la producción de IL-12 en los linfocitos, incrementan la producción de IgA e IgG y disminuyen la $\left\{\begin{array}{l}\text { Punto buena práctica: Sí, } \\ 100 \%\end{array}\right.$ concentración de IgE total. Se han utilizado desde hace décadas como adyuvante en la inmunoterapia debido a su efecto modulador. ${ }^{96,97}$

\section{Capítulo 9. ITSC: seguridad de la inmunoterapia con alérgenos, eventos adversos y su manejo (cuadro 9.1)}

\section{Cuadro 9.1. Resumen de eventos adversos

En relación con la ITA (ITSC o ITSL), ¿es necesaria la premedicación con antihistamínico

$\mathrm{H}_{1}$ de segunda generación o antileucotrieno para evitar o disminuir sus efectos adver-

Sugieren: Sí

$100 \%$ sos locales o sistémicos leves?

¿Se considera efectivo el uso de antileucotrienos para evitar o disminuir los efectos adversos en la ITA?

En relación con la inmunoterapia (ITSC o ITSL), ¿la premedicación reduce o evita la anafilaxia?

En pacientes que se encuentran con ITA con veneno de himenópteros (VIT) y que presentan reacción adversa sistémica a la ITA, ¿qué se recomienda?

- Premedicación con antihistamínicos H1 de segunda generación

Recomiendan: Sí

- Premedicación con omalizumab para prevenir los efectos adversos a la aplicación de esta

Un paciente que presenta una reacción adversa con síntomas sistémicos, ¿podría ser tratado con antihistamínicos $\mathrm{H}_{1}$ o corticosteroide sistémico antes o en vez de adrenalina?

- Con afección a un órgano o sistema (por ejemplo, únicamente urticaria o rinorrea)

- Con afección a 2 o más órganos (por ejemplo, rinorrea y urticaria)

¿La adrenalina es el medicamento de elección para el manejo inicial de anafilaxia?

Posterior a un efecto adverso grave (anafilaxia), ¿se debe prescribir corticosteroide sistémico?

Después de un evento adverso a la inmunoterapia, ¿se debe ajustar la dosis o concentración?

- ¿En caso de reacción local?

- ¿En caso de reacción local extensa $(>2.5 \mathrm{~cm})$ o repetitiva?

- ¿En caso de reacción sistémica?
Sugieren: Sí.

Para afección respiratoria: betaagonis-

tas.

Para afección cutánea o nasal: antihistamínico

Recomiendan: No (¡el diagnóstico es anafilaxia!)

Recomiendan: Sí.

Dosis: $0.01 \mathrm{~mL} / \mathrm{kg}$, máximo, $0.5 \mathrm{~mL} \quad 100 \%$

$$
\text { intramuscular }
$$

Sugieren: Sí, si hubo hipotensión (reduce riesgo de anafilaxia bifásica)

$100 \%$

$100 \%$

Sugieren: No

$100 \%$

Sugieren: Sí

$100 \%$

Recomiendan: Sí

Ajustado** 


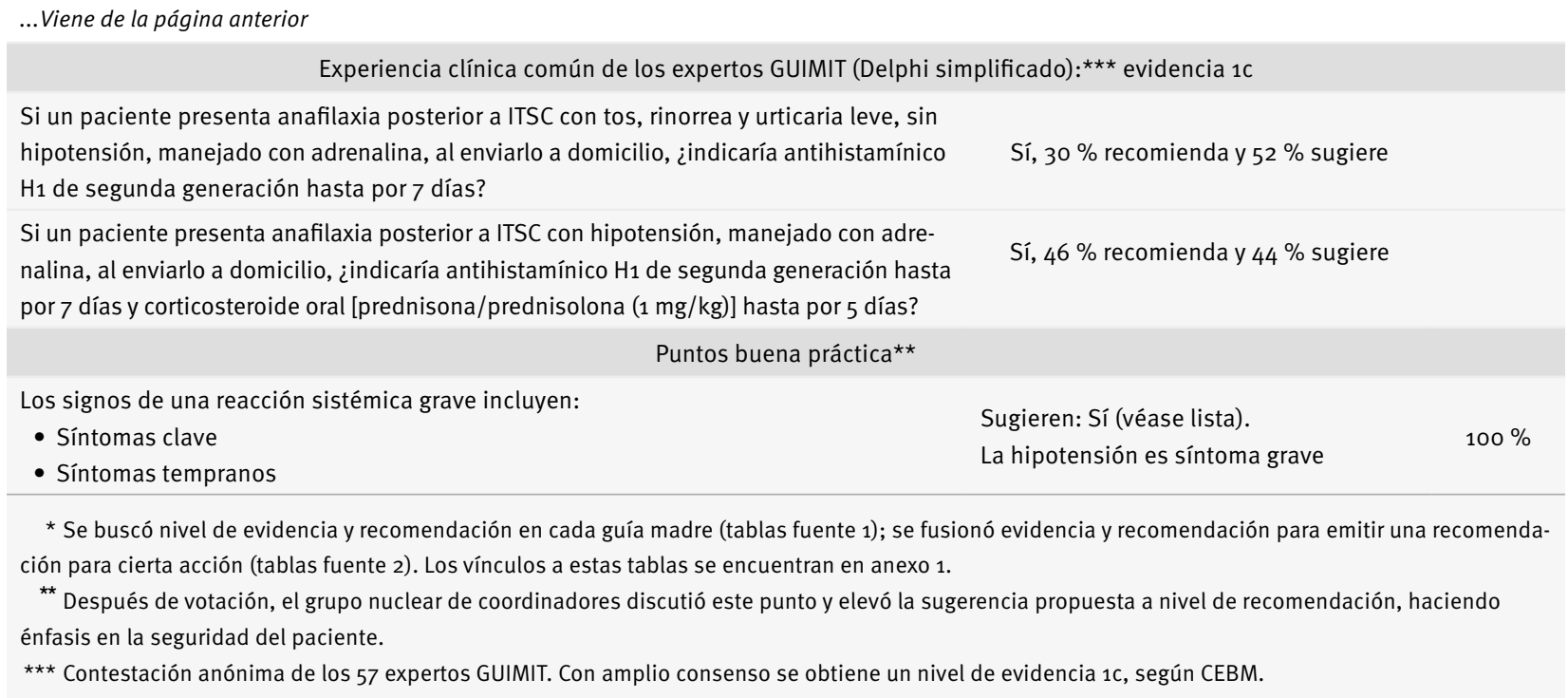

\subsection{Introducción}

Las reacciones locales (RL) son frecuentes en la ITA. En la ITSC, más de la mitad de los pacientes en algún momento presenta erupción en el lugar de la aplicación (véase apartado 4.4), en tanto que la ITSL en la modalidad europea en la cual casi no hay fase de aumento de dosis, hasta $70 \%$ podría presentar algún síntoma local en la cavidad oral las primeras semanas (véase capítulo 5). También se llegan a presentar RS y, eventualmente, anafilaxia o, muy rara vez, choque anafiláctico. En el apartado 4.4 y capítulo 5 se revisaron los factores de riesgo para la aparición de RS y en el capítulo 7, los requerimientos indispensables y óptimos sugeridos por GUIMIT para dar un manejo rápido y oportuno en caso de una RS en el lugar donde se aplica la ITA. En este capítulo se revisa la utilidad de la medicación previa (conocida como premedicación), los síntomas y la clasificación de la gravedad de las RS y su manejo, al igual que las acciones posteriores a una RS.

\subsection{Premedicación para prevenir eventos adversos leves, pero no anafilaxia}

Con base en la información de las GM, el médico puede llevar a cabo medicación previa con antihistamínicos $\mathrm{H} 1$ no sedantes de segunda generación o antileucotrienos ${ }^{98}$ para disminuir la intensidad y frecuencia de las RL. Los antihistamínicos H1 pueden también ser útiles para disminuir la frecuencia de las RS o impedirlas si se toman una o dos horas antes de la aplicación de la ITA. Sin embargo, la medicación previa no puede prevenir la anafilaxia; tanto en la ITSC como en ITSL tiene un buen perfil de seguridad y no afecta la eficacia de la ITA. ${ }^{99,100}$

En casos seleccionados, los expertos de GUIMIT sugieren medicación con antihistamínico H1 una a dos horas antes de aplicar la ITSC, para reducir las RL y RS leves en pacientes que las han presentado. Especialmente cuando se usan esquemas agrupados (en racimo, rápidos y ultrarrápidos), aumenta la seguridad (véase apartado 4.4) y durante la fase de aumento de dosis puede ser de utilidad para no detener el aumento de la dosis por reacciones adversas.

En los pacientes manejados con VIT que presenten RS, además de administrar antihistamínicos $\mathrm{H} 1$ o antileucotrienos se puede evaluar pretratamiento con anticuerpo 
monoclonal contra receptor de IgE varias semanas antes del reinicio de la VIT, para disminuir el riesgo de otra RS. Considerando su eficacia, pero también su costo, los expertos de GUIMIT sugieren iniciar la aplicación de omalizumab desde cinco semanas antes del reinicio de la VIT (aplicar cinco, tres y una semana antes), ajustando según el peso y niveles de IgE sérica total y continuar durante cuatro a seis meses del tratamiento con VIT, en conjunto con un antihistamínico H1 de segunda generación no sedante.

\subsection{Síntomas sugestivos de reacción adversa sistémica y síntomas de alarma}

Aun cuando la mayoría de las guías internacionales de inmunoterapia no incluyen lineamientos acerca de los datos clínicos que pueden preceder a una RS grave, la guía alemana de inmunoterapia los menciona, así como la guía de anafilaxia de la World Allergy Organization. La regla general es que mientras más breve el tiempo entre la aplicación de la ITA y el inicio del primer síntoma, más grave la posible RS. Es sumamente raro que una anafilaxia inicie con síntomas después de los primeros 30 minutos siguientes a la aplicación.

\subsubsection{Síntomas y signos tempranos de anafilaxia}

Algunos síntomas y signos tempranos de anafilaxia que se mencionan en la literatura son sensación de quemazón o prurito en las palmas de las manos y plantas de los pies, miedo o ansiedad (sense of pending doom), prurito perianal o perigenital, urgencia para orinar o defecar o cólicos uterinos, o sabor metálico; los niños pueden presentar cambios de comportamiento o debilidad, ataque de estornudos o prurito generalizado previos a los síntomas cardiovasculares o respiratorios propios de la anafilaxia.

\subsubsection{Síntomas y signos clásicos de anafilaxia}

En el cuadro 9.2 se enumeran los síntomas y signos clásicos de la anafilaxia, considerando diferentes escenarios clínicos. ${ }^{101} \mathrm{El}$ cuadro 9.3 muestra una propuesta de cómo clasificar la gravedad de la anafilaxia, ${ }^{102}$ aunque existe discusión internacional acerca del mejor sistema para este fin. ${ }^{103-105}$ Una vez que el paciente presenta disminución de la tensión arterial (hipotensión), se considera choque anafiláctico. Afortunadamente, una vez detectada la anafilaxia y con un buen manejo se puede reducir el riesgo de su evolución a choque, pero no siempre.

\subsection{Clasificación de las reacciones adversas sistémicas a la ITA (ITSC, ITSL y VIT)}

Un grupo de expertos coordinó un esfuerzo por parte de la World Allergy Organization para clasificar las reacciones sistémicas secundarias a la ITSC y posteriormente se acordó que la clasificación también era válida para las RS posteriores a la ITSL (figura 9.1).

\subsection{Tratamiento de las reacciones sistémicas y la anafilaxia}

Si el paciente presenta una reacción adversa posterior a la administración de la ITA que involucre a un solo órgano o sistema, se define como RS, que puede ser leve, moderada o grave, según la intensidad del síntoma. El tratamiento de una RS que no sea anafilaxia puede ser con antihistamínico H1 de segunda generación. Si el órgano involucrado es la vía respiratoria baja, el primer medicamento será un broncodilatador inhalado de acción rápida. Si la reacción progresa y se extiende a otro u otros órganos se iniciará tratamiento de anafilaxia.

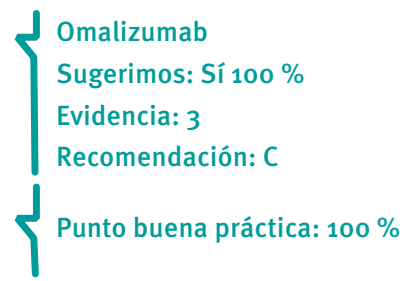

Sugerimos: Sí $100 \%$

Evidencia: 3 


\begin{tabular}{|c|c|c|c|}
\hline \multirow{2}{*}{ Escenario clínico } & \multicolumn{3}{|c|}{ Sistema } \\
\hline & Tegumentario (piel) & Respiratorio/digestivo & Cardiovascular \\
\hline $\begin{array}{l}\text { Inicio agudo (minutos a algunas } \\
\text { horas) }\end{array}$ & $\begin{array}{l}\text { Ronchas generalizadas, pru- } \\
\text { rito o enrojecimiento, edema } \\
\text { de labios, lengua y úvula, y } \\
\text { al menos un signo o síntoma } \\
\text { respiratorio/digestivo o } \\
\text { cardiovascular }\end{array}$ & $\begin{array}{l}\text { Disnea, sibilancias, estridor, } \\
\text { reducción del flujo espiratorio } \\
\text { pico (PEF), hipoxemia }\end{array}$ & $\begin{array}{l}\text { Reducción de la tensión arterial o } \\
\text { síntomas asociados de disfunción } \\
\text { orgánica (hipotonía, colapso, } \\
\text { síncope, incontinencia) }\end{array}$ \\
\hline $\begin{array}{l}2 \text { o más de lo siguiente ocurre } \\
\text { rápidamente después de la } \\
\text { exposición a un probable alérgeno } \\
\text { (minutos a algunas horas) }\end{array}$ & $\begin{array}{l}\text { Ronchas generalizadas, pruri- } \\
\text { to, enrojecimiento, edema de } \\
\text { labios, lengua y úvula }\end{array}$ & $\begin{array}{l}\text { Disnea, sibilancias, estridor, } \\
\text { reducción del flujo espiratorio } \\
\text { pico, hipoxemia. } \\
\text { Síntomas gastrointestinales per- } \\
\text { sistentes (dolor abdominal tipo } \\
\text { cólico, vómito) }\end{array}$ & $\begin{array}{l}\text { Reducción de la tensión arterial } \\
\text { o síntomas asociados (hipotonía } \\
\text { o colapso, síncope, incontinencia) }\end{array}$ \\
\hline $\begin{array}{l}\text { Reducción de la tensión arterial } \\
\text { después de la exposición a un } \\
\text { alérgeno conocido para ese } \\
\text { paciente }\end{array}$ & & & $\begin{array}{l}\text { Niños: tensión arterial sistólica } \\
\text { baja (específica para la edad) o } \\
\text { > } 30 \text { \% de descenso. } \\
\text { Adultos: tensión arterial sistólica } \\
\text { < } 90 \text { mm Hg ó > } 30 \text { \% de disminu- } \\
\text { ción de la basal }\end{array}$ \\
\hline
\end{tabular}

Adaptado de Muraro A, Roberts G, Worm M, et al. Anaphylaxis: guidelines from the European Academy of Allergy and Clinical Immunology. Allergy. 2014;69(8):1026-1045. ${ }^{101}$

Sin embargo, si el paciente presenta síntomas en dos o más órganos o sistemas, por definición es anafilaxia y su tratamiento será tal como se describe en el cuadro 9.4. La adrenalina es el único tratamiento farmacológico de primera elección para el tratamiento de anafilaxia. Se recomienda aplicar por vía intramuscular con el fin de acelerar su absorción sistémica, ya que durante la anafilaxia disminuye la perfusión del tejido subcutáneo, además del blanqueamiento local por vasoconstricción intensa. Se administra a razón de $0.01 \mathrm{~mL} / \mathrm{kg} /$ dosis hasta $0.50 \mathrm{~mL}$. Se puede repetir cada cinco

Adrenalina intramuscular Recomendamos: Sí, $100 \%$ Evidencia: 2a Recomendación: A

\begin{tabular}{|c|c|c|c|c|}
\hline \multirow{2}{*}{ Grado } & \multicolumn{4}{|c|}{ Sistema } \\
\hline & Tegumentario (piel) & Digestivo & Respiratorio & Cardiovascular \\
\hline I & $\begin{array}{l}\text { Prurito, enrojecimiento, } \\
\text { urticaria angioedema }\end{array}$ & - & - & - \\
\hline II & $\begin{array}{l}\text { Prurito, enrojecimiento, } \\
\text { urticaria angioedema }\end{array}$ & Náuseas, calambres & $\begin{array}{l}\text { Rinorrea, ronquera, } \\
\text { disnea }\end{array}$ & $\begin{array}{l}\text { Taquicardia (elevación } \geq 20 / \text { minuto } \\
\text { respecto a la frecuencia basal), } \\
\text { hipotensión (caída } \geq 20 \mathrm{~mm} / \mathrm{Hg} \text { res- } \\
\text { pecto a la medición basal), arritmia }\end{array}$ \\
\hline III & $\begin{array}{l}\text { Prurito, enrojecimiento, } \\
\text { urticaria, angioedema }\end{array}$ & Vómito, evacuación & $\begin{array}{l}\text { Edema laríngeo, bronco- } \\
\text { espasmo, cianosis }\end{array}$ & Choque \\
\hline IV & $\begin{array}{l}\text { Prurito, enrojecimiento, } \\
\text { urticaria angioedema }\end{array}$ & Vómito, evacuación & Paro respiratorio & Paro circulatorio \\
\hline
\end{tabular}

Adaptado de Ring J, Messmer K. Incidence and severity of anaphylactoid reactions to colloid volume substitutes. Lancet. 1977;1(8009):466-469. ${ }^{102}$ 
1

Establecer protocolo escrito de emergencia para detección y tratamiento de anafilaxia y ensayarlo regularmente

2

Descontinuar o eliminar desencadenante, si es posible

3

Valorar estado circulatorio, vía aérea, respiración, estado mental, piel y peso del paciente

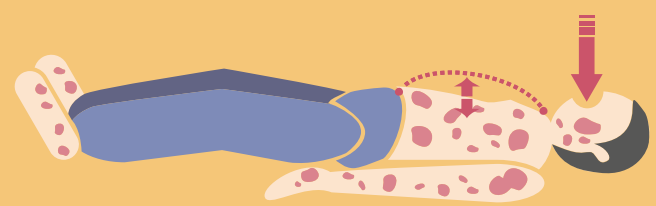

4

Solicitar ayuda: equipo de resucitación, servicio de urgencias.

De inmediato y simultáneamente realizar pasos 4,5 y 6

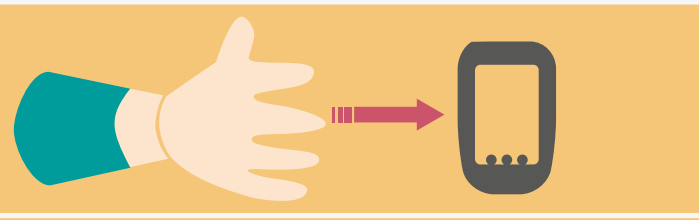

5

Inyectar adrenalina (epinefrina) intramuscular en la parte media-anterolateral del muslo, $0.01 \mathrm{~mL} / \mathrm{kg}$ del vial comercial (solución 1:1000 $=1 \mathrm{mg} / \mathrm{mL}$ ), máximo $0.5 \mathrm{~mL}$ adulto y $0.3 \mathrm{~mL}$ niño;

6 si necesario, repetir dosis 5-15 minutos

Colocar al paciente en decúbito o posición cómoda si hay disnea o vómito; elevar extremidades inferiores; una fatalidad puede ocurrir en segundos si el paciente se pone de pie inmediatamente

7

Proporcionar oxígeno suplementario con alto flujo (6-8 L/minuto) con mascarilla o establecer vía endotraqueal de ser necesario

8

Establecer acceso intravenoso con catéter de gran calibre (14-16). De ser necesario, administrar rápidamente $1-2 \mathrm{~L}$ de solución salina (0.9\% isotónica) (5-10 mL/ kg en 5-10 minutos en adultos y $10 \mathrm{~mL} / \mathrm{kg}$ en niños)

9

Realizar reanimación cardiopulmonar con compresiones continuas en tórax, en cualquier momento de ser necesario

\section{Además...}

Vigilar, en intervalos frecuentes y regulares, presión arterial, función y frecuencia cardiaca, estado respiratorio y oxigenación (monitoreo continuo, de ser posible)
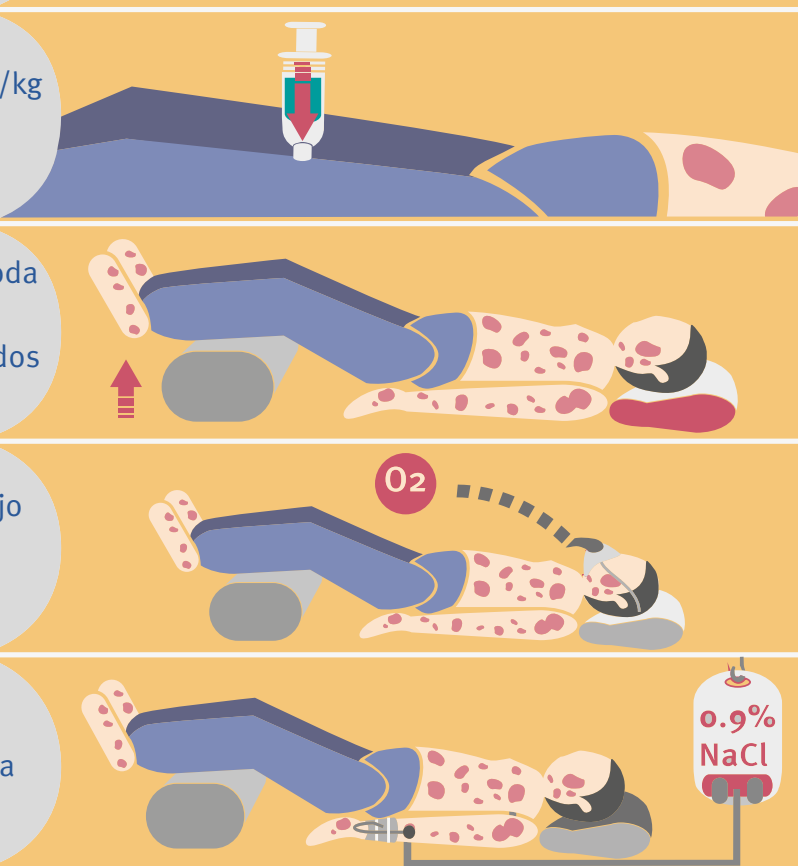

$0.9 \%$ $\mathrm{NaCl}$
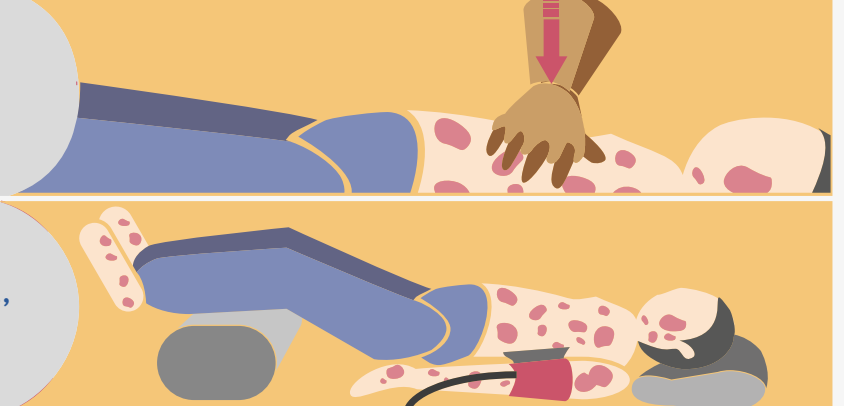

Figura 9.1. Sistema de graduación de las reacciones sistémicas de inmunoterapia subcutánea de la World Allergy Organization. 
o 10 minutos en caso necesario. La única excepción podrían ser los pacientes con anafilaxia bajo tratamiento con betabloqueadores, en cuyo caso se recomienda, además, 20 a $30 \mu \mathrm{g} / \mathrm{kg} / \mathrm{dosis}$ de glucagón hasta $1 \mathrm{mg}$, para mejorar la respuesta a la adrenalina que podría estar parcialmente bloqueada.

Cuadro 9.4. Sistema de graduación de las reacciones sistémicas de inmunoterapia subcutánea de la World Allergy Organization
\begin{tabular}{cccc} 
Grados de la reacción* \\
\hline 1
\end{tabular}$\quad 3 \quad 4 \quad 5$

\begin{tabular}{|c|c|c|c|c|}
\hline $\begin{array}{l}\text { Signos o síntomas de un } \\
\text { sistema } \\
\text { Cutáneo } \\
\text { Prurito, urticaria, enroje- } \\
\text { cimiento, calor localizado } \\
\text { o angioedema en más de } \\
\text { dos sitios (no laríngeo, } \\
\text { de lengua ni úvula) }\end{array}$ & $\begin{array}{l}\text { Signos o síntomas de } \\
\text { más de un sistema } \\
\text { (mencionados en grado } 1 \text { ) }\end{array}$ & $\begin{array}{l}\text { Respiratorio inferior } \\
\text { Asma (por ejemplo, caída } \\
\text { de FEP }>40 \% \text { o VEF }{ }_{1} \text { que } \\
\text { no responde al broncodi- } \\
\text { latador inhalado) }\end{array}$ & $\begin{array}{l}\text { Respiratorio superior } \\
\text { o inferior } \\
\text { Falla respiratoria con o } \\
\text { sin pérdida de la con- } \\
\text { ciencia }\end{array}$ & Muerte \\
\hline 0 bien & 0 bien & O bien & O bien & \\
\hline $\begin{array}{l}\text { Respiratorio superior } \\
\text { Rinitis (estornudos, rino- } \\
\text { rrea, obstrucción nasal } \\
\text { o prurito nasal) o aclara- } \\
\text { miento o prurito faríngeo } \\
\text { o tos percibida de origen } \\
\text { superior, no pulmonar, } \\
\text { tráquea o laringe }\end{array}$ & $\begin{array}{l}\text { Respiratorio inferior } \\
\text { Asma: tos, sibilancias, } \\
\text { dificultad respiratoria } \\
\text { (por ejemplo, caída del } \\
\text { FEP }<40 \% \text { o VEF } 1 \text { que } \\
\text { responde a broncodilata- } \\
\text { dor inhalado) }\end{array}$ & $\begin{array}{l}\text { Respiratorio alto } \\
\text { Edema de laringe, } \\
\text { lengua o úvula, con o sin } \\
\text { estridor }\end{array}$ & $\begin{array}{l}\text { Cardiovascular } \\
\text { Hipotensión con o sin } \\
\text { pérdida de conciencia }\end{array}$ & \\
\hline 0 bien & 0 bien & & & \\
\hline $\begin{array}{l}\text { Conjuntival } \\
\text { Eritema conjuntival, } \\
\text { prurito o epífora }\end{array}$ & $\begin{array}{l}\text { Gastrointestinal } \\
\text { Cólico, vómito, diarrea }\end{array}$ & & & \\
\hline O bien & O bien & & & \\
\hline $\begin{array}{l}\text { Otros. } \\
\text { Náusea, sabor metálico, } \\
\text { cefalea }\end{array}$ & $\begin{array}{l}\text { Otros. } \\
\text { Cólicos uterinos }\end{array}$ & & & \\
\hline Criterio médico & Adrenalina & Adrenalina & Adren & \\
\hline
\end{tabular}

*Cada grado está basado en un sistema orgánico involucrado y en la severidad de la reacción. Una reacción de un único sistema orgánico (cutáneo, conjuntival, de vías respiratorias altas, de vías respiratorias inferiores, gastrointestinal, cardiovascular, y otros), pero no asma, gastrointestinal o cardiovascular está clasificado como un grado 1. Los síntomas o signos de más de un sistema orgánico o asma, del sistema gastrointestinal o cardiovascular están clasificados como grado 2 ó 3 . El grado es determinado por el juicio clínico del médico. Los síntomas que tienen lugar durante los primeros minutos después de la inyección pueden indicar anafilaxia severa. Los síntomas leves pueden llevar rápidamente a anafilaxia severa y muerte. Si los signos o síntomas no están incluidos en la tabla o resulta difícil la diferenciación entre una reacción sistémica y vasovagal (que puede ocurrir en cualquier intervención médica), será necesario registrar comentarios, según convenga. Los pacientes pueden tener sensación de muerte inminente, especialmente en los grados 2, 3 y 4. El grado final de la reacción no se determina hasta que finalice el episodio, sin considerar la medicación administrada. NOTA: Los niños con anafilaxia raras veces verbalizan una sensación de muerte inminente, por lo que los cambios de comportamiento pueden ser un signo de anafilaxia, por ejemplo, que estén muy quietos, irritables o de mal humor.

$\mathrm{FEP}=$ flujo espiratorio pico, $\mathrm{VEF}_{1}=$ volumen espiratorio forzado en el primer segundo.

Ajustado de Cox L, Larenas-Linnemann D, Lockey RF, Passalacqua G. Speaking the same language: the World Allergy Organization Subcutaneous Immunotherapy Systemic Reaction Grading System. J Allergy Clin Immunol. 2010;125(3):569-574. ${ }^{104}$ 


\subsection{Tratamiento posterior a una reacción sistémica o anafilaxia}

Ninguna de las GM aborda este aspecto. Después de una RS, el paciente quedará en observación por mínimo 30 minutos después de la resolución del evento. Después de un episodio de anafilaxia, se deberá observar y monitorear al paciente por lo menos durante una hora. Al dar de alta al paciente, GUIMIT sugiere medicar por una semana con un antihistamínico H1 no sedante de segunda generación, además de ajuste temporal en el manejo de mantenimiento del asma, de ser necesario.

Después de un evento de anafilaxia con hipotensión (choque anafiláctico) se recomienda $1 \mathrm{mg} / \mathrm{kg} /$ día de corticosteroides sistémicos, máximo $50 \mathrm{mg}$ en dosis única matutina de prednisona o equivalente por cinco días, junto con antihistamínico H1 sistémico de segunda generación, para reducir el riesgo de una reacción bifásica. El médico podría considerar hospitalizar al paciente para observación por 12 a 24 horas, en caso de que llegase a presentar una reacción bifásica.

\subsection{Ajustes en la dosis y el esquema de la ITA después de reacciones adversas}

Con base en lo expuesto anteriormente, dependiendo de la gravedad de la reacción adversa, GUIMIT sugiere el ajuste de la dosis de la ITA. La mayoría de las reacciones adversas son locales leves y no ameritan el ajuste de dosis, ya que no se han relacionado con RS. Pero después de RL grandes $(>3 \mathrm{~cm})$, sobre todo en reacciones extensas repetitivas, se ha observado aumento en el riesgo de RS. ${ }^{106}$ En estos casos, GUIMIT sugiere ajustar el esquema de ITA a la última dosis con buena tolerancia. Para todas las RS, las GM y GUIMIT sugieren ajustar la dosis de ITA, que dependiendo de la gravedad será a una dosis previa o la décima parte de la última dosis tolerada. Después de un choque anafiláctico o múltiples RS, GUIMIT sugiere ponderar los beneficios de continuar la ITA contra sus riesgos, porque un paciente que ha presentado RS tendrá mayor riesgo de volver a presentarla. Hay que considerar que la práctica de ajustar la dosis de ITA es en gran parte anecdótica y no se basa en evidencia, sino en la experiencia de los alergólogos.

\section{Capítulo 10. Futuro: nuevas indicaciones y modalidades de la inmunoterapia en investigación (cuadro 10.1)}

\subsection{Introducción}

Actualmente la administración de ITA por vía subcutánea y sublingual ha demostrado adecuada eficacia y seguridad. Está establecido que se logra revertir la inflamación alérgeno-específica en el paciente a partir del primer año de aplicación y durante todo el tratamiento (mínimo por tres años) y lo más importante es que se mantiene un beneficio clínico a largo plazo una vez completada (véase capítulos 4 y 5). Esfuerzos internacionales han propuesto nuevas vías de administración (figura 10.1), con el objetivo de reducir el tiempo de tratamiento o contar con alternativas para su administración cuando se presentan efectos adversos.

En esta sección presentamos la evidencia actual sobre la administración de ITA por vía intralinfática (ITIL), epicutánea (ITEP) e intranasal (ITIN) en escenarios clínicos particulares. También se ha comprobado la eficacia y seguridad de alérgenos recombinantes y péptidos sintéticos. Finalmente, agentes biológicos administrados concomitantemente con la ITA pueden mejorar su seguridad (figura 10.2).

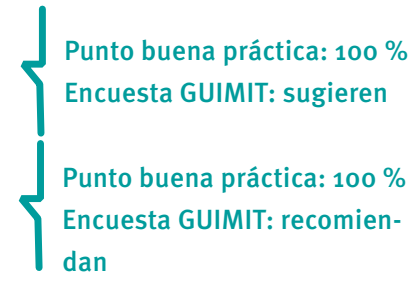

Reacción local aislada
Sugerimos: No
Evidencia: II
Recomendación: C
RL grande, repetitiva o RS
Sugerimos Sí
Evidencia: 3
Recomendación: no emitida 


\section{Cuadro 10.1. Resumen del futuro de las nuevas indicaciones y modalidades de la inmunoterapia en investigación}

En el paciente adolescente $o$ adulto con RA monosensibilizado, la aplicación de extractos alergénicos por vía intralinfática ha mostrado seguridad y eficacia?

$\begin{array}{lc}\text { Sin evidencia suficiente } & 87 \% \\ \text { Sin evidencia suficiente } & 96 \% \\ \text { Sin evidencia suficiente } & 100 \%\end{array}$

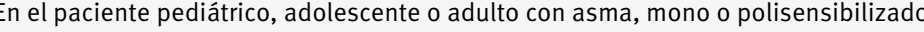
¿la aplicación de extractos alergénicos por vía intralinfática ha mostrado seguridad

Sin evidencia suficiente $100 \%$ y eficacia?

En el paciente adolescente o adulto con RA, mono o polisensibilizado, ¿la aplicación de extractos alergénicos en mucosa nasal ha mostrado seguridad

Sugieren: No

$100 \%$ y eficacia?

En el paciente pediátrico con RA monosensibilizado, ¿la aplicación de extractos alergénicos en mucosa nasal ha mostrado seguridad y eficacia?

Sugieren: No

$100 \%$

En el paciente pediátrico, adolescente o adulto con RA monosensibilizado, ¿la aplicación de extractos alergénicos por vía epicutánea ha mostrado seguridad

Sin evidencia suficiente y eficacia?

En el paciente pediátrico, adolescente o adulto con alergia a polen de pastos, ¿la aplicación de extractos alergénicos por vía epicutánea ha mostrado seguridad y eficacia?

Sugieren: Sí

$100 \%$

En el paciente pediátrico, adolescente o adulto con asma mono o polisensibilizado, ¿la aplicación de extractos alergénicos por vía epicutánea ha mostrado seguridad y eficacia?

¿La administración de ITA con alérgenos recombinantes en adolescentes o adultos con alergias respiratorias es segura y eficaz?

¿La administración de ITA con alérgenos recombinantes en paciente pediátrico con alergias respiratorias es segura y eficaz?

En pacientes mayores de 6 años con alergia a himenóptera que presenten mala tolerancia a VIT, ¿la utilización concomitante de omalizumab mejora la tolerancia y disminuye los efectos adversos?

En pacientes mayores de 6 años con alergia respiratoria que presenten mala tolerancia a ITA, ¿la utilización concomitante de omalizumab mejora la tolerancia y disminuye los efectos adversos?

Experiencia clínica común de los expertos GUIMIT (Delphi simplificado): ** evidencia 1C

En pacientes mexicanos con alergia y pobre tolerancia a ITSC y sin posibilidad de ITSL, ¿consideraría ITIL?

- ¿Con rinoconjuntivitis alérgica?

Tal vez, $7 \%$ recomienda, $33 \%$ sugiere

$$
\text { y } 33 \% \text { neutral }
$$

- ¿Con asma alérgica?

\section{Punto de buena práctica}

Promover la realización de protocolos de investigación clínica en pacientes mexicanos sobre la utilización de ITIL, ITEP e ITSC con alérgenos recombinantes
Sí, 7 \% recomienda, $41 \%$ sugiere

y $31 \%$ neutral

\footnotetext{
* Se buscó nivel de evidencia y recomendación en cada guía madre (tablas fuente 1); se fusionó evidencia y recomendación para emitir una recomendación para cierta acción (tablas fuente 2 ). Los vínculos a estas tablas se encuentran en anexo 1.

** Contestación anónima de los 57 expertos GUIMIT. Con amplio consenso se obtiene un nivel de evidencia 1c, según CEBM.

$\mathrm{RA}=$ rinitis alérgica, ITA = Inmunoterapia con alérgeno, VIT = inmunoterapia con veneno de himenópteros, ITSC = inmunoterapia subcutánea, ITSL = inmunoterapia sublingual, ITEP = inmunoterapia epicutánea, ITIL = inmunoterapia intralinfática, ITIN = inmunoterapia intranasal.
} 


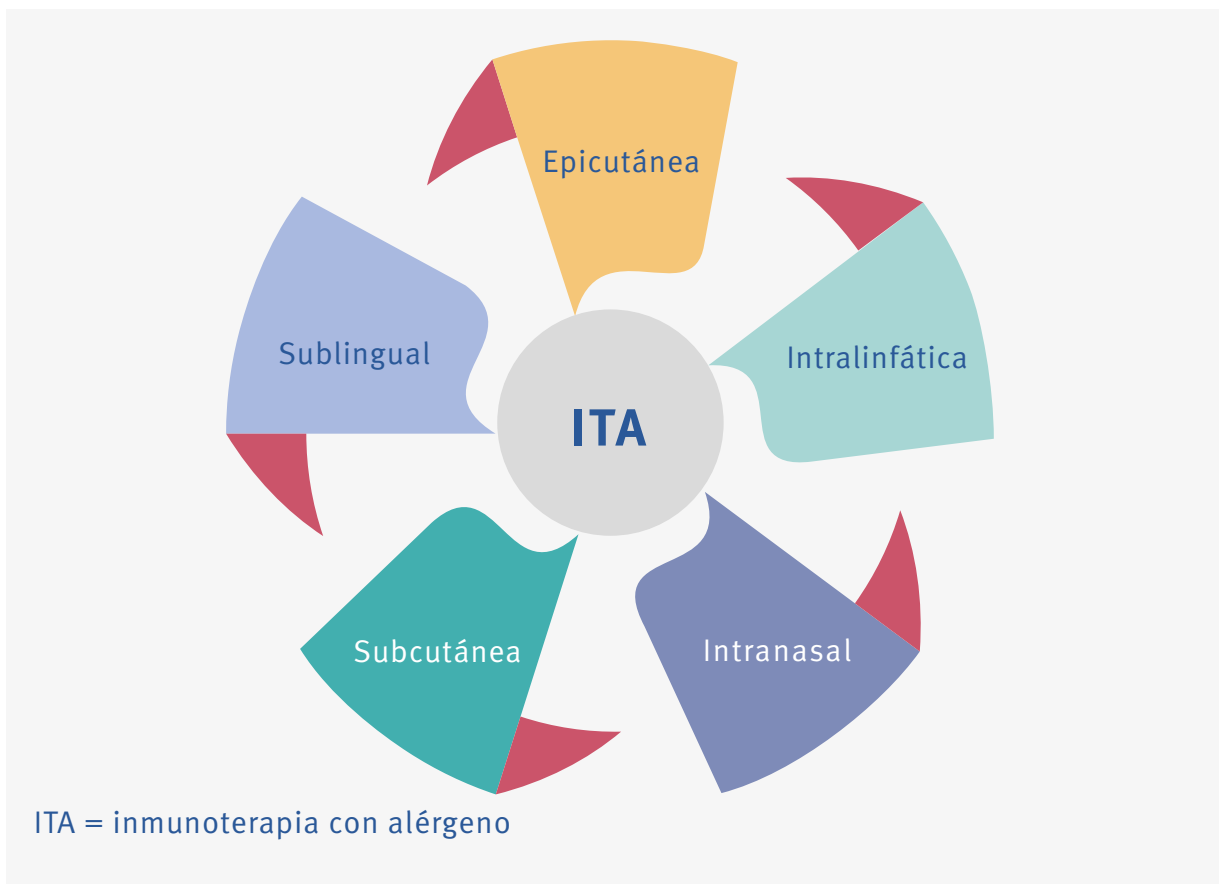

Hasta el momento no contamos comercialmente con los extractos alergénicos ni con los dispositivos utilizados en los ensayos clínicos donde se han empleado las rutas de administración comentadas. GUIMIT busca promover la investigación clínica en población mexicana.

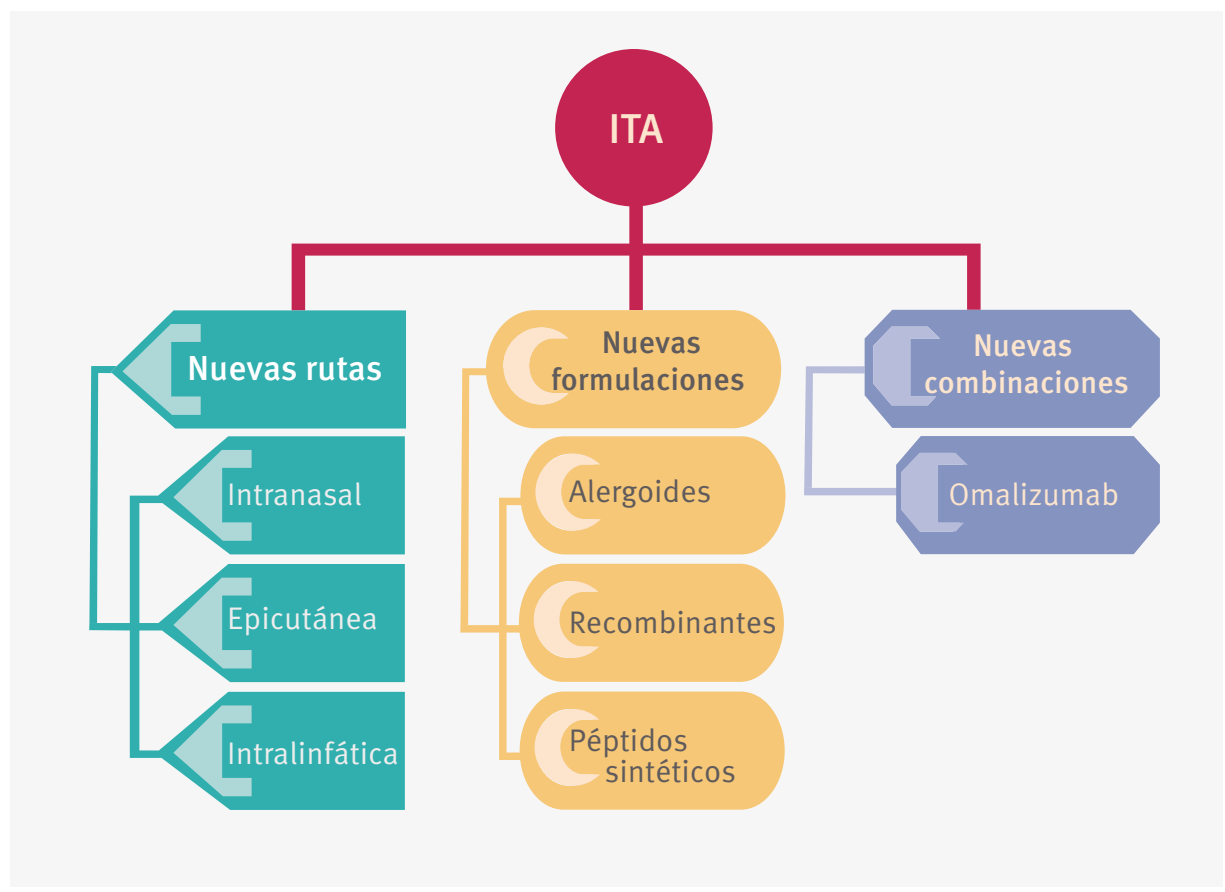

Figura 10.1. Nuevas vías de administración de la inmunoterapia alergénica: subcutánea, sublingual, epicutánea, intralinfática e intranasal.

Figura 10.2. Inmunoterapia con alérgenos: formulaciones y formas de administración diferentes a las clásicas. 


\subsection{Rinitis alérgica e inmunoterapia intralinfática}

En el paciente adolescente o adulto con RA monosensibilizado, la aplicación de ITIL en estudios con un diseño sólido han mostrado beneficio clínico en los pacientes: disminución de síntomas y de uso de medicamento, mejoría en la calidad de vida, además de que es muy segura. Las ventajas también incluyen un muy reducido número de aplicaciones (únicamente tres con intervalos de cuatro semanas), menor tiempo de duración (ocho semanas en total) y una muy considerable reducción en la cantidad de alérgeno que se administra (1/1000 de la dosis ITSC). El procedimiento se realiza mediante punción directa con aguja en un ganglio linfático inguinal y guiado por ultrasonido (figura 10.3); no se requiere sedación ni analgesia ya que ha sido referido como "menos doloroso que una venopunción".

GUIMIT no emite recomendación ni sugerencia ya que en México no se dispone de los extractos utilizados en otros países y no se han llevado a cabo estudios en la población nacional, por lo que GUIMIT promueve la realización de protocolos de investigación clínica en este sentido.

No existe evidencia científica suficiente que respalde la utilización de ITIL en población pediátrica con rinitis alérgica mono o polisensibilizada, ni en pacientes polisensibilizados. GUIMIT no emite ni recomendación ni sugerencia.

\subsection{Asma e inmunoterapia intralinfática}

No se han realizado estudios clínicos sobre la utilización de extractos alergénicos para ITIL en población pediátrica, adolescentes o adultos con el diagnóstico de asma alérgica. GUIMIT no emite recomendación ni sugerencia.

\subsection{Rinitis alérgica e inmunoterapia intranasal}

A finales del siglo XX, la administración de ITIN se propuso como alternativa a los pacientes con mala tolerancia a ITSC. Los ensayos clínicos demostraron adecuada eficacia y seguridad (en cuanto a reacciones alérgicas graves) de ITIN comparable con ITSC. Sin embargo, los pacientes presentaron menor adherencia al tratamiento debido a los efectos adversos locales asociados con dicha ruta de administración. En México no se dispone de los extractos utilizados ni de los dispositivos para su administración.

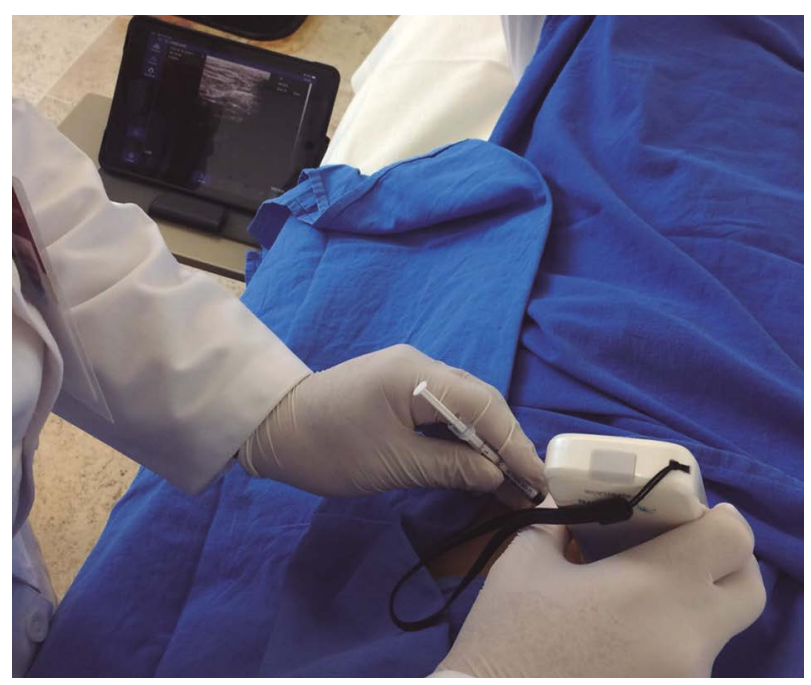

Figura 10.3. Administración de una dosis de inmunoterapia intralinfática en el primer estudio mexicano con esta modalidad. Cortesía del doctor José Luis Gálvez. 
GUIMIT sugiere no utilizar ITIN en pacientes con mala tolerancia a ITSC, en quienes deberá considerares ITSL.

\subsection{Rinitis alérgica e inmunoterapia epicutánea}

En el paciente con RA polisensibilizado (pediátrico, adolescente o adulto), la aplicación de ITEP ha mostrado beneficio clínico: disminución de síntomas y de uso de medicamento, mejoría en calidad de vida y seguridad. Se utilizan parches adheribles que contienen los alérgenos, manteniéndolos en contacto directo con la epidermis de los antebrazos entre ocho y 48 horas; la aplicación es semanal (figura 10.4). GUIMIT sugiere utilizar ITEP en el paciente con RA sensibilizado a polen de pastos (baja calidad de evidencia). En México actualmente no contamos con extractos ni con el dispositivo para su administración.

GUIMIT estimula la promoción de la realización de protocolos de investigación clínica con ITEP en población mexicana. No existe evidencia científica que respalde la utilización de extractos alergénicos para ITEP en población pediátrica, adolescentes o adultos con diagnóstico de RA polisensibilizados a extractos no homólogos, ni en pacientes con diagnóstico de asma alérgica. $\mathrm{Al}$ respecto no se han realizado estudios clínicos.

\subsection{ITA con alérgenos recombinantes}

Los avances en tecnología de ADN recombinante han permitido el desarrollo de alérgenos recombinantes sintetizados únicamente con moléculas alergénicas. Estos son equiparables a sus homólogos naturales en cuanto a inmunogenicidad, aunque su alergenicidad está reducida ya que son estructuras muy pequeñas. En los últimos años se ha demostrado la eficacia y seguridad de alérgenos recombinantes en la administración de ITSC.

GUIMIT sugiere utilizar ITSC con alérgenos recombinantes en adolescentes o adultos con alergia respiratoria, si bien actualmente en México no se comercializan extractos para su administración.

No existe evidencia científica que respalde la utilización de ITSC con alérgenos recombinantes en población pediátrica, que promete ser una variante con mejor perfil

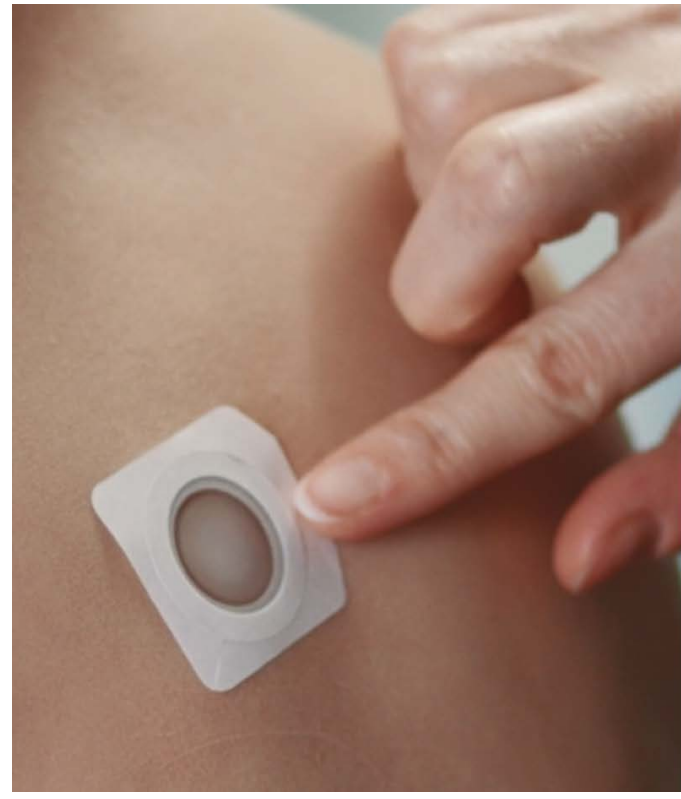

http://www.revistaalergia.mx

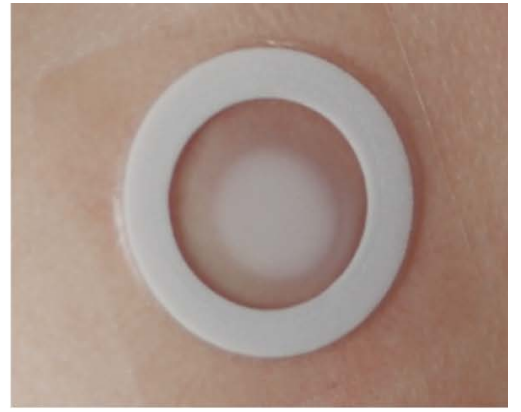

Figura 10.4. Aplicación de parche de inmunoterapia epicutánea con cacahuate. Viaskin Peanut@ (2018, DBV Technologies) y la inmunoterapia epicutánea están en investigación clínica y no han sido aprobados para su comercialización dentro o fuera de Estados Unidos. La fotografía se reproduce con permiso de DBV Technologies. 
de seguridad. No se han realizado estudios clínicos. En el cuadro 10.2 se presenta un resumen de las ventajas y desventajas para las vías de administración actuales y en investigación para la ITA.

\subsection{Administración concomitante de omalizumab e ITA}

La utilización de omalizumab concomitantemente a la administración de ITSC (sobre todo durante la fase de incremento de dosis, las pautas rápidas o ultrarrápidas) ha demostrado seguridad, eficacia y mejor tolerancia a la ITSC.

GUIMIT sugiere utilizar omalizumab en pacientes $>6$ años con alergia a veneno de himenópteros y mala tolerancia a la administración de VIT (presencia de RS) o con alergia respiratoria y mala tolerancia a la administración de ITSC (presencia de RS).

\subsection{Inmunoterapia con extracto de látex}

La inmunoterapia con látex fue considerada en el scope para la realización de GUIMIT, sin embargo, ninguna de las tres GM emite recomendación sobre su uso. Aunque existen inconsistencias en los datos epidemiológicos reportados sobre alergia al látex, esta afecta principalmente a población en riesgo: portadores de malformación congénita, en particular mielomeningocele $(>25 \%),{ }^{107}$ personal de salud $(10-30 \%),{ }^{108}$ y trabajadores del caucho. GUIMIT recomienda la utilización de material libre de látex en pacientes con factores de riesgo y perfil positivo de sensibilización alérgica.
Se considera punto de buena práctica promover la realización de protocolos de investigación clínica en población pediátrica mexicana

\begin{tabular}{|c|c|c|c|c|}
\hline Ruta & Uso clínico & $\begin{array}{l}\text { Alérgenos } \\
\text { (ejemplos) }\end{array}$ & Ventajas & Desventaja \\
\hline ITSC & $\begin{array}{l}\text { - Alergia respiratoria. } \\
\text { - Alergia a picadura } \\
\text { de himenóptero }\end{array}$ & $\begin{array}{l}\text { - Intradomiciliarios (ácaros, } \\
\text { cucaracha, hongos, animales) } \\
\text { - Extradomiciliarios (árboles, } \\
\text { pastos, malezas) }\end{array}$ & $\begin{array}{l}\text { - Administración mensual } \\
\text { - Muy eficaz } \\
\text { - Efecto a largo plazo }\end{array}$ & $\begin{array}{l}\text { - Reacciones locales y } \\
\text { sistémicas } \\
\text { - Duración administración } \\
\text { > } 3 \text { años } \\
\text { - Costo }\end{array}$ \\
\hline ITSL & $\begin{array}{l}\text { - Alergia respiratoria } \\
\text { - Alergia al látex }\end{array}$ & $\begin{array}{l}\text { - Intradomiciliarios (ácaros, } \\
\text { cucaracha, hongos, animales) } \\
\text { - Extradomiciliarios (árboles, } \\
\text { pastos, malezas) }\end{array}$ & $\begin{array}{l}\text { - Muy segura } \\
\text { - Muy eficaz } \\
\text { - Efecto a largo plazo }\end{array}$ & $\begin{array}{l}\text { - Administración diaria } \\
\text { - Duración administración } \\
>3 \text { años } \\
\text { - Costo }\end{array}$ \\
\hline ITEP & $\begin{array}{l}\text { - Alergia respiratoria } \\
\text { - Alergia alimentaria }\end{array}$ & $\begin{array}{l}\text { - Pastos } \\
\text { - Leche, huevo, cacahuate }\end{array}$ & $\begin{array}{l}\text { - Administración semanal } \\
\text { - Administración diaria en } \\
\text { alimentos }\end{array}$ & $\begin{array}{l}\text { - Efecto adverso local. } \\
\text { - Duración administración } \\
\text { por años }\end{array}$ \\
\hline ITIL & - Alergia respiratoria & $\begin{array}{l}\text { - Pastos } \\
\text { - Abedul } \\
\text { - Gato }\end{array}$ & $\begin{array}{l}\text { - Duración de la adminis- } \\
\text { tración } 8 \text { semanas } \\
\text { - Más económica }\end{array}$ & $\begin{array}{l}\text { - Aplicación por médico } \\
\text { capacitado } \\
\text { - Equipo (ultrasonido) }\end{array}$ \\
\hline ITIN & - Alergia respiratoria & $\begin{array}{l}\text { - Pastos } \\
\text { - Malezas } \\
\text { - Ácaros }\end{array}$ & - Muy segura & $\begin{array}{l}\text { - Efectos adversos locales } \\
\text { molestos } \\
\text { - Mal apego terapéutico }\end{array}$ \\
\hline ITO & - Alergia alimentaria & - Leche, huevo, cacahuate & $\begin{array}{l}\text { - Segura } \\
\text { - Aumenta umbral de } \\
\text { síntomas } \\
\text { - Muy económica }\end{array}$ & - Efecto durante ITA \\
\hline
\end{tabular}

ITA = inmunoterapia con alérgeno, ITSC = inmunoterapia subcutánea, ITSL = inmunoterapia sublingual, ITEP = inmunoterapia epicutánea, $I T I L=$ inmunoterapia intralinfática, ITIN = inmunoterapia intranasal, ITO = inmunoterapia ora $\left.\right|^{2}$ 
En cuanto a ITA al látex, los estudios que reportan eficacia datan de hace más de una década ${ }^{109,110}$ o son de baja calidad. ${ }^{5} \mathrm{Al}$ igual que para ITA, a mayor dosis mayor eficacia, pero también mayor riesgo de anafilaxia: uno de los pocos reportes de anafilaxia con ITSL fue con un extracto de látex. ${ }^{111}$ Además, en este momento no contamos con un extracto estandarizado en México. Por ello, GUIMIT sugiere solo emplear ITA con extracto de látex en el contexto de investigación clínica, de preferencia ITSL.

\subsection{Conclusión}

En la actualidad, el estudio sobre las enfermedades alérgicas, desde los mecanismos moleculares hasta la clínica, y el desarrollo incesante de la tecnología en información y comunicación permiten que todos los días haya innovaciones con verdadero impacto en su entendimiento. GUIMIT considera punto de buena práctica la actualización permanente de los profesionales de la salud, la promoción de la educación continua y la creación de redes de intercambio académico.

\section{Capítulo 11. Aplicación de GUIMIT 2019: facilitadores, obstáculos y diseminación}

Para que los conceptos expresados en GUIMIT 2019 logren el objetivo de homogeneizar la práctica de la ITA o VIT en México, se pueden indicar varios pasos:

- Dar a conocer la existencia de la guía.

- Promover el conocimiento del contenido de GUIMIT 2019.

- Implementar GUIMIT 2019.

Conforme a la experiencia con GUIMIT 2011, es claro que se puede facilitar la difusión de la guía a diferentes niveles:

- Publicándola en el órgano de la especialidad de mayor difusión en Latinoamérica, Revista Alergia México.

- Creando expectativa de su lanzamiento con una encuesta a todos los alergólogos (figura A1) acerca de puntos controversiales.

- Presentándola en foros nacionales de la especialidad.

- Promoviéndola con los directores de los centros formadores, pidiéndoles su aportación al contenido desde el primer paso del desarrollo de la guía.

- Promoviéndola entre los residentes de alergia, proponiendo a CONICA algunas preguntas acerca de GUIMIT para ser incluidas en el examen de certificación de la especialidad.

Todos estos puntos están en proceso al momento de la publicación del presente documento.

Entre los obstáculos, en primer lugar, se puede mencionar el conocido rechazo al cambio, inherente al ser humano. Además, las dosis propuestas en GUIMIT contienen mayor cantidad de alérgeno que las utilizadas actualmente en algunos lugares. Aumentar la concentración del tratamiento de mantenimiento aumentará el costo y también las reacciones adversas. Estos escenarios pueden causar rechazo. Por este motivo se optó por presentar todas las opciones de extractos alergénicos, tanto los estandarizados como los no estandarizados, los internacionales y nacionales, entendiendo que las segundas opciones son las de menor costo, aunque no siempre de calidad semejante a las de alto costo. 
Aunque el costo se podría elevar al usar alérgenos de mayor calidad o de mayor dosis terapéutica recomendada, se ha documentado que el manejo adecuado de ITSC e ITSL finalmente reduce el costo a largo plazo de la enfermedad alérgica ${ }^{12,113}$ y la frecuencia de crisis asmáticas. ${ }^{35}$

GUIMIT contiene varias herramientas que podrían contribuir en su implementación. En los capítulos 4 a 6 se apoya en cuadros y figuras para la explicación de la dosificación. Además, contiene cuadros-resumen para facilitar la presentación gráfica de sus conceptos más importantes, por ejemplo, para diapositivas durante presentaciones en foros.

En la actualidad, en México carecemos de herramientas para vigilar su aplicación y auditar a los centros, sin embargo, será gratificante y estimulante observar el efecto deseado en el paciente con ITA apropiada, ITSC, ITSL o VIT.

\section{Financiamiento}

GUIMIT se desarrolló como una iniciativa académica de expertos en ITA, estimulada por los colegios nacionales de la especialidad, los cuales, sin embargo, no tuvieron injerencia en el contenido ni realizaron aportaciones económicas. Para cubrir los gastos de la reunión presencial y de la publicación de GUIMIT se recibió apoyo de ALK, Sanfer, Inmunotek, Alerquim, Mylan, Senosiain, Laboratorio de Diagnóstico Molecular, Pisa de México y Glenmark México. En la parte inicial de GUIMIT, todos los autores declararon la existencia o no de potenciales conflictos de intereses.

\section{Agradecimientos}

A los doctores Martín Bedolla Barajas y Teresa Plascencia Sánchez, por su participación en parte del capítulo 7, y a quien nos asesoró en los aspectos legales del capítulo 7, que prefiere quedar en anonimato. De igual forma, nuestra gratitud a Alondra RodríguezMonroy y Miriam Rodríguez.

\section{Referencias}

1. Larenas-Linnemann D, Ortega-Martell JA, Del Río-Navarro B, Rodríguez-Pérez N, Arias-Cruz A, Estrada A, et al. Guía Mexicana de Práctica Clínica de Inmunoterapia 2011. Rev Alerg Mex. 2011;58(1):3-75.

2. Esposito S, Isidori C, Pacitto A, Salvatori C, Sensi L, Frati F, et al. Epicutaneous immunotherapy in rhinoconjunctivitis and food allergies: a review of the literature. J Transl Med. 2018;16(1):329. DOI: 10.1186/ s12967-018-1701-6

3. Senti G, Freiburghaus AU, Larenas-Linnemann D, Hoffmann HJ, Patterson AM, Klimek L, et al. Intralymphatic immunotherapy: update and unmet needs. Int Arch Allergy Immunol. 2019;178(2):141149. DOI: $10.1159 / 000493647$

4. Brouwers MC, Kho ME, Browman GP, Burgers JS, Cluzeau F, Feder G, et al. AGREE II: advancing guideline development, reporting and evaluation in health care. CMAJ. 2010;63(12):1308-1311. DOI: 10.1503/cmaj.090449

5. Larenas-Linnemann DES, Antolin-Amerigo D, Parisi C, Nakonechna A, Luna-Pech JA, Wedi B, et al. National clinical practice guidelines for allergen immunotherapy: an international assessment applying AGREE-II. Allergy. 2018;73(3):664-672. DOI: 10.1111/all.13316

6. Roberts G, Pfaar O, Akdis CA, Ansotegui IJ, Durham SR, Gerth van Wijk R, et al. EAACl Guidelines on allergen immunotherapy: allergic rhinoconjunctivitis. Allergy. 2018;73(4):765-798. DOI: 10.1111/all.13317

7. Halken S, Larenas-Linnemann D, Roberts G, Calderon MA, Angier E, Pfaar O, et al. EAACI guidelines on allergen immunotherapy: Prevention of allergy. Pediatr Allergy Immunol. 2017;28(8):728-745. DOI: 10.1111/pai.12807 
8. Pfaar O, Bachert C, Bufe A, Buhl R, Ebner C, Eng P, et al. Guideline on allergen-specific immunotherapy in IgE-mediated allergic diseases: S2k Guideline of the German Society for Allergology and Clinical Immunology (DGAKI), the Society for Pediatric Allergy and Environmental Medicine (GPA), the Medical Association of German Allergologists (AeDA), the Austrian Society for Allergy and Immunology (OGAl), the Swiss Society for Allergy and Immunology (SGAI), the German Society of Dermatology (DDG), the German Society of Oto-Rhino-Laryngology, Head and Neck Surgery (DGHNO-KHC), the German Society of Pediatrics and Adolescent Medicine (DGKJ), the Society for Pediatric Pneumology (GPP), the German Respiratory Society (DGP), the German Association of ENT Surgeons (BV-HNO), the Professional Federation of Paediatricians and Youth Doctors (BVKJ), the Federal Association of Pulmonologists (BDP) and the German Dermatologists Association (BVDD). Allergo J Int. 2014;23(8):282-319. DOI: 10.1007/ S40629-014-0032-2

9. Cox L, Nelson H, Lockey R, Calabria C, Chacko T, Finegold I, et al. Allergen immunotherapy: a practice parameter third update. J Allergy Clin Immunol. 2011;127(Suppl 1):S1-S55. Disponible en: https:// www.aaaai.org/Aaaai/media/MediaLibrary/PDF\%20Documents/Practice\%20and\%2oParameters/ Allergen-immunotherapy-Jan-2011.pdf

10. Heinzerling L, Mari A, Bergmann KC, Bresciani M, Burbach G, Darsow U, et al. The skin prick testEuropean standards. Clin Transl Allergy. 2013;3(1):3. DOI: 10.1186/2045-7022-3-3

11. Rueff F, Bergmann KC, Brockow K, Fuchs T, Grubl A, Jung K, et al. [Skin tests for diagnostics of allergic immediate-type reactions. Guideline of the German Society for Allergology and Clinical Immunology]. Pneumologie. 2011;65(8):484-495. DOI: 10.1055/s-0030-1256476

12. Bernstein IL, Li JT, Bernstein DI, Hamilton R, Spector SL, Tan R, et al. Allergy diagnostic testing: an updated practice parameter. Ann Allergy Asthma Immunol. 2008;100(Suppl 3):S1-S148.

13. Larenas-Linnemann D, Luna-Pech JA, Mosges R. Debates in allergy medicine: allergy skin testing cannot be replaced by molecular diagnosis in the near future. World Allergy Organ J. 2017;10(1):32. DOI: 10.1186/s40413-017-0164-1

14. Larenas-Linnemann DE, Fogelbach GA, Alatorre AM, Cruz AA, Colin DD, Pech JA, et al. Patterns of skin prick test positivity in allergic patients: usefulness of a nationwide SPT chart review. Allergol Immunopathol (Madr). 2011;39(6):330-336. DOI: 10.1016/j.aller.2010.09.006

15. Larenas-Linnemann D, Michels A, Dinger H, Shah-Hosseini K, Mosges R, Arias-Cruz A, et al. Allergen sensitization linked to climate and age, not to intermittent-persistent rhinitis in a cross-sectional cohort study in the (sub)tropics. Clin Transl Allergy. 2014;4:20. DOI: 10.1186/2045-7022-4-20

16. Canonica GW, Baena-Cagnani CE, Bousquet), BousquetPJ, Lockey RF, Malling HJ, et al. Recommendations for standardization of clinical trials with Allergen Specific Immunotherapy for respiratory allergy. A statement of a World Allergy Organization (WAO) taskforce. Allergy. 2007;62(3):317-324. DOI: 10.1111/j.1398-9995.2006.01312.x

17. Nassiri M, Babina M, Dolle S, Edenharter G, Rueff F, Worm M. Ramipril and metoprolol intake aggravate human and murine anaphylaxis: evidence for direct mast cell priming. J Allergy Clin Immunol. 2015;135(2):491-499. DOI: 10.1016/j.jaci.2014.09.004

18. Larenas-Linnemann D, Esch RE, Guidos-Fogelbach G, Rodríguez-Pérez N. A comparison of in vitro potency between European and Mexican allergen extracts and US (CBER/FDA) reference extracts. Allergol Immunopathol (Madr). 2010;38(4):170-173. DOI: 10.1016/j.aller.2009.11.005

19. Oppenheimer J, Nelson HS. Skin testing: a survey of allergists. Ann Allergy Asthma Immunol. 2006;96(2 Suppl 1):S6-S12.

20. Nugent JS, Quinn JM, McGrath CM, Hrncir DE, Boleman WT, Freeman TM. Determination of the incidence of sensitization after penicillin skin testing. Ann Allergy Asthma Immunol. 2003;90(4):398-403. DOI: 10.1016/S1081-1206(10)61823-6

21. Jensen-Jarolim E, Jensen AN, Canonica GW. Debates in allergy medicine: molecular allergy diagnosis with ISAC will replace screenings by skin prick test in the future. World Allergy Organ J. 2017;10(1):33. DOI: $10.1186 /$ S40413-017-0162-3

22. Matricardi PM, Kleine-Tebbe J, Hoffmann HJ, Valenta R, Hilger C, Hofmaier S, et al. EAACI molecular allergology user's guide. Pediatr Allergy Immunol. 2016;27(Suppl 23):1-250. DOI: 10.1111/pai.12563 
23. Boyce JA, Assa'ad A, Burks AW, Jones SM, Sampson HA, Wood RA, et al. Guidelines for the diagnosis and management of food allergy in the United States: summary of the NIAID-sponsored expert panel report. Nutr Res. 2011;31(1):61-75. DOI: 10.1016/j.nutres.2011.01.001

24. Canonica GW, Ansotegui IJ, Pawankar R, Schmid-Grendelmeier P, van Hage M, Baena-Cagnani CE, et al. A WAO-ARIA-GA²LEN consensus document on molecular-based allergy diagnostics. World Allergy Organ J. 2013;6(1):17. DOI: 10.1186/1939-4551-6-17

25. Hoffmann HJ, Santos AF, Mayorga C, Nopp A, Eberlein B, et al. The clinical utility of basophil activation testing in diagnosis and monitoring of allergic disease. Allergy. 2015;70(11):1393-1405. DOI: 10.1111/all.12698

26. Wang J, Godbold JH, Sampson HA. Correlation of serum allergy (IgE) tests performed by different assay systems. J Allergy Clin Immunol. 2008;121(5):1219-1224. DOI: 10.1016/j.jaci.2007.12.1150

27. Hamilton RG, Williams PB; Specific IgE Testing Task Force of the American Academy of Allergy A, Immunology, American College of Allergy, Asthma, and Immunology. Human IgE antibody serology: a primer for the practicing North American allergist/immunologist. J Allergy Clin Immunol. 2010;126(1):3338. DOI: 10.1016/j.jaci.2010.03.014

28. Heffner KL, Kiecolt-Glaser JK, Glaser R, Malarkey WB, Marshall GD. Stress and anxiety effects on positive skin test responses in young adults with allergic rhinitis. Ann Allergy Asthma Immunol. 2014;113(1):13-18. DOI: 10.1016/j.anai.2014.03.008

29. Brandström J, Nopp A, Johansson SG, Lilja G, Sundqvist AC, Borres MP, et al. Basophil allergen threshold sensitivity and component-resolved diagnostics improve hazelnut allergy diagnosis. Clin Exp Allergy. 2015;45(9):1412-1418. DOI: 10.1111/cea.12515

30. Moreno C, Justicia JL, Quiralte J, Moreno-Ancillo A, Iglesias-Cadarso A, Torrecillas M, et al. Olive, grass or both? Molecular diagnosis for the allergen immunotherapy selection in polysensitized pollinic patients. Allergy. 2014;69(10):1357-1363. DOI: 10.1111/all.12474

31. Sastre J, Landivar ME, Ruiz-Garcia M, Andregnette-Rosigno MV, Mahillo I. How molecular diagnosis can change allergen-specific immunotherapy prescription in a complex pollen area. Allergy. 2012;67(5):709711. DOI: $10.1111 /$ j.1398-9995.2012.02808.x

32. Bousquet J, Anto JM, Akdis M, Auffray C, Keil T, et al. Paving the way of systems biology and precision medicine in allergic diseases: the MeDALL success story: mechanisms of the Development of ALLergy; EU FP7-CP-IP; Project No: 261357; 2010-2015. Allergy. 2016;71(11):1513-1525. DOI: 10.1111/all.12880

33. Letrán A, Espinazo M, Moreno F. Measurement of IgE to pollen allergen components is helpful in selecting patients for immunotherapy. Ann Allergy Asthma Immunol. 2013;111(4):295-297. DOI: 10.1016/j.anai.2013.07.005

34. Werfel T, Asero R, Ballmer-Weber BK, Beyer K, Enrique E, Knulst AC, et al. Position paper of the EAACl: food allergy due to immunological cross-reactions with common inhalant allergens. Allergy. 2015;70(9):1079-1090. DOI: 10.1111/all.12666

35. Virchow JC, Backer V, Kuna P, Prieto L, Nolte H, Villesen HH, et al. Efficacy of a house dust mite sublingual allergen immunotherapy tablet in adults with allergic asthma: a randomized clinical trial. JAMA. 2016;315(16):1715-1725. DOI: 10.1001/jama.2016.3964

36. Shamji MH, Durham SR. Mechanisms of allergen immunotherapy for inhaled allergens and predictive biomarkers. J Allergy Clin Immunol. 2017;140(6):1485-1498. DOI: 10.1016/j.jaci.2017.10.010

37. Sampson HA, O’Mahony L, Burks AW, Plaut M, Lack G, Akdis CA. Mechanisms of food allergy. J Allergy Clin Immunol. 2018;141(1):11-19. DOI: 10.1016/j.jaci.2017.11.005

38. Burks AW, Calderon MA, Casale T, Cox L, Demoly P, Jutel M, et al. Update on allergy immunotherapy: American Academy of Allergy, Asthma \& Immunology/European Academy of Allergy and Clinical Immunology/PRACTALL consensus report. J Allergy Clin Immunol. 2013;131(5):1288-1296. DOI: 10.1016/j.jaci.2013.01.049

39. Bousquet J, Lockey R, Malling HJ. Allergen immunotherapy: therapeutic vaccines for allergic diseases. A WHO position paper. J Allergy Clin Immunol. 1998;102(4 Pt 1):558-562.

40. Canonica GW, Cox L, Pawankar R, Baena-Cagnani CE, Blaiss M, Bonini S, et al. Sublingual immunotherapy: World Allergy Organization position paper 2013 update. World Allergy Organ J. 2014;7(1):6. DOI: 10.1186/1939-4551-7-6 
41. Palomares 0 , Akdis $M$, Martin-Fontecha $M$, Akdis CA. Mechanisms of immune regulation in allergic diseases: the role of regulatory T and B cells. Immunol Rev. 2017;278(1):219-236. DOI: 10.1111/imr.12555

42. Varricchi G, Harker J, Borriello F, Marone G, Durham SR, Shamji MH. T follicular helper (Tfh) cells in normal immune responses and in allergic disorders. Allergy. 2016;71(8):1086-1094. DOI: 10.1111/ all.12878

43. Sage PT, Sharpe AH. T follicular regulatory cells. Immunol Rev. 2016;271(1):246-259. DOI: 10.1111/imr.12411

44. Shamji MH, Kappen JH, Akdis M, Jensen-Jarolim E, Knol EF, Kleine-Tebbe J, et al. Biomarkers for monitoring clinical efficacy of allergen immunotherapy for allergic rhinoconjunctivitis and allergic asthma: an EAACI position paper. Allergy. 2017;72(8):1156-1173. DOI: 10.1111/all.13138

45. Weber RW. Guidelines for using pollen cross-reactivity in formulating allergen immunotherapy. J Allergy Clin Immunol. 2008;122(1):219-221. DOI: 10.1016/j.jaci.2008.05.034.

46. Esch RE. Allergen immunotherapy: what can and cannot be mixed? J Allergy Clin Immunol. 2008;122(3):659-660. DOI: 10.1016/j.jaci.2008.07.018

47. Rodríguez-Pérez N, Ambriz-Moreno MJ, Pizarro-Esquivel U. Reacciones sistémicas no fatales por inmunoterapia y pruebas cutáneas. Rev Alerg Mex. 2002;49(3):69-73.

48. González-Díaz SN, De la Rosa-López JH, Arias-Cruz A, Macías-Weinmann A, Herrera-Castro D, RodríguezOrtiz P, et al. Reacciones sistémicas relacionadas a la inmunoterapia con alergenos en Monterrey, México. Rev Alerg Mex. 2011;58(2):79-86.

49. Epstein TG, Liss GM, Murphy-Berendts K, Bernstein DI. Risk factors for fatal and nonfatal reactions to subcutaneous immunotherapy: national surveillance study on allergen immunotherapy (2008-2013). Ann Allergy Asthma Immunol. 2016;116(4):354-359. DOI: 10.1016/j.anai.2016.02.001

50. Bernstein DI, Wanner M, Borish L, Liss GM, Immunotherapy Committee, American Academy of Allergy, Asthma and Immunology. Twelve-year survey of fatal reactions to allergen injections and skin testing: 1990-2001. J Allergy Clin Immunol. 2004;113(6):1129-1136. DOI: 10.1016/j.jaci.2004.02.006

51. Casanovas M, Martin R, Jiménez C, Caballero R, Fernández-Caldas E. Safety of an ultra-rush immunotherapy build-up schedule with therapeutic vaccines containing depigmented and polymerized allergen extracts. Int Arch Allergy Immunol. 2006;139(2):153-158. DOI: 10.1159/000090392

52. Schaffer FM, Naples AR, Ebeling M, Hulsey TC, Garner LM. The safety of self-administered allergen immunotherapy during the buildup and maintenance phases. Int Forum Allergy Rhinol. 2015;5(2):149156. DOI: 10.1002 /alr.21443

53. Consejo de Salubridad General. Modelo de seguridad del paciente. México: Consejo de Salubridad General; 2015 .

54. Malling HJ. Minimising the risks of allergen-specific injection immunotherapy. Drug Saf. 2000;23(4):323332. DOI: 10.2165/00002018-200023040-00005

55. Amin HS, Liss GM, Bernstein DI. Evaluation of near-fatal reactions to allergen immunotherapy injections. J Allergy Clin Immunol. 2006;117(1):169-175. DOI: 10.1016/j.jaci.2005.10.010

56. De Groot H, Bijl A. Anaphylactic reaction after the first dose of sublingual immunotherapy with grass pollen tablet. Allergy. 2009;64(6):963-964. DOI: 10.1111/j.1398-9995.2009.01998.x

57. Cochard MM, Eigenmann PA. Sublingual immunotherapy is not always a safe alternative to subcutaneous immunotherapy. J Allergy Clin Immunol. 2009;124(2):378-379. DOI: 10.1016/j.jaci.2009.04.040

58. Nichani JR, De Carpentier J. Safety of sublingual grass pollen immunotherapy after anaphylaxis. J Laryngol Otol. 2009;123(6):683-684. DOI: 10.1017/Soo22215108002879

59. Greenhawt M, Oppenheimer J, Nelson M, Nelson H, Lockey R, Lieberman P, et al. Sublingual immunotherapy: a focused allergen immunotherapy practice parameter update. Ann Allergy Asthma Immunol. 2017;118(3):276-282. DOI: 10.1016/j.anai.2016.12.009

6o. Masuyama K, Goto M, Takeno S, Ohta N, Okano M, Kamijo A, et al. Guiding principles of sublingual immunotherapy for allergic rhinitis in Japanese patients. Auris Nasus Larynx. 2016;43(1):1-9. DOI: 10.1016/j.anl.2015.08.015

61. Ohashi-Doi K, Kito H, Du W, Nakazawa H, Ipsen H, Gudmann P, et al. Bioavailability of house dust mite allergens in sublingual allergy tablets is highly dependent on the formulation. Int Arch Allergy Immunol. 2017;174(1):26-34. DOI: 10.1159/000479693 
62. Scadding GW, Calderon MA, Shamji MH, Eifan AO, Penagos M, Dumitru F, et al. Effect of 2 years of treatment with sublingual grass pollen immunotherapy on nasal response to allergen challenge at 3 years among patients with moderate to severe seasonal allergic rhinitis: the GRASS randomized clinical trial. JAMA. 2017;317(6):615-625. DOI: 10.1001/jama.2016.21040

63. Larenas-Linnemann D, Esch R, Plunkett G, Brown S, Maddox D, Barnes C, et al. Maintenance dosing for sublingual immunotherapy by prominent European allergen manufacturers expressed in bioequivalent allergy units. Ann Allergy Asthma Immunol. 2011;107(5):448-458. DOI: 10.1016/j. anai.2011.07.001

64. Sander I, Fleischer C, Meurer U, Bruning T, Raulf-Heimsoth M. Allergen content of grass pollen preparations for skin prick testing and sublingual immunotherapy. Allergy. 2009;64(10):1486-1492. DOI: 10.1111/j.1398-9995.2009.02040.x

65. Larenas-Linnemann DE, Mösges R. Dosing of European sublingual immunotherapy maintenance solutions relative to monthly recommended dosing of subcutaneous immunotherapy. Allergy Asthma Proc. 2016;37(1):50-56. DOI: 10.2500/aap.2016.37.3907

66. Larenas-Linnemann D, Cruz AA, Gutiérrez IR, Rodriguez P, Shah-Hosseini K, Michels A, et al. European and Mexican vs US diagnostic extracts of Bermuda grass and cat in skin testing. Ann Allergy Asthma Immunol. 2011;106(5):421-428. DOI: 10.1016/j.anai.2010.11.020

67. Nolte H, Plunkett G, Grosch K, Larsen JN, Lund K, Bollen M. Major allergen content consistency of SQ house dust mite sublingual immunotherapy tablets and relevance across geographic regions. Ann Allergy Asthma Immunol. 2016;117(3):298-303. DOI: 10.1016/j.anai.2016.07.004

68. Durham SR, Yang WH, Pedersen MR, Johansen N, Rak S. Sublingual immunotherapy with once-daily grass allergen tablets: a randomized controlled trial in seasonal allergic rhinoconjunctivitis. J Allergy Clin Immunol. 2006;117(4):802-809. DOI: 10.1016/j.jaci.2005.12.1358

69. Didier A, Malling HJ, Worm M, Horak F, Jager S, Montagut A, et al. Optimal dose, efficacy, and safety of once-daily sublingual immunotherapy with a 5 -grass pollen tablet for seasonal allergic rhinitis. J Allergy Clin Immunol. 2007;120(6):1338-1345. DOI: 10.1016/j.jaci.2007.07.046

70. Valovirta E, Jacobsen L, Ljorring C, Koivikko A, Savolainen J. Clinical efficacy and safety of sublingual immunotherapy with tree pollen extract in children. Allergy. 2006;61(10):1177-1783. DOI: 10.1111/j.13989995.2006.01190.x

71. Skoner D, Gentile D, Bush R, Fasano MB, McLaughlin A, Esch RE. Sublingual immunotherapy in patients with allergic rhinoconjunctivitis caused by ragweed pollen. J Allergy Clin Immunol. 2010;125(3):660666. DOI: 10.1016/j.jaci.2009.12.931

72. Creticos PS, Esch RE, Couroux P, Gentile D, D’Angelo P, Whitlow B, et al. Randomized, double-blind, placebo-controlled trial of standardized ragweed sublingual-liquid immunotherapy for allergic rhinoconjunctivitis. J Allergy Clin Immunol. 2014;133(3):751-758. DOI: 10.1016/j.jaci.2013.10.041

73. Creticos PS, Maloney J, Bernstein DI, Casale T, Kaur A, Fisher R, et al. Randomized controlled trial of a ragweed allergy immunotherapy tablet in North American and European adults. J Allergy Clin Immunol. 2013;131(5):1342-1349. DOI: 10.1016/j.jaci.2013.03.019

74. Esch RE, Bush RK, Peden D, Lockey RF. Sublingual-oral administration of standardized allergenic extracts: phase 1 safety and dosing results. Ann Allergy Asthma Immunol. 2008;100(5):475-481. DOI: 10.1016/S1081-1206(10)60474-7

75. Bergmann KC, Demoly P, Worm M, Fokkens WJ, Carrillo T, Tabar Al, et al. Efficacy and safety of sublingual tablets of house dust mite allergen extracts in adults with allergic rhinitis. J Allergy Clin Immunol. 2014;133(6):1608-1614. DOI: 10.1016/j.jaci.2013.11.012

76. Demoly P, Okamoto Y, Yang WH, Devillier P, Bergmann KC. 300 IR HDM tablet: a sublingual immunotherapy tablet for the treatment of house dust mite-associated allergic rhinitis. Expert Rev Clin Immunol. 2016;12(11):1141-1151. DOI: 10.1080/1744666X.2016.1237288

77. Mosbech H, Canonica GW, Backer V, De-Blay F, Klimek L, Broge L, et al. SQ house dust mite sublingually administered immunotherapy tablet (ALK) improves allergic rhinitis in patients with house dust mite allergic asthma and rhinitis symptoms. Ann Allergy Asthma Immunol. 2015;114(2):134-140. DOI: 10.1016/j.anai.2014.11.015 
78. Matsuoka T, Bernstein DI, Masuyama K, Nolte H, Okamiya K, Seitzberg D, et al. Pooled efficacy and safety data for house dust mite sublingual immunotherapy tablets in adolescents. Pediatr Allergy Immunol. 2017;28(7):661-667. DOI: 10.1111/pai.12747

79. Henmar H, Frisenette SM, Grosch K, Nielsen K, Smith G, Sonderkaer S, et al. Fractionation of source materials leads to a high reproducibility of the SQ house dust mite SLIT-tablets. Int Arch Allergy Immunol. 2016;169(1):23-32. DOI: 10.1159/000444016

80. Haugaard L, Dahl R, Jacobsen L. A controlled dose-response study of immunotherapy with standardized, partially purified extract of house dust mite: clinical efficacy and side effects. J Allergy Clin Immunol. 1993;91(3):709-722. DOI: 10.1016/0091-6749(93)90190-Q

81. Larenas-Linnemann D. Direct comparison of efficacy of sublingual immunotherapy tablets for rhinoconjunctivitis. Ann Allergy Asthma Immunol. 2016;116(4):274-286. DOI: 10.1016/j.anai.2016.02.008

82. Okamoto Y, Fujieda S, Okano M, Yoshida Y, Kakudo S, Masuyama K. House dust mite sublingual tablet is effective and safe in patients with allergic rhinitis. Allergy. 2017;72(3):435-443. DOI: 10.1111/all.12996

83. Larenas-Linnemann D, Matta JJ, Shah-Hosseini K, Michels A, Mösges R. Skin prick test evaluation of Dermatophagoides pteronyssinus diagnostic extracts from Europe, Mexico, and the United States. Ann Allergy Asthma Immunol. 2010;104(5):420-425. DOI: 10.1016/j.anai.2010.03.009

84. Moreno-Ancillo A, Moreno C, Ojeda P, Domínguez C, Barasona MJ, García-Cubillana A, et al. Efficacy and quality of life with once-daily sublingual immunotherapy with grasses plus olive pollen extract without updosing. J Investig Allergol Clin Immunol. 2007;17(6):399-405.

85. Marogna M, Spadolini I, Massolo A, Zanon P, Berra D, Chiodini E, et al. Effects of sublingual immunotherapy for multiple or single allergens in polysensitized patients. Ann Allergy Asthma Immunol. 2007;98(3):274-280. DOI: 10.1016/S1081-1206(10)60718-1

86. Swamy RS, Reshamwala N, Hunter T, Vissamsetti S, Santos CB, Baroody FM, et al. Epigenetic modifications and improved regulatory T-cell function in subjects undergoing dual sublingual immunotherapy. J Allergy Clin Immunol. 2012;130(1):215-224. DOI: 10.1016/j.jaci.2012.04.021

87. Smits HH, Engering A, van Der Kleij D, De Jong EC, Schipper K, van Capel TM, et al. Selective probiotic bacteria induce IL-10-producing regulatory $T$ cells in vitro by modulating dendritic cell function through dendritic cell-specific intercellular adhesion molecule 3-grabbing nonintegrin. J Allergy Clin Immunol. 2005;115(6):1260-1267. DOI: 10.1016/j.jaci.2005.03.036

88. Tankersley MS, Ledford DK. Stinging insect allergy: state of the art 2015. J Allergy Clin Immunol Pract. 2015;3(3):315-322. DOI: 10.1016/j.jaip.2015.03.012

89. Patel S, Ledford D. Killer Insects: Who is at risk for anaphylaxis? Curr Treat Options Allergy. 2016;3(3):235242. DOI: $10.1007 / \mathrm{S} 40521-016-0086-0$

90. Calabria CW, Hauswirth DW, Rank M, Sher L, Larenas-Linnemann D. American Academy of Asthma, Allergy \& Immunology membership experience with venom immunotherapy in chronic medical conditions and pregnancy, and in young children. Allergy Asthma Proc. 2017;38(2):121-129. DOI: 10.2500/aap.2017.38.4024

91. Pérez-Vanzzini R, González-Díaz SN, Arias-Cruz A, Palma-Gómez S, Yong-Rodríguez A, Gutierrez-Mujica J, et al. Hipersensibilidad a la picadura de mosquito manifestada como síndrome de Skeeter. Rev Alerg Mex. 2015;62(1):83-87. DOI: 10.29262/ram.v62i1.62

92. Peng Z, Xu WW, Sham Y, Lam H, Sun D, Cheng L, et al. Mosquito salivary allergen Aed a 3: cloning, comprehensive molecular analysis, and clinical evaluation. Allergy. 2016;71(5):621-628. DOI: 10.1111/ all.12812

93. Dhami S, Nurmatov U, Arasi S, Khan T, Asaria M, Zaman H, et al. Allergen immunotherapy for allergic rhinoconjunctivitis: a systematic review and meta-analysis. Allergy. 2017;72(11):1597-1631. DOI: 10.1111/all.13201

94. Celi G, Brusca I, Scala E, Villalta D, Pastorello E, Farioli L, et al. House dust mite allergy in Italy-Diagnostic and clinical relevance of Der p 23 (and of minor allergens): a real-life, multicenter study. Allergy. 2019. DOI: $10.1111 /$ all.13776

95. Turkeltaub PC, Campbell G, Mosimann JE. Comparative safety and efficacy of short ragweed extracts differing in potency and composition in the treatment of fall hay fever. Use of allergenically bioequivalent 
doses by parallel line bioassay to evaluate comparative safety and efficacy. Allergy. 1990;45(7):528546. DOI: 10.1111/j.1398-9995.1990.tboo529.x

96. Villa E, Garelli V, Braido F, Melioli G, Canonica G. May we strengthen the human natural defenses with bacterial lysates? World Allergy Organ J. 2010;3(Suppl8):S17-S23. DOI: 10.1097/WOX.ob013e3181eeocfd

97. Alecsandru D, Valor L, Sánchez-Ramón S, Gil J, Carbone J, Navarro J, et al. Sublingual therapeutic immunization with a polyvalent bacterial preparation in patients with recurrent respiratory infections: immunomodulatory effect on antigen-specific memory $\mathrm{CD}_{4}+\mathrm{T}$ cells and impact on clinical outcome. Clin Exp Immunol. 2011;164(1):100-107. DOI: 10.1111/j.1365-2249.2011.04320.x

98. Wohrl S, Gamper S, Hemmer W, Heinze G, Stingl G, Kinaciyan T. Premedication with montelukast reduces local reactions of allergen immunotherapy. Int Arch Allergy Immunol. 2007;144(2):137-142. DOI: 10.1159/000103225

99. Nielsen L, Johnsen CR, Mosbech H, Poulsen LK, Malling HJ. Antihistamine premedication in specific cluster immunotherapy: a double-blind, placebo-controlled study. J Allergy Clin Immunol. 1996;97(6):1207-1213. DOI: 10.1016/Soo91-6749(96)70186-0

100. Muller U, Hari Y, Berchtold E. Premedication with antihistamines may enhance efficacy of specificallergen immunotherapy. J Allergy Clin Immunol. 2001;107(1):81-86. DOI: 10.1067/mai.2001.111852

101. Muraro A, Roberts G, Worm M, Bilò MB, Brockow K, Fernández Rivas M, et al. Anaphylaxis: guidelines from the European Academy of Allergy and Clinical Immunology. Allergy. 2014;69(8):1026-1045. DOI: 10.1111/all.12437

102. Ring J, Messmer K. Incidence and severity of anaphylactoid reactions to colloid volume substitutes. Lancet. 1977;1(8009):466-469. DOI: 10.1016/S0140-6736(77)91953-5

103. Eller E, Muraro A, Dahl R, Mortz CG, Bindslev-Jensen C. Assessing severity of anaphylaxis: a data-driven comparison of 23 instruments. Clin Transl Allergy. 2018;8:29. DOI: 10.1186/s13601-018-0215-X

104. Cox L, Larenas-Linnemann D, Lockey RF, Passalacqua G. Speaking the same language: the World Allergy Organization Subcutaneous Immunotherapy Systemic Reaction Grading System. J Allergy Clin Immunol. 2010;125(3):569-574. DOI: 10.1016/j.jaci.2009.10.060

105. Simons FE, Ebisawa M, Sánchez-Borges M, Thong BY, Worm M, Tanno LK, et al. 2015 update of the evidence base: World Allergy Organization anaphylaxis guidelines. World Allergy Organ J. 2015;8(1):32. DOI: 10.1186/s40413-015-0080-1

106. Roy SR, Sigmon JR, Olivier J, Moffitt JE, Brown DA, Marshall GD. Increased frequency of large local reactions among systemic reactors during subcutaneous allergen immunotherapy. Ann Allergy Asthma Immunol. 2007;99(1):82-86. DOI: 10.1016/S1081-1206(10)60626-6

107. Bernardini R, Novembre E, Ingargiola A, Veltroni M, Mugnaini L, Cianferoni A, et al. Prevalence and risk factors of latex sensitization in an unselected pediatric population. J Allergy Clin Immunol. 1998;101(5):621-625. DOI: 10.1016/So091-6749(98)70169-1

108. Garabrant DH, Schweitzer S. Epidemiology of latex sensitization and allergies in health care workers. J Allergy Clin Immunol. 2002;110(Suppl 2):S82-95.

109. Nettis E, Colanardi MC, Soccio AL, Marcandrea M, Pinto L, Ferrannini A, et al. Double-blind, placebocontrolled study of sublingual immunotherapy in patients with latex-induced urticaria: a 12-month study. Br J Dermatol. 2007;156(4):674-681. DOI: 10.1111/j.1365-2133.2006.07738.x

110. Cisteró-Bahima A, Sastre J, Enrique E, Fernández M, Alonso R, Quirce S, et al. Tolerance and effects on skin reactivity to latex of sublingual rush immunotherapy with a latex extract. J Investig Allergol Clin Immunol. 2004;14(1):17-25. Disponible en: http://www.jiaci.org/issues/vol14issue01/17-25.pdf

111. Antico A, Pagani M, Crema A. Anaphylaxis by latex sublingual immunotherapy. Allergy. 2006;61(10):12361237. DOI: 10.1111/j.1398-9995.2006.01155.x

112. Hankin CS, Cox L, Bronstone A, Wang Z. Allergy immunotherapy: reduced health care costs in adults and children with allergic rhinitis. J Allergy Clin Immunol. 2013;131(4):1084-1091. DOI: 10.1016/j. jaci.2012.12.662

113. Bachert C, Noergaard-Andreasen J. Cost-effectiveness of immunotherapy in the treatment of seasonal allergic rhinitis: identifying product-specific parameters of relevance for health care decision-makers and clinicians. Int Arch Allergy Immunol. 2015;168(3):213-217. DOI: 10.1159/000443272 


\section{Anexo 1}

Los datos fuente de GUIMIT fueron registrados en dos tipos de tablas fuente. Las tablas fuente 1 son las preguntas clínicas clave con las contestaciones, su nivel de evidencia y recomendación encontradas en las guías madre de cada capítulo. Las tablas fuente 2 son las preguntas clínicas clave y la fusión de la evidencia y las recomendaciones para dar cierta respuesta; se incluyeron las respuestas sugeridas para GUIMIT, las cuales se emitieron tomando en cuenta la evidencia y el nivel de recomendación de las guías madre, el costo y la seguridad, la posible preferencias de los pacientes para cierta acción según la experiencia de los expertos GUIMIT y la realidad local. A esos archivos fuente se tiene acceso con los DOI que se enlistan abajo; en los navegadores web se adiciona antes https://www.doi.org/, ejemplo: https://www.doi.org/10.13140/RG.2.2.23800.90888

\begin{tabular}{|c|c|}
\hline & DOI \\
\hline \multicolumn{2}{|l|}{ Apartado 1.1} \\
\hline - Tabla fuente 1 & $10.13140 / R G .2 .2 .23800 .90888$ \\
\hline - $\quad$ Tabla fuente 2 & $10.13140 / R G .2 .2 .13734 \cdot 57925$ \\
\hline \multicolumn{2}{|l|}{ Apartado 1.2} \\
\hline - Tabla fuente 1 & 10.13140/RG.2.2.15798.14407 \\
\hline - $\quad$ Tabla fuente 2 & $10.13140 / R G .2 .2 .18314 .72640$ \\
\hline \multicolumn{2}{|l|}{ Capítulo 2} \\
\hline - $\quad$ Tabla fuentes 1 y 2 & $10.13140 / R G .2 .2 .29865 \cdot 44648$ \\
\hline \multicolumn{2}{|l|}{ Capítulo 3} \\
\hline - $\quad$ Tabla fuente 1 & No aplica \\
\hline \multicolumn{2}{|l|}{ Apartado 4.1} \\
\hline - Tabla fuente 1 & $10.13140 / R G .2 \cdot 2.24043 \cdot 39209$ \\
\hline - $\quad$ Tabla fuente 2 & $10.13140 / R G .2 .2 .13977 .06247$ \\
\hline \multicolumn{2}{|l|}{ Apartado 4.2} \\
\hline - Tabla fuente 1 & $10.13140 / R G .2 .2 .17168 .66560$ \\
\hline - $\quad$ Tabla fuente 2 & $10.13140 / R G .2 .2 .25557 .27364$ \\
\hline \multicolumn{2}{|l|}{ Capítulo 5} \\
\hline - Tabla fuente 1 & $10.13140 / R G .2 .2 .24436 .60803$ \\
\hline - $\quad$ Tabla fuente 2 & 10.13140/RG.2.2.13295.48806 \\
\hline \multicolumn{2}{|l|}{ Capítulo 6} \\
\hline - Tabla fuente 1 & $10.13140 / R G .2 \cdot 2 \cdot 32264.06409$ \\
\hline - $\quad$ Tabla fuente 2 & $10.13140 / R G .2 \cdot 2 \cdot 24714 \cdot 31680$ \\
\hline \multicolumn{2}{|l|}{ Capítulo 7} \\
\hline - $\quad$ Tabla fuente 1 & $10.13140 / R G .2 \cdot 2 \cdot 31736.49922$ \\
\hline - $\quad$ Tabla fuente 2 & 10.13140/RG.2.2.28381.05603 \\
\hline \multicolumn{2}{|l|}{ Capítulo 8} \\
\hline - Tabla fuente 1 & $10.13140 / R G .2 \cdot 2 \cdot 32746.57282$ \\
\hline - $\quad$ Tabla fuente 2 & $10.13140 / R G .2 \cdot 2 \cdot 32327.14248$ \\
\hline \multicolumn{2}{|l|}{ Capítulo 9} \\
\hline - Tabla fuente 1 & $10.13140 / R G .2 .2 .13281 .56163$ \\
\hline - $\quad$ Tabla fuente 2 & 10.13140/RG.2.2.16637.00481 \\
\hline \multicolumn{2}{|l|}{ Capítulo 10} \\
\hline - $\quad$ Tabla fuente 1 & 10.13140/RG.2.2.11349.06 \\
\hline - $\quad$ Tabla fuente 2 & 10.13140/RG.2.2.18059.95522 \\
\hline
\end{tabular}


